Portland State University

PDXScholar

\title{
Development and Applications of High Resolution Kinetic Atmospheric Pressure Ionization Mass Spectrometry in Atmospheric Chemistry
}

David Michael Myton

Portland State University

Follow this and additional works at: https://pdxscholar.library.pdx.edu/open_access_etds Let us know how access to this document benefits you.

\section{Recommended Citation}

Myton, David Michael, "Development and Applications of High Resolution Kinetic Atmospheric Pressure Ionization Mass Spectrometry in Atmospheric Chemistry" (1991). Dissertations and Theses. Paper 1209. https://doi.org/10.15760/etd.1208

This Dissertation is brought to you for free and open access. It has been accepted for inclusion in Dissertations and Theses by an authorized administrator of PDXScholar. Please contact us if we can make this document more accessible: pdxscholar@pdx.edu. 
DEVELOPMENT AND APPLICATIONS OF HIGH RESOLUTION KINETIC ATMOSPHERIC PRESSURE IONIZATION MASS SPECTROMETRY IN ATMOSPHERIC CHEMISTRY

by

DAVID MICHAEL MYTON

A dissertation submitted in partial fulfillment of the requirements for the degree of

DOCTOR OF PHILOSOPHY

in

ENVIRONMENTAL SCIENCES AND RESOURCES:

CHEMISTRY

Portland State University

1991 


\section{TO THE OFFICE OF GRADUATE STUDIES:}

The members of the Committee approve the dissertation of David Michael Myton presented July 3, 1991.

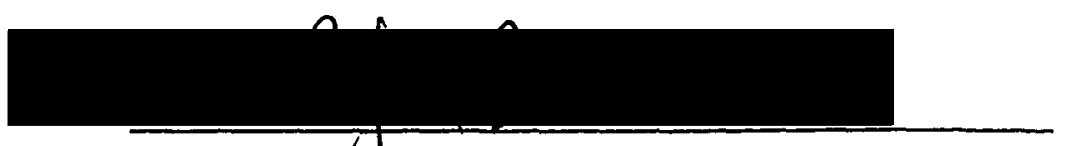

Robert J. O'Brien

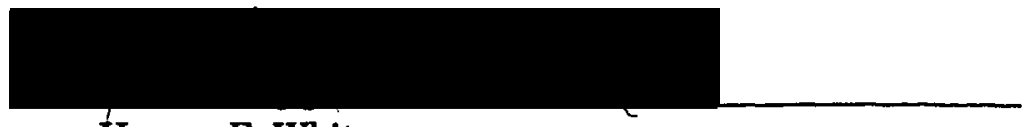

Horace F. White

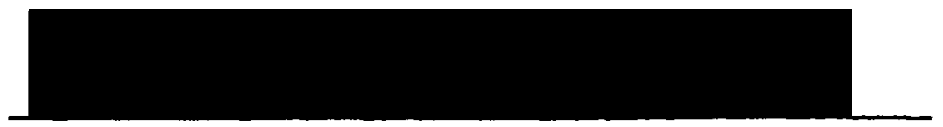

Carl C. Wamser
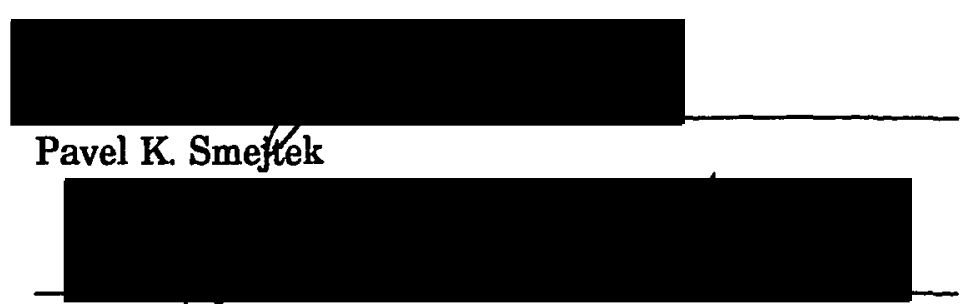

John G. Rueter

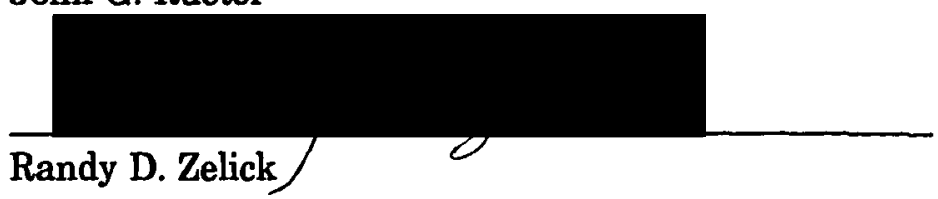

APPROVED:

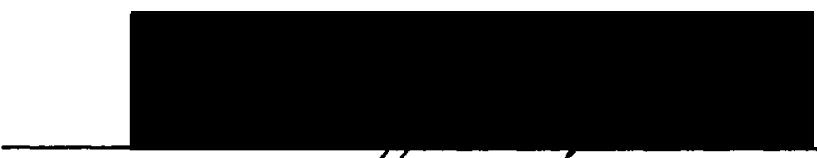

Pavel K. Smejtek, Director, Environmental Sciences and Resources Ph.D. Program

C. William Savery, Interim Vice Provost for Garaduate Studies and Research 
AN ABSTRACT OF THE DISSERTATION OF David Michael Myton for the

Doctor of Philosophy in Environmental Science and Resources: Chemistry presented July 3, 1991.

Title: Development and Applications of High Resolution Kinetic Atmospheric Pressure Ionization Mass Spectrometry in Atmospheric Chemistry APPROVED BY THE MEMBERS OF THE DISSERTATION COMMITTEE:

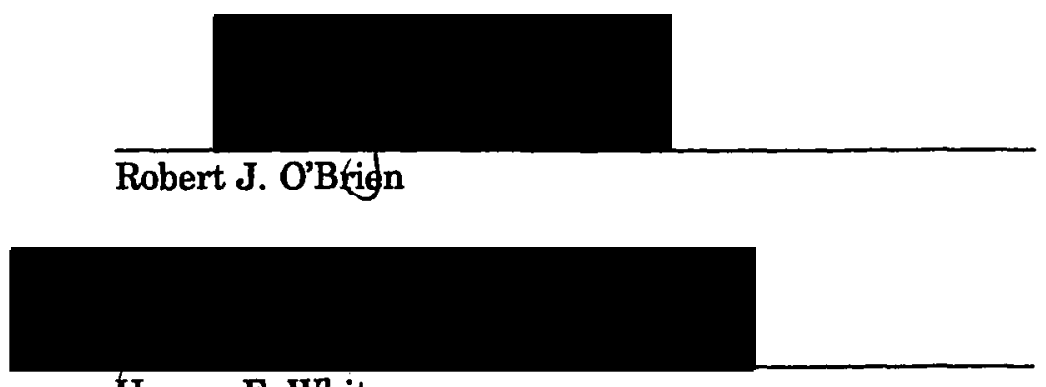

Horace F. White

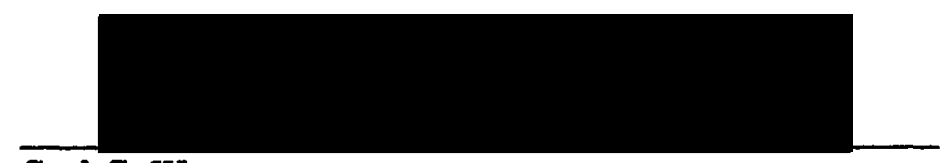

Carl C. Wamser

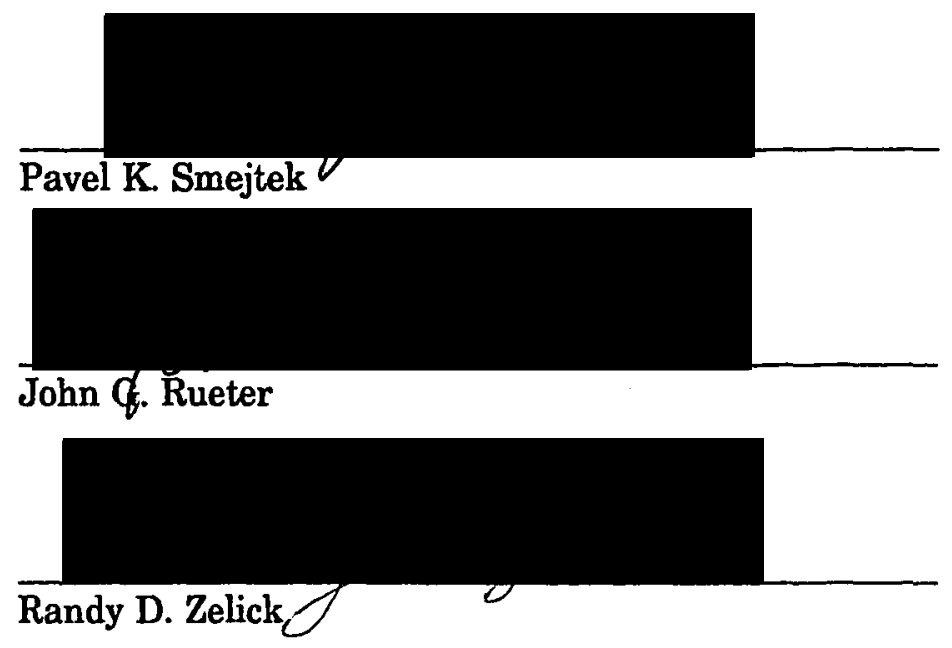


Much important work has been done to understand reaction pathways and identify products, yields, and reaction rates for atmospheric oxidation processes. Non-methane hydrocarbons (NMHCs) are the most significant of the organic compounds present in the atmosphere from a chemical perspective and are released into the atmosphere from both natural and anthropogenic sources. The oxidation of these hydrocarbons by hydroxyl radical HO generates products that may themselves be toxic, that play a major role in the formation of photochemical smog, and that to a lesser extent contribute to the formation of acid precipitation. NMHCs have chemical reactivities many times that of methane, the most abundant $\mathrm{HC}$ in the atmosphere. However, the atmospheric oxidation processes of less than $50 \%$ of atmospheric NMHCs are known.

A new experimental technique is needed that can provide insight into atmospheric oxidation products, reaction intermediates, and the relative importance of secondary reaction pathways that follow the initial attack of $\mathrm{HO}$ upon a hydrocarbon. The technique should operate at atmospheric pressure to better represent natural reaction processes and conditions, and provide a rapid and direct measure of product identities and yields. In this study we will describe the development and application of a technique that we believe meets these requirements, a technique we call High Resolution Kinetic Atmospheric Pressure Ionization Mass Spectrometry (HRKAPIMS).

We begin with the use of atmospheric pressure ionization mass spectrometry in studies of atmospheric oxidation processes. We first describe a potential pitfall in the use of APIMS for the analysis of smog chamber experiments, a common APIMS application, discussing methods to eliminate 
interference reactions that would otherwise make interpretation difficult. A new experimental approach to the use of APIMS for the analysis of oxidation processes is next described and its use demonstrated. The oxidation of toluene by APIsource-generated HO produces oxidation products that are protonated and detected by the mass spectrometer. With this approach, we observe all the products found in a variety of previous studies employing a large array of experimental setups and analytical instrumentation. This is significant because our experiments are carried out in a far simpler experimental environment. Toluene is chosen for these experiments because it is an important constituent in polluted urban atmospheres with a complex oxidation mechanism that remains poorly understood.

We describe the development of HRKAPIMS, a powerful new approach that allows the simultaneous detection of stable products along with free radical intermediates. The use of nitric oxide to affect product yields is demonstrated, giving valuable insights into reaction kinetics and mechanisms.

We also address the theoretical aspects of HRKAPIMS, describing semiempirical calculations to estimate gas-phase basicities for a wide variety of compounds and discuss the errors implicit in this approach. The use of gas-phase basicities is discussed in terms of mass spectrometric analysis and analyte response. Kinetic and thermodynamic modeling is used to address the issues of APIMS and HRKAPIMS sensitivity and response and gain insights into the conditions necessary for linear response and quantitative detection of analytes. 


\section{ACKNOWLEDGEMENTS}

I would like to recognize and thank my graduate advisor and mentor, $\mathrm{Dr}$ R.J. O'Brien, for his support, guidance, and help throughout this project. I appreciate the support I have received through the Department of Chemistry and the Environmental Sciences and Resources Program, support both from the staff and faculty, as well as financially. I am certainly grateful for the help and encouragement of Lorne Isabelle of the Oregon Graduate Institute in the daily operation and troubleshooting of the mass spectrometer. Dr. A.H. Grange deserves special mention for sharing with me his interest in APIMS, and the skills and training I needed to complete this project. I have appreciated the support and friendship of my fellow students and colleagues, in particular Dr. Linda George, Dr. Wen Pan, Dr. Tom Hard, Dr. Corny Chan, and Xiong Pan. Special appreciation belong to my family, Mary and Ben, whose love and support and confidence have never wavered. Finally, and most importantly, I acknowledge my Creator, Lord, and Savior, Jesus Christ. 


\section{TABLE OF CONTENTS}

\section{PAGE}

ACKNOWLEDGEMENTS $\ldots \ldots \ldots \ldots \ldots \ldots \ldots \ldots \ldots \ldots$ ii

LIST OF TABLES $\ldots \ldots \ldots \ldots \ldots \ldots \ldots \ldots \ldots \ldots \ldots \ldots$ vii

LIST OF FIGURES $\ldots \ldots \ldots \ldots \ldots \ldots \ldots \ldots \ldots \ldots \ldots \ldots \ldots$

LIST OF ABBREVIATIONS AND ACRONYMS $\ldots \ldots \ldots \ldots \ldots \ldots \ldots$ xii

\section{CHAPTER}

I OVERVIEW OF ATMOSPHERIC OXIDATION PROCESSES . . . 1

Introduction $\ldots \ldots \ldots \ldots \ldots \ldots \ldots \ldots \ldots$

Atmospheric Oxidations $\ldots \ldots \ldots \ldots \ldots \ldots \ldots$

Biogenic Emissions

Anthropogenic Emissions

Photochemical Smog

Hydroxyl Radical Chemistry $\ldots \ldots \ldots \ldots \ldots \ldots$

Current Methods in Atmospheric Chemistry

A New Technique: HRKAPIMS

Research Goals

II SUPPRESSION OF SPURIOUS OXIDATION PRODUCTS IN AN ATMOSPHERIC PRESSURE IONIZATION SOURCE . . . . 12

Overview ...................... 12

Introduction $\ldots \ldots \ldots \ldots \ldots \ldots \ldots \ldots \ldots \ldots \ldots \ldots \ldots$

HO Source Reactions

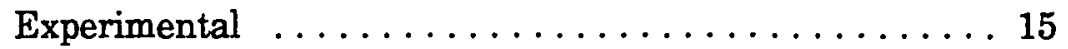

Results and Discussion $\ldots \ldots \ldots \ldots \ldots \ldots$ 
Mass Spectrometry

Kinetic Modeling

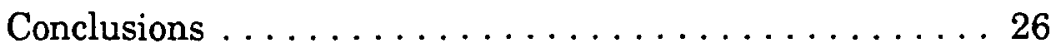

Other Radical Scavengers

New Applications

III STUDIES OF ATMOSPHERIC HO OXIDATION MECHANISMS BY IN SITU HIGH RESOLUTION ATMOSPHERIC PRESSURE

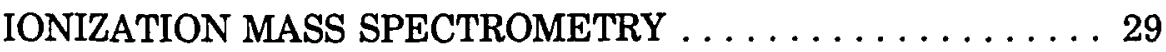

Overview ..................... 29

Introduction $\ldots \ldots \ldots \ldots \ldots \ldots \ldots \ldots \ldots \ldots$

Experimental $\ldots \ldots \ldots \ldots \ldots \ldots \ldots \ldots \ldots \ldots \ldots$

Results and Discussion $\ldots \ldots \ldots \ldots \ldots \ldots \ldots$

Toluene Products

Empirical Formulas

Past Toluene Studies

API Source Chemistry

Conclusions ..................... 50

IV HIGH-RESOLUTION KINETIC ATMOSPHERIC PRESSURE IONIZATION MASS SPECTROMETRY (HRKAPIMS) . . . . . . 52

Overview .....................52

Introduction $\ldots \ldots \ldots \ldots \ldots \ldots \ldots \ldots \ldots \ldots \ldots$

HO Chemistry

Oxidation Product Measurements

HRKAPIMS

Results and Discussion $\ldots \ldots \ldots \ldots \ldots \ldots \ldots$

Experimental

Free Radical Intermediates

Free Radical Intermediate Measurements

Chemical Modeling

Conclusions 
V SEMIEMPIRICAL CALCULATIONS OF GAS-PHASE BASICITIES WITH APPLICATIONS TO MASS SPECTROMETRY . . . . . 72

Overview .................. 72

Introduction $\ldots \ldots \ldots \ldots \ldots \ldots \ldots \ldots \ldots \ldots$

Experimental $\ldots \ldots \ldots \ldots \ldots \ldots \ldots \ldots \ldots \ldots \ldots$

Results and Discussion ...............75

Conclusions $\ldots \ldots \ldots \ldots \ldots \ldots \ldots \ldots \ldots$

VI ANALYTE RESPONSE AND QUANTITATION IN ATMOSPHERIC PRESSURE IONIZATION MASS SPECTROMETRY . . . . . . 91

Overview .................... 91

Introduction $\ldots \ldots \ldots \ldots \ldots \ldots \ldots \ldots \ldots \ldots$

Quantitation in Mass Spectrometry .......... 93

Ionization Techniques

Quantitation in API

Chemical Modeling $\ldots \ldots \ldots \ldots \ldots \ldots \ldots \ldots$

Equilibrium Expressions

Kinetic Modeling-Rate Constants

Kinetic Modeling-Batch Mode

Conclusions ...................... 125

VII CONCLUSIONS AND APPLICATIONS $\ldots \ldots \ldots \ldots \ldots$

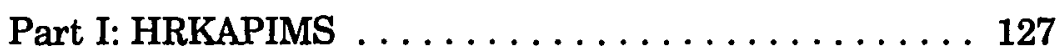

Oxidation of Small Hydrocarbons

Part II: Analyte GB and API Response $\ldots \ldots \ldots \ldots 134$

Gas-phase Basicities

Analyte Response in API

Summary $\ldots \ldots \ldots \ldots \ldots \ldots \ldots \ldots \ldots \ldots \ldots \ldots$

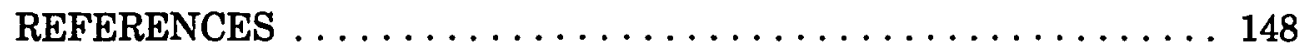




\section{LIST OF TABLES}

I Atmospheric Reaction Pathways and Selected Gas-

Phase Basicities for Methane and Ethane ........ 14

II Mechanism for Kinetic Modeling of $\mathrm{HO}$ and CO Reactions

in Hydrocarbon Oxidations . . . . . . . . . . 20

III Toluene Oxidation Products Found Using API Source Reactions . 36

IV Empirical Formula Combinations for Selected Experimental

Masses .................... 42

V Experimental Masses of Five Free Radical Toluene

Oxidation Intermediates $\ldots \ldots \ldots \ldots \ldots$

VI Kinetic Modeling Mechanism for HRKAPIMS Source Reactions . . 66

VII Comparison of the Gas-phase Basicities and Adjusted Heats of

Formation for Protonated and Unprotonated Species . . . . 76

VIII Regression Analysis of Calculated Versus Experimental Gas-phase

Basicities and Corrected Heats of Formation ....... 82

IX Heats of Formation for Hydrated Furan and Ethanol . . . . . 88

X Comparison of Initial Analyte Response vs.

Gas-phase Basicity ............... 103

XI Mechanism for Kinetic Modeling of Hydronium Hydration . . . . 115

XII Semiempirical Calculations of Heats of Reaction for Hydration

$\mathrm{BH}^{+}+\mathrm{H}_{2} \mathrm{O}<->\mathrm{BH}^{+} \bullet \mathrm{H}_{2} \mathrm{O} \ldots \ldots \ldots \ldots \ldots \ldots \ldots$ 
XIII Regression Analysis of Free Energies of Hydration as a Function of Analyte GB for $\mathrm{BH}^{+} \bullet\left(\mathrm{H}_{2} \mathrm{O}\right)_{\mathrm{n}-1}+\mathrm{H}_{2} \mathrm{O}<-->\mathrm{BH}^{+} \bullet\left(\mathrm{H}_{2} \mathrm{O}\right) \mathrm{n} .118$

XIV Batch Mode Model of API Response ............. 121

XV Partial Methane Photooxidation Mechanism .......... 129

XVI Partial Ethene Photooxidation Mechanism ............ 131

XVII Partial Propene Photooxidation Mechanism .......... 132

XVIII Partial Butane Photooxidation Mechanism .......... 135

XIX Gas-phase Basicities based on Semiempirical Heats

of Formation $\ldots \ldots \ldots \ldots \ldots \ldots \ldots \ldots \ldots$

XX Gas-phase Basicity Calculations for Toluene Free Radical

Intermediates and Products . . . . . . . . . . . 144 


\section{LIST OF FIGURES}

1. Sources and Structures for Selected Non-methane Hydrocarbons (NMHCs) emitted from Biogenic Sources . . . . . . . . 4

2. API Reaction Vessel Analysis of Methyldeuterated Toluene .... 18

3. Kinetic Modeling of HO Reactions in the API Source . . . . . . 22

4. Kinetic Modeling of HO Reactions in an API Source in the Presence of Carbon Monoxide . . . . . . . . . . 25

5. Mass Spectral Sequence Illustrating the Photooxidation of

$\mathrm{D}_{8}$ Toluene in an Oxygen Carrier Gas .......... 34

6. Mass Spectra Showing the Course of a Typical HRKAPIMS

Experiment $\ldots \ldots \ldots \ldots \ldots \ldots \ldots \ldots \ldots \ldots \ldots \ldots \ldots \ldots \ldots \ldots$

7. Normalized Ion Intensity vs. Scan Number for

Methylhexadienedial ................6 62

8. Partial Toluene Oxidation Mechanism Showing the Production of

Several Free Radical Intermediates and Stable Products . . 65

9. Experimental vs. Modeled Ion Intensities for Toluene Free

Radical Intermediates $\ldots \ldots \ldots \ldots \ldots \ldots \ldots$

10. Comparisons of Calculated and Experimental $\Delta \mathrm{H}_{\mathrm{r}}(\mathrm{B}) \ldots \ldots \ldots 8$

11. Comparisons of Calculated and Experimental $\Delta \mathrm{H}_{\mathrm{r}}\left(\mathrm{BH}^{+}\right) \ldots \ldots 84$

12. Comparisons of Calculated and Experimental GB $\ldots \ldots \ldots 85$ 
13. Experimental Ion Intensities for Toluene Oxidation Products by Analyte Gas-phase Basicity . . . . . . . . 99

14. Analyte Response as a Function of Gas-phase Basicity and Initial Water Concentration in Thermodynamic Equilibrium Case $(\mathrm{R} 10) \ldots \ldots \ldots \ldots \ldots$

15. Sensitivity, Relative to Pyridine, in an API Source as a Function of Analyte GB ............... 106

16. Analyte Response in Steady State Model (R13) as a Function of GB and $\left[\mathrm{H}_{3} \mathrm{O}^{+}\right]_{0} \ldots \ldots \ldots \ldots \ldots \ldots \ldots \ldots$

17. Analyte Response in Steady State Model (R13) as a Function of GB and $\left[\mathrm{H}_{2} \mathrm{O}\right]_{0} \ldots \ldots \ldots \ldots \ldots \ldots \ldots \ldots \ldots \ldots$

18. Analyte Response in Steady State Model (R13) as a Function of GB and $k_{d} \ldots \ldots \ldots \ldots \ldots \ldots \ldots \ldots \ldots \ldots \ldots$

19. Analyte Response in Steady State Model (R13) as a Function of GB and $k_{f} \ldots \ldots \ldots \ldots \ldots \ldots \ldots \ldots \ldots \ldots$

20. Kinetic Modeling of Hydration Reactions for Water with Hydronium Ions $\ldots \ldots \ldots \ldots \ldots \ldots \ldots \ldots \ldots$

21. Free Energy for the Hydration Reactions of Protonated Analytes as a Function of GB $\ldots \ldots \ldots \ldots \ldots \ldots \ldots \ldots$

22. Forward Rate Constants for Protonation as a Function of Analyte GB . . . . . . . . . . . . . . . . 119

23. Batch-mode Modeling of API Source Reactions at Two

Detection Rates . . . . . . . . . . . . . . 122 
24. Batch-mode Modeling of Analyte Response as a Function of Initial Analyte Concentration $\ldots \ldots \ldots \ldots \ldots \ldots \ldots$

25. Experimental Analyte Response Using TAGA APIMS as a Function of Analyte Concentration . . . . . . . . 124

26. Batch-mode Modeling of Analyte Response for Mixtures . . . . . 125

27. Low Resolution Mass Spectra From APIMS Analysis of Butane . 141

28. Partial Toluene Photooxidation Mechanism Showing Formation of Major Ring-opened Products and Free Radical Intermediates $\ldots \ldots \ldots \ldots \ldots \ldots \ldots \ldots \ldots$ 


\section{LIST OF ABBREVIATIONS AND ACRONYMS}

$\Delta \mathrm{G}(\mathrm{R} 1)$

$\Delta \mathrm{H}(\mathrm{R} 1)$

$\Delta \mathrm{H}_{\mathrm{r}}(\mathrm{B})$

$\Delta \mathrm{H}_{r}\left(\mathrm{BH}^{+}\right)$

$\Delta \mathrm{S}(\mathrm{R} 1)$

$\Delta \mathbf{S}_{\sigma \mathrm{n}}$

AM1

APCI

API

APIMS

$\mathrm{B}, \mathrm{BH}^{+}$

CD

CI

CID

CO

D

EB

EI

FAB

FTIR
Free energy of Reaction 1

Enthalpy of Reaction 1

Heat of formation for an unprotonated analyte

Heat of formation for a protonated analyte

Entropy of Reaction 1

Entropy from internal/external symmetry values

Third generation semiempirical parameterization

Atmospheric pressure chemical ionization

Atmospheric pressure ionization

Atmospheric pressure ionization mass spectrometry

Generic gas phase bases: unprotonated and protonated

Corona discharge- ionization source for API

Chemical ionization- MS ionization method

Collision induced dissociation

Carbon monoxide

Diffusion coefficient

Electrostatic sector/Magnetic sector mass analyzer

Electron impact- standard MS ionization method

Fast atom bombardment

Fourier transform infrared (spectroscopy) 
GB

GC

GC/MS

$\mathrm{HC}$

HCHD

$\mathrm{HO}$

HPLC

HRKAPIMS

IMMS

$\mathrm{K}_{\mathrm{eq}}(\mathrm{R} 1)$

LC

LC/MS

MIKES

MINDO/3

MNDO

MNDO-PM3

MO

MOLY

MOPAC

MS

MS/MS

NAAQS

NMHC

NO
Gas-phase basicity, $\mathrm{GB}=-\Delta \mathrm{G}_{\mathrm{rxn}}\left(\mathrm{B}+\mathrm{H}^{+} \rightarrow \mathrm{BH}^{+}\right)$

Gas chromatography

Gas chromatography/mass spectrometry

Hydrocarbon

Hydroxycyclohexadienyl radical, $\mathrm{HO}$ adduct to benzene

Hydroxyl radical

High performance liquid chromatography

High resolution kinetic APIMS

Ion mobility mass spectrometry

Equilibrium constant for Reaction 1

Liquid chromatography

Liquid chromatography/mass spectrometry

Mass-analyzed ion kinetic energy spectroscopy

Second generation semiempirical parameterization

First generation semiempirical parameterization

Fourth generation semiempirical parameterization

Molecular orbital (theory)

Molecular structure input program

Molecular Orbital PACkage, semiempirical program

Mass spectrometry

Tandem mass spectrometry/mass spectrometry

National Ambient Air Quality Standards

Non-methane hydrocarbon

Nitric oxide 
$\mathrm{NO}_{x}$

PA

PAN

PHPMS

QCPE

$\mathrm{RO}, \mathrm{RO}_{2}$

RT

Sciex

TAGA

VOC
Sum of $\mathrm{NO}$ and $\mathrm{NO}_{2}$

Proton affinity, $\mathrm{PA}=-\Delta \mathrm{H}_{\mathrm{rxn}}\left(\mathrm{B}+\mathrm{H}^{+} \rightarrow \mathrm{BH}^{+}\right)$

Peroxy acetyl nitrate

Pulsed high pressure mass spectrometry

Quantum chemistry program exchange

Generic Oxy- and Peroxy radical species

Product of the gas constant and temperature

Manufacturer of a commercial APIMS system

Model name of a commercial APIMS system

Volatile organic compound 


\title{
CHAPTER I
}

\section{OVERVIEW OF ATMOSPHERIC OXIDATION PROCESSES}

\author{
"To most people solutions mean finding the answer, \\ but to chemists solutions are things that \\ are still all mixed up." (Davis 1969)
}

\section{INTRODUCTION}

Concerns about the changing state of the atmosphere, and the possible effects such changes could have, is a matter of constant attention in the news media. Mankind has had a dramatic role in producing or facilitating many of these changes through the release of a wide range of substances into the air. In general, public awareness and concern over environmental issues continues to increase, and discussions about greenhouse gases, toxic air pollutants, acid rain, global warming and the ozone hole have become commonplace. While such discussions are not new from a scientific perspective, public attention regarding the delicate balance of chemical, biological and physical processes in the atmosphere has provided an additional impetus for research into these processes.

The following paragraphs will outline the sources of organic compounds in the atmosphere and identify some areas where further work is needed to understand oxidation processes. Current methods used to study atmospheric oxidations are reviewed and their shortcomings are described. Finally, a new approach 
to studying atmospheric oxidation processes will be introduced which will be described, and used to address current problems in atmospheric chemistry, in the chapters which follow.

\section{ATMOSPHERIC OXIDATIONS}

A wide variety of organic compounds are present in the lower atmosphere. A database of volatile organic compounds (VOCs) present in the atmosphere was recently compiled by the Environmental Protection Agency (Shah and Singh, 1988). This database included a total of 320 VOCs, 261 of which had been measured outdoors and 66 had been measured indoors. These compounds, released from both natural and anthropogenic sources, contribute directly and indirectly to the total chemistry of the troposphere. As examples: photochemical smog is formed when sunlight impinges upon organic compounds in the presence of the oxides of nitrogen, and acid deposition results from the oxidation of hydrocarbons, nitrogen and sulfur oxides. Furthermore, many compounds that are released into the atmosphere are potentially toxic or may form toxic products as a result of atmospheric oxidation processes (Grosjean, 1991; Dumdei et al., 1988).

From the standpoint of atmospheric oxidation processes, the nonmethane hydrocarbons (NMHCs) are among the most important reactive species in the atmosphere. Methane is, of course, an important hydrocarbon due to its ubiquitous presence in the troposphere at relatively high levels. However, methane's chemical reactivity, as a fully hydrogenated compound, is significantly less than that of most NMHCs. Hydrocarbons are released into the atmosphere from the decomposition 
of organic matter, from living plants and animals, and from the activities of mankind.

\section{$\underline{\text { Biogenic Emissions }}$}

The first suggestion of the importance of vegetation as a major source of organic compounds in the atmosphere came from Went (1960). Organic compounds are believed to be emitted through natural processes from a wide range of plant species (Zimmerman, 1979), yet emission rates have been measured for less than 100 plant species (Tingey et al., 1979; Lamb, Westberg, and Allwire, 1985). Early estimates of annual worldwide emissions of VOCs from vegetation were in the range of (200-400) x10 $12 \mathrm{~g} / \mathrm{yr}$ (Rasmussen and Went, 1965). Estimates of worldwide emission rates have only increased in more recent studies (Rasmussen, 1972; Zimmerman, 1978; Rasmussen and Khalil, 1988; Zimmerman, Greenberg, and Westberg, 1988). Isoprene and the terpenes lead known biogenic emissions, with estimated global carbon inputs of at least $3.5 \times 10^{14}$ and $4.8 \times 10^{14} \mathrm{~g}(\mathrm{C}) / \mathrm{yr}$ respectively (Zimmerman et al., 1978). The chemical structures, and examples of the biogenic sources, of several members of the terpene family are shown in Figure 1 (Seinfeld, 1986). The rate of reaction for isoprene, the largest single component of biogenic emissions, with hydroxyl radical (HO) is nearly a factor of 50 greater than that of standard urban hydrocarbon mixtures (Killus and Whitten, 1984). This illustrates isoprene's much greater reactivity in the atmosphere, and is typical of NMHC reaction rates in general. A large $\mathrm{HO}$ reaction rate will be reflected in the rapid consumption of the organic compound and the corresponding rapid increase in its atmospheric oxidation products. In spite of the importance of 
Isoprene $\left(\mathrm{C}_{5} \mathrm{H}_{8}\right) \quad$ Emitted by oak, sycamore, willow, balsam poplar, aspen, spruce and others.<smiles>C=CC(=C)C</smiles>

$\alpha$-Pinene $\left(\mathrm{C}_{10} \mathrm{H}_{16}\right) \quad$ Emitted by numerous pines, firs, spruce, hemlock and cyprus.

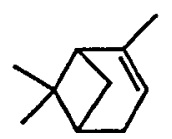

$\beta$-Pinene $\left(\mathrm{C}_{10} \mathrm{H}_{16}\right) \quad$ Emitted by California black sage, Loblolly pine, spruce and redwood.

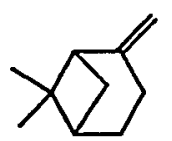

$$
\begin{array}{ll}
p \text {-Cymene }\left(\mathrm{C}_{10} \mathrm{H}_{16}\right) & \begin{array}{l}
\text { Emitted by California black sage and from } \\
\text { "disturbed" eucalyptus foilage; found in }
\end{array} \\
\text { gum turpentines of Scotch and other pines. }
\end{array}
$$

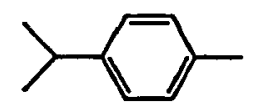

\section{$d$-Limonene $\left(\mathrm{C}_{10} \mathrm{H}_{16}\right)$ Emitted by Loblolly pine, California black sage, found in the gum turpentine of numerous pines and the essential oils

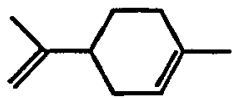 derived from some fruits.}

Figure 1. Sources and structures for selected non-methane hydrocarbons (NMHCs) emitted from biogenic sources. Emission rates and reactivity are discussed in the text. Source: Seinfeld (1986).

isoprene, and terpenes in general, their atmospheric oxidation processes remain vaguely understood are the subject of continued research (Tuazon and Atkinson, 1990).

In general, biogenic sources of VOCs are in rural settings and, while they comprise a large fraction of the total world emissions, their impact on urban air 
pollution has often been considered small. One reason for this is that measurements of ambient concentrations of biogenic NMHCs rarely exceed $5 \%$ of the total (Arnts and Meeks, 1981). This is probably a result of the much higher chemical reactivity of isoprene, as has already been mentioned. More recently however the inability of many cities to meet the National Ambient Air Quality Standards (NAAQS) has directed attention to the oxidation of biogenic emissions as sources of ozone in urban settings (Chameides et al., 1988).

\section{Anthropogenic Emissions}

Nearly all of the 320 VOCs compiled in the EPA database are emitted as a result of anthropogenic activities (Shah and Singh, 1988). Aromatic hydrocarbons, a subset of the VOCs, are important players in the formation of air pollution. Aromatic hydrocarbons comprise $25-40 \%$ of gasoline in the United States and are widely used as solvents (O'Brien and Hightower, 1981). Of the total evaporative (fuel spills and displaced vapors from fuel tanks) and tailpipe emissions, 10-30\% are aromatic (Black, High, and Lang, 1980). These compounds, for which toluene is representative, are highly reactive and are often the most abundant of all nonmethane hydrocarbons in polluted urban air. With the Clean Air Amendments of 1990 the number of regulated air pollutants increased from six (CO, nitric dioxide $\left(\mathrm{NO}_{2}\right), \mathrm{SO}_{2}$, particulates, ozone and lead) to a list of 189 hazardous air pollutants, and a large number of these are aromatic compounds.

\section{Photochemical Smog}

Photochemical smog forms when sunlight impinges on mixtures of organic compounds and oxides of nitrogen $\left(\mathrm{NO}_{\mathrm{x}}\right)$. Nitric oxide (NO) is a by-product of 
combustion, where high temperatures dissociate molecular oxygen and nitrogen to form NO. NO is converted to nitrogen dioxide $\left(\mathrm{NO}_{2}\right)$ through photooxidation reactions; $\mathrm{NO}_{\mathrm{x}}$ refers to the total of both $\mathrm{NO}$ and $\mathrm{NO}_{2}$. Photochemical smog occurs in areas where high levels of $\mathrm{NO}_{\mathrm{x}}$ and VOCs, organic compounds from natural processes and/or unburnt fuels from automobiles and/or stationary power facilities) are both present in high concentrations. Photochemical smog has been shown to occur in some rural settings, i.e. above the rain forest canopy, and some models suggest that much more stringent anthropogenic emissions standards would be necessary to meet urban air quality standards if biogenic emissions and processes proceed as modeled (Chameides et al., 1988).

The atmospheric fates of many compounds are well understood, particularly those compounds with 4 or less carbon atoms. Unfortunately, most biogenic and anthropogenic sources release larger, more complex compounds. Aromatic compounds, principally from anthropogenic sources, are among the most important reactive compounds in the atmosphere (Seinfeld, 1989). However, known reactions for mechanisms of even the more common of aromatics, toluene for example, can only account for about $50 \%$ of the overall reaction byproducts (Tuazon et al., 1984). A better understanding of the reaction mechanisms of both biogenic and anthropogenic VOCs is needed if accurate models of tropospheric chemistry are to be developed (Pierotti et al., 1990).

\section{HYDROXYL RADICAL CHEMISTRY}

Most reactive chemical species emitted into the atmosphere, with the exceptions of carbon dioxide and water, are in reduced chemical states. These 
include saturated and unsaturated hydrocarbons, hydrogen sulfide, as well as nitric oxide and sulfur dioxide which are oxidized further to nitrates and sulfates). The bulk of atmospheric chemistry involves the subsequent oxidation of these compounds and the removal of the oxidized forms from the atmosphere.

The primary agent of photochemical oxidations is the hydroxyl radical (HO). Hydroxyl radical oxidation processes are termed photochemical since the three primary sources of hydroxyl radicals are the photodissociation of ozone, photodissociation of carbonyl compounds and photodissociation of nitrous acid (Seinfeld, 1989). Atmospheric oxidizers like the hydroxyl radical act as detergents in the air as they transform insoluble pollutant gases into water-soluble compounds which can be eliminated from the atmosphere in precipitation (Graedel and Crutzen, 1989).

Due to the importance of hydroxyl radicals in atmospheric chemistry, much attention and study has been given to their reactions. The products of atmospheric oxidations are also important. Oxidized forms are typically soluble in rainwater, thus increasing the $\mathrm{pH}$ of precipitation, and some have been shown to be mutagenic (Dumdei et al., 1988). High levels of hydrocarbons in polluted atmospheres result in the production of ozone, a major component in photochemical smog. In order to better understand atmospheric oxidative processes, atmospheric chemistry in general, and to develop models by which changes in the atmosphere can be predicted and evaluated, an understanding of the rates, intermediates and products of hydroxyl radical oxidations is required. 
Current Methods in Atmospheric Chemistry

Hydroxyl radical reactions for organic species present in both natural and polluted atmospheres have been the subject of much study (Atkinson et al., 1979). $\mathrm{HO}$ is the major initiator of the photochemical oxidations that ultimately convert organic compounds present in the atmosphere to $\mathrm{CO}_{2}$ and water. The importance of $\mathrm{HO}$ radicals in the production of photochemical air pollution was first speculated upon by Leighton (1961). Since then, studies into HO radical chemistry have focused on three areas: measuring reaction rate constants and activation energies, identifying products of atmospheric oxidation, and elucidating reaction mechanisms. Each area of study has relied on different sets of experimental techniques to address a particular portion of $\mathrm{HO}$ radical chemistry, but few techniques address all aspects. Since some techniques (e.g. discharge flow) are normally carried out at very low pressures, the application of a particular experimental finding to atmospheric pressure processes must always be carefully considered.

Rate constants evaluated under traditional laboratory conditions are in generally good agreement with relative measurements obtained under simulated atmospheric conditions and, for most common species, the status of rate constant information for $\mathrm{HO} /$ hydrocarbon reactions is quite sound (Atkinson, 1986). The identification and quantitation of atmospheric hydrocarbon oxidation products (which generally contain $\mathrm{O}$ and/or $\mathrm{N}$ atoms as well as $\mathrm{C}$ and $\mathrm{H}$ ) has been widely addressed, using a great many techniques, yet the complete oxidation schemes and product yields remain unknown for many common compounds. The following is a sampling of the techniques that have been used in the analysis of atmospheric 
oxidation processes: gas chromatography (O'Brien et al., 1979; Leone et al., 1985;

Shepson et al., 1985; Atkinson et al., 1980), gas chromatography/mass spectrometry (Atkinson et al., 1980; Kenley, Davenport, and Hendry, 1981; Shepson, Edney, and Corse, 1984), high performance liquid chromatography (Fund and Grosjean, 1981; Besemer, 1982), tandem mass spectrometry (O'Brien et al., 1984), long path length Fourier transform infrared spectroscopy (Plum et al., 1983; Tuazon et al., 1986) and differential optical absorption spectroscopy (Tuazon et al., 1984; Bandow, Washida, and Akimoto, 1985).

Many of the aforementioned techniques have been used in studies of toluene oxidation products. Although tentative toluene oxidation mechanisms have been based upon some studies (Leone et al., 1985; Dumdei et al., 1988; Dumdei and O'Brien, 1984; Bandow, Washida, and Akimoto, 1985; Atkinson et al., 1980) elucidation of the reaction mechanisms for toluene and other members of the benzene family remains a major area of uncertainty in atmospheric chemistry (Seinfeld, 1989).

The ability to detect reaction intermediates simultaneously with stable products would be an asset in elucidating the complex mechanisms typical of aromatic compounds. One technique, photoionization-mass spectrometry (Sloane, 1978) has found some success in this area. However, this technique is complex and of limited utility for the study of atmospheric processes since the experiments are conducted at very low pressure. Ionization is generally an energetic process and the parent molecule will fragment unless the excess energy can be lost through some vibration or collision. Ionization at atmospheric pressure reduces the 
fragmentation and allows the analysis to more closely mimic actual reactions in the atmosphere (Atkinson, 1986).

\section{A New Technique: HRKAPIMS}

Much important work has been done to understand reaction pathways, identify products, yields, and reaction rates for atmospheric oxidation processes. Yet with 50\% or less of the of the atmospheric oxidation processes known for many NMHCs (Seinfeld, 1989), there is still a significant need for further work. A new experimental technique is needed that can provide insight into atmospheric oxidation products, reaction intermediates, and the relative importance of secondary reaction pathways which follow the initial attack of $\mathrm{HO}$ upon the hydrocarbon. The technique should operate at atmospheric pressure to better represent natural reaction processes and conditions, and provide a rapid and direct measure of product identities and yields. In the following chapters we will describe and demonstrate a technique that we believe meets these requirements, a technique we call High Resolution Kinetic Atmospheric Pressure Ionization Mass Spectrometry (HRKAPIMS).

\section{$\underline{\text { Research Goals }}$}

The chapters which follow examine the application of HRKAPIMS to the study of atmospheric oxidation processes. In the first three chapters we discuss the experimental aspects of HRKAPIMS. We describe a potential pitfall in the use of atmospheric pressure ionization in the analysis of smog chamber experiments, a common APIMS application, discussing methods to eliminate interference reactions which would otherwise make interpretation difficult. A new experimental 
approach to the use of APIMS for the analysis of oxidation processes is described, and its use demonstrated. We describe the development of HRKAPIMS, a powerful new approach that allows the simultaneous detection of stable products along with free radical intermediates. The use of nitric oxide to affect product yields is demonstrated, giving valuable insights into reaction kinetics and mechanisms. The final chapters address the theoretical aspects of HRKAPIMS. We describe the use of semiempirical calculations to estimate gas-phase basicities (GBs) for a wide variety of compounds and discuss the errors implicit in this approach. The use of GBs is discussed in mass spectrometric analysis. Kinetic and thermodynamic modeling is used to address the issues of APIMS and HRKAPIMS sensitivity and response and gain insights into the conditions necessary for linear response and quantitative detection of analytes.

It is hoped that the information gained in this study will be useful in unraveling the atmospheric oxidation pathways of the organic compounds present in the troposphere. This information can also be of value in the development of more complete atmospheric oxidation models, used to evaluate and regulate anthropogenic emissions, and provide a basis for improved semiempirical methodology. 


\title{
CHAPTER II
}

\section{SUPPRESSION OF SPURIOUS OXIDATION PRODUCTS IN AN ATMOSPHERIC PRESSURE IONIZATION SOURCE}

\author{
"After chemists went to all the trouble to learn \\ how to mix iron and oxygen, they only \\ came up with rust." (Davis, 1969)
}

\section{OVERVIEW}

The hydroxyl radicals which form in the ionization chamber of an atmospheric pressure ionization source react with analyte molecules present in the sample stream to form oxidation products, partially consuming the analyte and generating interference peaks in the mass spectra. We demonstrate here the effectiveness of about $1 \%$ carbon monoxide in inhibiting these reactions, and discuss the use of other radical scavengers.

\section{INTRODUCTION}

Atmospheric pressure ionization has grown in importance as an ion source for mass spectrometry (APIMS) in a variety of applications including liquid chromatography/mass spectrometry (LC/MS), analysis of biological samples and the study of atmospheric oxidations (Mitchum and Korfmacher, 1983; Sakairi and Kambara, 1988; Eiceman et al., 1988). Atmospheric pressure ionization is also finding applications in ion mobility spectrometry where it has been used to 
determine gas phase proton affinities and gas phase ion/molecule reaction rate constants (Vandiver, Leasure, and Eiceman, 1985; Vandiver, 1987). The series of ion-molecule reactions occurring either in a corona discharge, or as a result of emissions from a radioactive nickel foil, quickly generate hydrated hydronium ions and hydroxyl radicals (HO), as summarized in Reaction 1 (Good, Durden, and Kebarle, 1970a). The electron in this reaction comprises the corona current.

$$
\mathrm{nH}_{2} \mathrm{O} \rightarrow \mathrm{HO} \cdot+\mathrm{H}_{3} \mathrm{O}^{+}\left(\mathrm{H}_{2} \mathrm{O}\right)_{\mathrm{n} \cdot 2}+\mathrm{e}^{-}
$$

In APIMS, molecules with gas phase basicities (GB) greater than water are generally protonated by these hydronium-water clusters and accelerated into the analyzer region of the mass spectrometer. The production of $\mathrm{HO}$ in the ion source through Reaction 1 can be a significant source of interference when using API.

\section{$\underline{\text { HO Source Reactions }}$}

The impact of $\mathrm{HO}$ reactions in our ion source became apparent to us as we used API in the analysis of simulated atmospheric oxidations. This interference may impact other applications of API as well. In a typical oxidation experiment, organic compounds contained within a reaction vessel are photo-oxidized in a process simulating atmospheric processes (Atkinson, 1986). Here, as in the atmosphere, hydroxyl radicals are the primary removal agent for these organics (Atkinson et al., 1980). HO, formed in the reaction vessel as a result of irradiation by ultraviolet light, initiates the oxidation of the compounds present. HO reactions with hydrocarbons (HCs) involve either the abstraction of a hydrogen atom from the compound or addition of the hydroxyl radical to an unsaturated carbon-carbon bond. Typical oxidation reactions are listed in Table I for methane and ethene. Mechanisms for larger hydrocarbons may be significantly more complex, yielding 
TABLE I

ATMOSPHERIC REACTION PATHWAYS AND SELECTED GAS-PHASE BASICITIES FOR METHANE AND ETHANE

METHANE

$\mathrm{HO}+\mathrm{CH}_{4} \rightarrow \mathrm{CH}_{3} \cdot+\mathrm{H}_{2} \mathrm{O}$

$\mathrm{CH}_{3} \cdot+\mathrm{O}_{2} \rightarrow \mathrm{CH}_{3} \mathrm{O}_{2}$.

$\mathrm{CH}_{3} \mathrm{O}_{2} \cdot+\mathrm{NO} \cdot \rightarrow \mathrm{NO}_{2} \cdot+\mathrm{CH}_{3} \mathrm{O}$.

$151^{*}$

$2 \mathrm{CH}_{3} \mathrm{O}_{2} \cdot \rightarrow 2 \mathrm{CH}_{3} \mathrm{O} \cdot+\mathrm{O}_{2}$

$163^{*}$

$\mathrm{CH}_{3} \mathrm{O}_{2} \cdot+\mathrm{HO}_{2} \cdot \rightarrow \mathrm{CH}_{3} \mathrm{OOH}+\mathrm{O}_{2}$

$154^{*}$

$\mathrm{CH}_{3} \mathrm{O}+\mathrm{O}_{2} \rightarrow \mathrm{CH}_{2} \mathrm{O}+\mathrm{HO}_{2}$.

164.3

$\mathrm{CH}_{2} \mathrm{O}+\mathrm{HO} \cdot \rightarrow \mathrm{CHO} \cdot+\mathrm{H}_{2} \mathrm{O}$

$149^{*}$

$\mathrm{CHO}+\mathrm{O}_{2} \rightarrow \mathrm{CO}+\mathrm{HO}_{2}$.

134.4

$\mathrm{HO}_{2}+\mathrm{NO} \cdot \rightarrow \mathrm{HO}$. $+\mathrm{NO}_{2}$.

$\sim 150$

$2 \mathrm{HO}_{2} \cdot \rightarrow \mathrm{H}_{2} \mathrm{O}_{2}+\mathrm{O}_{2}$

$\sim 154$

\section{ETHENE}

HO. $+\mathrm{CH}_{2}=\mathrm{CH}_{2} \rightarrow \mathrm{HOCH}_{2} \mathrm{CH}_{2}$.

155.6

$\mathrm{HOCH}_{2} \mathrm{CH}_{2} \cdot+\mathrm{O}_{2} \rightarrow \mathrm{HOCH}_{2} \mathrm{CH}_{2} \mathrm{O}_{2}$.

$171 *$

$2 \mathrm{HOCH}_{2} \mathrm{CH}_{2} \mathrm{O}_{2} \cdot \rightarrow 2 \mathrm{HOCH}_{2} \mathrm{CH}_{2} \mathrm{O} \cdot+\mathrm{O}_{2}$

$164^{*}$

$\mathrm{HOCH}_{2} \mathrm{CH}_{2} \mathrm{O}_{2} \cdot+\mathrm{NO} \cdot \rightarrow \mathrm{HOCH}_{2} \mathrm{CH}_{2} \mathrm{O} \cdot+\mathrm{NO}_{2}$.

$\mathrm{HOCH}_{2} \mathrm{CH}_{2} \mathrm{O} \cdot+\mathrm{O}_{2} \rightarrow \mathrm{HOCH}_{2} \mathrm{CHO}+\mathrm{HO}_{2}$.

$181^{*}$

$\mathrm{HOCH}_{2} \mathrm{CH}_{2} \mathrm{O} \rightarrow \mathrm{H}_{2} \mathrm{C}=\mathrm{O}+\mathrm{H}_{2} \mathrm{COH}$.

$191 *$

$\mathrm{H}_{2} \mathrm{COH}$. $+\mathrm{O}_{2}->\mathrm{H}_{2} \mathrm{C}=\mathrm{O}+\mathrm{HO}_{2}$.

164.3

Notes: Mechanisms from Atkinson and Lloyd (1984). Gasphase basicities $(\mathrm{kcal} / \mathrm{mol})$ for the italicized species are given in the last column, and may be compared with $\mathrm{GB}=159$ $\mathrm{kcal} / \mathrm{mol}$ for water. Values with an asterisk are GBs based on semi-empirical calculations using an approach described in Chapter V, others are from Lias, Liebman, and Levin (1984).

a wide array of oxidation products. Reactions involving the hydroxyl radicals in

Reaction 1 within the source can change the composition of the sample, producing oxidation products which consume reagent ions and generally make detection, identification and quantitation confusing and difficult.

In this chapter we describe our efforts to overcome the interferences to API analysis caused from reactions of the source-produced hydroxyl radicals through 
the addition of low levels of carbon monoxide. Ideally, a radical scavenger could be used to convert hydroxyl radicals to an unreactive species. However, such an open shell species could possibly affect the neutral or ion reactions in the source in other undesirable ways. We selected carbon monoxide, in spite of its closed-shell electronic structure, because of its availability, its general chemical inertness with species other than HO, its low gas-phase basicity, and consequently, its expected low impact on the ion/molecule chemistry. Added in sufficient quantity to make up for its relatively slow rate of reaction with $\mathrm{HO}, \mathrm{CO}$ efficiently converts $\mathrm{HO}$ to the far less reactive $\mathrm{HO}_{2}$ in the sequence

$$
\begin{gathered}
\mathrm{HO} \cdot+\mathrm{CO} \rightarrow \mathrm{H} \cdot+\mathrm{CO}_{2} \\
\mathrm{H} \cdot+\mathrm{O}_{2}+\mathrm{M} \rightarrow \mathrm{HO}_{2}+\mathrm{M}
\end{gathered}
$$

At atmospheric pressure, hydrogen atoms are converted to $\mathrm{HO}_{2}$ with very high efficiency. The $\mathrm{GBs}$ of $\mathrm{CO}, \mathrm{CO}_{2}, \mathrm{HO}_{2}$, and $\mathrm{H}_{2} \mathrm{O}_{2}$ are all below that of water (159 $\mathrm{kcal} / \mathrm{mol}$ ). Other radical scavengers are considered below.

\section{EXPERIMENTAL}

Our API source, developed for use with a high resolution double focusing mass spectrometer, has been characterized (Grange, O’Brien, and Barofsky, 1988b; Grange, O’Brien, and Barofsky, 1988c) and its use demonstrated (Grange, O'Brien, and Barofsky, 1988a). A glass reaction vessel containing synthetic air at 50\% relative humidity with $10 \mathrm{ppm}$ toluene and $10 \mathrm{ppm} \mathrm{NO}\left(90 \% \mathrm{NO}, 10 \% \mathrm{NO}_{2}\right)$ was irradiated with sixteen 40 watt fluorescent black lights (GE F40BL). Nitric oxide was measured with a ThermoElectron Chemiluminescence Analyzer. Hydroxyl 
radicals are generated in such reaction vessels by heterogeneous processes such as these involving oxides of nitrogen (Finlayson-Pitts and Pitts, 1986).

$$
\begin{gathered}
2 \mathrm{NO}_{2}+\mathrm{H}_{2} \mathrm{O} \stackrel{\text { wall }}{-\cdots} \mathrm{HNO}_{2}+\mathrm{HNO}_{3} \\
\mathrm{HNO}_{2}+\mathrm{hv} \rightarrow \mathrm{HO}+\mathrm{NO} .
\end{gathered}
$$

Hydroxyl radicals are regenerated homogeneously in reactions controlled by nitric oxide (Table I). In the API source, $\mathrm{HO}_{2} / \mathrm{RO}_{2}$ reactions (also Table I) may result in radical recombination a larger fraction of the time (Atkinson, 1986), due to a higher $\mathrm{RO}_{2} / \mathrm{NO}$ ratio than in the atmosphere. We have observed the production of NO in our corona discharge when run in air, finding in one measurement a concentration of $15 \mathrm{ppm}$ with a $0.2 \mu \mathrm{A}$ discharge current.

Photo-oxidation products from the reaction vessel were carried out in an airflow of $2.6 \mathrm{~cm}^{3} \mathrm{~min}^{-1}$ and then diluted 1:8 into a carrier stream of zero air to reduce relative humidity and improve sensitivity (Grange, 1988). A separate flow system added carbon monoxide to the carrier stream immediately prior to the API source for a $\mathrm{CO}$ concentration of $0.8 \%$, the minimum amount possible using pure $\mathrm{CO}$ and the flow controllers available to us. A corona discharge was sustained with currents on the order of $0.2 \mu \mathrm{A}$.

\section{RESULTS AND DISCUSSION}

\section{Mass Spectrometry}

Figure 2 shows three mass spectra taken from a reactor containing methyldeuterated toluene with $0.2 \mu \mathrm{A}$ corona current. This isotopic form is useful because it predominately forms oxidation products at even masses where the 
spectrometer background is lower (Dumdei and O'Brien, 1984; O'Brien et al., 1984). Figure $2 \mathrm{a}$ is a mass spectrum acquired after the addition of toluene to the reaction vessel but before irradiation has generated true oxidation products. The predominate peaks are the hydronium-ion water clusters $(\mathrm{m} / \mathrm{z} 37,55,73,91, \ldots)$ that are formed in the corona discharge, along with several persistent contaminants and possibly their oxidation products. The peak at $\mathrm{m} / \mathrm{z} 95$ is the charge transfer ion $\left(\mathrm{B}^{+}\right)$of toluene. Spurious oxidation products, formed when toluene present in the sample stream reacts with the source produced hydroxyl radicals, appear as $\left(\mathrm{BH}^{+}\right)$and are marked with circles. These products, which were not present before the addition of toluene to the reactor, have been independently identified (Dumdei and O'Brien, 1984; O'Brien et al., 1984). Figure 2b illustrates identical conditions except that $\mathrm{CO}(0.8 \%$ of the total flow $)$ has been added to the carrier gas entering the API source. Note the significant reduction in spurious background peaks as a result of the rapid consumption of $\mathrm{HO}$ by $\mathrm{CO}$ before $\mathrm{HO}$ initiated oxidations could occur. The competition between the hydrocarbon and carbon monoxide for hydroxyl radicals is kinetically modeled below. The final figure, 2c, shows a mass spectrum acquired after 3 hours of reactor illumination. Carbon monoxide is still present in the carrier gas as in Figure 2b. Bona fide oxidation products formed by irradiation in the reaction vessel are now present in the API source and are protonated without interference from source produced HO. Circles in Figure 2c now denote the flask-generated oxidation products of methyldeuterated toluene whose structures and masses may be found in the next chapter. 

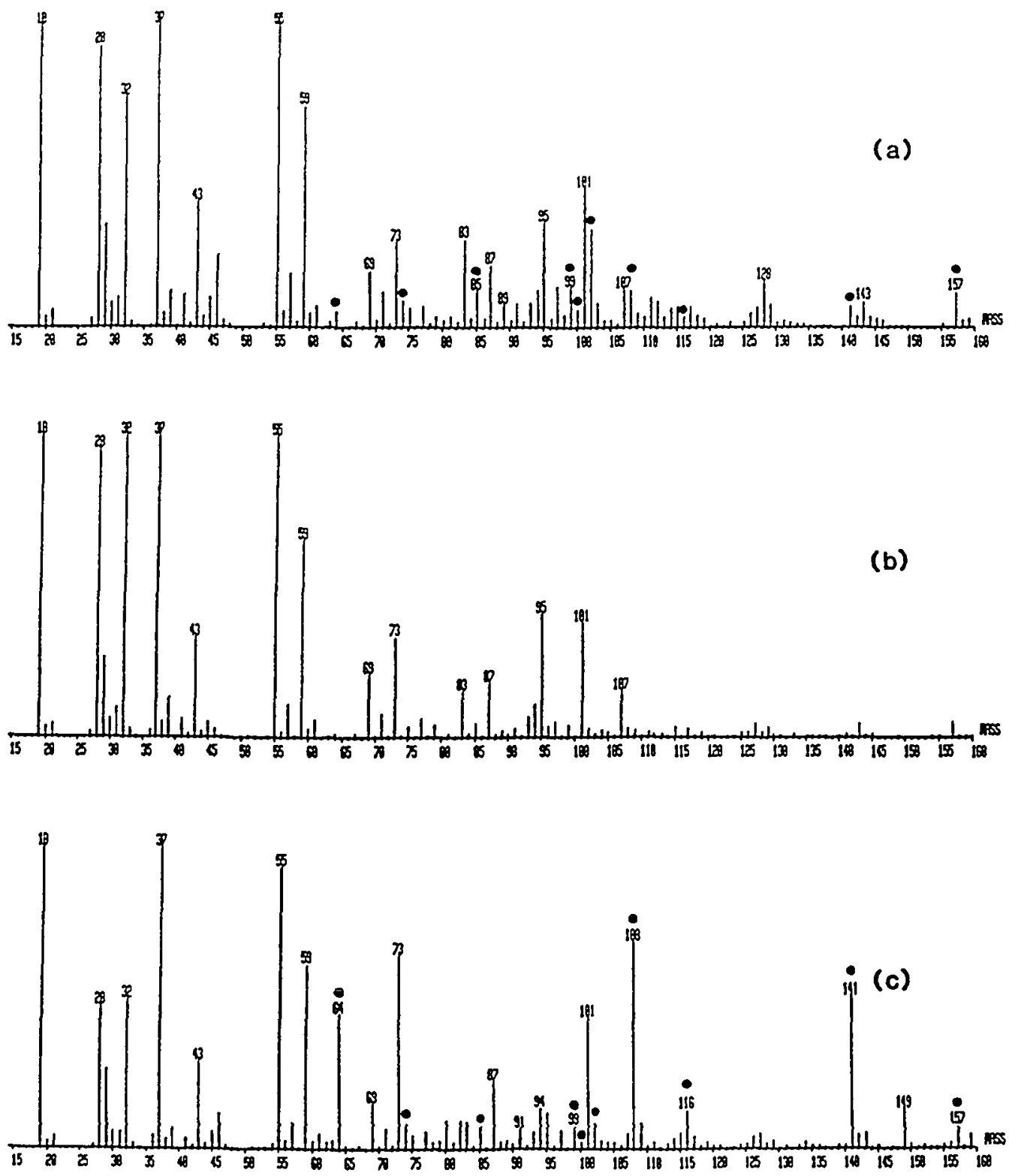

Figure 2. API reaction vessel analysis of methyldeuterated toluene. (a) Spectrum taken after addition of toluene but before any irradiation of the reaction vessel. Circles indicate spurious products not present in the background attributed to $\mathrm{HO}$ reactions. (b) With the addition of $0.8 \% \mathrm{CO}$ to the inlet flow suppressing formation of spurious products. (c) After 3 hours of irradiation the reaction vessel now contains the bona fide toluene oxidation products (circles) which are detected in the presence of CO. Source: Grange (1988). 


\section{Kinetic Modeling}

Although it is possible that some toluene oxidation is initiated by a process other than $\mathrm{HO}$ reaction, for instance quite near the corona needle tip where conditions may be more extreme than in the bulk of the discharge region, the effectiveness of $\mathrm{CO}$ in suppressing oxidation products implicates $\mathrm{HO}$ as the prime oxidant. Kinetic modeling of the reactions taking place in the source confirms this interpretation. The rate expressions for 30 reactions shown in Table II were numerically integrated, assuming 1 atm and 300K. These modeled reactions include $\mathrm{radical} / \mathrm{molecule}$ and $\mathrm{radical} / \mathrm{radical}$ reactions for the species $\mathrm{O}, \mathrm{H}, \mathrm{H}_{2}, \mathrm{HO}$, $\mathrm{HO}_{2}, \mathrm{H}_{2} \mathrm{O}_{2}, \mathrm{O}_{2}$ and $\mathrm{O}_{3}$ as well as the consumption of a generic hydrocarbon $(\mathrm{HC})$ by $\mathrm{HO}$ and $\mathrm{HO}_{2}$ radicals to form generic products. The toluene/HO and toluene/ $/ \mathrm{HO}_{2}$ rate constants are used here for the hydrocarbon. The initial $\mathrm{HO}$ concentration for the modeling was derived from the corona current, $0.2 \mu \mathrm{A}$ and the inlet flow to the API source of $20 \mathrm{~cm}^{3}$ minute ${ }^{-1}\left([\mathrm{HO}]_{0}=\left[\mathrm{H}_{3} \mathrm{O}^{+}\right]_{0}=0.2 \mu \mathrm{A} * 6.242 \times 10^{18}\right.$ ions coulomb $\mathrm{b}^{-1} / 0.333 \mathrm{~cm}^{3} \mathrm{sec}^{-1}=3.75 \times 10^{12}$ molecules $\mathrm{cm}^{-3}$ ). Figure 3 a models changes in concentration as a function of time for the reactions in Table II. After 1 millisecond, $12 \%$ of the initial hydrocarbon has been consumed by hydroxyl radicals. Hydroxyl radical concentration falls in the same time by $63 \%$ due to its reaction with $\mathrm{HC}$ and through other radical loss processes. The residence time in this source is 1.6 seconds based on a cell volume of $0.52 \mathrm{~cm}^{3}$ and the sample flow of $20 \mathrm{~cm}^{3} \mathrm{~min}^{-1}$. The modeling may not be quantitative because of uncertainties in the actual volume/time concentration profiles, as well as the source temperature, but are qualitatively correct. 
HO Chemistry. The HO concentration in an atmospheric pressure ionization source is directly dependent upon the magnitude of the corona discharge current or emission rate from the radioactive nickel foil. In our source, $0.2 \mu \mathrm{A}$ is the minimum stable corona discharge current, and it was used to minimize the interferences associated with $\mathrm{HO}$ reactions. Interferences are greater at higher currents. One effort (Eiceman et al., 1988) to identify the optimal conditions for APIMS has shown that a $2.0 \mu \mathrm{A}$ discharge results in a significantly larger analyte ion current and maintains a more stable discharge. Figure $3 \mathrm{~b}$ models the same species with the same concentrations but at this higher discharge current. The logarithmic scale of the y-axis in Figure 3a was selected to show the concentration

TABLE II

MECHANISM FOR KINETIC MODELING OF HO AND CO REACTIONS IN HYDROCARBON OXIDATIONS

\begin{tabular}{|c|c|c|c|c|c|c|c|}
\hline \multicolumn{2}{|c|}{ Reaction } & \multicolumn{6}{|c|}{ Reaction Rate Constan } \\
\hline $\mathrm{O}$ & $\mathrm{O}$ & M & $=$ & $\mathrm{O} 2$ & $\mathbf{M}$ & & $5.8 \mathrm{E}-32$ \\
\hline $\mathbf{H}$ & $\mathrm{O} 2$ & M & $=$ & $\mathrm{HO} 2$ & $\mathbf{M}$ & & 1.8E-32 \\
\hline $\mathrm{OH}$ & $\mathrm{OH}$ & & $=$ & $\mathrm{H} 2 \mathrm{O}$ & 0 & & $1.6 \mathrm{E}-12$ \\
\hline $\mathrm{OH}$ & 0 & & $=$ & $\mathbf{H}$ & $\mathrm{O} 2$ & & 3.8E-11 \\
\hline $\mathrm{OH}$ & $\mathrm{H}$ & & $=$ & $\mathrm{H} 2$ & 0 & & $1.2 \mathrm{E}-19$ \\
\hline $\mathrm{OH}$ & $\mathrm{H}$ & M & $=$ & $\mathrm{H} 2 \mathrm{O}$ & $\mathbf{M}$ & & $6.8 \mathrm{E}-31$ \\
\hline $\mathrm{OH}$ & $\mathrm{OH}$ & $\mathrm{M}$ & $=$ & $\mathrm{H} 2 \mathrm{O} 2$ & $\mathbf{M}$ & & $6.9 \mathrm{E}-31$ \\
\hline $\mathrm{HO} 2$ & $\mathbf{M}$ & & $=$ & $\mathrm{H}$ & $\mathrm{O} 2$ & $\mathbf{M}$ & $1.7 \mathrm{E}-42$ \\
\hline $\mathrm{HO} 2$ & $\mathrm{H}$ & & $=$ & $\mathrm{H} 2$ & $\mathrm{O} 2$ & & $1.3 \mathrm{E}-11$ \\
\hline $\mathrm{HO} 2$ & $\mathrm{H}$ & & $=$ & $2 \mathrm{OH}$ & & & $3.2 \mathrm{E}-11$ \\
\hline $\mathrm{HO} 2$ & $\mathrm{OH}$ & & $=$ & $\mathrm{H} 2 \mathrm{O}$ & $\mathrm{O} 2$ & & $7.0 \mathrm{E}-11$ \\
\hline $\mathrm{HO} 2$ & $\mathrm{HO} 2$ & & $=$ & $\mathrm{H} 2 \mathrm{O} 2$ & $\mathrm{O} 2$ & & $1.7 \mathrm{E}-12$ \\
\hline $\mathrm{H}$ & $\mathrm{O} 2$ & $\mathbf{M}$ & $=$ & $\mathrm{HO} 2$ & $\mathbf{M}$ & & 5.5E-32 \\
\hline $\mathrm{H} 2 \mathrm{O} 2$ & $\mathbf{H}$ & & $=$ & H2 & $\mathrm{HO} 2$ & & 5.0E-15 \\
\hline 0 & $\mathrm{O} 2$ & $\mathbf{M}$ & $=$ & $\mathrm{O} 3$ & $\mathbf{M}$ & & 5.7E-34 \\
\hline $\mathrm{OH}$ & $\mathrm{O} 3$ & & $=$ & $\mathrm{HO} 2$ & $\mathrm{O} 2$ & & $6.8 \mathrm{E}-14$ \\
\hline 0 & $\mathrm{HO} 2$ & & $=$ & $\mathrm{OH}$ & $\mathrm{O} 2$ & & $5.7 \mathrm{E}-11$ \\
\hline 0 & $\mathrm{O} 3$ & & $=$ & 202 & & & 8.0E-12 \\
\hline $\mathrm{H}$ & $\mathrm{HO} 2$ & & $=$ & $\mathrm{H} 2 \mathrm{O}$ & 0 & & 3.0E-12 \\
\hline
\end{tabular}


TABLE II

\section{MECHANISM FOR KINETIC MODELING OF HO AND CO REACTIONS IN HYDROCARBON OXIDATIONS (continued)}

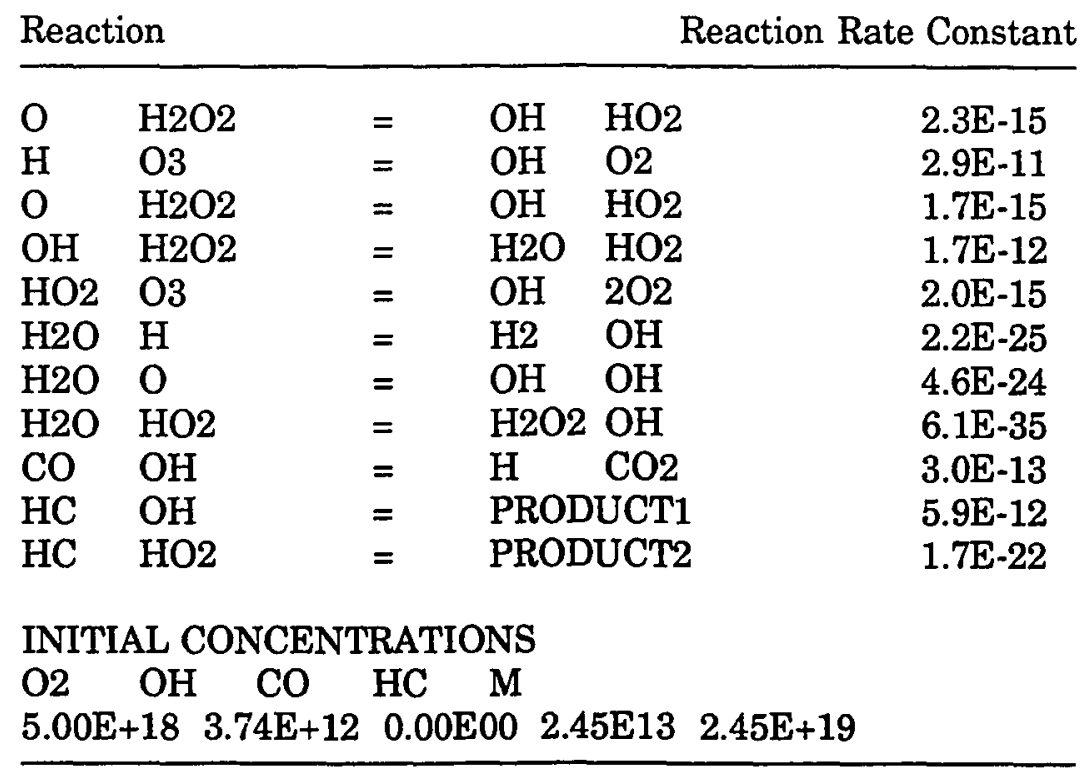

Note: Rate constants at $\mathrm{T}=300 \mathrm{~K}$ in units of $\mathrm{cm}^{3}$ molecules ${ }^{-1}$ $\mathrm{sec}^{-1}$ or $\mathrm{cm}^{6}$ molecules $\mathrm{sec}^{-1}$ as appropriate, where e represents the base ten exponent. Initial concentrations for $\mathrm{HO}$ and $\mathrm{CO}$ were adjusted to provide different inputs for Figures 2 and 3. A $0.2 \mu \mathrm{A}$ discharge current corresponds to a $3.74 \times 10^{12}$ molecules $\mathrm{cm}^{-3} \mathrm{HO}$ concentration; $0.8 \% \mathrm{CO}$ corresponds to 1.96 x $10^{17}$ molecules $\mathrm{cm}^{-3}$.

changes of all species, but it compresses the scale for the hydrocarbon's

consumption. At the larger $\mathrm{HO}$ concentration in Figure $3 \mathrm{~b}$, the decrease in HC concentration due to $\mathrm{HO}$ reaction is very apparent, and the oxidation products are also more abundant in agreement with experimental results. The source sampling rate influences modeled radical concentrations in a similar fashion, with higher flow rates resulting in proportionately lower initial radical concentrations. 

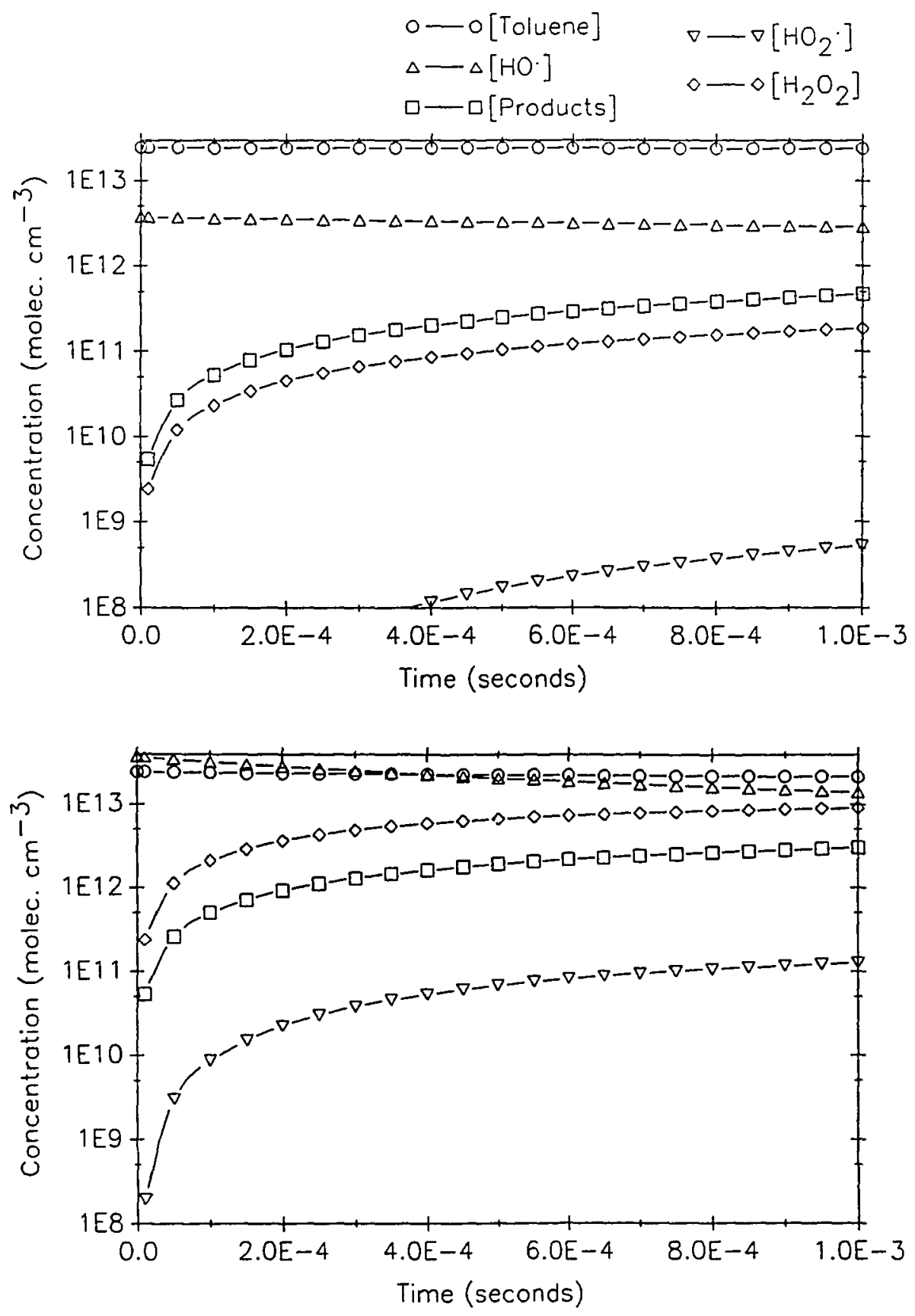

Figure 3. Kinetic modeling of HO reactions in the API source. (a) Hydronium ion concentration equivalent to a $0.2 \mu \mathrm{A}$ discharge. After 1 millisecond, $12 \%$ of the initial compound is converted by $\mathrm{HO}$ to product. (b) Modeling of a $2.0 \mu \mathrm{A}$ discharge. A substantial decrease in the $\mathrm{HC}$ concentration and increase in product formation is evident. $\mathrm{HC}$ consumption is non-linearly related to the initial $\mathrm{HC}$ concentration because of $\mathrm{HO}$ self reactions at higher concentrations. 
It should be noted that a significant APIMS signal from spurious oxidation products will be obtained even with only a slight oxidation of the parent hydrocarbon. In our source, toluene appears as a charge transfer ion proportionately less intense than its oxidation products. For hydrocarbons which appear as $\mathrm{BH}^{+}$ions, the much higher gas-phase basicities of the oxygen-containing oxidation products relative to their parent hydrocarbons result in even greater (relative to toluene) sensitivity for the oxidation products. For analytes below $\mathrm{GB} \approx 200$, a $9 \mathrm{kcal} / \mathrm{mole}$ difference in basicity was shown in one study (Sunner, Nicol, and Kebarle, 1988) to result in about a ten-fold reduction in relative API sensitivity. The response differences based on the relative sensitivities of the oxidation products will be most pronounced for saturated hydrocarbons, which have much lower GBs than alkenes or aromatics. For instance, the GB of propane is $142 \mathrm{kcal} / \mathrm{mole}$ while the basicity of one oxidation product, acetone, is more than 190 $\mathrm{kcal} / \mathrm{mole}$. Table I lists the GB values of a range of simple alkane and alkene oxidation products arising from the atmospheric oxidation of methane and ethene.

CO Chemistry. To demonstrate the effects of carbon monoxide on API source chemistry, the reactions in Table II were reintegrated using a CO concentration of $0.8 \%\left(1.96 \times 10^{17}\right.$ molecules $\left.\mathrm{cm}^{-3}\right)$. This concentration is somewhat more than necessary to suppress the source reactions of $\mathrm{HO}$ with toluene. The relative rates of the $\mathrm{HO}$ reactions with $\mathrm{CO}$ and with toluene indicate that $0.8 \%$ provides a four fold excess of $\mathrm{CO}$ beyond the level needed to assure that $99 \%$ of the hydroxyl radicals will be consumed with $\mathrm{CO}$. Figures $4 \mathrm{a}$ and $4 \mathrm{~b}$ show the immediate decrease in the HO concentration due to reaction of hydroxyl radicals with carbon monoxide, while the initial hydrocarbon concentration is unchanged. 
Figure $4 \mathrm{a}$ is modeled with a $0.2 \mu \mathrm{A}$ current whereas Figure $4 \mathrm{~b}$ models the higher $2.0 \mu \mathrm{A}$ discharge level. In each case where $\mathrm{CO}$ is present, the rapid conversion of $\mathrm{HO}$ to $\mathrm{HO}_{2}$ preserves the analyte for subsequent detection by the mass spectrometer and eliminates spurious signals at other masses corresponding to analyte or contaminant oxidation products. Of course, alkanes and alkenes would not be likely analytes for APIMS, but aromatics have been routinely measured with the Sciex TAGA system. Heteroatom containing organic analytes (likely candidates for APIMS analysis) will also react with $\mathrm{HO}$, usually with higher rates than the hydrocarbons from which they are derived. Since these analytes have appreciable GBs, their oxidation products may not have the high relative API sensitivity typical of the oxidation products of pure hydrocarbons.

$\mathrm{HO}_{2}$ Chemistry. Many compounds have rate constant ratios for reactions with $\mathrm{HO}_{2}$ vs. $\mathrm{HO}$ that are larger than in the case of toluene, and it is possible that conversion of $\mathrm{HO}$ to $\mathrm{HO}_{2}$ by $\mathrm{CO}$ might still allow some conversion of an analyte to oxidation products by $\mathrm{HO}_{2}$ reactions. Compared to $\mathrm{HO}, \mathrm{HO}_{2}$ abstracts aldehydic hydrogen atoms and adds to non-aromatic double bonds proportionately much faster than it reacts with toluene (e.g. by 8 and 5 orders of magnitude, respectively, for formaldehyde and ethene). API source reactions of ethene and formaldehyde with $\mathrm{HO}$ and $\mathrm{HO}_{2}$ were each modeled at $0.2 \mu \mathrm{A}$ corona current using available rate constants (Atkinson and Lloyd, 1984). Without CO, approximately 3\% of both compounds were consumed; after the addition of $0.8 \% \mathrm{CO}$, these losses were reduced to $0.08 \%$ for formaldehyde and $0.04 \%$ for ethene. This suggests that while $\mathrm{HO}_{2}$ reactions of many species are faster than toluene's, analyte concentrations will still not be significantly perturbed by $\mathrm{CO}$ conversion of $\mathrm{HO}$ to $\mathrm{HO}_{2}$. 

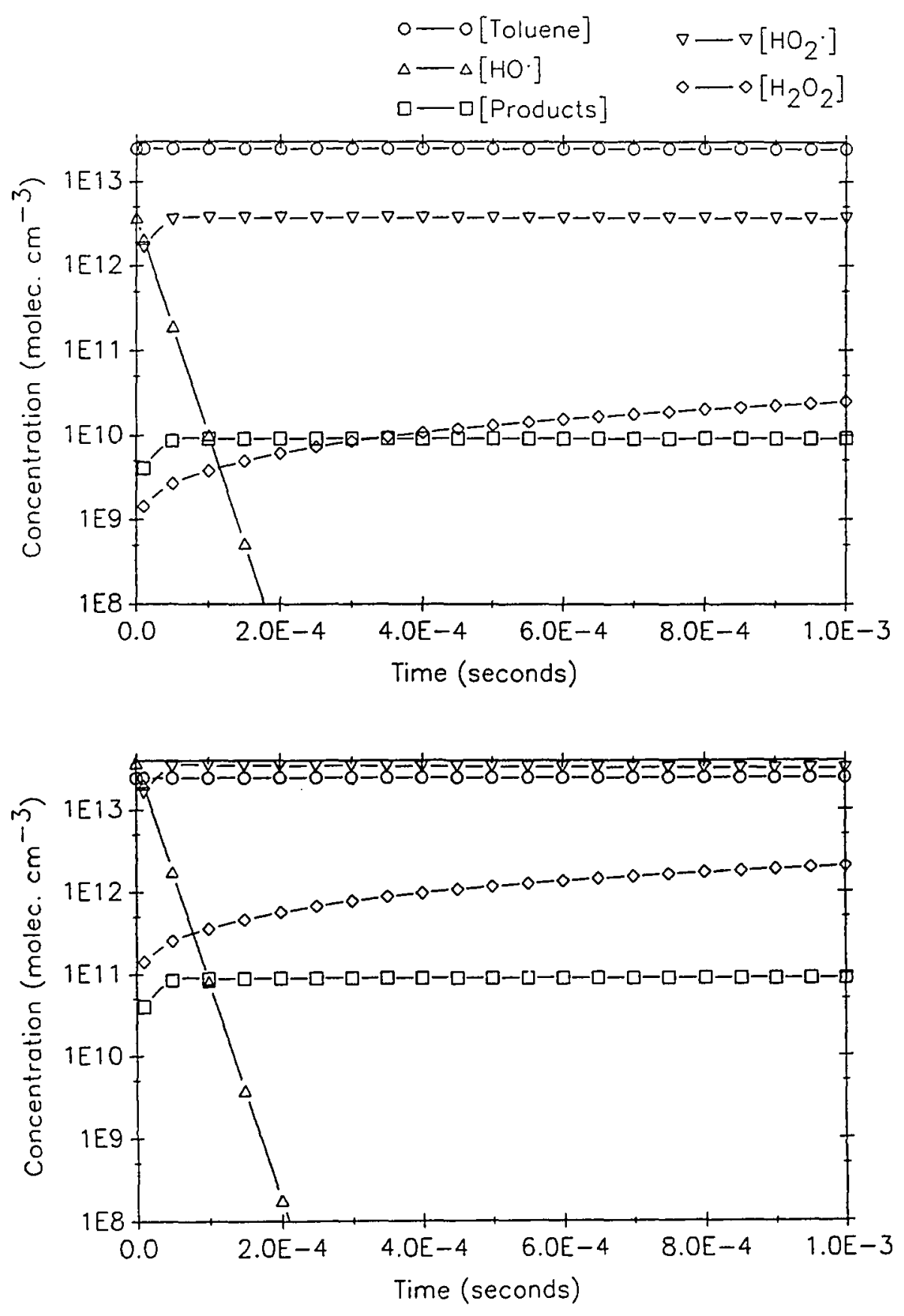

Figure 4. Kinetic modeling of HO reactions in an API source in the presence of carbon monoxide. Figures $4 \mathrm{a}$ and $4 \mathrm{~b}$ correspond to the same plots in Figure 3: (a) $0.2 \mu \mathrm{A}$ current without CO; (b) $2.0 \mu \mathrm{A}$ current plus $0.8 \% \mathrm{CO}$. $\mathrm{HO}$ is now prevented from initiating the oxidation of the hydrocarbons. Modeling based on the mechanism in Table II. 


\section{CONCLUSIONS}

The potential influence of source-produced hydroxyl radicals should be considered in any application involving atmospheric pressure ionization. We are aware of only one previous discussion of source-related chemistry in APIMS (Mahle, Cooks, and Kurzeniowski, 1988), viz. the observation of several hydrocarbon/oxygen adducts from an API source at elevated temperature, sampling an unspecified concentration of benzene, toluene, or other aromatic hydrocarbon. Although the authors suggested these products resulted from "probably ionic intermediates" in the source, we believe that HO-initiated reactions are a more likely cause, and that $\mathrm{CO}$ would be effective in alleviating their concern that "The extent to which oxygenated products can occur under normal API conditions indicates that caution should be exercised when interpreting these spectra" (Mahle, Cooks, and Korzeniowski, 1988).

We believe APIMS to have great potential for the analysis of oxidation products in atmospheric chemistry or combustion research but studies of oxidation products can be greatly complicated if significant $\mathrm{HO}$ radical reactions occur in the source. Carbon monoxide is a useful reagent for eliminating $\mathrm{HO}$ reactions, although its low reactivity with $\mathrm{HO}$ requires that fairly high concentrations be added. In our source, the small sampling rate facilitates the use of sufficiently high $\mathrm{CO}$ concentrations. In sources with larger sampling rates (requiring higher scavenger flow rates) or when analytes are more reactive and/or present at higher concentrations than in this study, a more reactive $\mathrm{HO}$ scavenger may be desirable to reduce the total amount of scavenger needed. 
The relationship between the minimum amount of $\mathrm{CO}$ necessary to avoid source reactions and the hydrocarbon reaction rate can be illustrated. The upper limit to analyte/HO rate constants is given by the gas phase collision rate, about $5 \times 10^{-10} \mathrm{~cm}^{-3} \mathrm{sec}^{-1}$. In order to assure that $99 \%$ of the available HO will react with $\mathrm{CO}$ and not with a highly reactive hydrocarbon present at $1 \mathrm{ppm}$, one must add at least $0.165 \% \mathrm{CO}$. However, few analytes would react as quickly as the collision rate. Extensive tabulations of $\mathrm{HO}$ reaction rate constants with a variety of organic compounds (Atkinson, 1986) will allow the assessment of HO reactions with many potential analytes and most compound families.

\section{Other Radical Scavengers}

HO scavengers other than $\mathrm{CO}$ could be considered. $\mathrm{H}_{2}$ cleanly converts $\mathrm{HO}$ to $\mathrm{HO}_{2}$, but at $300 \mathrm{~K}$ reacts 34 times slower than $\mathrm{CO}$, requiring correspondingly higher concentrations.

$$
\mathrm{HO}+\mathrm{H}_{2} \rightarrow \mathrm{H}_{2} \mathrm{O}+\mathrm{H}, \mathrm{H}+\mathrm{O}_{2}+\mathrm{M} \rightarrow \mathrm{HO}_{2}+\mathrm{M}
$$

Before this reagent is tried, the possibility of explosion should be considered.

$\mathrm{NO}_{2}$ reacts with hydroxyl radicals under atmospheric conditions 40 times faster than $\mathrm{CO}(\mathrm{R} 7) . \mathrm{NO}_{2}$ is available in permeation tubes, although these tubes may not have high enough permeation rates to be useful.

$$
\mathrm{HO}+\mathrm{NO}_{2}+\mathrm{M} \rightarrow \mathrm{HNO}_{3}+\mathrm{M}
$$

Any of the lighter hydrocarbons could be used, with the caveat that its oxidation products may appear in the mass spectrum, consuming reagent ions in the process. Thus it is desirable to use a reactive hydrocarbon (a gas might be most convenient for delivery) that generates oxidation products with low gas-phase 
basicity. Ethene (Table I) reacts with HO 30 times faster than $\mathrm{CO}$ and has few products with GB greater than the value of $159 \mathrm{kcal} /$ mole for water. Higher hydrocarbons, although they may react faster with $\mathrm{HO}$, have the disadvantage of producing a larger number of products, many with significant GBs.

\section{New Applications}

Although reactions of analytes with $\mathrm{HO}$ in an API source may be a nuisance in some applications, it should be possible to use the source-produced hydroxyl radicals for efficient study of atmospheric oxidation mechanisms and kinetics in a complete elimination of the reaction vessel. Such an approach would be useful for atmospheric chemistry or combustion research and will be discussed in detail in the following chapter. 


\title{
CHAPTER III
}

\section{STUDIES OF ATMOSPHERIC HO OXIDATION MECHANISMS BY IN SITU HIGH RESOLUTION ATMOSPHERIC PRESSURE IONIZATION MASS SPECTROMETRY}

\author{
"Some oxygen molecules help fires to burn while others \\ choose to help make water, so sometimes it is \\ brother against brother." (Davis, 1969)
}

\section{OVERVIEW}

In this chapter we describe a new approach to studying atmospheric oxidation mechanisms that uses the hydroxyl radicals created along with hydronium ions in a mass spectrometers' atmospheric pressure ionization source. Hydroxyl radicals formed in the source quickly react with organic compounds added to the sample line to initiate the formation of oxidation products from those compounds. These products are then efficiently protonated by the reagent hydronium ions and mass analyzed. APIMS source reactions are used to analyze toluene's oxidation products, which are shown by their high resolution masses to be identical to those found in previous experiments using a wide variety of other experimental approaches. The use of empirical formulas derived from accurate mass assignment using APIMS can reduce dependance on calibration standards, few of which are available for environmental analysis. 


\section{INTRODUCTION}

Atmospheric pressure ionization (API) has grown in importance as an ionization source in mass spectrometric analysis since its introduction by Horning et al. (1973). This technique offers significant advantages in mass spectrometry, including high ionization efficiencies (sensitivities in the ppt to ppb range), a dynamic range of up to 3 decades (Reid et al., 1978) and high selectivity for most compounds having proton affinities greater than water (Mitchum and Korfmacker, 1983). There are a variety of spectrometric applications for API, including the direct sampling of gases at ambient pressures from real or simulated atmospheres. Ambient pressure sampling is useful in the analysis of degradation pathways of trace organic compounds in atmospheric chemistry (Grange, O’Brien, and Barofsky, 1988a; Dumdei et al., 1988), an area of particular interest to us.

In positive ion API, the series of ion-molecule reactions occurring within the API source quickly leads to the generation of protonated analyte molecules, $\left(\mathrm{BH}^{+}\right)$, as illustrated by the simplified reaction mechanism shown below (Good, Durden, and Kebarle, 1970a; Proctor and Todd, 1983).

$$
\begin{gathered}
2 \mathrm{H}_{2} \mathrm{O}->\mathrm{H}_{3} \mathrm{O}^{+}+\mathrm{HO}+\mathrm{e}^{-} \\
\mathrm{H}_{3} \mathrm{O}^{+}+\mathrm{B}<-->\mathrm{BH}^{+}+\mathrm{H}_{2} \mathrm{O} \\
\mathrm{H}_{3} \mathrm{O}^{+}+\mathrm{nH}_{2} \mathrm{O}<-->\mathrm{H}_{3} \mathrm{O}^{+}\left(\mathrm{H}_{2} \mathrm{O}\right)_{\mathrm{n}} \\
\mathrm{H}_{3} \mathrm{O}^{+}\left(\mathrm{H}_{2} \mathrm{O}\right)_{\mathrm{n}}+\mathrm{B}<-->\mathrm{BH}^{+}\left(\mathrm{H}_{2} \mathrm{O}\right)_{m}+(\mathrm{n}+1-\mathrm{m}) \mathrm{H}_{2} \mathrm{O}
\end{gathered}
$$

The electron formed in Reaction 8 (R8) is removed at the corona needle, while the hydronium ion participates in proton transfer reactions with an analyte (B). Declustering of hydrated hydroniums and analytes, which are formed in Reactions 
10 and 11, occurs as the ions pass through a dry curtain gas (Reid et al., 1979) or a collision-induced dissociation (CID) region within the ion source (Kambara and Kanomata, 1977), depending on the design of the API source. Declustering concentrates the analyte signal at the single mass of $\mathrm{BH}^{+}$without the spectral complication of hydrating water molecules. An important feature of this reaction sequence is the production of the hydroxyl radical (HO) along with the first hydronium ion-water cluster in R8. Hydroxyl radicals are the primary oxidizing agent for trace organics found in the atmosphere (Atkinson et al., 1979), and in combustion processes (Atkinson, Bull, and Shuff, 1980).

The following paragraphs describe the development and applications of a novel application of API in studying atmospheric oxidation processes. Hydroxyl radicals produced in $\mathrm{R} 8$ initiate the oxidation of reactant molecules carried in the inlet sample stream. The oxidation products formed within the source mimic those formed by natural processes in the atmosphere. This technique provides significant advantages in the analysis of atmospheric oxidation processes, which we apply here to the chemical degradation of toluene. Toluene is of environmental significance because of its widespread use in fuels and its worldwide presence in the troposphere, measured at levels up $0.1 \mathrm{ppm}$ (Singh et al., 1985). Although much study has been made into toluene's oxidation mechanism, this mechanism has not yet been fully characterized, in part due to the large number of products, their structural complexity (Atkinson et al., 1980; Dumdei and O'Brien, 1984; Leone et al., 1985), and their propensity to adsorb on reaction vessel walls and plumbing (O'Brien et al., 1983). Because of the importance of aromatic compounds 
in the troposphere, unraveling their oxidation pathways remains one of the greatest needs in atmospheric chemistry research (Seinfeld, 1989).

\section{EXPERIMENTAL}

All mass spectrometry was performed on a VG 7070E-HF double-focusing high resolution mass spectrometer using an API source described elsewhere (Grange, O'Brien, and Barofsky, 1988b; Grange, O'Brien, and Barofsky, 1988c). Coupled with this high resolution mass spectrometer, the API source has provided resolutions of 2800 or more which is both necessary and sufficient to distinguish between oxidation products near 100 Daltons, differing in mass by as little as 0.036 Dalton $(\mathrm{M} / \Delta \mathrm{M}=100 / 0.036 \approx 2800)$ (Grange, O'Brien, and Barofsky, 1988a). This resolution corresponds to the mass difference between a carbonyl $\mathrm{R}_{2} \mathrm{C}=\mathrm{O}$ and an ethyl group $\mathrm{R}-\mathrm{CH}_{2}-\mathrm{CH}_{2}-\mathrm{R}$, moieties which are unresolvable with quadrupole mass filters or lower resolution magnetic sector instruments. Two isotopically labeled forms of toluene, methyldeuterated $\left(\mathrm{C}_{6} \mathrm{H}_{5} \mathrm{CD}_{3} \equiv \mathrm{D}_{3}\right)$ and perdeuterated $\left(\mathrm{C}_{6} \mathrm{D}_{5} \mathrm{CD}_{3} \equiv\right.$ $\left.\mathrm{D}_{8}\right)$, were used in addition to unlabeled toluene $\left(\mathrm{C}_{6} \mathrm{H}_{5} \mathrm{CH}_{3} \equiv \mathrm{H}_{8}\right)$ as a means to verify the product identifications and the reproducibility of the technique.

Toluene was delivered to the API source at a level of $2 \mathrm{ppm}$ in a $25 \mathrm{~cm}^{3}$ $\min ^{-1}$ oxygen carrier gas. Corona discharge currents were varied from 0.2 to $10 \mu \mathrm{A}$. The inlet flow rate to the ion source was generally $26 \mathrm{~cm}^{3} \mathrm{~min}^{-1}$. With a cell volume of $0.52 \mathrm{~cm}^{3}$, the neutral residence time in the source was on the order of 1.2 seconds. 


\section{RESULTS AND DISCUSSION}

\section{Toluene Products}

Mass spectra representative of API source reactions are shown in Figure 5. These were taken using toluene $D_{8}$ in an oxygen carrier gas with a $2.0 \mu \mathrm{A}$ discharge current. Figure 5a is a background spectrum acquired prior to the addition of toluene to the API source. Ion signals at $37,55,73,91$, etc. represent hydrated hydronium ions which are incompletely declustered in the CID region; most other peaks arise from persistent background contaminants. Figure $5 \mathrm{~b}$ is a spectrum acquired after toluene had been added to the carrier gas for a $2 \mathrm{ppm}$ concentration in the API source. The resulting oxidation products are now evident, particularly the $\mathrm{m} / \mathrm{z} 113$ peak arising from protonated benzaldehyde, and the ring opened products at $\mathrm{m} / \mathrm{z} 89,105$ and 133 . The role of hydroxyl radicals in initiating toluene's oxidation was confirmed by experiments in which $0.8 \% \mathrm{CO}$ was added to the airstream. Carbon monoxide is a stable species, whose only significant atmospheric loss process is by $\mathrm{HO}$-oxidation to $\mathrm{CO}_{2}$. The $\mathrm{CO}$ experiments (described in the previous chapter) were effective in the suppression of the observed toluene oxidation products.

Table III summarizes the toluene oxidation products identified using API source reactions. Although more than one isomeric form is possible at a given experimental mass, usually only one representative structure is named, based on a rational elemental composition containing carbon, hydrogen, oxygen and nitrogen. In most cases these isomeric forms would have functional groups (e.g. the methyl group) located at different positions in the molecule. However, three of the 30 


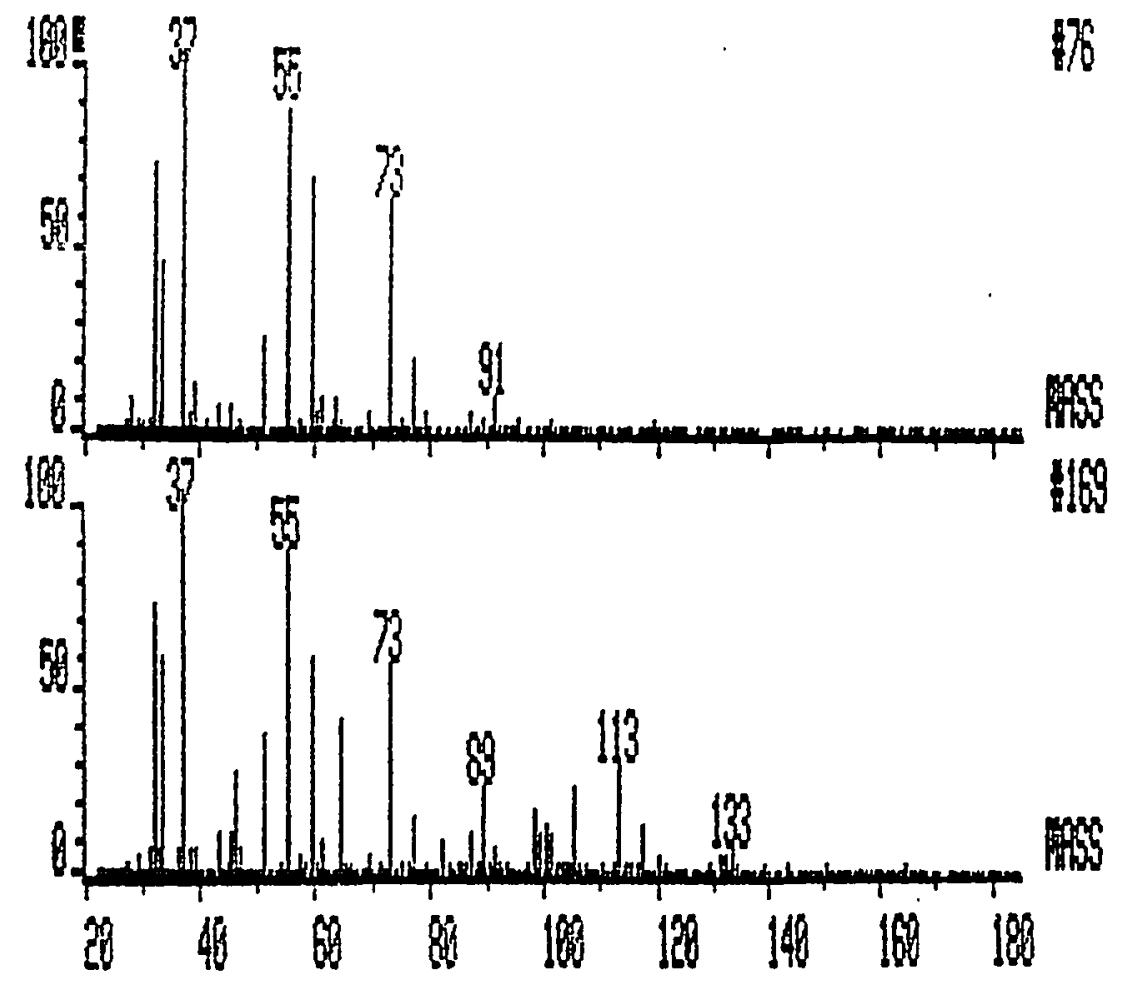

Figure 5. Mass spectral sequence illustrating the photooxidation of $\mathrm{D}_{8}$ toluene in an oxygen carrier gas. (a) Background spectrum: dominant peaks include hydrated hydronium ions $(\mathrm{m} / \mathrm{z} 37,55,73$, and several persistent background compounds; (b) After the addition of $2 \mathrm{ppm}$ toluene to the carrier gas, source produced $\mathrm{HO}$ radicals initiate toluene's oxidation. Prominent products include signals at $\mathrm{m} / \mathrm{z}$ 64, 89, 105, 113 and 133 (see Table III).

identified products which are isomeric in the perhydrogenated form are separated in the methyl- or perdeuterated forms. These compounds occur in toluene- $\mathrm{H}_{8}$ at 99.044, 123.048 and 125.058 Daltons. In these three cases, the deuterated forms of toluene further resolve the identities of these products using empirical formula information. Products whose $\mathrm{H}_{8}$ masses are similar to dominant background peaks can also be resolved by employing a deuterated form. Elemental analysis is discussed in detail below. 
For each compound, and for each of the three experiments, the experimental mass assignments are based on the protonated form of that compound $\left(\mathrm{BH}^{+}\right)$, except for toluene and phenol which were detected as charge transfer ions $\left(\mathrm{B}^{+}\right)$. The product masses are replaced with an asterisk when the peak was not detected or identified, usually because of a large background peak at the same nominal mass as the product. In such cases the smaller product peak may not be distinguishable on the shoulder of the background peak by the data processing unit of the mass spectrometer. The uncertainty in mass assignment which follows each product mass is the standard deviation in experimental masses based on a series of scans (generally 3-6). The differences between the experimental masses and calculated masses for each product are given in parentheses following each set of product mass and uncertainty. At the foot of the column for each isotopic form of toluene, the average of the differences, $\Delta \mathrm{m}$, between the calculated and experimental masses is shown, along with the corresponding standard deviation in those differences.

The mass assignments summarized in Table III for each isotopic form confirm the empirical formulas for toluene's primary oxidation products. An alternative description of instrument resolution can be derived from the average uncertainty in the mass assignments. This uncertainty, expressed as the standard deviation of the average mass differences (calcd-exptl), ranges from 0.004 to 0.008 Daltons, Table III. Using this alternative resolution definition, the uncertainty in

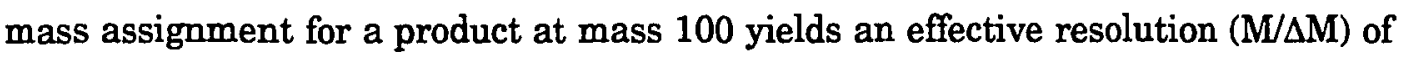
$(100 / .006) \approx 17,000$. This indicates the high degree of certainty which may be attributed to the mass assignments in these experiments. Although some of the 
TABLE III

TOLUENE OXIDATION PRODUCTS FOUND USING API SOURCE REACTIONS

\begin{tabular}{|c|c|c|c|}
\hline Product & [Isomers] &. $\mathrm{C}_{6} \mathrm{H}_{5} \mathrm{CD}_{3}$ &. $\mathrm{C}_{6} \mathrm{D}_{5} \mathrm{CD}_{3}$ \\
\hline
\end{tabular}

Acetic acid

[9] $61.023 \pm .014(-.006)$

$64.046+.007(-.002) \quad 64.042+.006(-.006)$

(Dumdei et al., 1988; Dumdei and O’Brien, 1984)

Furan

[13] $\quad 69.034 \pm .009(0.000)$

$69.042 \pm .014(+.008)$

(Shepson, Edney, and Corse, 1984)

Methyl vinyl ketone

[14] $\quad 71.048 \pm .007(-.002) \quad 74.068 \pm .006(-.001) \quad 77.075+.012(-.012)$

(Dumdei et al., 1988; Dumdei and O'Brien, 1984; Shepson, Edney, and Corse, 1984)

Methyl glyoxal

$$
\text { *. }
$$

$76.053 \pm .008(+.005)$

*.

(Dumdei et al., 1988; Dumdei and O’Brien, 1984; Bandow, Washida, and Akimoto, 1985; Gery et al., 1985)

Methyl furan

Butenedial

Hydroxyoxobutene
[16] $83.053 \pm .003(+.003)$

$86.067+.012(-.002)$
[17] $\quad 85.029 \pm .005(0.000) \quad 85.033 \pm .001(+.004) \quad 89.052 \pm .006(-.002)$

(Dumdei et al., 1988; Dumdei and O'Brien, 1984; Shepson, Edney, and Corse, 1984) 


\section{TABLE III}

\section{TOLUENE OXIDATION PRODUCTS FOUND USING API SOURCE REACTIONS}

(continued)

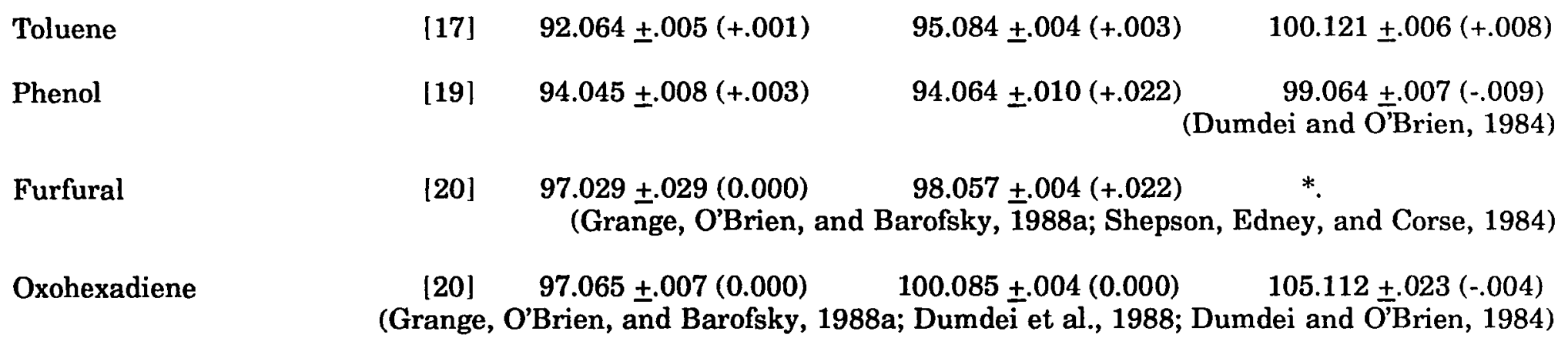

Methylbutendial

Hydroxypentadienal

Hydroxybutendial

Hydroxyoxobutanal

Oxohexadiene

[22] $\quad 99.044+.010(-.001)$ (Grange, O'Brien, and Barofsky, 1988, Dumdei et al., 1988; Dumdei and O’Brien, 1984)

[22] $99.044 \pm .010(-.001)$

*.

[22] $\quad 103.042 \pm .011(+.002)$

[20] $\quad 97.065 \pm .007(0.000)$

(Grange, O'Brien, and Barofsky, 1988a; Dumd 
TABLE III

TOLUENE OXIDATION PRODUCTS FOUND USING API SOURCE REACTIONS

(continued)

Benzaldehyde $\quad[24] \quad 107.050 \pm .012(0.000) \quad 108.051 \pm .003(-.005) \quad 113.086 \pm .014(-.001)$

Dumdei et al., 1988; Dumdei and O'Brien, 1984; O'Brien et al., 1979; Atkinson et al., 1989; Gery et al., 1985)

Cresol

[24] $\quad 109.071 \pm .000(+.006) \quad 112.083 \pm .005(-.001) \quad 116.110 \pm .012(+.001)$ (Dumdei and O'Brien, 1984; O'Brien et al., 1979; Gery et al., 1985; Atkinson et al., 1989)

Oxyhydroxyhexadiene

Hydroxymethylbutendial

Hydroxybenzaldehyde

Benzoic Acid

Dioxyheptadiene

Hydroxycresol

Trioxyhexene
$[25]$

[26] $\quad 115.039 \pm .008(-.001)$

[27] $123.048 \pm .024(+.003)$

[27] $\quad 123.048 \pm .024(+.003)$

[28] $125.058 \pm .026(-.002)$

[28] $\quad 125.058 \pm .026(-.002)$

[27] $127.030 \pm .007(-.010)$
$116.080+.003(+.001)$

$120.104+.010(.000)$

(Dumdei et al., 1988; Dumdei and O'Brien, 1984)

$118.058 \pm .009(0.000) \quad 120.070 \pm .007(-.001)$

(Dumdei et al., 1988; Dumdei and O’Brien, 1984)

$124.063 \pm .005(+.012)$

$128.062+.008(-.014)$

(Dumdei and O'Brien, 1984)

$123.049 \pm .003(+.005) \quad 128.062 \pm .008(-.014)$

(Dumdei and O’Brien, 1984)

$128.077 \pm .014(-.002) \quad 133.105 \pm .014(-.005)$

(Dumdei et al., 1988; Dumdei and O’Brien, 1984)

$128.077 \pm .014(-.002) \quad 131.094 \pm .014(-.004)$

(Dumdei and O'Brien, 1984)

$130.062 \pm .019(+.004) \quad 133.076 \pm .007(-.001)$ 
TABLE III

TOLUENE OXIDATION PRODUCTS FOUND USING API SOURCE REACTIONS

(continued)

(Dumdei et al., 1988; Dumdei and O'Brien, 1984)

Nitrotoluene

[30] $\quad 138.057 \pm .007(+.001) \quad 141.076 \pm .010(+.002)$

$145.086 \pm .014(-.013)$

(Dumdei and O'Brien, 1984; O'Brien et al., 1979; Gery et al., 1985; Atkinson et al., 1989)

Nitrophenol

[32]

$140.042 \pm .008(+.007)$

*.

$144.057+.011(-.003)$

(Dumdei and O'Brien, 1984; Gery et al., 1985)

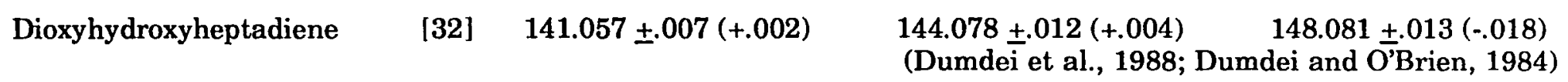

Nitrocresol

*.

$160.072+.007(-.016)$

(Dumdei and O’Brien, 1984; Gery et al., 1985)

Benzylnitrate

*

*.

$161.107 \pm .007(+.013)$

(Dumdei and O'Brien, 1984; O’Brien et al., 1979; Gery et al., 1985; Atkinson, et al., 1989)

$\Delta \mathrm{m} \pm \sigma($ Dalton $) \quad+0.0005 \pm .0041 \quad+0.0034 \pm .0067 \quad 0.0015 \pm .0083$

Notes: Columns give the mass for the protonated form of each analyte $(\mathrm{BH}+)$ except for toluene and phenol which occur as charge transfer ions $\left(\mathrm{B}^{+}\right)$. Square brackets enclose the number of CHON compounds falling within \pm 0.036 Dalton of the assigned structure. Experimental mass uncertainties are $1 \sigma$ based upon averages of 3-6 replicate scans. The values in parentheses are differences between actual and experimental masses (actual-experimental). The average mass differences and standard deviations of mass differences are given at the foot of the column for each isotopic form. References indicate independent experiments which identified the same oxidation product. 
product peaks reported here were observed at very low ion intensities (Fig. 5), it is significant that accurate mass assignments for these products were still obtained. It is possible that additional products were formed yet not identified due to their low ion intensities; further work in this area is still needed.

\section{Empirical Formulas}

The assignment of empirical formulas based on accurate masses acquired using APIMS may deserve further discussion. While the resolution provided by our instrument is lower than that in a typical high-resolution EI analysis, the double focusing electrostatic/magnetic sector (EB) configuration of the mass analyzer provides resolutions that are high relative to any other API technique known to us. For any single mass there are a number of possible combinations of atoms which lie within any arbitrary mass window around each compound in Table III. Our previously reported resolution $\geq 2800$ for this instrument (Grange, O'Brien, Barofsky, 1988a) corresponds to a mass window of 0.036 Daltons for a nominal mass of 100 Daltons. This window is $\geq$ four times the standard deviation (4.5\%) of assigned masses achieved in Table III, which range from 0.004-0.008 Dalton. Table III includes in square brackets the number of combinations of carbon, hydrogen, oxygen and nitrogen atoms which lie within this \pm 0.036 Dalton window for the $\mathrm{H}_{8}$ experiments. Two examples of these combinations are shown in

Table IV. They are based on the experimental masses of two oxidation products: $\mathrm{m} / \mathrm{z} 125.058$ (dioxyheptadiene or hydroxycresol) and 138.057 (nitrotoluene). For our purposes here, we have allowed as maximums: 10 carbons, 20 hydrogens, 10 oxygens and 5 nitrogen atoms. Each row in Table IV represents a unique 
empirical formula where the number of each atom type is in its respective column, the calculated mass for that empirical formula is given next, followed by the mass difference between the experimental value and the respective calculated value (calcd-exptl).

The product peak at 125.058 Daltons has 28 possible empirical formula solutions using the parameters described above. Most of these are nonrational, based on rules of chemical bonding. Rational structures that can be hypothesized: $\mathrm{C}_{2} \mathrm{H}_{7} \mathrm{O}_{5} \mathrm{~N}$, a pentahydroxy amino ethane and $\mathrm{C}_{6} \mathrm{H}_{7} \mathrm{O}_{2} \mathrm{~N}$, a dihydroxy amino benzene. These structures have masses 0.026 and 0.010 below the assigned structure, respectively, but they do not include an additional hydrogen from proton transfer reactions with the reagent ions. If the ion signal arose from these compounds they would be expected as charge transfer species. Three other structures $\left(\mathrm{C}_{2} \mathrm{H}_{9} \mathrm{O}_{4} \mathrm{~N}_{2}\right.$, a tetrahydroxy diamino ethane $(-0.002) ; \mathrm{C}_{3} \mathrm{H}_{9} \mathrm{O}_{5}$ hexahydroxy propane $(-0.013)$ and $\mathrm{C}_{6} \mathrm{H}_{9} \mathrm{ON}_{2}$ diamino hydroxy benzene $(+0.013)$ ) are reasonable in their bonding and include an additional proton to account for protonation by hydroniums. However, the formation of reduced-nitrogen oxidation products in 4 of these species and of a multiply hydroxylated species in the fifth is inconsistent with the oxidizing nature of the corona discharge. The only viable formula from this list is $\mathrm{C}_{7} \mathrm{H}_{9} \mathrm{O}_{2}$, corresponding to either heptadiendial or hydroxycresol $(+0.002)$. The deuterated toluene oxidation experiments confirm the formation of both these individual products, as shown in Table III. Mechanisms for the oxidation of toluene to these products have been hypothesized (Dumdei and O'Brien, 1984; Dumdei et al., 1988), and heptadiendial is a major product under API source conditions. The second example given in Table IV is attributed to nitrotoluene, $\mathrm{m} / \mathrm{z} 138.057$. 
TABLE IV

EMPIRICAL FORMULA COMBINATIONS FOR SELECTED EXPERIMENTAL MASSES

\begin{tabular}{|c|c|c|c|c|c|c|c|}
\hline \multicolumn{2}{|c|}{ Experimental } & \multirow[b]{2}{*}{$\mathrm{H}$} & \multirow[b]{2}{*}{0} & \multirow[b]{2}{*}{ D } & \multirow[b]{2}{*}{$\mathbf{N}$} & Calculated & \multirow{2}{*}{$\begin{array}{l}\Delta \mathrm{Mas} \\
\text { (calcd-exptl }\end{array}$} \\
\hline Mass & $\mathrm{C}$ & & & & & Mass & \\
\hline & 0 & 5 & 4 & 0 & 4 & 125.031 & -.027 \\
\hline & 0 & 7 & 3 & 0 & 5 & 125.055 & $-.003^{*}$ \\
\hline & 0 & 13 & 7 & 0 & 0 & 125.066 & $.008^{*}$ \\
\hline & 0 & 15 & 6 & 0 & 1 & 125.090 & .032 \\
\hline & 1 & 7 & 4 & 0 & 3 & 125.044 & -.014 \\
\hline & 1 & 9 & 3 & 0 & 4 & 125.068 & .009 \\
\hline & 1 & 11 & 2 & 0 & 5 & 125.091 & .033 \\
\hline & 2 & 7 & 5 & 0 & 1 & 125.032 & -.026 \\
\hline & 2 & 9 & 4 & 0 & 2 & 125.056 & $-.002^{*}$ \\
\hline & 2 & 11 & 3 & 0 & 3 & 125.080 & .022 \\
\hline & 3 & 3 & 1 & 0 & 5 & 125.034 & -.024 \\
\hline & 3 & 9 & 5 & 0 & 0 & 125.045 & -.013 \\
\hline & 3 & 11 & 4 & 0 & 1 & 125.069 & .011 \\
\hline & 3 & 13 & 3 & 0 & 2 & 125.093 & .035 \\
\hline & 4 & 3 & 2 & 0 & 3 & 125.023 & -.035 \\
\hline & 4 & 5 & 1 & 0 & 4 & 125.046 & -.012 \\
\hline & 4 & 7 & 0 & 0 & 5 & 125.070 & .012 \\
\hline & 4 & 13 & 4 & 0 & 0 & 125.081 & .023 \\
\hline & 5 & 5 & 2 & 0 & 2 & 125.035 & -.023 \\
\hline & 5 & 7 & 1 & 0 & 3 & 125.059 & $.001 *$ \\
\hline & 5 & 9 & 0 & 0 & 4 & 125.083 & .025 \\
\hline & 6 & 5 & 3 & 0 & 0 & 125.024 & -.034 \\
\hline & 6 & 7 & 2 & 0 & 1 & 125.048 & -.010 \\
\hline & 6 & 9 & 1 & 0 & 2 & 125.072 & .013 \\
\hline \multirow[t]{4}{*}{125.058} & 7 & 9 & 2 & 0 & 0 & 125.060 & $.002 *$ \\
\hline & 7 & 11 & 1 & 0 & 1 & 125.084 & .026 \\
\hline & 9 & 3 & 0 & 0 & 1 & 125.027 & -.031 \\
\hline & 10 & 5 & 0 & 0 & 0 & 125.039 & -.019 \\
\hline
\end{tabular}

No. of solutions $=28$

$\begin{array}{rrrllll}0 & 4 & 4 & 0 & 5 & 138.026 & -.031 \\ 0 & 10 & 8 & 0 & 0 & 138.038 & -.019 \\ 0 & 12 & 7 & 0 & 1 & 138.061 & .004^{*} \\ 0 & 14 & 6 & 0 & 2 & 138.085 & .028 \\ 1 & 6 & 4 & 0 & 4 & 138.039 & -.018 \\ 1 & 8 & 3 & 0 & 5 & 138.063 & .006^{*} \\ 1 & 14 & 7 & 0 & 0 & 138.074 & .017 \\ 2 & 6 & 5 & 0 & 2 & 138.028 & -.029\end{array}$


TABLE IV

\section{EMPIRICAL FORMULA COMBINATIONS FOR SELECTED EXPERIMENTAL MASSES \\ (continued)}

\begin{tabular}{|c|c|c|c|c|c|c|c|}
\hline \multicolumn{6}{|c|}{ Experimental } & \multicolumn{2}{|l|}{ Calculated } \\
\hline Mass & $\mathrm{C}$ & $\mathrm{H}$ & $\mathrm{O}$ & $\mathrm{D}$ & $\mathbf{N}$ & Mass & (calcd-exptl) \\
\hline & 2 & 8 & 4 & 0 & 3 & 138.052 & $-.006^{*}$ \\
\hline & 2 & 10 & 3 & 0 & 4 & 138.075 & .018 \\
\hline & 3 & 8 & 5 & 0 & 1 & 138.040 & -.017 \\
\hline & 3 & 10 & 4 & 0 & 2 & 138.064 & $.007^{*}$ \\
\hline & 3 & 12 & 3 & 0 & 3 & 138.088 & .031 \\
\hline & 4 & 4 & 1 & 0 & 5 & 138.042 & -.015 \\
\hline & 4 & 10 & 5 & 0 & 0 & 138.053 & $-.004 *$ \\
\hline & 4 & 12 & 4 & 0 & 1 & 138.077 & .020 \\
\hline & 5 & 4 & 2 & 0 & 3 & 138.030 & -.027 \\
\hline & 5 & 6 & 1 & 0 & 4 & 138.054 & $-.003^{*}$ \\
\hline & 5 & 8 & 0 & 0 & 5 & 138.078 & .021 \\
\hline & 5 & 14 & 4 & 0 & 0 & 138.089 & .032 \\
\hline & 6 & 6 & 2 & 0 & 2 & 138.043 & -.014 \\
\hline & 6 & 8 & 1 & 0 & 3 & 138.067 & .010 \\
\hline & 6 & 10 & 0 & 0 & 4 & 138.091 & .034 \\
\hline & 7 & 6 & 3 & 0 & 0 & 138.032 & -.025 \\
\hline 138.057 & 7 & 8 & 2 & 0 & 1 & 138.056 & $-.002 *$ \\
\hline & 7 & 10 & 1 & 0 & 2 & 138.079 & .022 \\
\hline & 8 & 10 & 2 & 0 & 0 & 138.068 & .011 \\
\hline & 8 & 12 & 1 & 0 & 1 & 138.092 & .035 \\
\hline & 9 & 2 & 0 & 0 & 2 & 138.022 & -.035 \\
\hline & 10 & 4 & 0 & 0 & 1 & 138.034 & -.023 \\
\hline
\end{tabular}

No. of solutions $=30$

Notes: Empirical formulas based on the following maximum numbers of atoms: Carbon-10, Hydrogen-20, Oxygen-10, Nitrogen-5. The absolute value of the mass difference between the experimental and calculated values was less than or equal to 0.036 Daltons, corresponding to an effective resolution of 2700. Masses indicated with asterisks lie within the $1 \sigma$ resolution of 0.008 Daltons.

Among the thirty possible empirical formulas listed, only ten give rise to viable structures for charge transfer or proton transfer reactions. While charge transfer reactions do predominate for toluene and phenol, proton transfer is the 
predominant pathway for all other known products. Possible empirical formulas, correct in their bonding but without a protonating hydrogen, include: $\mathrm{C}_{3} \mathrm{H}_{10} \mathrm{O}_{4} \mathrm{~N}_{2}$ diaminotetrahydroxypropane $(+0.007) ; \mathrm{C}_{4} \mathrm{H}_{10} \mathrm{O}_{5}$ pentahydroxybutane $(-0.004)$; $\mathrm{C}_{6} \mathrm{H}_{6} \mathrm{O}_{2} \mathrm{~N}_{2}$ dicyanooxyhydroxybutane (-0.014); $\mathrm{C}_{7} \mathrm{H}_{6} \mathrm{O}_{3}$ hydroxybenzoic acid (-0.025) and $\mathrm{C}_{8} \mathrm{H}_{12} \mathrm{O}$ dioxyoctatriene $(+0.035)$. All these compounds would be expected to appear as a protonated $\left(\mathrm{BH}^{+}\right)$ion, and the latter two are well outside the $1 \sigma$ error bounds. The nitrogen containing compounds may be further discounted for including reduced amine species in an oxidizing environment. The pentahydroxy compound is a very unlikely oxidation product, as is dioxyoctatriene, which contains one more carbon atom than toluene. Hydroxybenzoic acid is a conceivable toluene oxidation product, but its mass difference lies $6 \sigma$ from the experimental value and it would be expected to occur as an $\mathrm{BH}^{+}$ion rather than as the observed $\mathrm{B}^{+}$mass. Several empirical formulas do allow for proton transfer: $\mathrm{C}_{3} \mathrm{H}_{8} \mathrm{O}_{5} \mathrm{~N}$ aminotetrahydroxyoxypropane (-0.017); $\mathrm{C}_{4} \mathrm{H}_{12} \mathrm{O}_{4} \mathrm{~N}$ aminotetrahydroxybutane $(+0.020)$; $\mathrm{C}_{7} \mathrm{H}_{10} \mathrm{ON}_{2}$ diaminobenzyl alcohol $\left((+0.022)\right.$ and $\mathrm{C}_{8} \mathrm{H}_{12} \mathrm{ON}$ cyanooxyheptatriene $(+0.035)$. As before, amines and cyano functionalities are not typical of the oxidizing nature of the source region nor of atmospheric oxidations in general. The remaining empirical formula is $\mathrm{C}_{7} \mathrm{H}_{8} \mathrm{O}_{2} \mathrm{~N}$, nitrotoluene, whose empirical formula is confirmed in the $\mathrm{D}_{3}$ and $\mathrm{D}_{8}$ experiments.

\section{$\underline{\text { Past Toluene Studies }}$}

Each of the oxidation products listed in Table III has been found in at least one other investigation of toluene's atmospheric degradation, examples are given for each compound in Table III. These previous inquiries used techniques which 
were very different from the approach used here but they yielded similar results. The techniques included GC or GC/MS (O'Brien et al., 1979; Shepson, Edney, and Corse, 1984), direct FTIR analysis of smog chambers (Bandow, Washida, and Akimoto, 1985), direct-probe-injection methane CI MS/MS analysis of wall washings (Dumdei and O'Brien, 1984), APIMS (Grange, O'Brien, and Barofsky, 1988a), APIMS/MS (Dumdei et al., 1988; O’Brien et al., 1984), and multimode analysis of irradiated Teflon chambers (Gery et al., 1985; Atkinson et al., 1989).

Of particular interest is confirmation of ring fragmentation products. Fragmentation products found in this gas phase technique are identical to compounds found in extracts taken by washing the walls of 22-liter reaction vessels (Dumdei and O'Brien, 1984), the most thorough prior characterization of the toluene oxidation process. Although that study (Dumdei and O'Brien, 1984) was questioned by some as suffering from possible heterogeneous effects, the confirmation of nearly every oxidation product found by Dumdei and O'Brien in the present study suggests that heterogeneous effects did not alter product identities from those characteristic of gas-phase reactions. The presence of most toluene oxidation products on the reaction vessel walls emphasizes the importance of wall adsorption of gas-phase oxidation products in simulated atmospheric reaction chambers as discussed by O'Brien et al. (1983). It also serves to highlight the simplicity of in situ APIMS in minimizing the effects of heterogeneous processes.

Although the volume of our API reaction chamber is small compared to that of a typical reaction vessel, the residence time for oxidation products within the API source is smaller still. Using a protonation rate constant of $3 \times 10^{-9} \mathrm{~cm}^{3}$ molecules ${ }^{-1} \sec ^{-1}$ (Horning et al., 1973) and a corona current of $2 \mu \mathrm{A}$ (yielding 
$\left[\mathrm{H}_{3} \mathrm{O}^{+}\right]_{o}=2.0 \mu \mathrm{A} * 6.242 \times 10^{18}$ ions coulomb ${ }^{-1} / 0.433 \mathrm{~cm}^{3} \mathrm{sec}^{-1}=2.88 \times 10^{13}$ molecules $\mathrm{cm}^{-3}$ ), the time until product protonation is on the order of $1 \times 10^{-5}$ seconds. Once protonated, the oxidation product ions are accelerated by the $3 \mathrm{kV}$ electric field into the analyzer sector of the mass spectrometer after a residence time of 0.46 $\mathrm{cm} / 2 \times 10^{4} \mathrm{~cm} \mathrm{sec}{ }^{-1}=2.3 \times 10^{-5} \mathrm{sec}$. In contrast, neutrals diffuse to the API source walls much more slowly, on the order of $4.2 \times 10^{-2} \mathrm{sec}(0.46 \mathrm{~cm}$ needle to wall distance $/ 11.0 \mathrm{~cm} \mathrm{sec}{ }^{-1}$ based on a root mean square diffusion distance $\mathrm{x}=(2 \mathrm{Dt})^{1 / 2}$ using a typical $\mathrm{D}$ of $\left.60 \mathrm{~cm}^{2} / \mathrm{sec}\right)$.

Previous studies of toluene's atmospheric oxidation have identified additional compounds which were not found in this study. These products include: acetylene and acetaldehyde (O'Brien et al., 1979); pyruvic acid, acetal, propenal, hexadienedial, hydroxydioxohexenal, hydroxyoxyhexenal (Dumdei et al., 1988); dinitrotoluene and nitrobenzaldehyde (Dumdei and O'Brien, 1984; Gery et al., 1985); maleic acid (Bandow, Washida, and Akimoto, 1985); formaldehyde and formic acid (O’Brien et al., 1979; Bandow, Washida, and Akimoto, 1985); PAN (Dumdei et al., 1988; Gery et al., 1985; Shepson, Edney and Corse, 1984; Bandow, Washida, and Akimoto, 1985 and many older studies); formaldehyde, methyl nitrite and methyl-p-benzoquinone (Gery et al., 1985); CO (Gery et al., 1985; O'Brien et al., 1983; Shepson, Edney, and Corse, 1984), and $\mathrm{C}_{6} \mathrm{H}_{4} \mathrm{O}_{2}$ (Shepson, Edney, and Corse, 1984). Many of these products are believed to result from secondary reactions of the primary oxidation products formed in the reaction vessel. As examples, the $\mathrm{C}_{6}$ tricarbonyls have been attributed to secondary reactions of cresol (Dumdei et al., 1988), and PAN is attributed to reactions of methylglyoxal (Bandow, Washida, and Akimoto, 1985). One would not expect to find extensive 
secondary products when directly employing source reactions, due to the short residence time of products before protonation and extraction to the analyzer region. Assuming equal initial $\mathrm{H}_{3} \mathrm{O}^{+}$and $\mathrm{HO}$ concentrations, the net rate for protonation is about 10-100 times faster than that of $\mathrm{HO}$ reaction, based on $\mathrm{k}$ (proton transfer $)=3 \times 10^{-9} \mathrm{~cm}^{-3} \mathrm{~s}^{-1}$ (Bohme, Mackay, and Tanner, 1979), $\mathrm{k}(\mathrm{HO}+$ toluene) $=5.9 \times 10^{-12}$ (Atkinson and Lloyd, 1984), and the fact that most toluene oxidation products protonate 2-50 times faster than toluene itself. Thus it is expected that products should be protonated, and the resultant $\mathrm{BH}^{+}$ions extracted, before either can react extensively with $\mathrm{HO}$.

Although the compounds thought to be secondary toluene oxidation products in one study (Dumdei et al., 1988) indeed may have resulted from their reaction with $\mathrm{HO}$ in the remote smog chamber, it is also possible that some may have resulted from the action of source-produced $\mathrm{HO}$ on primary oxidation products produced in the reaction vessel. A radical scavenger (e.g. carbon monoxide) can be employed to eliminate such a permutation of smog chamber oxidation products or ambient trace organics. This was the approach described in Chapter II.

Although this study is primarily qualitative, an analysis of relative response factors among analytes in APIMS by Sunner, Nicol, and Kebarle (1988) may be pertinent to the relative sensitivity for the hydrocarbon oxidation products detected here. In that study, API sensitivities were found to roughly correlate with the gasphase basicity (GB) of an analyte when analyte GB is below a threshold of about $200 \mathrm{kcal} / \mathrm{mole}$, and to be uniformly high above this GB threshold. While the experimental data showed considerable scatter, relative sensitivities decreased by over an order of magnitude for each $10 \mathrm{kcal} /$ mole decrease in GB below the 200 
kcal breakpoint. The reduced relative sensitivities for very low GB compounds such as carbon monoxide and formaldehyde will account for our not detecting them in this study, even if they were formed in the API source. However, the toluene oxidation products which we do detect here have GBs which range from less than 160 to $230 \mathrm{kcal} / \mathrm{mole}$. Many of these compounds have GBs which fall well below the $200 \mathrm{kcal} / \mathrm{mole}$ breakpoint found for the Sciex TAGA system (Sunner, Nicol, and Kebarle, 1988). This suggests that the falloff region may occur at lower GB in our instrument. Moreover, the TAGA system has been used (Dumdei et al., 1988) to determine products with GBs below 165 , suggesting analyte sensitivity may depend heavily on instrumental and experimental parameters. Further study is necessary.

\section{API Source Chemistry}

We know of only one previous observation of reactivity within an API source, the observation by Mahle, Cooks, and Korzeniowski (1983) of reaction products of benzene, toluene, and other aromatic hydrocarbons. These experiments were carried out with a heated API source on an MS/MS instrument and also using a mass-analyzed ion kinetic spectroscopy (MIKES) source. We here discuss the API work. Benzene was observed to generate strong oxygen-adduct ion signals at $\mathrm{m} / \mathrm{z}=94$ and 95 corresponding to $(\mathrm{B}+16)^{+}$and $(\mathrm{B}+17)^{+}$. The authors used $\mathrm{H}_{2}{ }^{18} \mathrm{O}$ with benzene to determine that the oxygen did not come from water, and they employed declustering to show that the oxygen adduct was not weakly bound. Spectra from toluene and $o$-xylene were shown and were similar to benzene but contained a larger array of products. Several other aromatic hydrocarbons were stated to give 
similar results, all of which were considered to be "suggestive of cationic intermediates".

The high temperature $\left(150\right.$ or $200^{\circ} \mathrm{C}$ ) of the reported (Mahle, Cooks, and Korzeniowski, 1983) API experiments places the chemical reactivity into a different kinetic regime than reactions in our unheated source, a regime even less understood mechanistically than the low temperature kinetics (see for instance, Atkinson, 1986). However, we may speculate on the possible mechanistic pathways which might explain the observations of Mahle, Cooks, and Korzeniowski. HO is believed to add to aromatic hydrocarbons, which are then partially converted to phenolic products at lower temperatures. However, the inverse Arrhenius behavior observed at higher temperatures (Perry, Atkinson, and Pitts, 1977; Tully et al., 1981) indicates that the $\mathrm{HO}$ adduct dissociates, and with benzene the more likely reaction is abstraction of a ring hydrogen atom. The failure of Mahle, Cooks, and Korzeniowski to find ${ }^{18} \mathrm{O}$ incorporation with benzene is consistent with this interpretation. If a ring $\mathrm{H}$ atom is abstracted, it then could be replaced with oxygen to form a dioxygen adduct which could be protonated to yield the minor product near m/z 110 apparent in Figure 1 of Mahle, Cooks, and Korzeniowski. Alternatively, the $\mathrm{O}_{2}$ adduct could lose an oxygen atom to source-produced NO, or two $\mathrm{O}_{2}$ adduct radicals could eliminate $\mathrm{O}_{2}$, forming an $\mathrm{O}$ adduct which would be protonated to form the ${ }^{16} \mathrm{O}$ phenol at 94 Daltons.

Figure 1 of Mahle, Cooks, and Korzeniowski also shows a strong signal due to phenol- $\mathrm{H}^{+}$at 95 Daltons, and Figure 2 in the same paper gives similar peaks attributable to cresol ${ }^{+}$and cresol- $\mathrm{H}^{+}$when using toluene. These products are less easily explained mechanistically, but the protonated ions are consistent with our 
observation of cresol- $\mathrm{H}^{+}$from toluene in our low temperature source. Figure 2 of Mahle, Cooks, and Korzeniowski (1983) presents a toluene spectrum different from that obtained in our low temperature source (Figure $5 \mathrm{~b}$ ), but the major peaks in both the toluene and o-xylene spectra can be attributed to reaction mechanisms analogous to those of benzene described above. There are similarities to our spectra as well, for instance the peak at $\mathrm{m} / \mathrm{z} 107$ may be protonated benzaldehyde and $m / z=125$ may be the ring-opened compound, both of which we found as major products (see Table III). All of these mechanistic comments are speculative however, pending further API source studies conducted at varying temperatures.

\section{CONCLUSIONS}

Although the detailed nature of the reactions occurring within an API source remains to be explored, the similarity of the oxidation products we observe to those found in a wide array of other techniques (Table III) indicates an API source can be used to generate both the hydroxyl radicals necessary to initiate oxidation processes, and the hydroniums needed to protonate the resulting oxidation products. High resolution mass assignments for toluene's oxidation products, resulting from the coupling of our API source with a high resolution mass spectrometer, facilitates assignment of empirical formulas for these products. Deuterium labeling on the reactant hydrocarbon assists greatly in the interpretation of oxidation product spectra, but considerable inferences may be drawn simply from the high-resolution masses of the perhydrogenated oxidation products. The use of in situ API source reactions thus offers significant 
advantages over techniques which require the synthesis of authentic reference compounds to verify the identities of the oxidation products.

The use of API source reactions to generate in situ oxidation products also offers several unique advantages over traditional reactor experiments. These advantages include: simplification of the experimental procedures, elimination of the time consuming set-up and irradiation of a simulated atmosphere, minimizing the persistent questions of wall adsorption by polar compounds of low vapor pressure (O'Brien et al., 1983; O'Brien et al., 1984) and eliminating the necessity for chromatographic separation of a complex array of reaction products.

The API source utilized in this study (Grange, O'Brien, and Barofsky, 1988b; Grange, O’Brien, and Barofsky, 1988c) was designed for sampling atmospheric oxidation products from the open atmosphere, rather than for in situ kinetic studies. It seems likely that improvements in source design will produce an apparatus with even greater suitability for the study of atmospheric HO kinetics. 


\section{CHAPTER IV}

\section{HIGH-RESOLUTION KINETIC ATMOSPHERIC PRESSURE IONIZATION MASS SPECTROMETRY (HRKAPIMS)}

\section{"A scientific fact was only a theory}

as a child." (Davis, 1969)

\section{OVERVIEW}

Reactions of hydroxyl radical (HO) with organic compounds are of fundamental importance in air chemistry because they dominate the low temperature oxidations which maintain the cleanliness of the global atmosphere. At the same time, these reactions contribute to undesirable phenomena, such as photochemical smog and acid precipitation. We have developed a new technique, High-Resolution Kinetic Atmospheric Pressure Ionization Mass Spectrometry (HRKAPIMS), for the direct study of these atmospheric oxidations. This technique allows the identification of both stable reaction products and free radical reaction intermediates by empirical mass assignments. Furthermore, studies of reaction kinetics are possible by observing the effect of added reagents on product yields. This versatile technique offers significant advantages for the chemical analysis of atmospheric oxidations, as we demonstrate here for toluene (methylbenzene), a widespread constituent of the lower atmosphere, whose origin is almost entirely through the use of fuels and solvents. 


\section{INTRODUCTION}

\section{HO Chemistry}

$\mathrm{HO}$ is known to be an important catalyst in combustion (Atkinson, Bull, and Shuff, 1980), and the importance of HO radicals in the production of secondary air pollution (e.g photochemical smog) was first speculated upon by Leighton in 1961 (Leighton, 1961). The role of $\mathrm{HO}$ in maintaining a low, stable, trace-gas composition for the global atmosphere was first alluded to by Weinstock (Weinstock, 1969), who pointed out its role in oxidizing $\mathrm{CO}$ to $\mathrm{CO}_{2}$. $\mathrm{HO}$ is also responsible for the removal of most atmospheric organic compounds of natural or industrial origin. Studies of $\mathrm{HO}$ reactivity with organic compounds have focused on three areas: measuring rate constants for HO/organic reactions, identifying the products of atmospheric oxidation processes, and elucidating oxidation reaction mechanisms.

HO/organic reactions have been studied in laboratory systems ranging from very low pressure mass spectrometers to simulated atmosphere containment vessels called smog chambers. Experimental determinations of reaction rate constants is an area of broad interest and the HO reaction rates are generally well understood for many organic compounds (Atkinson, 1986; Atkinson, in press). These rate constants, measured under rigorous laboratory conditions, are in good agreement with relative rate measurements made under simulated atmospheric conditions (Atkinson, 1986), corroborating HO's presumed control of organic reactivity in the open atmosphere. 
Atmospheric oxidation, initiated by $\mathrm{HO}$, results in intermediate oxidation products which incorporate $\mathrm{O}$ and/or $\mathrm{N}$ atoms into the organic, yielding stable products such as aldehydes, nitrates, and many others. The identification and quantitation of these oxidation products has been widely addressed, yet the complete oxidation schemes and product yields remain unknown for many common compounds (Atkinson et al., 1989). Gery et al. (1985) have concluded that HOalkylbenzene chemistry has remained elusive due to the high reactivity of $\mathrm{HO}$ radicals and their low concentrations, thus making the HO chemistry difficult and expensive to simulate and monitor.

\section{Oxidation Product Measurements}

A summary of the experimentation required in several recent studies may give some insights into the difficulties and expense generally associated with studies of atmospheric oxidation. Atkinson et al. (1989) used a $6400 \mathrm{~L}$ Teflon irradiated chamber to generate toluene oxidation products. Gas chromatography with flame ionization detection was used to analyze products which had been collected onto a Tenax solid absorption columns. The system was first calibrated using authentic samples. Gas chromatography-mass spectrometry was used to analyze gaseous samples. Chemiluminescence analysis was used to measure NO and the sum of initial $\mathrm{NO}, \mathrm{NO}_{2}$ and $\mathrm{CH}_{3} \mathrm{ONO}$ concentrations. Gery et al. (1985) also used a Teflon reaction vessel, in their case a $200 \mathrm{~L}$ chamber surrounded by 34 UV fluorescent lamps. Nitrous acid was generated using liquid phase reactions of sodium nitrite with sulfuric acid. Toluene was measured using a GC with flameionization detector and a heated trap. GC with electron capture detection was 
used to monitor PAN, methylglyoxal and organic nitrates trapped on a Carbowax column. Glyoxal and methylglyoxal were collected with a bubbler containing an absorbing reagent, 2,4-dinitrophenylhydrazine, and the derivatives analyzed using high performance liquid chromatography (HPLC). Qualitative analysis of some products was conducted using GC/MS and others using GC with flame-ionization and/or thermionic-specific detectors. A chemiluminescent $\mathrm{NO}_{\mathrm{x}}$ analyzer was used in the NO-only mode for the oxides of nitrogen, and ozone was monitored using a different chemiluminescent analyzer. Carbon monoxide was monitored using GC and formaldehyde analyzed using a colorimetric analyzer. Not all of these species are directly monitored by HRKAPIMS; chemiluminescent detectors are needed to measure nitrogen oxides, and other methods (i.e. GC) would be necessary to measure compounds with low gas-phase basicities such as carbon monoxide, carbon dioxide and PAN.

Additional examples of the experimental techniques and studies used in the analysis of toluene oxidation include: gas chromatography (O'Brien et al., 1979; Shepson et al., 1985; Atkinson et al., 1980; Leone et al., 1985; Atkinson, Carter, and Winer, 1983; Dumdei et al., 1988), gas chromatography/mass spectrometry (Atkinson et al., 1980; Shepson, Edney, and Corse, 1984; Kenley, Davenport, and Hendry, 1981), tandem mass spectrometry (Dumdei et al., 1988; Dumdei and O'Brien, 1984; O’Brien, et al., 1984), long path length Fourier transform infrared spectroscopy (Bandow, Washida, and Akimoto, 1985; Plum et al., 1983; Tuazon et al., 1986; Tuazon et al., 1984), high performance liquid chromatography (Fund and Grosjean, 1981; Besemer, 1982) and differential optical absorption spectroscopy (Tuazon et al., 1984; Tuazon et al., 1986; Bandow, Washida, and Akimoto, 1985). 
These techniques and others have identified a wide array of toluene oxidation products, but although tentative oxidation mechanisms have been based upon some studies (Atkinson et al., 1989; Gery et al., 1985; Atkinson et al., 1980; Leone et al., 1985; Dumdei et al., 1988; Dumdei and O’Brien, 1984; Bandow, Washida, and Akimoto, 1985; Atkinson and Lloyd, 1984), elucidation of the reaction mechanisms of toluene and other members of the benzene family remains a major area of uncertainty in atmospheric chemistry (Seinfeld, 1989). The ability to detect reaction intermediates simultaneously with stable products would be an asset in elucidating such mechanisms. Zellner, Fritz, and Preidel (1985) have detected the hydroxy-cyclohexadienyl radicals formed from the $\mathrm{HO}$ addition reaction with benzene using ultraviolet (UV) laser absorption. However experiments that measured the rates of reaction with $\mathrm{NO}$ and $\mathrm{NO}_{2}$ were conducted at near 20 Torr and may not reflect the processes occurring in the atmosphere (Atkinson et al., 1989). Photoionization mass spectrometry (Sloane, 1978) has found some success in this area yet this technique is very complex and of limited utility for the study of atmospheric processes (Atkinson, 1986). Experiments such as this, which are conducted at low pressures, may not simulate well the actual reaction pathways which occur at atmospheric pressure. Collisions with neutral molecules at higher pressures can deactive excited molecules, reducing the chances of dissociation.

In a recent review article Niki concludes "... further quantification of reaction products by means of various complementary analytical tools is urgently needed to establish the reaction pathways occurring in the HO-initiated oxidation of aromatic hydrocarbons under atmospheric conditions." (Niki and Maker, 1990) Such an analytical tool should provide insights into the formation of atmospheric 
oxidation products, reaction intermediates, and the relative importance of the secondary reaction pathways that follow the initial attack of $\mathrm{HO}$ upon the organic. The technique should operate at atmospheric pressure to better represent natural reaction processes and conditions, and provide a rapid and direct measure of product identities and yields. We believe HRKAPIMS can be such a technique.

\section{HRKAPIMS}

We have previously developed and characterized an atmospheric pressure ionization (API) source for a high resolution, double-focusing mass spectrometer (Grange, O'Brien, and Barofsky, 1988b; Grange, O’Brien, and Barofsky, 1988c). The API source uses a positive corona discharge at a high-voltage needle tip to generate hydrated proton clusters in the effective net reaction (Good, Durden, and Kebarle, 1970a)

$$
\mathrm{nH}_{2} \mathrm{O} \rightarrow \mathrm{H}^{+}\left(\mathrm{H}_{2} \mathrm{O}\right)_{m}+(\mathrm{n}-1-\mathrm{m}) \mathrm{H}_{2} \mathrm{O}+\mathrm{HO} \bullet+\mathrm{e}^{-}
$$

Although hydrocarbons (compounds of carbon and hydrogen only) such as toluene generally have low proton affinities and are detected with low sensitivity, their nitrogen- or oxygen-atom containing oxidation products $(\mathrm{P})$ have much higher proton affinities and can be detected at the ppb to ppt range (Mitchum and Korfmacher, 1983) as an ion current of $\mathrm{PH}^{+}$in the mass spectrometer. This is accomplished through protonation (R13) and subsequent dehydration (R14), both occurring in the API source of the mass spectrometer.

$$
\begin{gathered}
\mathrm{H}^{+}\left(\mathrm{H}_{2} \mathrm{O}\right)_{\mathrm{m}}+\mathrm{P} \rightarrow \mathrm{PH}^{+}\left(\mathrm{H}_{2} \mathrm{O}\right)_{\mathrm{q}}+(\mathrm{m}+1-\mathrm{q}) \mathrm{H}_{2} \mathrm{O} \\
\mathrm{PH}^{+}\left(\mathrm{H}_{2} \mathrm{O}\right)_{\mathrm{q}}->\mathrm{PH}^{+}+\mathrm{qH}_{2} \mathrm{O}
\end{gathered}
$$


This configuration has successfully identified atmospheric oxidation products formed in simulated atmospheres (Grange, O'Brien, and Barofsky, 1988a). When sampling real or simulated atmospheres, HO formed in the API source by R12 can greatly complicate mass spectral interpretation by reacting with atmospheric constituents to form oxidation products not present in the sample. As discussed in Chapter II the HO-initiated API source reactions can be suppressed by the addition of ca. $1 \%$ carbon monoxide to scavenge HO. The suppression of oxidation products by $\mathrm{CO}$ provides strong evidence that the oxidations are initiated by source-produced $\mathrm{HO}$, rather than by other processes in the immediate vicinity of the corona needle.

Alternatively, we have demonstrated in the previous chapter the potential for producing and evaluating atmospheric oxidation products directly within the API ion source. These experiments form the basis for the technique we here call HRKAPIMS, in which the hydroxyl radicals produced in $\mathrm{R} 12$ initiate the oxidation of a hydrocarbon introduced into the sample stream, and the proton clusters are used to detect the resultant oxidation products. In an analysis of toluene oxidation, discussed in Chapter III using three isotopically different forms of toluene, we identified 29 distinct oxidation products formed within the ion source. All of these products had been identified in one or more previous studies using other techniques, although only one previous study (Dumdei and O'Brien, 1984) was able to identify such a large array of products. The standard deviation between the observed and actual masses for the stable toluene oxidation products was $\leq 0.008$ atomic mass units, which allows assignment of empirical formulas in most cases without the necessity of reference compounds. A single HRKAPIMS 
experiment provides the information in Chapter III, as well as information in this chapter on detection and identification of reaction free radical intermediates and the effects of changing reagent concentrations on product ratios.

\section{RESULTS AND DISCUSSION}

\section{Experimental}

The experiments described below and the experimental conditions associated with this discussion are the same as Chapter III. They are in fact the same experiments. Toluene concentrations on the order of $2 \mathrm{ppm}$ were employed and a corona current of $0.2 \mu \mathrm{A}$ produces an initial HO concentration of $3.7 \times 10^{12}$ molecules $\mathrm{cm}^{-3}$.

Mass Spectra. Mass spectra representative of API source reactions are shown in Figure 6 where perdeuterated toluene $\left(C_{7} D_{8}=100.113\right.$ Dalton $)$ was delivered to the API source in a zero air carrier gas. Figure $6 \mathrm{a}$ is a background spectrum in which ion signals at $\mathrm{m} / \mathrm{z} 37,55,73$ and $91 \ldots$ arise from hydrated hydronium ions which were incompletely declustered in the CID region; other peaks constitute a persistent background. Figure $6 \mathrm{~b}$ illustrates conditions where toluene has been added to the carrier gas entering the API source. Prominent evident toluene oxidation products are the ring-opened dialdehydes at 105.088 and 133.105 Daltons shown in Figure 6b. Toluenes' stable oxidation products were discussed in the previous chapter. The effect of $\mathrm{NO}$ on source reactions is evident in Figure 1c. Here, upon addition of $10 \mathrm{ppm}$ NO to the inlet air stream, the product ratios have shifted to favor the 133.105 Daltons product in preference to the 105.088 Daltons product and the yield of nitrotoluene (145.086 Daltons) has 

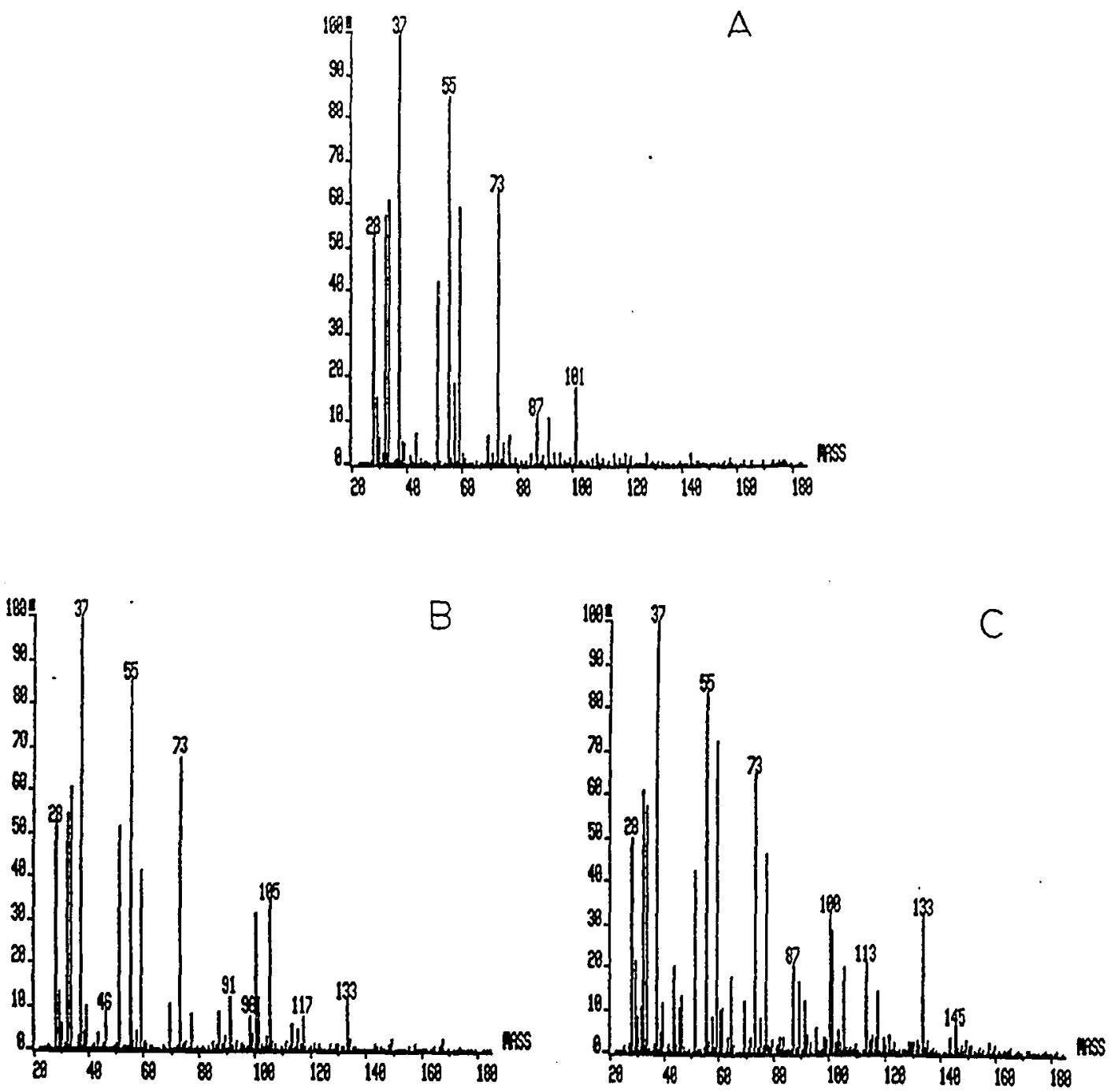

Figure 6. Mass spectra showing the course of a typical HRKAPIMS experiment. (a) Background spectrum in which predominant peaks include water clusters $(\mathrm{m} / \mathrm{z} 19,37,55,73, \ldots)$ and persistent background peaks. (b) With $2 \mathrm{ppm}$ perdeuterated toluene in air present in the ion source the major oxidation products are evident at $\mathrm{m} / \mathrm{z} 105$ and 133. (c) After the addition of $10 \mathrm{ppm}$ NO the product ion intensities shift to the formation of the ring fragmentation product methylheptadienedial at $\mathrm{m} / \mathrm{z} 133$ and nitrotoluene $\mathrm{m} / \mathrm{z} 145$.

also increased. The semi-quantitative analysis of the effect of NO concentration on the free radical intermediates of toluene oxidation is addressed in a later section. 
Product Ion Currents. The consistent ability of API source reactions to reproduce photo-oxidation processes is illustrated in Figure 7, which compares three plots of normalized ion intensity versus scan number for methylhexadienedial (C7 in Figure 8) formed under API source reactions. The three separate plots correspond to the three isotopic forms of toluene used in these experiments, which were conducted on different days, using oxygen as the carrier gas. The experimental masses of this product are 125.058, 128.077 and 133.105 Daltons in the $H_{8}, D_{3}$ and $D_{8}$ forms of toluene respectively. The horizontal axis is not identical in each of the three experiments, but each numbered region (1-6) represents the same changes in experimental conditions, described below. The differences in the horizontal axes are based solely on the sequence and numb er of scans taken under each condition. Ion intensities are normalized to show the maximum peak in each scan at $100 \%$. Regions $1-3$ chart ion intensity before the addition of toluene to the inlet flow and represent the background levels, while regions 4-6 are after the addition of toluene. Regions 1 and 4 indicate scans where the corona current was increased in increments from 0.2 to $10 \mu \mathrm{A}$, generally to include $0.2,0.5,1.0,2.0,5.0$ and $10 \mu \mathrm{A}$. Regions 2 and 5 record the addition of nitric oxide (NO) at levels of $0,2,5,10$ and $38 \mathrm{ppm}$ at a constant current of $0.2 \mu \mathrm{A}$, and scans in regions 3 and 6 were acquired while the current was again varied from 0.2 to $10 \mu \mathrm{A}$ at a constant NO level of $10 \mathrm{ppm}$. The 1.2 second residence time within the API source allows the experimental conditions to be quickly and easily adjusted. Regions 4 and 6 in Figure 7 show marked increases in ion intensity resulting from the higher discharge current. Increasing the corona discharge current increases the concentrations of both 

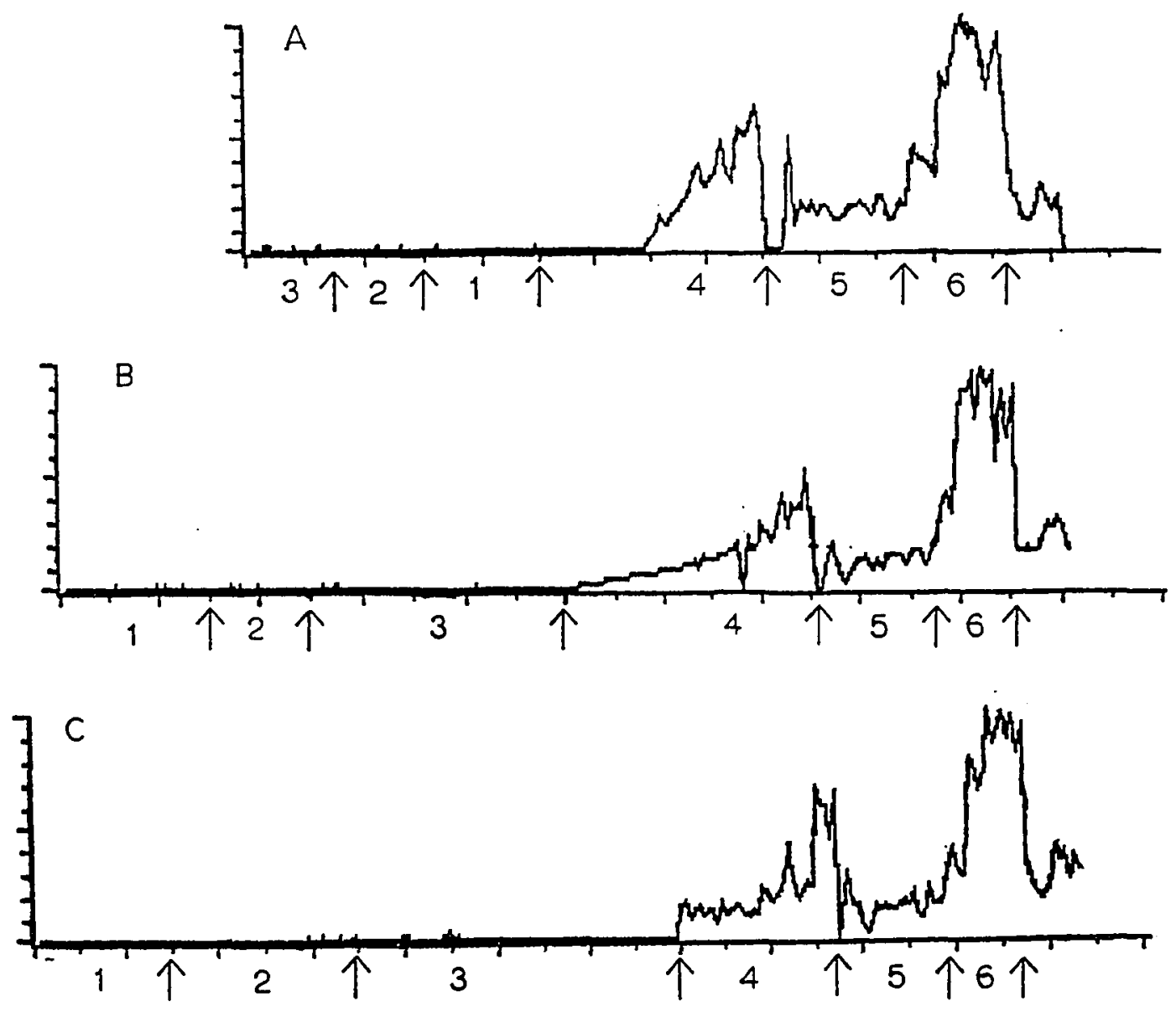

Figure 7. Normalized ion intensity vs. scan number for methylhexadienedial. In the three isotopic forms of toluene: (a) hydrogenated, (b) methyldeuterated, and (c) perdeuterated, the product appears at $\mathrm{m} / \mathrm{z}=125.058,128.077$, and 133.105 respectively. Each region, described in the text, represents differing experimental conditions affecting product yields and distributions.

hydroxyl radical and hydronium, increasing the extent of $\mathrm{HO}$ initiated oxidation and the availability of hydroniums to protonate the products.

\section{Free Radical Intermediates}

In analyzing the stable toluene oxidation products produced in the API source, we found that the concurrent presence of $\mathrm{HO}$ and $\mathrm{H}_{3} \mathrm{O}^{+}$water clusters, and 
the relatively short time scale for their reactions, allows free radical reaction intermediates to be protonated and measured simultaneously with the stable products. Five such reaction intermediates, detected in our experiments with toluene, are listed in Table V. The experimental data represent three separate experiments using toluene $\mathrm{CH}_{3} \mathrm{C}_{6} \mathrm{H}_{5}$, methyldeuterated toluene $\mathrm{CD}_{3} \mathrm{C}_{6} \mathrm{H}_{5}$, and perdeuterated toluene $\mathrm{CD}_{3} \mathrm{C}_{6} \mathrm{D}_{5}$; the intermediates are therefore measured at different masses in each of the three experiments. The experimentally determined accurate mass is given along with the standard deviation of 3 to 6 replicate measurements. The mass differences (shown in parentheses) between the proposed structures and the observed masses compare favorably with those obtained for the stable products discussed in Chapter III.

\section{TABLE V}

\section{EXPERIMENTAL MASSES OF FIVE FREE RADICAL TOLUENE OXIDATION INTERMEDIATES}

\begin{tabular}{|c|c|c|c|}
\hline &. $\mathrm{C}_{6} \mathrm{H}_{5} \mathrm{CH}_{3}$ &. $\mathrm{C}_{6} \mathrm{H}_{5} \mathrm{CD}_{3}$ &. $\mathrm{C}_{6} \mathrm{D}_{5} \mathrm{CD}_{3}$ \\
\hline b1 & $110.086 \pm .023(+.013)$ & $113.091 \pm .012(-.006)$ & $118.126 \pm .029(+.003)$ \\
\hline $\mathrm{d} 1$ & $142.066 \pm .023(+.003)$ & $145.092 * \quad(+.010)$ & $150.096 \pm .022(-.017)$ \\
\hline $\mathrm{d} 2$ & $126.064 \pm .009(-.004)$ & $129.080 \pm .016(-.007)$ & $134.105 \pm .023(-.013)$ \\
\hline e2 & $174.037 * \quad(-.016)$ & $177.054 * \quad(-.018)$ & $182.082 \pm .012(-.021)$ \\
\hline e3 & $158.084 \pm .020(+.026)$ & $161.097 *$ & $166.044 * \quad(-.064)$ \\
\hline
\end{tabular}

Notes: Masses in each isotopically labeled form are given for the protonated radical $(\mathrm{PH}+)$, whose structure is given in Figure 8. $1 \sigma$ uncertainties are based upon 3-6 multiple determinations. Values in parentheses are differences between observed and actual molecular weights. *-insufficient data to assign uncertainty

\section{Free Radical Intermediate Measurements}

Zellner, Fritz, and Preidel (1985) have measured reaction rates for $\mathrm{NO}, \mathrm{NO}_{2}$ and $\mathrm{O}_{2}$ with the hydroxycyclohexadienyl (HCHD) radical. These experiments found 
that the reaction of $\mathrm{HCHD}$ with $\mathrm{NO}$ was independent of the $\mathrm{O}_{2}$ concentration. This apparently conflicts with earlier descriptions of toluene photooxidation including Atkinson and Lloyd (1984) and may agree with the recent findings of Atkinson et al. (1989) who found that the production of nitrotoluene did not extrapolate to zero in the absence of $\mathrm{NO}_{2}$. However since the rates of Zellner were measured at low pressures conclusions drawn from this experiment cannot be immediately applied directly to processes at atmospheric pressure. This uncertainty lead to the observation (Atkinson 1990) that "... at the present time the actual reactions of the hydroxycyclohexadienyl radicals formed from the $\mathrm{OH}$ radical reactions with the aromatic hydrocarbons are not known."

One persistent obstacle to the measurement of aromatic hydrocarbon oxidation products is the difficulty associated with finding them. While a particular study may report finding $55-75 \%$ of the reacted carbon (Gery et al., 1985) this generally requires using very high concentrations of $\mathrm{NO}$ and $\mathrm{NO}_{2}$ which force the oxidation toward those products more easily detected. Experiments that use lower levels of nitric oxides typical of the real atmosphere form different products which are more difficult to detect experimentally. As a result the product yields which can be accounted for in more realistic studies are significantly lower.

\section{Chemical Modeling}

The NO concentration plays an important role at branch points in most atmospheric oxidation sequences. Figure 8 presents a simplified reaction mechanism for toluene oxidation that reflects the potential influence of $\mathrm{NO}$ on the formation of various toluene oxidation products. This mechanism and its rate 


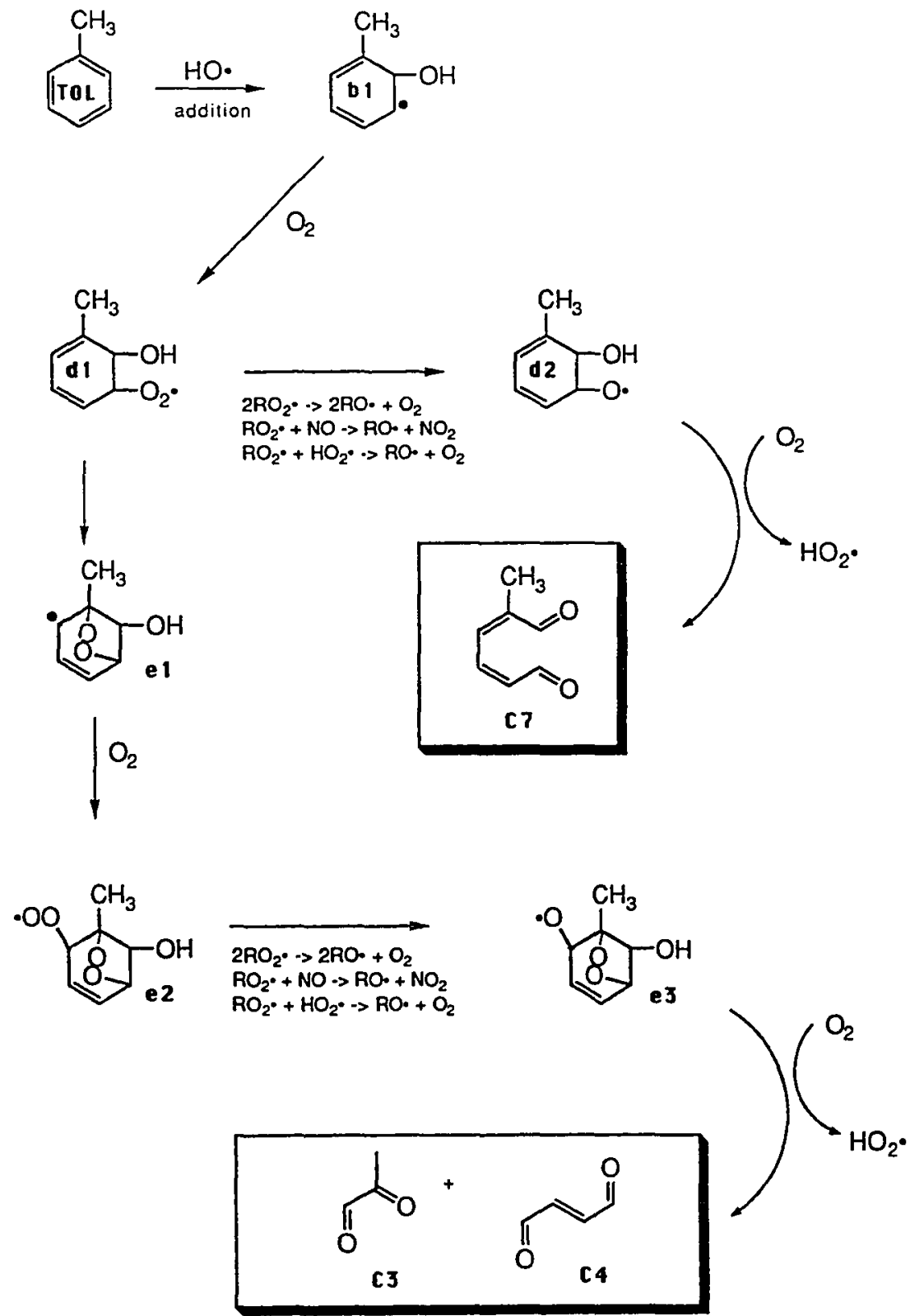

Figure 8. Partial toluene oxidation mechanism showing the production of several free radical intermediates and stable products. Experimental accurate mass assignments for the stable products are in Chapter III, masses for the free radical intermediates in Table V.

constants are given in Table VI and are taken largely from Atkinson and Lloyd (1984). It should be emphasized that many of the rate constants may be 
TABLE VI

KINETIC MODELING MECHANISM FOR HRKAPIMS SOURCE REACTIONS

Reaction

Rate Constant

\begin{tabular}{|c|c|c|c|c|c|c|c|}
\hline TOL & $\mathrm{OH}$ & & $=$ & B1 & & & 5.9E-12 \\
\hline B1 & $\mathrm{O} 2$ & & $=$ & D1 & & & $3.3 \mathrm{E}-15$ \\
\hline D1 & NO & & $=$ & D2 & $\mathrm{NO} 2$ & & $7.0 \mathrm{E}-12(7 \mathrm{E}-11)$ \\
\hline D1 & D1 & & $=$ & $\mathrm{D} 2$ & $\mathrm{O} 2$ & & $4.3 \mathrm{E}-15$ \\
\hline D1 & $\mathrm{HO} 2$ & & $=$ & $\mathrm{D} 2$ & $\mathrm{OH}$ & $\mathrm{O} 2$ & 8.5E-12 \\
\hline $\mathrm{D} 2$ & $\mathrm{O} 2$ & & $=$ & $\mathrm{C7}$ & $\mathrm{HO} 2$ & & $7.0 \mathrm{E}-15$ \\
\hline D1 & & & $=$ & E1 & & & $8.0 \mathrm{E} 4$ \\
\hline E1 & $\mathrm{O} 2$ & & $=$ & $\mathrm{E} 2$ & & & $1.0 \mathrm{E}-12$ \\
\hline E2 & NO & & $=$ & E3 & $\mathrm{NO} 2$ & & $7.0 \mathrm{E}-12(7 \mathrm{E}-11)$ \\
\hline $\mathrm{E} 2$ & $\mathrm{E} 2$ & & $=$ & E3 & 02 & & $4.3 \mathrm{E}-16$ \\
\hline $\mathrm{E} 2$ & $\mathrm{HO} 2$ & & $=$ & E3 & $\mathrm{OH}$ & $\mathrm{O} 2$ & 8.5E-12 \\
\hline $\mathrm{E} 2$ & $\mathrm{~A} 2$ & & $=$ & E3 & A3 & $\mathrm{O} 3$ & $4.3 \mathrm{E}-16$ \\
\hline $\mathrm{E} 2$ & D1 & & $=$ & E3 & $\mathrm{D} 2$ & $\mathrm{O} 2$ & $4.3 \mathrm{E}-16$ \\
\hline E3 & $\mathrm{O} 2$ & & $=$ & $\mathrm{C} 4$ & $\mathrm{C3}$ & $\mathrm{HO} 2$ & $7.0 \mathrm{E}-15$ \\
\hline B1 & $\mathrm{H} 3 \mathrm{O}$ & & $=$ & B1H & $\mathrm{H} 2 \mathrm{O}$ & & $3.0 \mathrm{E}-9$ \\
\hline D1 & H3O & & $=$ & D1H & $\mathrm{H} 2 \mathrm{O}$ & & 3.0E-9 \\
\hline $\mathrm{D} 2$ & $\mathrm{H} 3 \mathrm{O}$ & & $=$ & $\mathrm{D} 2 \mathrm{H}$ & $\mathrm{H} 2 \mathrm{O}$ & & $3.0 \mathrm{E}-9$ \\
\hline E1 & $\mathrm{H} 3 \mathrm{O}$ & & $=$ & E1H & $\mathrm{H} 2 \mathrm{O}$ & & $3.0 \mathrm{E}-9$ \\
\hline $\mathrm{E} 2$ & $\mathrm{H} 3 \mathrm{O}$ & & $=$ & E2H & $\mathrm{H} 2 \mathrm{O}$ & & $3.0 \mathrm{E}-9$ \\
\hline E3 & $\mathrm{H} 3 \mathrm{O}$ & & $=$ & $\mathrm{E} 3 \mathrm{H}$ & $\mathrm{H} 2 \mathrm{O}$ & & 3.0E-9 \\
\hline C7 & $\mathrm{H} 3 \mathrm{O}$ & & $=$ & $\mathrm{C} 7 \mathrm{H}$ & $\mathrm{H} 2 \mathrm{O}$ & & 3.0E-9 \\
\hline $\mathrm{C} 4$ & $\mathrm{H} 3 \mathrm{O}$ & & $=$ & $\mathrm{C} 4 \mathrm{H}$ & $\mathrm{H} 2 \mathrm{O}$ & & 3.0E-9 \\
\hline C3 & $\mathrm{H} 3 \mathrm{O}$ & & $=$ & $\mathrm{C} 3 \mathrm{H}$ & $\mathrm{H} 2 \mathrm{O}$ & & 3.0E-9 \\
\hline 0 & 0 & $\mathbf{M}$ & $=$ & $\mathrm{O} 2$ & $\mathbf{M}$ & & 5.8E-32 \\
\hline $\mathrm{H}$ & $\mathrm{O} 2$ & $\mathbf{M}$ & $=$ & HO2 & $\mathbf{M}$ & & $1.8 \mathrm{E}-32$ \\
\hline $\mathrm{OH}$ & $\mathrm{OH}$ & & $=$ & $\mathrm{H} 2 \mathrm{O}$ & 0 & & $1.6 \mathrm{E}-12$ \\
\hline $\mathrm{OH}$ & 0 & & $=$ & $\mathrm{H}$ & 02 & & $3.8 \mathrm{E}-11$ \\
\hline $\mathrm{OH}$ & $\mathrm{H}$ & & $=$ & $\mathrm{H} 2$ & 0 & & $1.2 \mathrm{E}-19$ \\
\hline $\mathrm{OH}$ & $\mathrm{H}$ & $\mathbf{M}$ & $=$ & $\mathrm{H} 2 \mathrm{O}$ & $\mathbf{M}$ & & $6.8 \mathrm{E}-31$ \\
\hline $\mathrm{OH}$ & $\mathrm{OH}$ & $\mathbf{M}$ & $=$ & $\mathrm{H} 2 \mathrm{O} 2$ & $\mathbf{M}$ & & $6.9 \mathrm{E}-31$ \\
\hline $\mathrm{HO} 2$ & $\mathbf{M}$ & & $=$ & $\mathrm{H}$ & 02 & $\mathbf{M}$ & 1.7E-42 \\
\hline $\mathrm{HO} 2$ & $\mathrm{H}$ & & $=$ & $\mathrm{H} 2$ & $\mathrm{O} 2$ & & $1.3 \mathrm{E}-11$ \\
\hline $\mathrm{HO} 2$ & $\mathrm{H}$ & & $=$ & $2 \mathrm{OH}$ & & & 3.2E-11 \\
\hline $\mathrm{HO} 2$ & $\mathrm{OH}$ & & $=$ & $\mathrm{H} 2 \mathrm{O}$ & $\mathrm{O} 2$ & & 7.0E-11 \\
\hline $\mathrm{HO} 2$ & $\mathrm{HO} 2$ & & $=$ & $\mathrm{H} 2 \mathrm{O} 2$ & $\mathrm{O} 2$ & & $1.7 \mathrm{E}-12$ \\
\hline $\mathrm{H} 2 \mathrm{O} 2$ & $\mathrm{H}$ & & $=$ & $\mathrm{H} 2$ & $\mathrm{HO} 2$ & & $5.0 \mathrm{E}-15$ \\
\hline $\mathrm{H}$ & $\mathrm{O} 2$ & M & $=$ & $\mathrm{HO} 2$ & $\mathbf{M}$ & & $5.5 \mathrm{E}-32$ \\
\hline $\mathrm{O}$ & $\mathrm{O} 2$ & $\mathrm{M}$ & $=$ & 03 & $\mathbf{M}$ & & $5.7 \mathrm{E}-34$ \\
\hline $\mathrm{OH}$ & $\mathrm{O} 3$ & & $=$ & $\mathrm{HO} 2$ & $\mathrm{O} 2$ & & $6.8 \mathrm{E}-14$ \\
\hline 0 & $\mathrm{HO} 2$ & & $=$ & $\mathrm{OH}$ & 02 & & $5.7 \mathrm{E}-11$ \\
\hline
\end{tabular}


TABLE VI

KINETIC MODELING MECHANISM FOR HRKAPIMS

SOURCE REACTIONS

(continued)

Reaction

Rate Constant

$\begin{array}{llllll}\mathrm{O} & \mathrm{O} 3 & = & 2 \mathrm{O} 2 & 8.0 \mathrm{E}-12 \\ \mathrm{H} & \mathrm{HO} 2 & = & \mathrm{H} 2 \mathrm{O} & 3.0 \mathrm{E}-12 \\ \mathrm{O} & \mathrm{H} 2 \mathrm{O} 2 & = & \mathrm{OH} & \mathrm{HO} 2 & 2.3 \mathrm{E}-15 \\ \mathrm{H} & \mathrm{O} 3 & = & \mathrm{OH} & \mathrm{O} 2 & 2.9 \mathrm{E}-11 \\ \mathrm{O} & \mathrm{H} 2 \mathrm{O} 2 & = & \mathrm{OH} & \mathrm{HO} 2 & 1.7 \mathrm{E}-15 \\ \mathrm{OH} & \mathrm{H} 2 \mathrm{O} 2 & = & \mathrm{H} 2 \mathrm{HO} 2 & 1.7 \mathrm{E}-12 \\ \mathrm{HO} 2 & \mathrm{O} 3 & = & \mathrm{OH} 2 \mathrm{O} 2 & 2.0 \mathrm{E}-15 \\ \mathrm{H} 2 \mathrm{O} & \mathrm{H} & = & \mathrm{H} 2 \mathrm{OH} & 2.2 \mathrm{E}-25 \\ \mathrm{H} 2 \mathrm{O} & \mathrm{O} & = & \mathrm{OH} \mathrm{OH} & 4.6 \mathrm{E}-24 \\ \mathrm{H} 2 \mathrm{O} & \mathrm{HO} 2 & = & \mathrm{H} 2 \mathrm{OH} & 6.1 \mathrm{E}-35\end{array}$

\$INITIAL CONDITIONS

$\begin{array}{llll}\text { TEMP } & \text { NO } & \text { O2 } & \text { OH } \\ \text { H3O } & \text { TOL } & \text { H2O } & \text { M }\end{array}$

$2.98 \mathrm{E}+02 \quad 1.225 \mathrm{E}+16 \quad 5.0 \mathrm{E}+18 \quad 3.740 \mathrm{E}+13$

$3.740 \mathrm{E}+13 \quad 2.450 \mathrm{E}+13 \quad 1.0 \mathrm{E}+16 \quad 2.5 \mathrm{E}+19$

Notes: Toluene oxidation products are identified in Figure 8 and modeling results presented in Figure 9. Reaction rate constants are from Atkinson and Lloyd (1984) where available (see discussion in text). $\mathrm{RO}_{2}{ }^{\bullet}+\mathrm{NO}$ reactions were modeled at the faster $7 \times 10^{-11}$ rate. Rate constants at $\mathrm{T}=300 \mathrm{~K}$ in units of $\mathrm{cm}^{3}$ molecules ${ }^{-1} \mathrm{sec}^{-1}$ or $\mathrm{cm}^{6}$ molecules ${ }^{-2} \sec ^{-1}$ as appropriate, $\underline{e}$ indicates power of ten.

considered as provisional values, since no experimental measurements of their values are reliable. A new comprehensive kinetic model has been compiled by Carter (1990) to describe atmospheric oxidation processes. However in this model "no attempt to speculate on the nature and detailed reactions of the uncharacterized aromatic products" is made, and the rates of Atkinson and Lloyd (1984) appear to be the best available. 
Using the provisional rate constants (Atkinson and Lloyd, 1984), we found that NO was predicted to have a smaller effect on the intermediate concentrations than we observed experimentally. However, if we increased the rate constants for the reactions of $\mathrm{NO}$ with intermediates $\mathrm{d} 1$ and $\mathrm{e} 2$ by a factor of ten, we were able to reproduce the general trends in the experimental data. This is illustrated in Figure 9 which compares experimental ion intensities for five of the free radical intermediates listed in Table I, and identified in Figure 1, with the calculated results from the kinetic model in Table II. The measured protonated ion intensities $\left(\mathrm{b} 1 \mathrm{H}^{+}, \mathrm{d} 1 \mathrm{H}^{+}\right.$, etc.), based on an experiment using perdeuterated toluene, are shown as filled points in Figure 9 with error bars representing the experimental uncertainty. The open points (with curves) are the modeled concentrations calculated from the integration of Table VI. The experimental data (measured ion currents) were all multiplied by a single constant to bring them to the same scale as the calculated concentrations. The mechanism in Table VI contains a complete sequence of $\mathrm{HO} / \mathrm{HO}_{2}$ radical reactions, the toluene oxidation mechanism from Figure 8, and protonation steps for all reaction intermediates and stable products. In this simplified treatment, $\mathrm{H}_{3} \mathrm{O}^{+}$is the only source of protons, and all protonation reactions have the same rate constant (Bohme, Mackay, and Tanner, 1979). In fact, $\mathrm{H}_{3} \mathrm{O}^{+}$water clusters also serve as proton sources, and the protonation rate constants vary somewhat, resulting in somewhat different sensitivities for various products $P$. For oxidation products with low gas-phase basicities, transfer of protons back to water should be included as well. Full treatment of the processes in the source is complex, and beyond the scope of the presentation here. The intermediate concentrations are calculated by integrating 

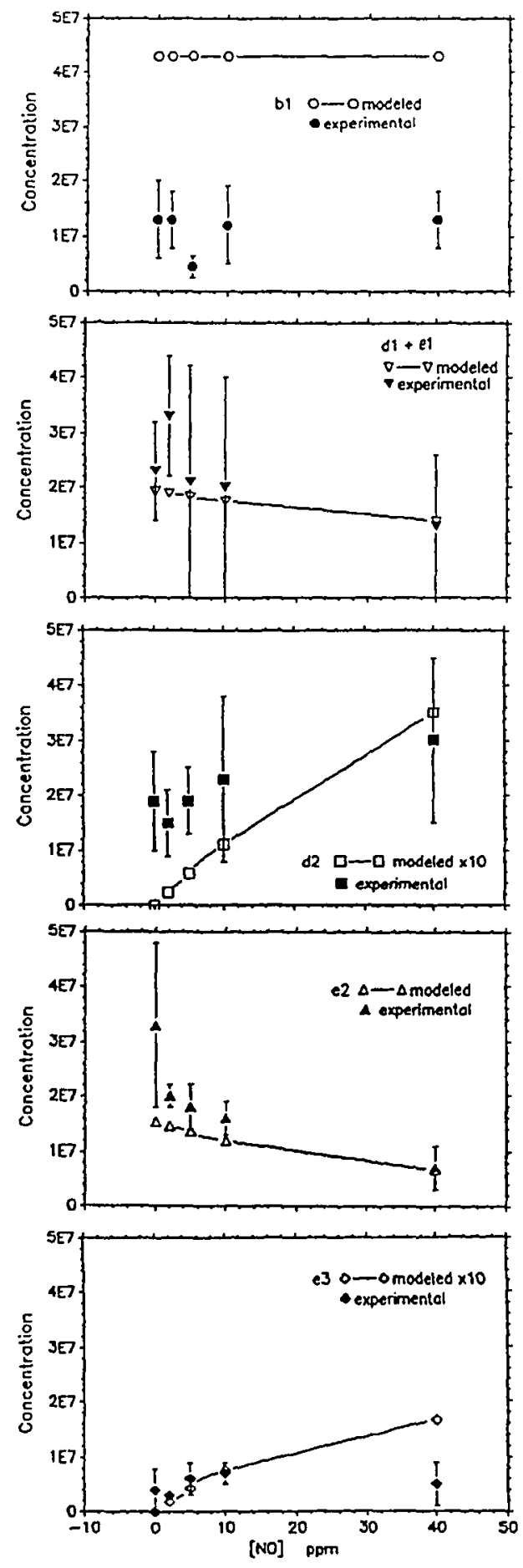

Figure 9. Experimental vs. Modeled ion intensities for toluene free radical intermediates. Modeled data from the mechanism in Table VI. Experimental values uniformly scaled to the modeling data. 
the mechanism until steady-state ion concentrations are achieved, requiring about 25 milliseconds reaction time with an initial $\mathrm{HO}=\mathrm{H}_{3} \mathrm{O}^{+}$concentration of $1.5 \mathrm{ppm}$. The residence time for neutrals in the source is about 1.6 seconds based on a flow of $20 \mathrm{~cm}^{3} \mathrm{~min}^{-1}$.

\section{CONCLUSIONS}

At this point in the development of HRKAPIMS, there remain uncertainties about the processes occurring within the API source and further study using compounds having understood chemistry will be required before full confidence in kinetic modeling can be developed. Since these data were obtained with an API source designed for atmospheric sampling rather than kinetic analysis, it seems likely that improvements in source design will also improve the quantitative abilities of HRKAPIMS. Nevertheless, the successful semi-quantitative modeling of NO effects suggests that reliable quantitative data can be obtained using this technique.

Although considerable knowledge regarding atmospheric oxidation mechanisms has been accumulated over the last several decades, especially for smaller hydrocarbons, a great deal of information remains to be unraveled, especially for single ring and polycyclic aromatic hydrocarbons. The ability of HRKAPIMS analysis to detect 29 stable products, as well as the 5 free radical intermediates, simultaneously under conditions similar to the ambient atmosphere places this technique in a unique class. Our detection here of the hydroxycyclohexadienyl radical suggests that under atmospheric conditions $\mathrm{O}_{2}$ addition to the aromatic ring is an important pathway, affirming the earlier 
proposed mechanisms. We believe that HRKAPIMS can be an important tool in the study of these compounds and will provide valuable insights into the details of aromatic hydrocarbon oxidation processes in the atmosphere. 


\title{
CHAPTER V
}

\section{SEMIEMPIRICAL CALCULATIONS OF GAS-PHASE BASICITIES WITH APPLICATIONS TO MASS SPECTROMETRY}

\author{
"We say the cause of perfume disappearing is evaporation. \\ Evaporation gets blamed for many things people forget \\ to put the top on." (Davis 1969)
}

\section{OVERVIEW}

The gas-phase basicity of a compound is important in a variety of chemical systems involving proton transfer reactions; these include the ionization steps in chemical ionization, fast atom bombardment, atmospheric pressure ionization mass spectrometry (APIMS) and ion mobility spectrometry. Gas phase basicities (GBs) for 127 organic compounds containing carbon, hydrogen, nitrogen and oxygen are calculated. Linear regression analysis of semi-empirical calculated heats of formation give GBs with an overall uncertainty of $3.1 \mathrm{kcal} / \mathrm{mol}$ for a subset of 99 compounds with GBs near 200 . The remaining 28 compounds are separated into 5 classes and their characteristic errors are discussed individually.

\section{INTRODUCTION}

The decreasing cost of computational power and the increasing availability of computational software have made semiempirical molecular orbital (MO) calculations available to an ever widening circle of chemists. The ability of 
semiempirical calculations to deal with large and complex molecules which would be prohibitive to study with ab initio methods encourages the use of MO theory in a variety of applications. In the field of mass spectrometry (MS) for instance, the relative sensitivity of analytes in atmospheric pressure ionization (API) and fast atom bombardment $(\mathrm{FAB})$ is a function of a compound's gas-phase basicity (GB) (Lacey and Keough, 1989; Sunner, Kulatunga, and Kebarle, 1986; Sunner, Nicol, and Kebarle, 1988; Sunner, Ikonomou, and Kebarle, 1988a; Sunner, Ikonomou, and Kebarle, 1988b). Response factors in ion mobility mass spectrometry (IMMS) are also dependent on a compound's basicity, when using an atmospheric pressure ionization source (Vandiver, Leasure, and Eiceman, 1985). Recent MO calculations compared the effectiveness of MINDO/3, MNDO and AM1 in the prediction of proton affinities (Voets et al., 1989) and hydrocarbon acidities (Kass 1990) and found AM1 superior. The heats of formation for protonated organics $\left(\mathrm{BH}^{+}\right)$are of particular interest, but less theoretical work has been done in this area than for species resulting from charge transfer $\left(\mathrm{B}^{+}\right)$or other processes. MINDO/3 and MNDO calculations have been performed on a variety of cations $\left(\mathrm{B}^{+}\right)$giving errors of -7 and $+9 \mathrm{kcal} / \mathrm{mol}$ respectively by parametization when compared to experimental values (Halim et al., 1986). The present work expands the number and variety of compounds examined with the AM1 parameterization by calculating heats of formation for 127 species in neutral and protonated forms. These compounds were selected as representative of several general classes of compounds in which analytical and environmental chemists might be interested. Furthermore, many of these compounds and their chemical classes are important in atmospheric chemistry and we are particularly interested in their detection using atmospheric 
pressure ionization mass spectrometry. Atmospheric oxidation processes result, for example, in the formation of ketones, aldehydes, alcohols, acids, nitro and nitrate compounds, etc. The calculated heats of formation are then used to derive gasphase basicities for the compounds. A newly developed optimization, MNDO-PM3 (Stewart 1989), which includes parameters for 12 elements, offers only slight improvement for the neutral $\mathrm{C}, \mathrm{H}, \mathrm{N}$ and $\mathrm{O}$ compounds evaluated here. MNDOPM3 was not utilized in this study.

Gas-phase basicities are important in mass spectrometry where the fundamental reaction is proton transfer from a reagent ion (for example: water, methane or ammonia) to the analyte. GB is defined as the negative of the free energy change for Reaction 15 (R15) (Lias, Liebman, and Levin, 1984) and is related to the equilibrium constant for proton transfer from water by Equation 1 (E1). Our own interest in calculating GB of CHNO compounds comes from a desire to quantify our APIMS studies of atmospheric hydrocarbon oxidations: Chapters IIIV, and Grange, O'Brien, and Barofsky (1988a). We express $K_{e q}$ in terms of protonation from a hydronium ion (R9). E1 would be similarly written for transfer from hydronium ion/water clusters, ammonia, methane or other reagents.

$$
\begin{gathered}
\mathrm{B}+\mathrm{H}^{+} \rightarrow \mathrm{BH}^{+} \\
\mathrm{H}_{3} \mathrm{O}^{+}+\mathrm{B} \rightarrow \mathrm{BH}^{+}+\mathrm{H}_{2} \mathrm{O} \\
\mathrm{K}_{\mathrm{eq}}(\mathrm{R} 9)=\left[\mathrm{BH}^{+}\right]\left[\mathrm{H}_{2} \mathrm{O}\right] /\left[\mathrm{H}_{3} \mathrm{O}^{+}\right][\mathrm{B}]=\exp \left(\left\{\mathrm{GB}(\mathrm{B})-\mathrm{GB}\left(\mathrm{H}_{2} \mathrm{O}\right)\right\} / \mathrm{RT}\right)
\end{gathered}
$$

Although extensive experimental values for the free energy of reaction $(\Delta \mathrm{G}(\mathrm{R} 15)=-\mathrm{GB})$ have been tabulated (Lias, Liebman, and Levin, 1984), experimental gas-phase basicities are unavailable for many compounds of environmental significance, in particular many atmospheric oxidation products. 
Toluene, for example, has over 30 identified primary photo-oxidation products (Dumdei and O'Brien, 1984; Shepson, Edney, and Corse, 1984; Dumdei et al., 1988; Grange, O'Brien, and Barofsky, 1988a; among others) but the GBs of only a few have been measured (Lias, Liebman, and Levin, 1984). In this study we calculated most of the compounds from Lias, Liebman, and Levin (1984) which might relate to atmospheric oxidation processes.

\section{EXPERIMENTAL}

All semiempirical calculations were carried out using the AM1 Hamiltonian (Dewar et al., 1985) in the program MOPAC 4.0 available from QCPE (Quantum Chemistry Program Exchange, Department of Chemistry, University of Indiana, Joliet IN 44444.). This parameterized form improves on the MNDO model with no increase in computational time. Parameters are available in this release for carbon, hydrogen, nitrogen and oxygen. All computer modeling was done on an Apollo DN10000 workstation with molecular structures input using MOLY-86. MOLY-86 (also available from QCPE) is an interactive molecular modeling system developed by Rohm and Haas, Inc., allowing entry, manipulation and preliminary optimization of molecular structures. Some modification of MOLY was required so that it would accept protonated species. MOPAC calculated the enthalpy of formation, bond lengths, bond orders and other parameters for any given structure.

\section{RESULTS AND DISCUSSION}

Table VII summarizes our results for 127 compounds, tabulating the derived heats of formation $\Delta \mathrm{H}_{1}(\mathrm{~B})$ for the unprotonated analyte $\mathrm{B}, \Delta \mathrm{H}_{\gamma}\left(\mathrm{BH}^{+}\right)$, for the 
TABLE VII

COMPARISON OF THE GAS-PHASE BASICITIES AND ADJUSTED

HEATS OF FORMATION FOR PROTONATED AND

UNPROTONATED SPECIES

\begin{tabular}{|c|c|c|c|c|c|c|}
\hline & \multicolumn{2}{|c|}{$\Delta \mathrm{H}_{\mathrm{f}}(\mathrm{B})$} & \multicolumn{2}{|c|}{$\Delta \mathrm{H}_{f}\left(\mathrm{BH}^{+}\right)$} & \multicolumn{2}{|l|}{ GB } \\
\hline & value & error & value & erius: & value & error \\
\hline nitric oxide & 0.3 & -21.2 & 231.2 & -28.8 & 120.2 & 1.2 \\
\hline carbon dioxide & -78.2 & 15.8 & 142.1 & 1.1 & 133.9 & 9.5 \\
\hline $\mathrm{N} 2 \mathrm{O}(\mathrm{NNO})$ & 27.2 & 7.2 & 246.5 & -2.5 & 136.3 & 4.9 \\
\hline hydrogen peroxide & -34.8 & -2.3 & 175.6 & 4.6 & 142.9 & -11.1 \\
\hline ethene & 52.9 & -1.1 & 263.5 & -3.4 & 144.2 & -1.9 \\
\hline phenol & -22.2 & 0.8 & 168.5 & 22.5 & 149.6 & -25.4 \\
\hline water & -58.2 & -0.4 & 137.9 & -3.1 & 159.0 & 0.0 \\
\hline cyclopropane & 16.8 & 3.8 & 206.2 & 7.7 & 166.0 & -6.0 \\
\hline methanol & -56.0 & -8.0 & 132.0 & -3.5 & 167.7 & -6.4 \\
\hline formaldehyde & -31.2 & -5.2 & 156.5 & -11.5 & 168.7 & 4.4 \\
\hline 2-butene & -3.7 & -0.7 & 180.8 & -2.2 & 171.5 & -0.1 \\
\hline hydrogen cyanide & 29.7 & -2.3 & 213.7 & -12.3 & 172.3 & 8.5 \\
\hline propene & 6.3 & -6.7 & 189.8 & -8.7 & 172.6 & 0.6 \\
\hline nitrobenzene & 24.2 & 8.2 & 208.0 & 19.5 & 172.9 & -12.7 \\
\hline dimethyl ether & -52.3 & -8.3 & 131.3 & 1.3 & 173.2 & -11.1 \\
\hline cyclobutene & 44.1 & 6.6 & 225.9 & 13.9 & 174.4 & -8.6 \\
\hline benzene & 20.9 & 0.9 & 204.3 & 0.3 & 175.0 & -0.6 \\
\hline cyclohexene & -10.2 & -9.2 & 170.5 & -4.5 & 175.6 & -5.9 \\
\hline ethanol & -61.5 & -5.5 & 118.7 & -2.3 & 175.8 & -4.4 \\
\hline nitroethane & -16.9 & 7.1 & 162.4 & 5.9 & 177.2 & 0.2 \\
\hline$n$-propyl alcohol & -68.2 & -7.2 & 111.0 & -3.0 & 177.8 & -5.2 \\
\hline nitromethane & -19.9 & -1.9 & 159.0 & -9.5 & 178.3 & 6.6 \\
\hline cyclopentene & 2.4 & -6.6 & 181.9 & -9.1 & 180.0 & 1.8 \\
\hline acetaldehyde & -41.0 & -1.0 & 135.6 & -3.4 & 180.3 & 1.7 \\
\hline methylbenzene (toluene) & 13.5 & 1.5 & 190.4 & 2.4 & 180.4 & -1.6 \\
\hline 1,3-butadiene & 28.6 & 2.6 & 204.6 & 5.6 & 181.3 & -3.6 \\
\hline methyl cyanide (acetonitrile) & 18.3 & 0.3 & 193.7 & -1.3 & 181.5 & 0.9 \\
\hline isopropyl alcohol & -66.6 & -1.6 & 108.6 & -0.4 & 181.5 & -1.9 \\
\hline ethylbenzene & 9.2 & 2.2 & 184.1 & 3.1 & 182.4 & -1.4 \\
\hline methyl ethyl ether & -57.7 & -5.7 & 117.9 & -0.1 & 182.5 & -6.1 \\
\hline ethyl cyanide (propionitrile) & 12.1 & 0.1 & 185.4 & 0.4 & 183.4 & -0.7 \\
\hline isobutanal & -51.8 & 0.2 & 122.0 & 1.0 & 183.5 & -1.3 \\
\hline$n$-butanal & -54.2 & -4.2 & 119.3 & -4.7 & 183.9 & 0.2 \\
\hline propanal & -47.6 & -2.6 & 125.7 & -5.3 & 184.3 & 2.4 \\
\hline isobutene & -1.6 & 2.4 & 170.8 & 4.8 & 184.6 & -2.7 \\
\hline dimethyl glyoxal & -70.2 & 7.8 & 101.5 & 8.5 & 185.2 & -1.0 \\
\hline
\end{tabular}


TABLE VII

COMPARISON OF THE GAS-PHASE BASICITIES AND ADJUSTED HEATS OF FORMATION FOR PROTONATED AND

UNPROTONATED SPECIES

(continued)

\begin{tabular}{|c|c|c|c|c|c|c|}
\hline & \multicolumn{2}{|l|}{$\Delta \mathrm{H}_{\mathrm{f}}(\mathrm{B})$} & \multicolumn{2}{|c|}{$\Delta \mathrm{H}_{\mathrm{f}}\left(\mathrm{BH}^{+}\right)$} & \multicolumn{2}{|l|}{ GB } \\
\hline & value & error & value & error & value & error \\
\hline pentanal & -60.7 & -5.7 & 111.6 & -6.4 & 185.2 & 0.4 \\
\hline PhCN (benzonitrile) & 51.4 & -0.6 & 223.7 & 1.7 & 185.6 & -2.5 \\
\hline acetic acid & -100.8 & 2.2 & 69.9 & -2.1 & 185.7 & 4.0 \\
\hline di-1-propenyl ether & -13.5 & -6.5 & 157.8 & -0.2 & 186.1 & -6.5 \\
\hline diethyl ether & -63.5 & -3.5 & 107.9 & 2.4 & 186.3 & -6.1 \\
\hline methacrolein & -23.5 & 1.5 & 147.3 & 2.3 & 186.5 & -0.9 \\
\hline propenal & -14.9 & 3.1 & 155.4 & 2.4 & 186.7 & 0.6 \\
\hline $\mathrm{NH} 2$ & 36.3 & -7.7 & 206.6 & -16.4 & 187.6 & 8.6 \\
\hline$t$-butyl alcohol & -70.3 & 4.7 & 99.9 & 2.9 & 187.7 & 1.8 \\
\hline 1,2-dimethylcyclobutene & 26.0 & 9.0 & 196.2 & 14.2 & 188.9 & -5.1 \\
\hline propanoic acid & -106.7 & 0.3 & 62.0 & -5.0 & 189.4 & 5.4 \\
\hline methoxybenzene (anisole) & -15.8 & 0.2 & 151.9 & 2.9 & 190.0 & -2.5 \\
\hline 1,2 dimethoxyethane & -97.2 & -16.2 & 69.2 & -10.3 & 190.1 & -5.7 \\
\hline furan & 2.4 & 10.4 & 170.3 & 5.3 & 190.2 & 5.2 \\
\hline di-n-butyl ether & -89.8 & -10.3 & 77.5 & -4.5 & 190.3 & -5.6 \\
\hline styrene & 36.9 & 1.9 & 204.5 & 5.5 & 190.8 & -3.4 \\
\hline acetone & -48.0 & 4.0 & 118.6 & 1.6 & 191.6 & 2.7 \\
\hline CH3CHCO (methyl ketene) & -13.9 & 11.1 & 152.5 & 11.5 & 191.6 & 0.0 \\
\hline 1,3-pentadiene & 19.1 & 1.1 & 185.6 & 3.6 & 191.7 & -2.2 \\
\hline cyclopentanone & -54.4 & -8.4 & 112.3 & -8.7 & 192.2 & 0.7 \\
\hline methyl ethyl ketone & -54.2 & 2.8 & 111.3 & 2.3 & 193.0 & 1.0 \\
\hline benzaldehyde & -9.2 & -0.2 & 156.3 & -0.7 & 193.4 & 1.0 \\
\hline dicyclopropyl ketone & 8.9 & -30.1 & 173.6 & -20.4 & 193.7 & -9.2 \\
\hline tetrahydrofuran & -54.1 & -10.1 & 110.9 & -12.1 & 193.9 & 2.5 \\
\hline methyl cyclopropyl ketone & -19.9 & 8.1 & 144.6 & 11.6 & 194.4 & -2.9 \\
\hline$t$-butyl-ONO ( $t$-butyl nitrite) & -44.9 & -3.9 & 118.7 & -0.3 & 194.9 & -3.0 \\
\hline methyl vinyl ketone & -23.9 & 5.1 & 139.2 & 3.2 & 194.9 & 2.5 \\
\hline 2-butenal & -26.2 & -4.2 & 137.3 & -6.7 & 195.0 & 3.1 \\
\hline dimethyl carbonate & -133.7 & -2.2 & 29.9 & -4.1 & 195.0 & 2.6 \\
\hline 2,5-dimethyl furan & -11.1 & 18.9 & 152.6 & 25.6 & 195.3 & -6.0 \\
\hline methyl isopropyl ketone & -58.1 & 4.9 & 105.6 & 3.6 & 195.3 & 2.0 \\
\hline di- $n$-pentyl ether & -103.2 & -13.2 & 60.7 & -10.3 & 195.7 & -2.2 \\
\hline diethyl ketone & -60.0 & 2.0 & 102.1 & 0.1 & 196.2 & 2.7 \\
\hline cyclohexanone & -62.1 & -8.1 & 100.1 & -9.9 & 196.6 & 2.6 \\
\hline di-isopropyl ether & -70.4 & 5.6 & 90.5 & 6.5 & 196.8 & -0.2 \\
\hline
\end{tabular}


TABLE VII

COMPARISON OF THE GAS-PHASE BASICITIES AND ADJUSTED HEATS OF FORMATION FOR PROTONATED AND

UNPROTONATED SPECIES

(continued)

\begin{tabular}{|c|c|c|c|c|c|c|}
\hline & \multicolumn{2}{|l|}{$\Delta \mathrm{H}_{r}(\mathrm{~B})$} & \multicolumn{2}{|c|}{$\Delta \mathrm{H}_{\mathrm{f}}\left(\mathrm{BH}^{+}\right)$} & \multicolumn{2}{|l|}{ GB } \\
\hline & value & error & value & error & value & error \\
\hline methyl $t$-butyl ketone & -58.8 & 10.2 & 102.2 & 8.2 & 197.4 & 2.9 \\
\hline 4-methylbenzaldehyde & -16.9 & 1.1 & 143.3 & -0.7 & 198.3 & 2.8 \\
\hline 2-methylfuran & -4.4 & 14.6 & 155.2 & 14.2 & 199.3 & 1.5 \\
\hline di-isopropyl ketone & -67.5 & 6.5 & 92.2 & 5.2 & 199.3 & 2.3 \\
\hline pyrrole & 38.3 & 12.3 & 198.3 & 14.3 & 199.4 & -0.9 \\
\hline benzoic acid & -66.7 & 3.3 & 91.5 & -5.5 & 199.5 & 9.9 \\
\hline methyl vinyl ether & -25.4 & -1.4 & 133.7 & -0.3 & 199.7 & 0.1 \\
\hline formamide & -44.1 & -0.1 & 114.7 & -8.3 & 199.9 & 9.3 \\
\hline pyrimidine & 42.2 & -3.8 & 201.4 & 0.4 & 200.5 & -3.0 \\
\hline methyl ethyl carbonate & -139.5 & 1.5 & 18.4 & -3.1 & 200.7 & 5.8 \\
\hline methyl phenyl ketone & -15.0 & 6.0 & 143.6 & 3.6 & 201.0 & 3.6 \\
\hline 2,5,8-trioxanonane & -142.2 & -23.2 & 9.8 & -17.2 & 202.8 & -4.6 \\
\hline diphenyl ketone (benzophenon & e) 19.5 & 7.5 & 175.0 & 8.0 & 204.0 & 0.9 \\
\hline ethyl vinyl ether & -30.9 & 3.1 & 124.4 & 0.4 & 204.7 & 4.3 \\
\hline aminobenzene (aniline) & 19.3 & -1.7 & 172.9 & -4.1 & 206.0 & 4.1 \\
\hline ammonia & -7.6 & 3.4 & 145.1 & -5.9 & 206.6 & 11.0 \\
\hline dimethylformamide & -36.1 & 9.9 & 116.9 & 8.9 & 206.7 & 2.8 \\
\hline 2,5-hexanedione & -90.9 & -1.9 & 57.6 & -5.9 & 207.3 & 5.8 \\
\hline methylamine & -7.7 & -2.7 & 143.1 & -2.9 & 207.7 & 2.0 \\
\hline dimethylamine & -6.0 & -1.5 & 143.6 & 3.6 & 209.8 & -3.0 \\
\hline pryidine & 30.7 & -2.3 & 181.0 & 3.0 & 209.8 & -3.3 \\
\hline trimethylamine & -2.2 & 3.8 & 146.6 & 11.6 & 211.8 & -5.5 \\
\hline ethylamine & -13.6 & -2.6 & 132.5 & -4.5 & 212.8 & 4.3 \\
\hline$n$-propylamine & -20.3 & -3.3 & 125.0 & -6.0 & 215.3 & 5.2 \\
\hline$i$-propylamine & -19.2 & 0.8 & 124.3 & -2.7 & 217.2 & 6.2 \\
\hline 2-oxy-3-penten-4-ol & -74.8 & 17.2 & 65.0 & -1.0 & 220.5 & 21.2 \\
\hline$t$-butylamine & -21.3 & 7.7 & 118.4 & 2.4 & 221.5 & 8.5 \\
\hline triethylamine & -18.2 & 3.8 & 120.9 & 9.9 & 221.6 & -2.9 \\
\hline formic acid & -88.1 & 2.4 & 87.0 & -9.0 & 181.1 & 10.7 \\
\hline methyl formate & -89.1 & -4.1 & 79.6 & -12.4 & 189.3 & 8.3 \\
\hline ethyl formate & -94.1 & -2.1 & 73.5 & -6.5 & 189.8 & 4.5 \\
\hline$n$-propyl formate & -100.6 & 9.4 & 65.6 & 4.6 & 191.4 & 5.0 \\
\hline$n$-butyl formate & -107.8 & -4.8 & 57.8 & -10.2 & 192.6 & 5.7 \\
\hline
\end{tabular}


TABLE VII

COMPARISON OF THE GAS-PHASE BASICITIES AND ADJUSTED

HEATS OF FORMATION FOR PROTONATED AND

UNPROTONATED SPECIES

(continued)

\begin{tabular}{|c|c|c|c|c|c|c|}
\hline & \multicolumn{2}{|l|}{$\Delta \mathrm{H}_{\mathrm{r}}(\mathrm{B})$} & \multicolumn{2}{|c|}{$\Delta \mathrm{H}_{\mathrm{f}}\left(\mathrm{BH}^{+}\right)$} & \multicolumn{2}{|l|}{ GB } \\
\hline & value & error & value & error & value & error \\
\hline ethyl acetate & -100.0 & 6.0 & 57.3 & -1.7 & 201.9 & 9.0 \\
\hline methyl benzoate & -53.5 & 15.5 & 102.6 & 9.6 & 202.8 & 7.3 \\
\hline carbon monoxide & -6.1 & 20.4 & 185.3 & -11.7 & 164.3 & 29.9 \\
\hline diatomic nitrogen & 10.4 & 10.4 & 234.1 & -13.4 & 129.2 & 18.2 \\
\hline diatomic oxygen (triplet) & -27.2 & -27.2 & 241.1 & -23.9 & 81.6 & -13.4 \\
\hline ethane & -16.3 & 3.7 & 216.0 & 14.0 & 119.0 & -16.8 \\
\hline propane & -24.1 & 0.9 & 207.0 & 16.0 & 120.5 & -21.5 \\
\hline isobutane & -29.1 & 2.9 & 199.8 & 29.8 & 122.4 & -33.1 \\
\hline cyclohexane & -38.0 & -9.0 & 177.5 & 10.5 & 136.6 & -24.4 \\
\hline 1,4-butanediol & -118.9 & -16.9 & 56.6 & 4.6 & 175.4 & -22.6 \\
\hline 1,4-dimethoxybutane & -111.2 & -13.2 & 59.6 & 13.6 & 181.7 & -27.3 \\
\hline 1,2-cyclohexanedione & -79.1 & -9.1 & 92.7 & 1.7 & 186.5 & -10.9 \\
\hline 1,3-cyclohexanedione & -84.3 & -5.3 & 83.8 & 8.8 & 190.7 & -13.8 \\
\hline oxirane & -9.2 & 3.8 & 177.6 & 12.6 & 170.1 & -10.5 \\
\hline 2-methyloxirane & -15.8 & 7.2 & 134.1 & -13.9 & 210.1 & 23.2 \\
\hline cyclopropene & 72.3 & 6.3 & 225.9 & -8.1 & 206.2 & 16.2 \\
\hline 1-methylcyclopropene & 62.5 & 4.5 & 235.4 & 17.4 & 184.8 & -13.2 \\
\hline propyne & 41.8 & -3.2 & 252.6 & 24.6 & 141.8 & -32.2 \\
\hline 2-butyne & 36.0 & 1.0 & 244.8 & 31.8 & 144.1 & -34.9 \\
\hline methylnitrite & -31.5 & -15.5 & 149.4 & -7.6 & 175.6 & -9.1 \\
\hline ethylnitrite & -37.2 & -12.2 & 158.1 & 14.1 & 160.5 & -29.0 \\
\hline$i$-propylnitrite & -42.0 & -10.0 & 160.2 & 28.2 & 152.6 & -41.5 \\
\hline
\end{tabular}

Note: All enthalpies and gas-phase basicities in kcal/mol. The first column in each case gives the derived thermodynamic value corrected for systematic offsets using the best fit line given in Table VIII. Compounds are listed in order of increasing derived GB. Following each column of derived values is the difference between that value and the experimental value (Lias, Liebman, and Levin, 1984), (calcd exptl). Compounds below the second line were excluded from the linear regression analysis of Table VIII.

protonated analyte $\mathrm{BH}^{+}$, and the GB for each compound. Semiempirical calculations for each analyte provided the heats of formation for each form, B and 
$\mathrm{BH}^{+}$. The calculated values were then compared to the published experimental values and linear regression analysis provided the best fit lines for each data set. The corrected values for enthalpy of formation given in Table VII are the MOPAC calculated values after adjustment using the regression analysis results which are summarized in Table VIII.

$$
\Delta \mathrm{H}_{\mathrm{r}}(\mathrm{B})_{\text {corr. }}=\left\{\Delta \mathrm{H}_{\mathrm{r}}(\mathrm{B})_{\text {MOPAC }}-\text { Intercept }\right\} / \text { Slope }
$$

The GB of each analyte was computed from the corrected heats of formation of the unprotonated and protonated analytes as described below, where $\Delta G(R 15), \Delta H(R 15)$ and $\Delta S(R 15)$ refer respectively to the free energy change, enthalpy of reaction and entropy change for Reaction 15. GB values themselves were also corrected for systematic offsets in the same manner as for $\Delta H(B)_{\text {corr. }}$ in (E3).

$$
\begin{gathered}
\mathrm{GB}(\mathrm{B})=-\Delta \mathrm{G}(\mathrm{R} 15)=-[\Delta \mathrm{H}(\mathrm{R} 15)-\mathrm{T} \Delta \mathrm{S}(\mathrm{R} 15)] \\
\Delta \mathrm{H}(\mathrm{R} 15)=\left(\Delta \mathrm{H}\left(\mathrm{BH}^{+}\right)-\left[\Delta \mathrm{H}(\mathrm{B})+\Delta \mathrm{H}\left(\mathrm{H}^{+}\right)\right]\right. \\
\Delta \mathrm{S}(\mathrm{R} 15)=\Delta \mathrm{S}\left(\mathrm{H}^{+}\right)+\Delta \mathrm{S}\left(\mathrm{B}-\mathrm{BH}^{+}\right) \\
\mathrm{GB}(\mathrm{B})=-\Delta \mathrm{H}\left(\mathrm{BH}^{+}\right)+\Delta \mathrm{H}(\mathrm{B})+\Delta \mathrm{H}\left(\mathrm{H}^{+}\right)+\mathrm{T} \Delta \mathrm{S}(\mathrm{R} 15)
\end{gathered}
$$

In all cases the proton heat of formation $356.7 \mathrm{kcal} / \mathrm{mol}$ was used (Lias, Liebman, and Levin, 1984), as was the entropy term for proton transfer $\mathrm{T} \Delta \mathrm{S}\left(\mathrm{H}^{+}\right)=-7.8$ $\mathrm{kcal} / \mathrm{mol}$ (Chase et al., 1982). The contribution to the entropy change for the half reaction $\left(\mathrm{B} \rightarrow \mathrm{BH}^{+}\right)$can be approximated by the rotational entropy change $\Delta \mathrm{S}_{\infty n}$ (Moylan and Brauman, 1983). This "trivial" entropy contribution can be found by comparing the symmetry numbers of reactant and products (Bailey and Monahan, 1978). These values, taken from Lias, Liebman, and Levin (1984), typically gave $\mathrm{T} \Delta \mathrm{S}_{\mathrm{\sigma n}}<1 \mathrm{kcal} / \mathrm{mol}$. Proton affinities are readily derived from the heats of formation (Voets et al., 1989) and are not tabulated here. A sample calculation 
provided near the end of the chapter demonstrates these calculations and discusses their application to compounds not measured experimentally. A more complete discussion of proton affinities, heats of formation for protonated and unprotonated forms, structures and in a few cases the dissociations of protonated forms, as well as the errors associated with functional group classes, is beyond the scope of this study but preliminary findings are discussed in the summary, Chapter VII. The signed differences between the experimentally measured (Lias, Liebman, and Levin, 1984) and theoretically derived values are shown after each column of calculated values (derived - measured) in Table VII.

Table VIII presents several statistical measures of agreement between the experimental and theoretical values for each graph. For the purposes of this analysis, 99 compounds were used to determine the best fit line based on the corrected heats of formation and experimental values. The remaining 28 compounds, separated in Table VII by a solid line, are discussed in the following paragraph. Figures 10 and 11 graphically compare the corrected heats of formation for $\mathrm{B}$ and $\mathrm{BH}^{+}$, listed in Table VII, with the experimental values. Superimposed on each graph is a line of unit slope and zero intercept. Figure 13 compares the corrected GB values with the experimental values. Again the solid line is for a perfect correlation between experimental and derived values. Three values are given in Table VIII for each data set which compare the errors implicit in the semiempirical calculations. The standard deviations of the signed differences from Table VII give errors of $7.77,8.41$ and $5.80 \mathrm{kcal} / \mathrm{mol}$ respectively for the heats of formation of $\mathrm{B}, \mathrm{BH}^{+}$and GB. Table VIII also gives the standard 
TABLE VIII

\section{REGRESSION ANALYSIS OF CALCULATED VERSUS EXPERIMENTAL GAS-PHASE BASICITIES AND CORRECTED HEATS OF FORMATION}

\begin{tabular}{rrrr} 
& $\Delta \mathrm{H}_{\mathrm{r}}(\mathrm{B})$ & $\Delta \mathrm{H}_{\mathrm{r}}(\mathrm{BH}+)$ & \multicolumn{1}{c}{$\mathrm{GB}(\mathrm{B})$} \\
\cline { 2 - 4 } $\mathrm{n}:$ & 99 & 99 & 99 \\
Slope: & 1.0267 & 0.9362 & 0.9056 \\
Intercept (kcal): & 0.5293 & 14.747 & 17.760 \\
$\mathrm{R}:$ & 0.9835 & 0.9847 & 0.9471
\end{tabular}

Error based on signed differences

Standard deviation:

Error based on absolute value of differences

$\begin{array}{cccc}\text { Average Difference: } & 5.596 & 6.173 & 4.178 \\ \text { Standard Deviation: } & 5.386 & 5.708 & 4.017\end{array}$

Notes: Linear regression analysis for MOPAC calculated values compared to experimental values. This information is then used to derive the corrected theoretical heats of formation and gas-phase basicities given in Table VII. All errors are based on the difference between the derived value and the experimental value (Lias, Liebman, and Levin, 1984) $\left(\mathrm{AM} 1_{\text {derived }}\right.$-exptl).

deviation of the absolute values of the errors which are $5.39,5.71$ and 4.02 $\mathrm{kcal} / \mathrm{mol}$ for the heats of formation of $\mathrm{B}, \mathrm{BH}^{+}$and $\mathrm{GB}$ respectively.

The AM1 parameterization has several known deficiencies (Dewar et al., 1985) in its ability to evaluate heats of formation. However, a large error in the heat of formation for a compound need not produce a large error in the resulting GB. If AM1 has difficulty evaluating a given structure in the unprotonated form, that error may also appear in the protonated form and would then cancel in the calculation of the gas-phase basicity. This is borne out in Table VIII where the errors in GB are slightly lower than those for either heat of formation. The 28 


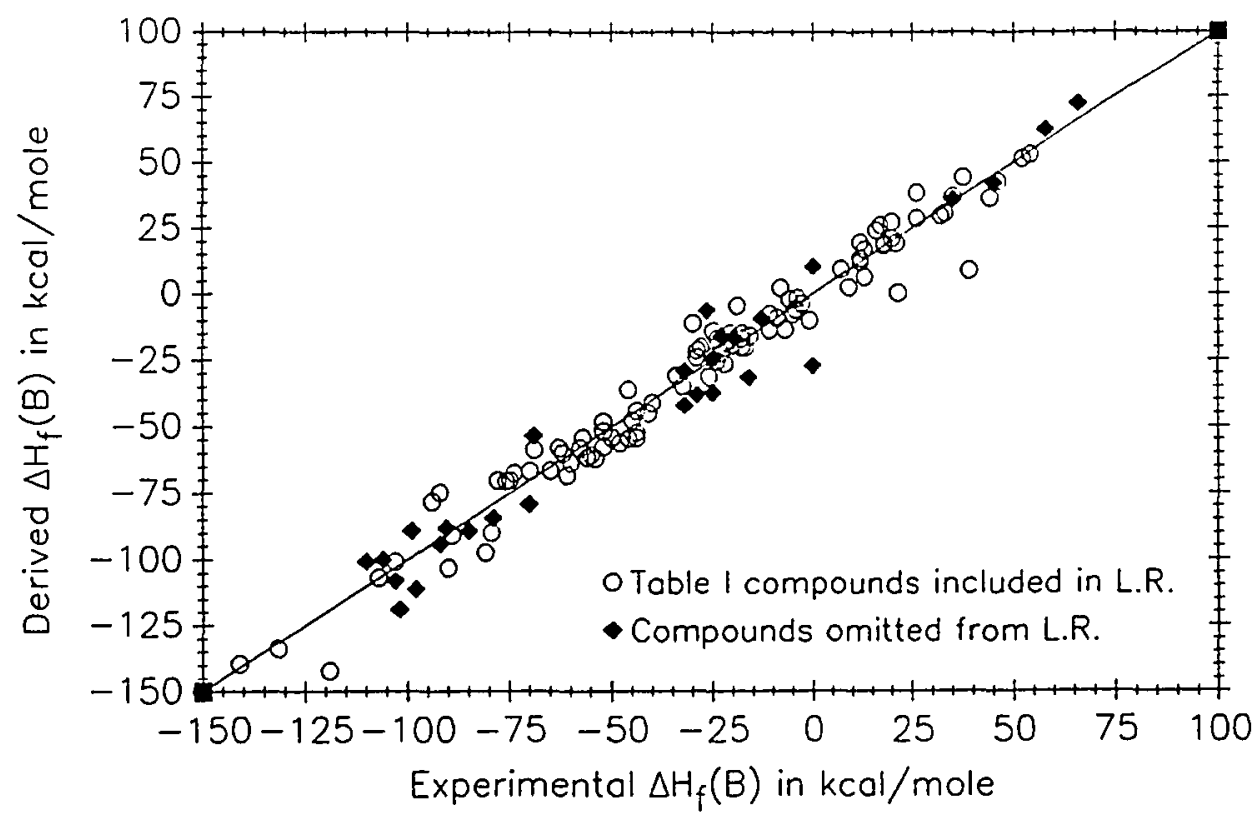

Figure 10. Comparisons of calculated and experimental $\Delta H_{(}(B)$. Experimental values taken from Lias, Liebman, and Levin (1984). Theoretical values taken from Table VII are based on MOPAC calculations adjusted with the linear regression analysis in Table VIII $\left(\Delta \mathrm{H}_{1}(\mathrm{~B})_{\text {corrected }}=\left[\Delta \mathrm{H}_{S}(\mathrm{~B})_{\mathrm{AMI} \text { calculated }}-0.53\right] / 1.03\right)$. The solid line represents a perfect correlation, slope $=1$ and intercept $=0$.

compounds not included in the 3 regression analyses were excluded based on characteristic deficiencies. Categories of neutral compounds identified previously as being poorly modeled with AM1 include diatomics, geometrically crowded molecules and compounds with both nitrogen and oxygen functionalities (Dewar et al., 1985). In most cases, these compounds also had large errors in their GBs. Large errors have also been reported with AM1 for nitro compounds (Stewart 1989), but nitro compounds evaluated here were within the uncertainty of other groups, perhaps because protonation did not affect the source of the error. Organic nitrates were also modeled adequately, but nitrites had large and unpredictable 


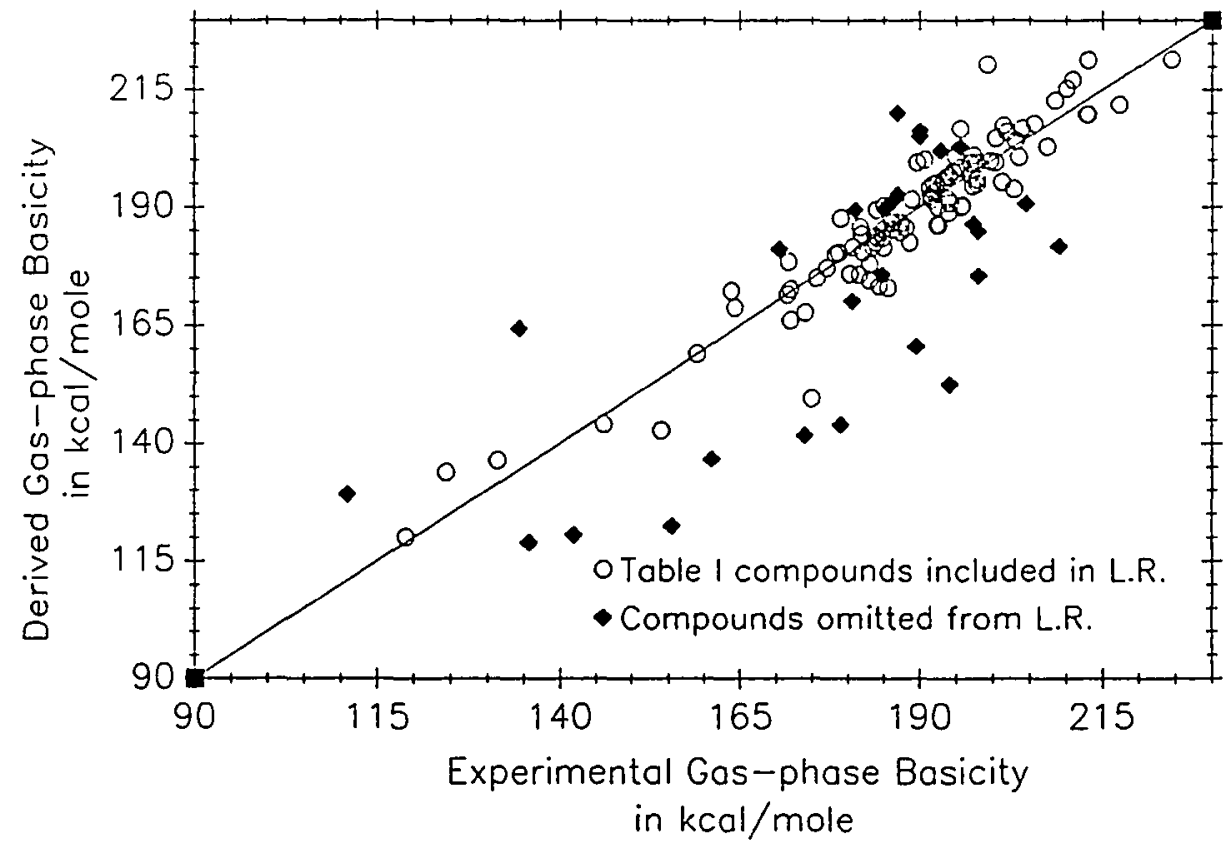

Figure 11. Comparisons of calculated and experimental $\Delta \mathrm{H}_{(}\left(\mathrm{BH}^{+}\right)$. Experimental values taken from Lias, Liebman, and Levin (1984). Theoretical values taken from Table VII are based on MOPAC calculations adjusted with the linear regression analysis in Table VIII $\left(\Delta \mathrm{H}_{r}\left(\mathrm{BH}^{+}\right)_{\text {corrected }}=\left[\Delta \mathrm{H}_{\mathrm{r}}\left(\mathrm{BH}^{+}\right)_{\mathrm{AM} 1 \text { calculated }}-14.75 \mathrm{y} / 0.94.\right)\right.$. The solid line represents a perfect correlation, slope $=1$ and intercept $=0$.

errors. Four strained ring compounds, oxiranes and cyclopropenes, resulted in larger errors than for other small rings such as cyclopropane or cyclobutene.

The diatomic molecules oxygen, nitrogen and carbon monoxide had, as expected, large errors in GB, $+14.9,+18.2$ and $+29.9 \mathrm{kcal} / \mathrm{mol}$ respectively. Some of the largest errors seem to be associated with alkanes and alkynes. Unprotonated alkanes have been shown to have an incremental error in the heat of formation of the unprotonated species. This error increases with increasing chain length at $-1.9 \mathrm{kcal} / \mathrm{mol}$ per methylene group (Dewar et al., 1985). Including this correction has a small effect in the overall accuracy since most of the error in GB for alkanes 


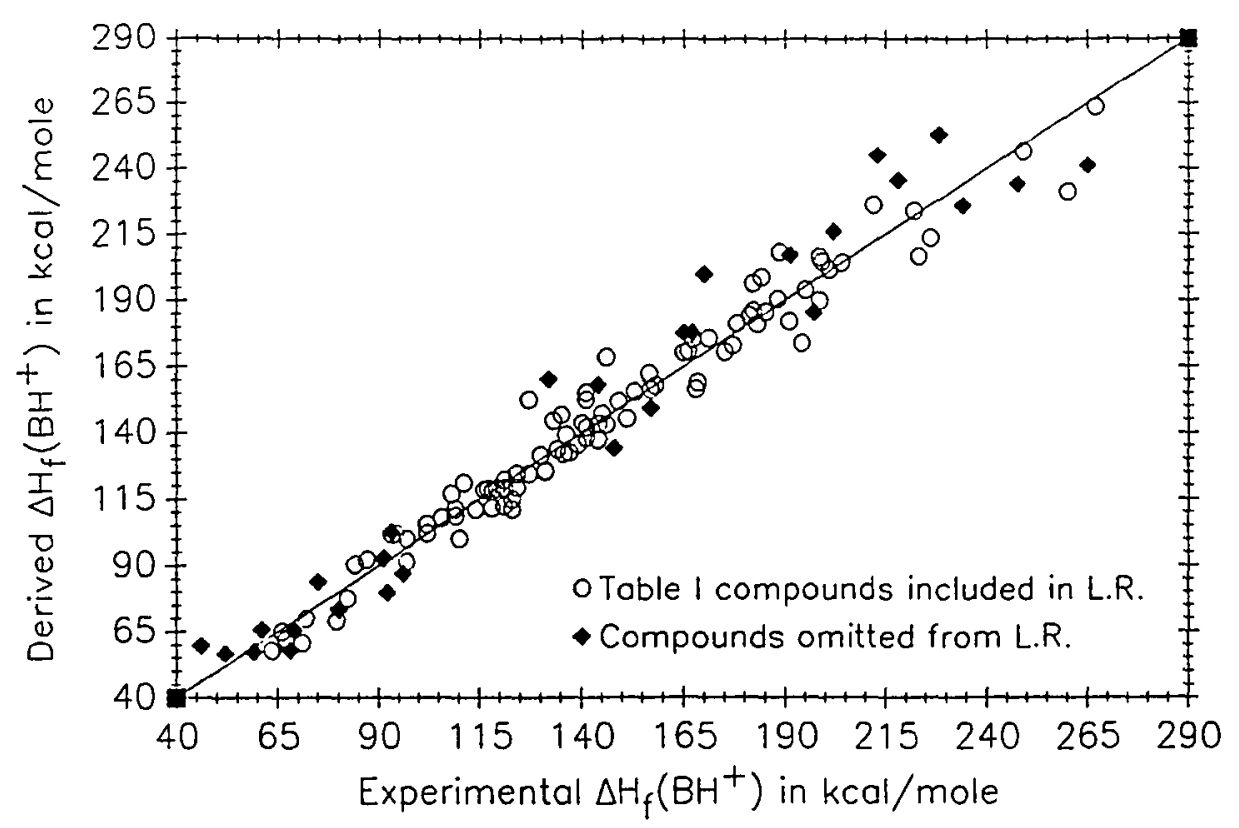

Figure 12. Comparisons of calculated and experimental GB.

Experimental values taken from Lias, Liebman, and Levin (1984). Theoretical values taken from Table VII are based on MOPAC calculations adjusted with the linear regression analysis in Table VIII $\left(\mathrm{GB}_{\text {corrected }}=\left[\mathrm{GB}_{\mathrm{AM1} \text { calculated }}-17.8\right] / 0.91\right)$. The solid line represents a perfect correlation, slope $=1$ and intercept $=0$.

arises from the protonated species. The exclusion of alkanes for the purpose of GB calculations is not a serious limitation for APIMS. The relative basicities of alkanes are generally below the reagent hydronium's basicity and they are not typically detected as protonated species. Similarly, the energies of the protonated alkynes are not well estimated using this parameterization of AM1. One additional group not included in the regression analysis and not previously identified as poorly estimated with semiempirical methods are the esters. The errors in ester family compounds excluded from the linear regression show systematic positive offsets in GB ranging from +5.0 to $+15.0 \mathrm{kcal} / \mathrm{mol}$. 
Uncertainties in the relative gas-phase basicities based on equilibrium measurements are small, $0.5 \mathrm{kcal} / \mathrm{mol}$ (Keesee and Castleman, 1986). In practice it is the relative basicity of a compound compared to the proton transfer reagent which is important in determining API sensitivity. In assigning an absolute basicity scale the smaller error associated with assigning relative uncertainties must be combined with the larger uncertainties in fixing the placement of reference compounds. This latter uncertainty is at least $2 \mathrm{kcal} / \mathrm{mol}$ and much more for compounds at high or low values of GB (Lias, Liebman, and Levin, 1984). For the basicities calculated here, a routine propagation of random errors indicates that the actual error in the derived absolute basicities $\left(\left[(4.0)^{2}-(2.5)^{2}\right]^{0.5}=3.1 \mathrm{kcal}\right)$ is only slightly greater than the cumulative experimental uncertainty. This is impressive since neither $\mathrm{M}^{+}$nor $\mathrm{MH}^{+}$ions were included in the AM1 parameterization data base.

The experimental sensitivity of analytes in APIMS has been studied as a function of the compounds' GB (Sunner, Nicol, and Kebarle, 1988; Sunner, Ikonomou, and Kebarle, 1988a). For compounds below about $195 \mathrm{kcal} / \mathrm{mol}$, sensitivity was found to be logarithmically proportional to GB, increasing about 1 decade for a $9 \mathrm{kcal} / \mathrm{mol}$ increase in GB. Above the breakpoint GB value near 195 $\mathrm{kcal} / \mathrm{mol}$, APIMS response was similar for all compounds. Thus, a $3.1 \mathrm{kcal} / \mathrm{mol}$ uncertainty in assigning the basicity of a compound will not have any effect on its anticipated API response if its GB is above $200 \mathrm{kcal} / \mathrm{mol}$. However, for a compound below this breakpoint, the uncertainty in assigning the GB using either experimental or semiempirical methods may have a large effect on the predicted API sensitivity. Since the experimental measures of API sensitivity themselves 
show wide scatter (Sunner, Nicol, and Kebarle, 1988) the magnitude of the uncertainty may be difficult to assess.

The effect of hydration on the sensitivity of certain compounds when detected using APIMS has also been investigated (Sunner, Nicol, and Kebarle, 1988; Nicol, Sunner, and Kebarle, 1988). The unusually low sensitivities for some compounds was shown to result from the unfavorable energies of hydration associated with carbon and sulfur bases. Protonation of furan at the $\alpha$-carbon is favored over protonation on the oxygen (Houriet, Schwarz, and Schleyer, 1981), and AM1 reproduces this carbon base behavior. However, this carbon protonated species has a low ability to form hydrogen bonds in hydration. Experimental measurements of hydration enthalpies were made with furan using Pulsed High Pressure Mass Spectrometry (PHPMS) (Nicol, Sunner, and Kebarle, 1988) and a value of $\Delta \mathrm{H}=-10.4 \mathrm{kcal} / \mathrm{mol}$ was reported for the first hydration reaction. Experimental measurements of the higher order hydration reactions were not reported. Uncorrected MOPAC calculations of the hydration energies for furan and ethanol are summarized in Table IX and show excellent agreement with the respective experimental measurements. Proton transfer reactions generally occur from hydrated hydronium clusters when the water levels are high, as commonly found in APIMS. Compounds which are able to accept the proton along with some portion of the hydration molecules are thus more likely to be protonated. It is clear in Table IX that hydration of ethanol, typical of the compounds whose sensitivity was proportional to GB, is much more favorable than for furan whose experimentally measured sensitivity was many orders of magnitude less. The 
TABLE IX

HEATS OF FORMATION FOR HYDRATED FURAN AND ETHANOL

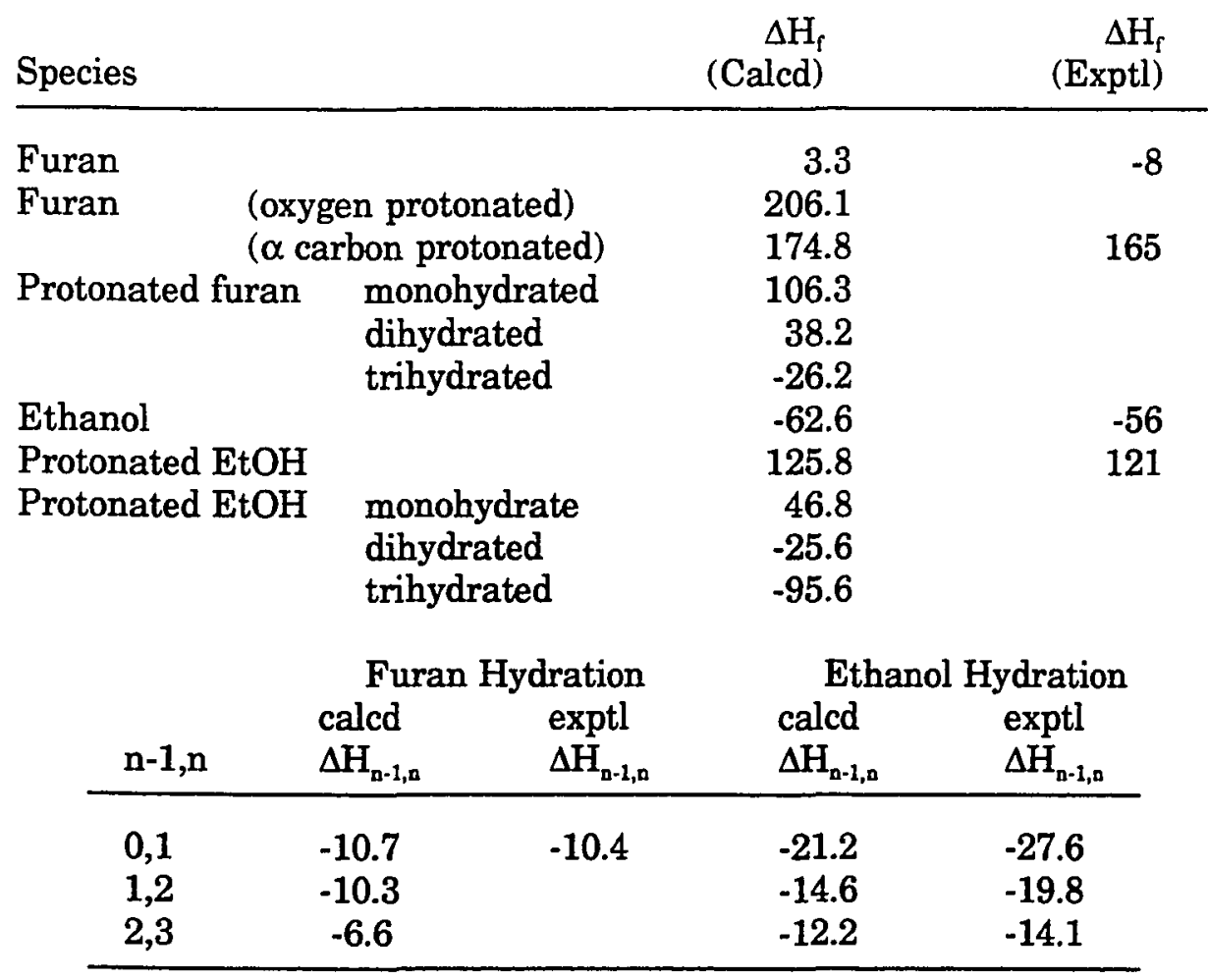

Notes: All enthalpies in units of $\mathrm{kcal} / \mathrm{mol}$. Enthalpies of hydration reactions are for $\mathrm{BH}^{+} \cdot\left(\mathrm{H}_{2} \mathrm{O}\right)_{\mathrm{n}-1}+\mathrm{H}_{2} \mathrm{O}=\mathrm{BH}^{+} \cdot\left(\mathrm{H}_{2} \mathrm{O}\right)_{\mathrm{n}}$. Experimental measurements of furan hydration from Nicol, Sunner, and Kebarle (1988), ethanol hydration from Hiraoka, Heinrich, and Morise (1986).

ability of AM1 to evaluate these hydration energies is also of direct applicability to APIMS when the reagent ions occur as hydrates.

\section{CONCLUSIONS}

The procedure whereby AMI-derived heats of formation may be used to derive the 'best-fit' value of gas-phase basicity can be illustrated. As an example, we choose hydrogen peroxide, a compound included in Table VII. The heats of 
formation for $\mathrm{H}_{2} \mathrm{O}_{2}$ in the unprotonated $\left(\Delta \mathrm{H}_{\mathrm{f}}(\mathrm{B})=-35.2 \mathrm{kcal} / \mathrm{mol}\right)$ and protonated $\left(\Delta \mathrm{H}_{\mathrm{r}}\left(\mathrm{BH}^{+}\right)=179.1 \mathrm{kcal} / \mathrm{mol}\right)$ forms are first obtained from the semiempirical calculations with MOPAC. (By way of comparison, Lias, Liebman, and Levin (1984) report $\left.\Delta \mathrm{H}_{\mathrm{r}} \mathrm{B}\right)=-32.5$ and $\Delta \mathrm{H}_{\mathrm{f}}\left(\mathrm{BH}^{+}\right)=171.0 \mathrm{kcal} / \mathrm{mol}$.) Using the slopes and intercepts from Table VIII in Equation 2, the AM1 values are corrected for systematic offsets. $\Delta \mathrm{H}_{\mathrm{r}}(\mathrm{B})_{\text {corr. }}=\left\{\Delta \mathrm{H}_{\mathrm{r}}(\mathrm{B})_{\mathrm{MOPAC}}-\right.$ Intercept $\} /$ Slope $=\{-35.2-0.5293\}$ $\mathrm{kcal} / \mathrm{mol} / 1.0267=-34.8 \mathrm{kcal} / \mathrm{mol}$. Similarly, $\Delta \mathrm{H}_{\mathrm{r}}\left(\mathrm{BH}^{+}\right)_{\text {corr. }}$ is corrected to 175.6 $\mathrm{kcal} / \mathrm{mol}$. The gas-phase basicity is first calculated from the adjusted heats of formation for the unprotonated and protonated species using equation $6 . \quad G B(B)=-$ $\Delta \mathrm{H}_{\mathrm{r}}\left(\mathrm{BH}^{+}\right)_{\text {corr. }}+\Delta \mathrm{H}_{\mathrm{f}}(\mathrm{B})_{\text {corr. }}+\Delta \mathrm{H}_{\mathrm{f}}\left(\mathrm{H}^{+}\right)+\mathrm{T} \Delta \mathrm{S}(1)=-(175.55)+(-34.8)+(365.7)+[(-7.8$ $+-0.4)]=147.14 \mathrm{kcal} / \mathrm{mol}$. The final term combines the entropy for the proton $(-7.8$ $\mathrm{kcal} / \mathrm{mol})$, and a second term $(-0.4 \mathrm{kcal} / \mathrm{mol})$ for the "trivial" entropy loss. When evaluating the GB for a compound not in Lias, Liebman, and Levin (1984), the magnitude of the "trivial" entropy loss can be estimated from the symmetry changes for the molecule (Bailey and Monahan, 1978; Moylan and Brauman, 1983). In the direct count method (Bishop and Laidler, 1965) the symmetry change for hydrogen peroxide protonation is approximated by $\operatorname{RT} \ln (1 / 2)=-0.4$, where the fraction $1 / 2$ is based on there being two paths to protonate the molecule but four paths for deprotonation. The final step is to correct the GB for systematic offsets, as was done for the enthalpies. $\mathrm{GB}(\mathrm{B})_{\text {corr. }}=\{147.14-17.76\} \mathrm{kcal} / \mathrm{mol} / 0.9056=$ $142.9 \mathrm{kcal} / \mathrm{mol}$.

Gas-phase basicities are important in many chemical applications. These include studies of gas-phase proton transfer reactions, evaluation of solvation and hydration effects and APIMS. Experimentally determined GBs are not available 
for many compounds of interest in environmental or atmospheric chemistry. The ability of semiempirical calculations to predict GB theoretically to within a few kilocalories of experimental uncertainty should have important implications for analytical chemists in a variety of applications. Chapter VII demonstrates the calculations of GB for a range of compounds for which experimental values were not available. These compounds include nitrites, nitrates and nitro compounds as well as a variety of multifunctional compounds typical of atmospheric oxidation processes. We also demonstrate the use of semiempirical calculations to evaluate whether HRKAPIMS could be effectively used to study the oxidation products of several organic compounds. 


\section{CHAPTER VI}

\section{ANALYTE RESPONSE AND QUANTITATION IN ATMOSPHERIC PRESSURE IONIZATION MASS SPECTROMETRY}

"One way to tell for sure if a sweater is made of wool is to hold it over a flame. If it burnt slowly it was wool." (Davis, 1969)

\section{OVERVIEW}

In this chapter we address the quantitative capabilities of atmospheric pressure ionization mass spectrometry. The general nature of quantitative analysis for mass spectrometry is first discussed in terms of the different ionization processes commonly used. Past measurements of API response are reviewed and compared with the results of chemical modeling. Three distinct and complementary approaches are used to model the nature of API response. Solving the thermodynamic equilibrium expressions for proton transfer reactions is the simplest and most direct approach. A steady state model can be used which assumes equilibrium is reached where the sources and sinks for a species sum to zero. Finally, the kinetic modeling approach integrates the simultaneous chemical rate expressions that determine API response to provide a more complete analysis.

\section{INTRODUCTION}

High resolution atmospheric pressure ionization mass spectrometry (HRKAPIMS) offers many advantages for the analysis of environmental and 
biological samples. Among these advantages are: the capability to directly measure from the gas phase without sample concentration or derivatization; the capability of generating oxidation products directly within the source; a high instrumental sensitivity and selectivity for organics that contain a heteroatom; and the ability to determine empirical formulas through accurate mass assignments. In addition, the ability to detect free radical reaction intermediates and study the effects of NO on product yields is beneficial when evaluating reaction mechanisms. These capabilities have been discussed in previous chapters. The direct analysis of mixtures by this soft ionization technique gives a parent ion spectrum free of fragmentation patterns (Grange, 1988) which would otherwise make interpretation complex.

Several areas of uncertainty remain to be explored, in particular the viability of obtaining quantitative measurements of analyte concentrations when using API. The following observations may help form a basis for further discussions. Carrol et al. (1981) have commented that "API spectra normally show relative concentrations of ions under conditions of chemical and thermal equilibrium, while EI and CI spectra reflect relative rates of ionization reactions." Eiceman et al. (1988) have noted that "the CD [corona discharge] is likely not in thermodynamic equilibrium". Kebarle (Sunner, Ikonomou, and Kebarle, 1988b) has concluded that "it is not clear what chemical and thermal equilibrium means in terms of ion intensities in the API source." In this chapter we will examine analyte sensitivity using API in an effort to address these uncertainties and better understand the processes occurring in an API source. The conclusions derived here may also have applications to the related ionization processes used in ion mobility 
spectrometry, fast atom bombardment and chemical ionization as well as to processes beyond mass spectrometry. As a result we hope to increase the now somewhat limited applications of API as an ionization technique.

\section{QUANTITATION IN MASS SPECTROMETRY}

\section{$\underline{\text { Ionization Techniques }}$}

We begin by reviewing the aspects of quantitative analysis which are relevant to all mass spectrometric techniques. Washburn and coworkers (Washburn, Wiley, and Rock, 1943; Washburn, Wiley, and Rock, 1945) are credited with having worked out the fundamental methods and calculations for quantitative analysis in mass spectrometry. There are several assumptions based upon their work which must be considered in any approach to quantitative mass spectrometry (Roboz, 1968). The wide variety of ionization techniques currently in use requires that these assumptions be applied appropriately, based on the particular conditions. These assumptions are as follows.

1. Each chemical compound will have its own characteristic mass spectrum and fragmentation pattern. API spectra are predominately parent ion spectra, free of fragmentation, as a result of the low energy proton transfer reactions and the thermalization of the ions due to the high collision rate at atmospheric pressure.

2. The response for any one compound is independent of the presence of any other compound present in the ion source. This is of particular importance in the analysis of mixtures where the signal intensities of the components must be linearly additive. Not all ionization processes used in mass spectrometry can meet this requirement under all experimental conditions, as we discuss below. A viable 
alternative would be to know how the relative response of any one analyte varies as a function of some intrinsic property (i.e. GB).

3. Finally, the measured signal intensity for an ion must be proportional to its concentration or its partial pressure in the ion source. As with the previous requirement. this is not always the case. Competition for the reagent ions in APIMS and depletion of the ions may result in differing response factors as a function of sample composition. It is important therefore to understand more about the experimental conditions under which depletion and competition may arise and how to avoid this situation.

The following paragraphs briefly review the basic ionization principles and the potential for quantitation in several common ionization processes which are used in mass spectrometry and which share certain similarities to API. This review will form a basis for comparison when API processes are later considered.

Chemical Ionization. In chemical ionization (CI) mass spectrometry sample ionization takes place along any of the three major reaction pathways: proton transfer, charge transfer, and cluster formation. API is a special case of chemical ionization, where ionization occurs at atmospheric pressure (760 Torr) rather than at the reduced pressures typical in CI (0.01-1 Torr). For this reason API is sometimes termed atmospheric pressure chemical ionization APCI (for instance by Sciex Corporation, manufacturers of a commercial APIMS system). Proton transfer reactions in CI occur at reduced pressures, where the choice of an ionization agent allows the degree of fragmentation to be controlled as a function of the exothermicity of the ionization reaction. Potential ionization reagents include hydrogen, methane, isobutane or ammonia. The most typical approach to 
quantitative analysis using a chemical ionization source involves the creation of a three point (minimum) calibration curve. The standard for the calibration is ideally the same as the analyte to be measured, presented in the same sample matrix as the unknown. Unfortunately, environmental samples may contain as many as 50-100 components, and there are a limited number of certified standards available for these compounds (Facchetti, 1989). The ability to perform quantitative analysis is thus dependent on the availability of reliable standards from either commercial sources or laboratory synthesis.

Fast Atom Bombardment. Fast atom bombardment (FAB) has become an important technique in the analysis of polar and nonvolatile compounds. There are at present two views on the mechanism of ionization in $\mathrm{FAB}$, the precursor model (Cooks and Busch, 1983) and the gas collision model (Sunner, Ikonomou, and Kebarle, 1988b). Analyte sensitivities in $\mathrm{FAB}$ are generally thought to relate to the analytes' proton affinity (PA), as well as to the surface activity of the compound relative to the sample matrix. Proton affinities are defined as the negative enthalpy of reaction for the reaction $\mathrm{B}+\mathrm{H}^{+}-->\mathrm{BH}^{+}$. Since gas-phase basicities are defined as the negative of the free energy for the same reaction, we can relate proton affinity and gas-phase basicities by the expression: GB = PA + T $\Delta S$. Kebarle has defined the preference factor in $\mathrm{FAB}$ as the ratio of ion intensities for an analyte and its matrix (Sunner, Kulatunga, and Kebarle, 1986). In this study Kebarle found that increasing the analyte concentration by 2 orders of magnitude had (within a factor of 2) no effect on the preference factor. The influence of surface activity and gas-phase basicity difference (GB) between analytes has also been examined (Lacey and Keough, 1989). In this study several pairs of 
compounds were selected for their similarities in surface activity or gas phase basicity or both. When a GB difference of $12.5 \mathrm{kcal} / \mathrm{mol}$ between analytes sharing similar surface activities were compared, the response of the lower GB compound was suppressed by a factor of 2.5 . When the surface activities were different, this same GB difference results in a suppression factor of 29 (Lacey and Keough, 1989). The nonlinearity of $\mathrm{FAB}$ response and the dependence on $\mathrm{GB}$ and surface activity make quantitation in $\mathrm{FAB}$ difficult.

Ion Mobility Mass Spectrometry. Ionization processes in ion mobility mass spectrometry (IMMS) share certain similarities with APIMS. In IMMS, analyte molecules are generally ionized by a radioactive Nickel-63 foil at atmospheric pressure and then admitted to chamber where their mobility in an electric field is measured against a counter flow of a neutral gas. Corona discharges have been compared to Nickel-63 sources as ionization sources for APIMS and found to be equivalent (Dzidic et al., 1976). Eiceman (Vandiver, Leasure, and Eiceman, 1985) has evaluated the response of several polycyclic aromatic hydrocarbons (PAH) alone, and in binary and tertiary mixtures, as a function of analyte proton affinities. The response curves for these compounds show linear behavior at lower concentrations where the levels of hydronium are presumably much larger than the analyte. At higher concentrations the sensitivity was found to diminish as the reagent hydronium ions are consumed. Eiceman found that small differences in proton affinity (PA) have large effects on the response factors in mixtures. In a binary mixture of naphthalene and pyrene, equal signal intensities were not obtained until the naphthalene concentration was nearly $10^{5}$ greater than that of pyrene (Vandiver, Leasure, and Eiceman, 1985). Naphthalene and pyrene differ in 
their proton affinities by only $12 \mathrm{kcal} / \mathrm{mol}\left(\mathrm{PA}_{\text {NAPHTHALENE }}\right)=196.3, \mathrm{PA}_{\text {PYRENE }}=208.5$ $\mathrm{kcal} / \mathrm{mol}$ (Lias, Liebman, and Levin, 1984)).

\section{Quantitation in API}

Corona Discharges. Some aspects of quantitative analysis using APIMS have been evaluated in the past. Eiceman et. al. (1988) examined the use of corona discharge in a Sciex TAGA 6000 APIMS, evaluating the experimental conditions under which the discharge was stable and reproducible. In addition to measuring the effects of source parameters such as needle current and alignment, response curves were obtained for triethylamine, ethyl acetate and dimethylmethylphosphonate. The response curves for the individual compounds were linear at low concentrations and showed a negative deviation at high concentrations. The relative responses of the three pure compounds were qualitatively proportional to their gas-phase basicity, the higher GB compound giving a larger ion intensity for a given concentration. Binary mixtures of the compounds were also evaluated. When there are not sufficient numbers of reagent ions, relative to the concentration of analytes, depletion of the reagents can occur. In such a case, the presence of a high GB compound suppresses the response of lower $\mathrm{GB}$ analytes in a manner similar to $\mathrm{FAB}$ ionization described earlier. Experimental conditions resulting in depletion may be apparent in the signal at the detector with the rapid falloff of the primary charge carriers (hydronium ions and their hydrates) (Eiceman et al., 1988).

Oxidation Studies. The use of API to semi-quantitatively examine oxidation products produced in a smog chamber has also been reported using a Sciex TAGA 
6000 APIMS (Dumdei et al., 1988). In this study, experimental ion intensities for the oxidation products were corrected based on three calibration compounds which had functionalities generally similar to the oxidation products themselves. These compounds, butanal, 2,4-hexadienal, and 4-hexen-3-one, had experimental ion intensities that varied by only a factor of 2 , from which it was concluded there was an uncertainty in the product yields of a factor of two or less. The GBs of these calibration compounds, calculated using semiempirical calculations described in Chapter V, are $187.3,196.5$ and $196.2 \mathrm{kcal} /$ mole respectively. The GBs of the reported products (Dumdei et al., 1988) cover a much wider span than this (ca. $160-230 \mathrm{kcal} / \mathrm{mol}$ ). Depletion of reagent ions is possible if the sum of all analytes exceeds the concentration of hydronium ions and their hydrates.

Analysis of toluene's oxidation products has been carried out in our own lab using API source reactions, which identified analytes in a mixture where the components had a range of GBs similar to Dumdei et al. (1988). The use of source reactions was discussed in Chapter III. In these experiments there was no apparent reduction in the levels of reagent ions, which were in large excess over the analytes in the mass spectra. Figure 13 plots the experimental ion intensities for some of the oxidation products of toluene as a function of their GB. While these data show considerable scatter, they clearly do not agree with the response observed by Sunner (Sunner, Nicol, and Kebarle, 1988) where a compound with GB of $165 \mathrm{kcal} / \mathrm{mol}$ was found to have a sensitivity four orders of magnitude less than a compound having a GB of $200 \mathrm{kcal} / \mathrm{mol}$. Although the yields of the various toluene oxidation products are unknown, it is extremely unlikely that they are 


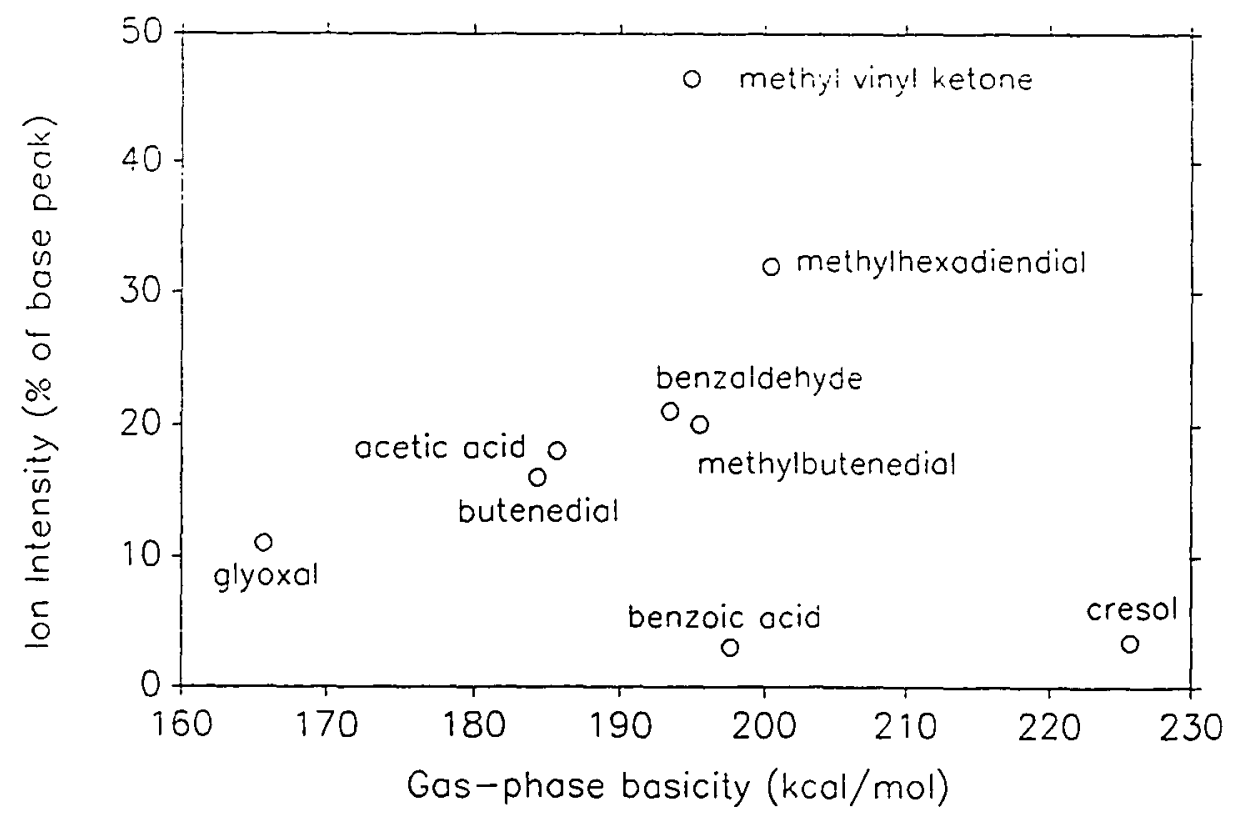

Figure 13. Experimental ion intensities for toluene oxidation products by analyte gas-phase basicity. Ion signals expressed as a percentage of the largest peak in the spectrum. GBs from Lias, Liebman, and Levin (1984) when available or calculated using the method of Chapter V. Experimental conditions described in Chapter III.

inversely proportional to GB so that compounds with very low GB will have very high yields and thus produce a relatively flat signal vs. GB.

\section{CHEMICAL MODELING}

There are several approaches one can take to examine the theoretical sensitivities of analytes in atmospheric pressure ionization mass spectrometry (APIMS). These approaches are separated here into the analysis of chemical equilibrium and the numerical integration of reaction rate equations. 
Equilibrium Expressions

A fundamental attribute among the many advantages attributed to positive ion APIMS is that protonated analytes can reach chemical and thermal equilibrium as a result of collisions occurring at the elevated pressure in the ion source (Mitchum and Korfmacher, 1983). After the formation of hydronium ions $\left(\mathrm{H}_{3} \mathrm{O}^{+}\right)$by ionization processes in the source (Good, Durden, and Kebarle, 1970a; Good, Durden, and Kebarle, $1970 \mathrm{~b}$ ), protons are transferred to analytes B by reactions such as $\mathrm{R} 9$.

$$
\mathrm{H}_{3} \mathrm{O}^{+}+\mathrm{B}<-->\mathrm{BH}^{+}+\mathrm{H}_{2} \mathrm{O}
$$

Thermodynamic Equilibrium Method. The first approach to examining APIMS sensitivities might therefore be to apply basic equilibrium theory to Reaction 9 (R9). While the relationships between ion intensities and thermodynamic properties have been introduced (Sunner, Nicol, and Kebarle, 1988), the treatment to follow represents a new effort to understand and predict API response from a theoretical standpoint.

Proton transfer reactions are actually much more complex than R9. Reversible proton transfer reactions occur from not only hydroniums but from the hydrated forms of hydroniums and varying numbers of hydrating water molecules may be transferred with the proton to the analyte. Proton transfer between analytes may occur as well. All these reactions are also presumably at equilibrium and will not change the equilibrium distributions among species in R9, so no loss of generality results from considering only $\mathrm{R} 9$. In the discussions to follow, square brackets are used to denote the concentration of the enclosed species. In order to describe analyte response as a fraction of the initial concentration of the compound 
detected $[B]_{0}$, we substitute for $[B]$ the equilibrium analyte concentration: $[B]=[B]_{0}$ $\left[\mathrm{BH}^{+}\right]$, where $\left[\mathrm{BH}^{+}\right]$is the equilibrium concentration of protonated analyte. The fraction of $B$ detected is thus a function of the equilibrium constant for the reaction and concentrations of hydroniums and water. The equilibrium constant $\mathrm{K}_{\mathrm{eq}}$, defined for (R9) in the usual way, is also related to the free energy of reaction by the expression $\Delta \mathrm{G}_{\mathrm{rxn}}(\mathrm{R} 9)=-\mathrm{RT} \ln \left(\mathrm{K}_{\mathrm{eq}}(\mathrm{R} 9)\right)$,

$$
\mathrm{K}_{\mathrm{eq}}(\mathrm{R} 9)=\left[\mathrm{BH}^{+}\right]\left[\mathrm{H}_{2} \mathrm{O}\right] /\left[\mathrm{H}_{3} \mathrm{O}^{+}\right][\mathrm{B}]
$$

and to the gas-phase basicities of the analyte and water. The gas-phase basicity

$$
\left[\mathrm{BH}^{+}\right] /\left[\mathrm{B}_{\mathrm{o}}\right]=\mathrm{K}_{\mathrm{eq}}(\mathrm{R} 9)\left[\mathrm{H}_{3} \mathrm{O}^{+}\right] /\left(\left[\mathrm{H}_{2} \mathrm{O}\right]+\mathrm{K}_{\mathrm{eq}}\left[\mathrm{H}_{3} \mathrm{O}^{+}\right]\right) .
$$

(GB) of a compound is defined as the negative of the free energy change for protonation $R 15, \Delta G(R 15)=-G B(B)$. This allows the equilibrium constant (E7) to be expressed in terms of the gas-phase basicity of the analyte and water (E9), and analyte response to be defined in terms of water and analyte concentrations (E10a and E10b).

$$
\begin{gathered}
\mathrm{B}+\mathrm{H}^{+}=\mathrm{BH}^{+} \\
\mathrm{K}_{\mathrm{eq}}(\mathrm{R} 9)=\exp \left(\left(\mathrm{GB}(\mathrm{B})-\mathrm{GB}\left(\mathrm{H}_{2} \mathrm{O}\right)\right) / \mathrm{RT}\right) \\
\text { Response } \equiv\left[\mathrm{BH}^{+}\right] /[\mathrm{B}]_{\mathrm{o}}=\mathrm{K}_{\mathrm{eq}}(\mathrm{R} 9)\left[\mathrm{H}_{3} \mathrm{O}^{+}\right] /\left(\left[\mathrm{H}_{2} \mathrm{O}\right]+\mathrm{K}_{\mathrm{eq}}(\mathrm{R} 9)\left[\mathrm{H}_{3} \mathrm{O}^{+}\right]\right) \\
\log (\text { Response }) \equiv \log \left(\mathrm{BH}^{+} / \mathrm{B}_{\mathrm{o}}\right)=\mathrm{GB}(\mathrm{B}) / 2.3 \mathrm{RT}-\left(\mathrm{GB}\left(\mathrm{H}_{2} \mathrm{O}\right) / 2.3 \mathrm{RT}\right. \\
\left.\left.\left.+\log \left(\left[\mathrm{H}_{3} \mathrm{O}^{+}\right] / \mathrm{H}_{2} \mathrm{O}\right]\right)-\log \left(1+\mathrm{K}_{\mathrm{eq}}(\mathrm{R} 9)\left[\mathrm{H}_{3} \mathrm{O}^{+}\right] / \mathrm{H}_{2} \mathrm{O}\right]\right)\right)
\end{gathered}
$$

Figure 14 plots the log of analyte response from E10b as a function of analyte GB. The set of curves shown is based on a range of relative humidities at a constant hydronium ion concentration of $1.25 \mathrm{e} 07$ molecules $\mathrm{cm}^{-3}$. The highest water concentration, $1.67 \mathrm{e} 17$, corresponds to about 5 Torr or $20 \%$ relative humidity. 


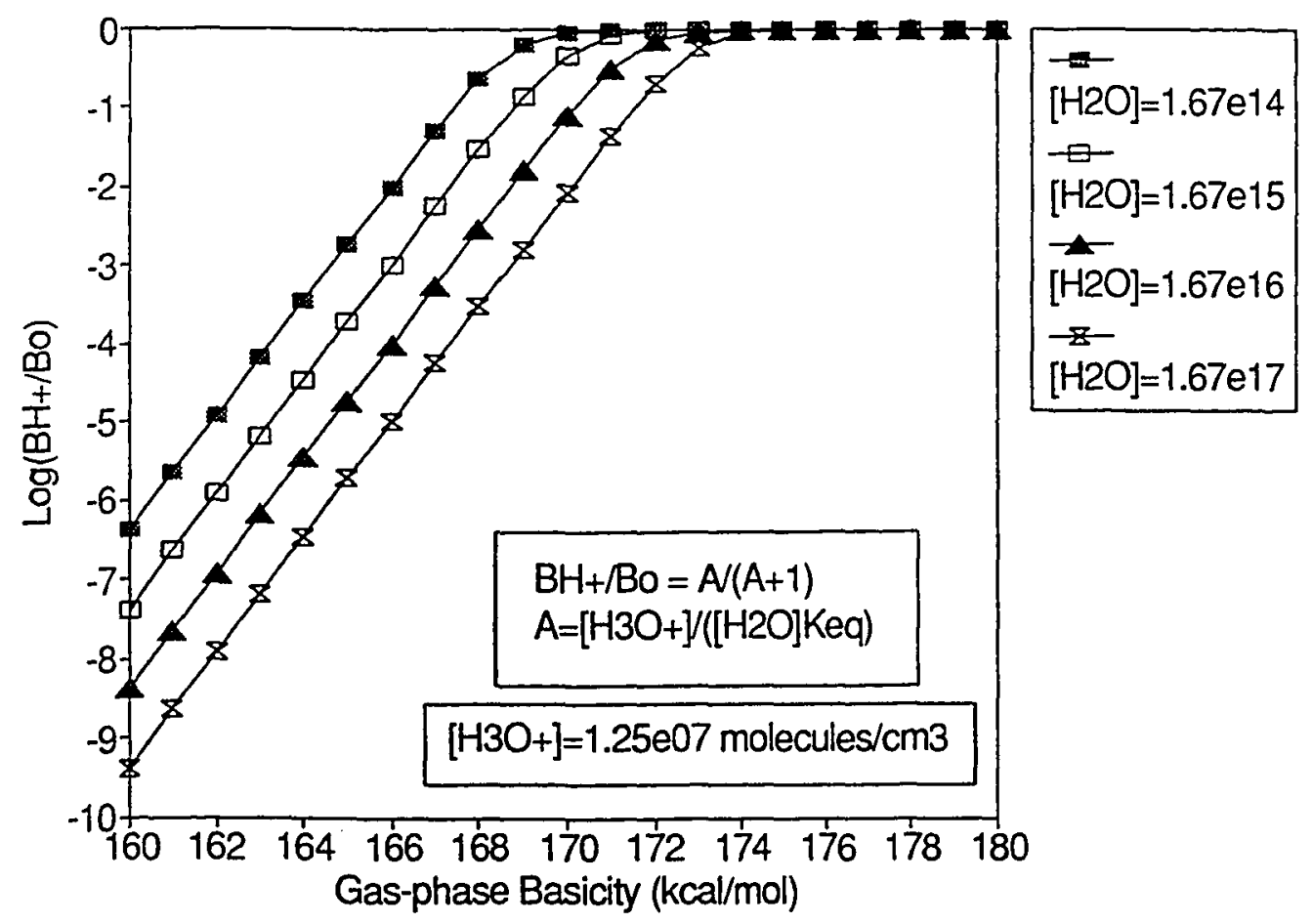

Figure 14. Analyte response as a function of gas-phase basicity and initial water concentration in thermodynamic equilibrium case (R10). Initial $\left[\mathrm{H}_{3} \mathrm{O}^{+}\right]=1.25 \mathrm{e} 07$ molecules $\mathrm{cm}^{-3}$.

The initial portions of the response curves in Figure 14 have slopes equal to $(2.3 \mathrm{RT})^{-1}$, which arises naturally out of Equation 10 and equates to a 7.3 decade increase in sensitivity for each $10 \mathrm{kcal} / \mathrm{mol}$ increase in gas-phase basicity. This value can be compared with the IMMS studies which found a 5 decade response difference between two compounds with a $12 \mathrm{kcal} / \mathrm{mol}$ difference in GB (Vandiver, Leasure, and Eiceman, 1985). Cooks and Busch (1983) used a mass-analyzed ion kinetic energy spectrometer (MIKES) to evaluate analyte proton affinities by comparing the dissociation ratios of proton bound dimers. Depending on the analyte series used, these experiments found log responses varying linearly by 2-3 decades per $5 \mathrm{kcal} / \mathrm{mol}$ difference in analyte proton affinities. Kebarle observed a 9 
$\mathrm{kcal} / \mathrm{mol}$ difference in GB to result in a factor of 10 difference in analyte response relative (Sunner, Nicol, and Kebarle, 1988b).

TABLE X

COMPARISON OF INITIAL ANALYTE RESPONSE VS. GAS-PHASE BASICITY

Study

Log(Analyte Response)

Thermodynamic Equilibrium Model; (Figure 14.)

Vandiver, Leasure, and Eiceman., 1985; (IMMS)

Cooks and Busch, 1983; (MIKES)

Sunner, Nicol, and Kebarle; (APIMS)

7.3 decade per $10 \mathrm{kcal} / \mathrm{mol}$

4.2 decade per $10 \mathrm{kcal} / \mathrm{mol}$

4-6 decades per $10 \mathrm{kcal} / \mathrm{mol}$

1 decade per $10 \mathrm{kcal} / \mathrm{mol}$

For compounds on the initial sloping portions of the response curves in Figure 14, response is thermodynamically controlled. The response for these compounds results from the proton transfer reactions reaching equilibrium before the reagent ions are consumed or the sample leaves the source region. These reactions are able to reach equilibrium because the extent of proton transfer to these weak bases is minimal. Decreasing the relative humidity at constant hydronium shifts the breakpoint GB for unit response to a lower value, since this results in a shift in the equilibrium toward more complete protonation. Increasing hydronium at constant relative humidity would have the same effect. The breakpoint $\mathrm{GB}$ can be defined from $\mathrm{E} 10 \mathrm{a}$ as the point at which analyte response = $1 / 2$; then in the denominator of $\mathrm{E} 10 \mathrm{a},\left[\mathrm{H}_{2} \mathrm{O}\right]=\mathrm{K}_{\mathrm{eq}}(\mathrm{R} 9)\left[\mathrm{H}_{3} \mathrm{O}^{+}\right]$. Rearranging this expression and solving for the breakpoint in terms of GB(B) gives Equation 11.

$$
\begin{aligned}
& \mathrm{K}_{\mathrm{eq}}=\left[\mathrm{H}_{2} \mathrm{O}\right] /\left[\mathrm{H}_{3} \mathrm{O}^{+}\right]=\exp \left\{(\mathrm{RT})^{-1}\left[\mathrm{~GB}(\mathrm{~B})-\mathrm{GB}\left(\mathrm{H}_{2} \mathrm{O}\right)\right]\right\} \\
& \mathrm{GB}(\mathrm{B})_{\text {BREAKPONTT }}=\mathrm{GB}\left(\mathrm{H}_{2} \mathrm{O}\right)-\mathrm{RT} \ln \left(\left[\mathrm{H}_{3} \mathrm{O}^{+}\right] /\left[\mathrm{H}_{2} \mathrm{O}\right]\right)
\end{aligned}
$$


Steady State Method. A second equilibrium approach considers the proton transfer reactions, and the subsequent removal of ionic species to the mass spectrometer, to be in steady state, with their overall concentrations not changing with time. This is a more comprehensive approach since it accounts for the removal of the reagent and analyte ions from the API source and the large effect this has on protonation of analytes. We begin by describing the sources and sinks of the protonated analyte $\left(\mathrm{BH}^{+}\right)$, which sum to zero under steady state conditions, E12. The term $\delta\left[\mathrm{BH}^{+}\right] / \delta \mathrm{t}$ is the change in concentration of the protonated species in time, $k_{f}$ and $k_{b}$ are the forward and reverse rate constants for $R 9 . k_{d}$ is the firstorder rate constant for detection, the rapid removal of ionized species by the applied $3 \mathrm{kV}$ electric field. Experimentally, the detection rate is determined by the potential gradient between the corona discharge needle and the first orifice. Typically, a $3 \mathrm{kV}$ difference is needed to initiate the corona discharge. For our source, $\mathrm{k}_{\mathrm{d}}=4.35 \times 10^{4}$ calculated from the $4.6 \mathrm{~mm}$ distance from the needle tip to the orifice and an ion velocity of $2 \times 10^{4} \mathrm{~cm} \mathrm{sec}^{-1}$ based on the potential gradient and distance (McDaniel, 1964).

Kebarle, using a Sciex TAGA 6000 APIMS, has reported relative API sensitivities as a function of analyte GB (Sunner, Nicol, and Kebarle, 1988; Sunner, Ikonomou, and Kebarle, 1988a), in terms of the kinetic and thermodynamic control of proton transfer. Relative analyte sensitivity was defined as the analyte ion counts per second per concentration unit, ratioed to the ion count per second per concentration for pyridine. Figure 15 reproduces Kebarle's figure, which was based on a series of experiments in which each analyte was ionized in the presence of unspecified concentrations of pyridine $\left(\mathrm{GB}_{\text {PYRIDINE }}=213\right.$ 
$\mathrm{kcal} / \mathrm{mole}$ ). Response curves were found to be linear on a log scale at low analyte concentrations with negative deviations at higher concentrations, presumably as the reagent ions are consumed. Compounds with gas-phase basicities greater than a threshold value were generally observed to have uniformly high and equal sensitivities. These compounds had sensitivities that were described as being kinetically controlled. Kinetically controlled compounds have large GBs which shift their proton transfer equilibrium far to the right. In the available residence time in the source they cannot reach proton transfer equilibrium and the extent of protonation is then a function of the residence time in the source. For compounds below this threshold (ca. GB=200 $\mathrm{kcal} / \mathrm{mol}$ ) the observed sensitivities decreased with decreasing analyte GB. The response of these lower GB compounds was termed thermodymamic. Thermodynamically controlled compounds have equilibria which are shifted to the left, allowing them to reach proton transfer equilibrium in the available source residence time. Increasing the distance between the needle and the orifice increases the residence time by decreasing the ion velocity and lengthening the ion path, and would be expected to increase analyte response for kinetically controlled species. This increased response is offset by having a smaller portion of the ionized particles impact the orifice as the distance increases (Sunner, Nicol, and Kebarle, 1988; Eiceman et al., 1988). Rearranging E12 expression, we can relate analyte response $\left(\left[\mathrm{BH}^{+}\right] /[\mathrm{B}]_{0}\right)$ to the equilibrium constant (E9), the concentrations of hydroniums and water, the protonation rate constant $k_{p}$, and the detection rate constant, $\mathbf{k}_{\mathbf{d}}$.

$$
\delta\left[\mathrm{BH}^{+}\right] / \delta \mathrm{t}=\mathrm{k}_{\mathrm{f}}\left[\mathrm{H}_{3} \mathrm{O}^{+}\right][\mathrm{B}]-\mathrm{k}_{\mathrm{b}}\left[\mathrm{H}_{2} \mathrm{O}\right]\left[\mathrm{BH}^{+}\right]-\mathrm{k}_{\mathrm{d}}\left[\mathrm{BH}^{+}\right]=0
$$




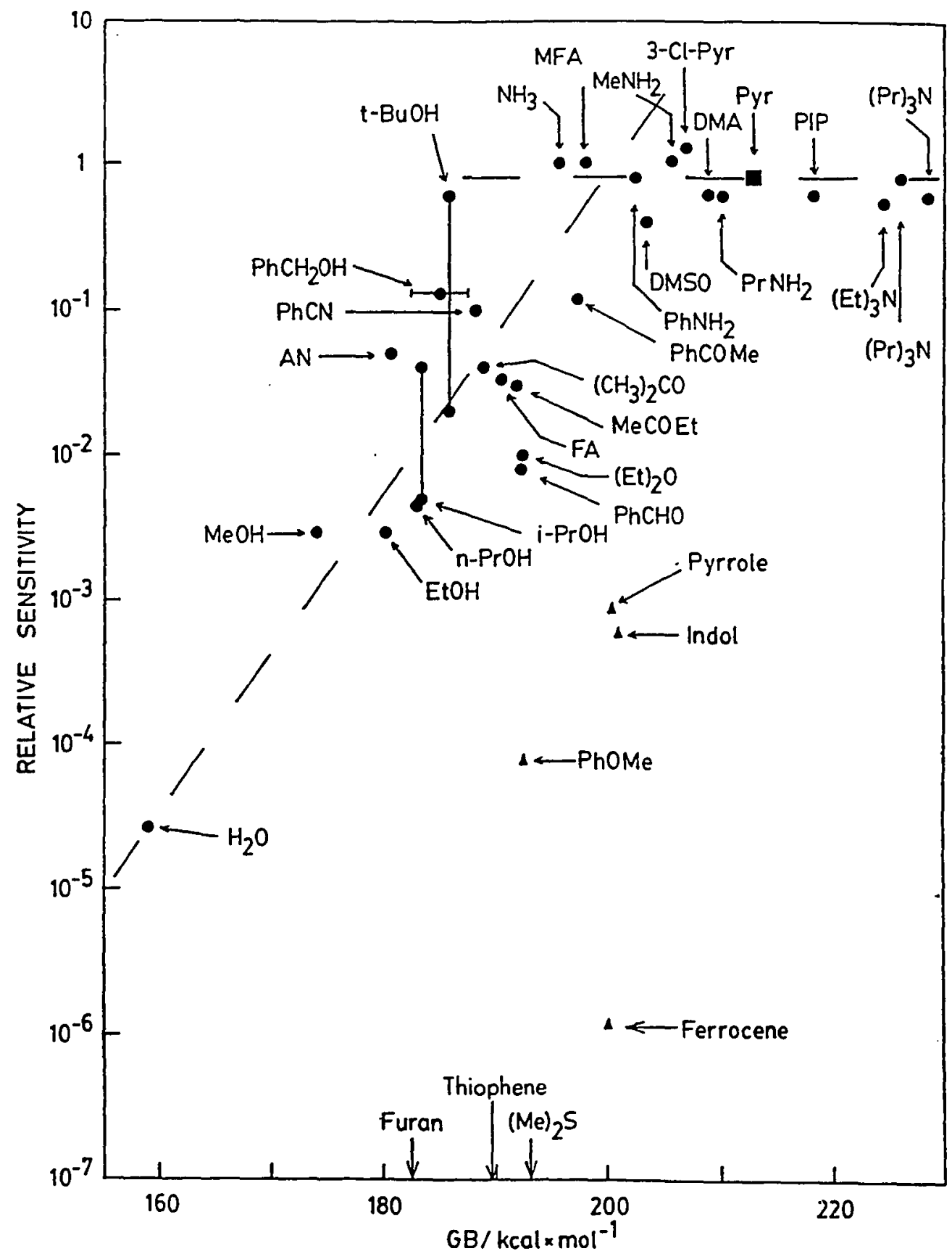

Figure 15. Sensitivity, relative to pyridine, in an API source as a function of analyte GB. Source: Sunner, Nicol, and Kebarle, 1988.

$$
\text { Response } \equiv\left[\mathrm{BH}^{+}\right] /[\mathrm{B}]_{\mathrm{o}}=\mathrm{k}_{q}\left[\mathrm{H}_{3} \mathrm{O}^{+}\right] /\left(\mathrm{k}_{\mathrm{f}}\left[\mathrm{H}_{3} \mathrm{O}^{+}\right]+\mathrm{k}_{\mathrm{b}}\left[\mathrm{H}_{2} \mathrm{O}\right]+\mathrm{k}_{\mathrm{d}}\right)
$$




$$
=\left[\mathrm{H}_{3} \mathrm{O}^{+}\right] /\left(\left[\mathrm{H}_{2} \mathrm{O}\right] / \mathrm{K}_{\mathrm{eq}}+\left[\mathrm{H}_{3} \mathrm{O}^{+}\right]+\mathrm{k}_{\mathrm{d}} / \mathrm{k}_{\mathrm{f}}\right)
$$

The two equivalent forms of Equation 13 are similar to E10 with the exception of the detection term. $K_{e q}$ could be replaced using $E 9$ to relate analyte response directly to analyte GB. Figures $16-19$ represent the solutions to E13 as the initial concentrations of reagents and reaction parameters are changed. Equation 13 was solved using a range of analyte GBs, holding all but one of the other parameters constant. Except when it was the parameter being varied: $\left[\mathrm{H}_{3} \mathrm{O}^{+}\right]=1.25 \mathrm{e} 07,\left[\mathrm{H}_{2} \mathrm{O}\right]=1.67 \mathrm{e} 17$ each in units of molecules $\mathrm{cm}^{-3}, \mathrm{k}_{\mathrm{f}}=3.0 \mathrm{e}-9 \mathrm{~cm}^{3} \mathrm{sec}$ molecules ${ }^{-1}$, and $k_{\mathrm{d}}=8.348 \mathrm{e} 4 \mathrm{sec}^{-1}$. The GB of water is $159 \mathrm{kcal} / \mathrm{mol}$ (Lias, Liebman, and Levin (1984). In order to better isolate the effect of GB in determining analyte response, all forward proton rate constants are assumed to be equal, $3 e-9$ molecules $\mathrm{cm}^{-3} \mathrm{sec}^{-1}$. Actual forward rates vary by a factor of three or less for most compounds (Bohme, Mackay, and Tanner, 1979). The rate of the reverse reaction, $\mathrm{H}_{2} \mathrm{O}+\mathrm{BH}^{+}-\rightarrow \mathrm{B}+\mathrm{H}_{3} \mathrm{O}^{+}$is then determined from $\mathrm{K}_{e q},\left(\mathrm{k}_{\mathrm{b}}=\mathrm{k}_{f} / \mathrm{K}_{\mathrm{eq}}\right)$.

The fundamental appearance of the curves, which incorporate the detection step, is the same as in Figure 14, which ignored the effects of the $3 \mathrm{kV}$ ionization potential. Figures 16-19 have a initial linear response region corresponding to achievement of thermodynamic equilibrium for the low GB compounds. The slope of the initial region is $1 / 2.3 \mathrm{RT}$, as in the case of Figure 14. Compounds above a breakpoint GB all reach a response plateau defined by the $k_{d}\left[\mathrm{H}_{3} \mathrm{O}^{+}\right] / \mathrm{k}_{\mathrm{f}}$ in $\mathrm{E} 13 \mathrm{~b}$. We can define the breakpoint in the response curve as occurring when $\left.\left[\mathrm{BH}^{+}\right] / \mathrm{B}\right]_{0}=\alpha$, where $\alpha$ is a number less than 1. This allows E12 to be rewritten in terms of the breakpoint GB, where $\alpha$ is the fraction of $B_{0}$ which is protonated.

$$
\mathrm{GB}_{\alpha}=2.3 \mathrm{RT} \log \left(\left(\alpha\left[\mathrm{H}_{2} \mathrm{O}\right]\right) /\left(\left[\mathrm{H}_{3} \mathrm{O}^{+}\right]-\alpha\left[\mathrm{H}_{3} \mathrm{O}^{+}\right]-\alpha \mathrm{k}_{\alpha} / \mathrm{k}_{\mathrm{f}}\right)\right)+\mathrm{GB}\left(\mathrm{H}_{2} \mathrm{O}\right)
$$


Steady State: Hydroniums. Increasing the hydronium ion concentration, Figure 15, increases the response for all analytes equally, but it does not change the breakpoint GB below which analyte response decreases. Experimentally, the reagent ion concentration can be increased by increasing the corona discharge current. The upper usable limit in the current arises from increased likelihood of a breakdown of the corona discharge into an arcing discharge. Unlike Figure 14, the maximum response is no longer unity. As a result of the removal of the ionized species, in particular reagent hydroniums, the analyte does not have the opportunity to fully participate in proton transfer reactions. This forms a kinetic limitation (expressed by the term $k_{d} / k_{f}$ in $\mathrm{E} 13 \mathrm{~b}$ ) to the extent of reaction and lowers the ultimate response possible for each set of conditions.

The limiting behavior of the curves in Figure 15 can be explained from Equation 13b. At low GB the equilibrium constant is small and the ratio of $\left[\mathrm{H}_{2} \mathrm{O}\right] / \mathrm{K}_{\mathrm{eq}}$ is much larger than either of the other two terms in the denominator. Response is thus linear in GB, as reflected the value of $\mathrm{K}_{\mathrm{eq}}$ and increasing the hydronium concentration increases the response of all compounds equally. At high GB the ratio of $\left[\mathrm{H}_{2} \mathrm{O}\right] / \mathrm{K}_{\text {eq }}$ is smaller than either of the denominator terms and response is no longer a function of GB.

Steady State: Water. Decreasing the water concentration, Figure 16, enhances analyte response by shifting the equilibrium R9 in favor of the species which have not reached maximum response. Compounds well below the breakpoint GB increase in response inversely proportionate to the decrease in water vapor concentration, while compounds with GB just below the breakpoint reach maximum response. This has the effect of shifting the breakpoint GB to 


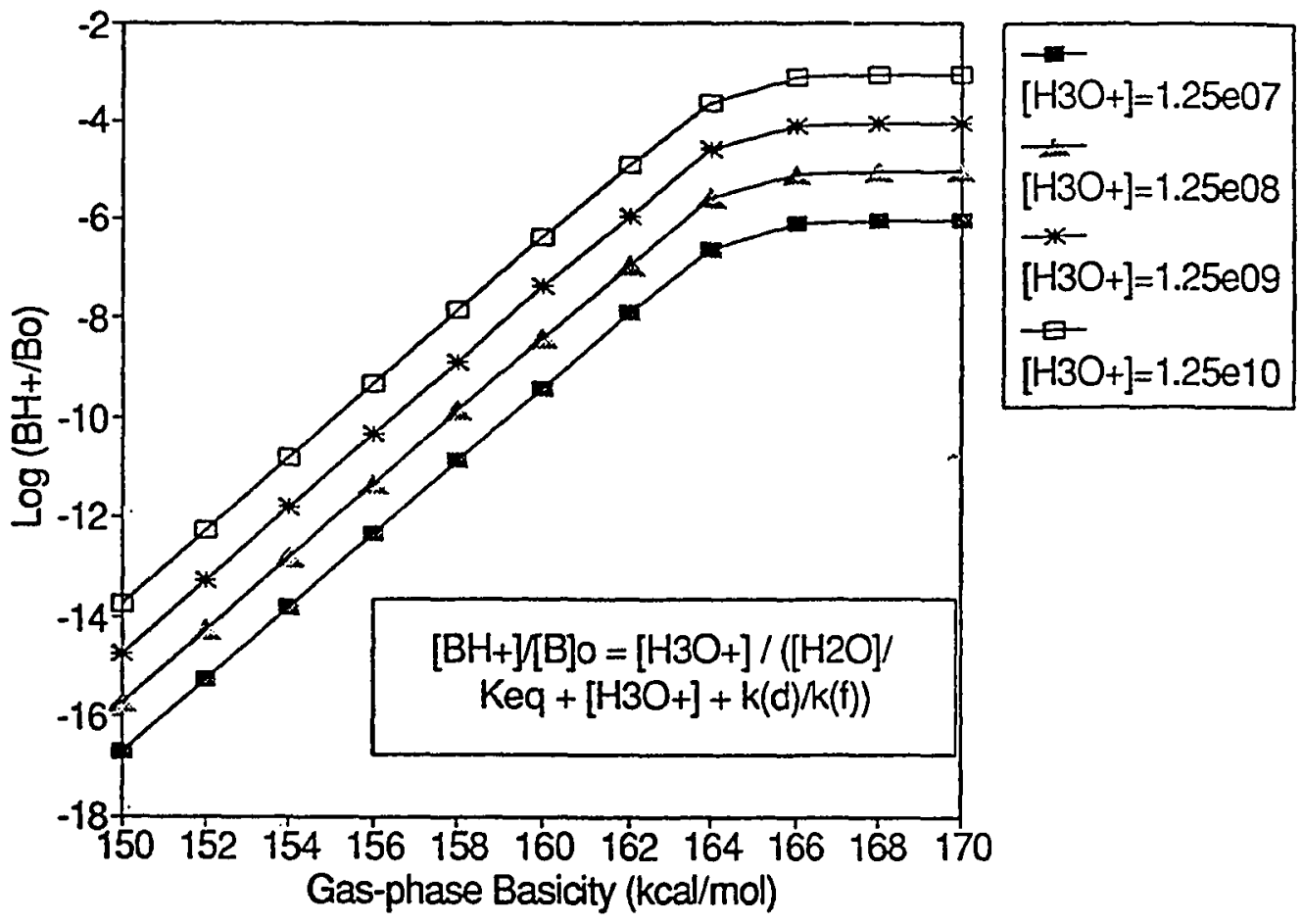

Figure 16. Analyte response in steady state model (R13) as a function of $\mathrm{GB}$ and $\left[\mathrm{H}_{3} \mathrm{O}^{+}\right]_{\mathrm{o}}$. Initial $\left[\mathrm{H}_{2} \mathrm{O}\right]=1.67 \mathrm{e} 17$ molecules $\mathrm{cm}^{-3}$, $\mathrm{k}_{\mathrm{d}}=4.35 \mathrm{e} 4 \mathrm{sec}^{-1}$, and $\mathrm{k}_{\mathrm{r}}=3.0 \mathrm{e}-9 \mathrm{~cm}^{3} \mathrm{sec}$ molecules $^{-1}$.

lower values. Reducing the humidity of an ambient sample, without removing analyte, presents unique problems. Semi-permeable membranes designed to selectively remove water vapor (Cochran, 1987; Cox and Earp, 1982; Singh and Salas, 1983) are one possibility, although loss of analyte to the membrane surface must be considered.

Water concentration only affects the region of the curves in Figure 17 at low $\mathrm{GB}$, small $\mathrm{K}_{\mathrm{eq}}$. As before, at low $\mathrm{GB}$ the ratio of $\left[\mathrm{H}_{2} \mathrm{O}\right] / \mathrm{K}_{\mathrm{eq}}$ is large compared to the other denominator terms and for a constant $\left[\mathrm{H}_{3} \mathrm{O}^{+}\right]$response will be dependent on the water concentration. At high $\mathrm{GB}$ values ratio of $\left[\mathrm{H}_{2} \mathrm{O}\right] / \mathrm{K}_{\text {eq }}$ becomes negligible and water is no longer a determining factor. 


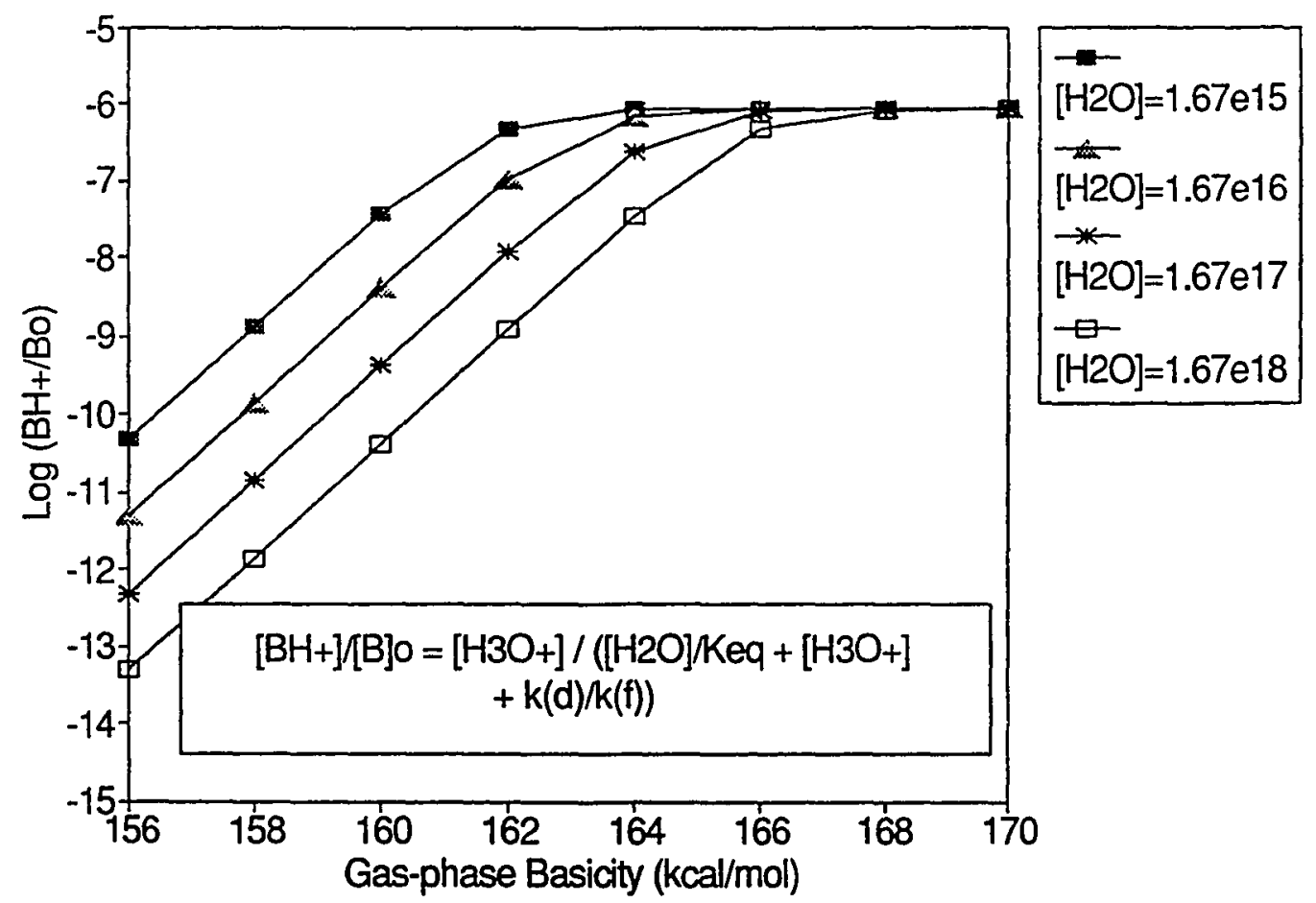

Figure 17. Analyte response in steady state model (R13) as a function of $\mathrm{GB}$ and $\left[\mathrm{H}_{2} \mathrm{O}\right]_{0}$. Initial $\left[\mathrm{H}_{3} \mathrm{O}^{+}\right]=1.25 \mathrm{e} 07$ molecules $\mathrm{cm}^{-3}$, $\mathrm{k}_{\mathrm{d}}=4.35 \mathrm{e} 4 \mathrm{sec}_{-1}$, and $\mathrm{k}_{\mathrm{f}}=3.0 \mathrm{e}-9 \mathrm{~cm}^{3} \mathrm{sec}$ molecules ${ }^{-1}$.

Steady State: Detection. The detection rate, as illustrated in Figure 18, has yet a different effect on analyte response. A large $k_{d}$ relates to the rapid removal of ions from the API source, and results in reduced response. Proton transfer reactions are in direct competition with the removal steps and large detection rates mean that the reagent hydroniums are removed from the reaction mix before quantitative protonation of the analytes can occur. Only at extremely slow proton transfer rates can analyte response become quantitative, equivalent to the results of Figure 14, solved without detection steps, where the response plateau at high GB corresponds to complete analyte protonation. When $k_{d}$ is varied, the response plateau varies in inverse proportion to $\mathbf{k}_{\mathbf{d}}$, until it reaches near unit response. 


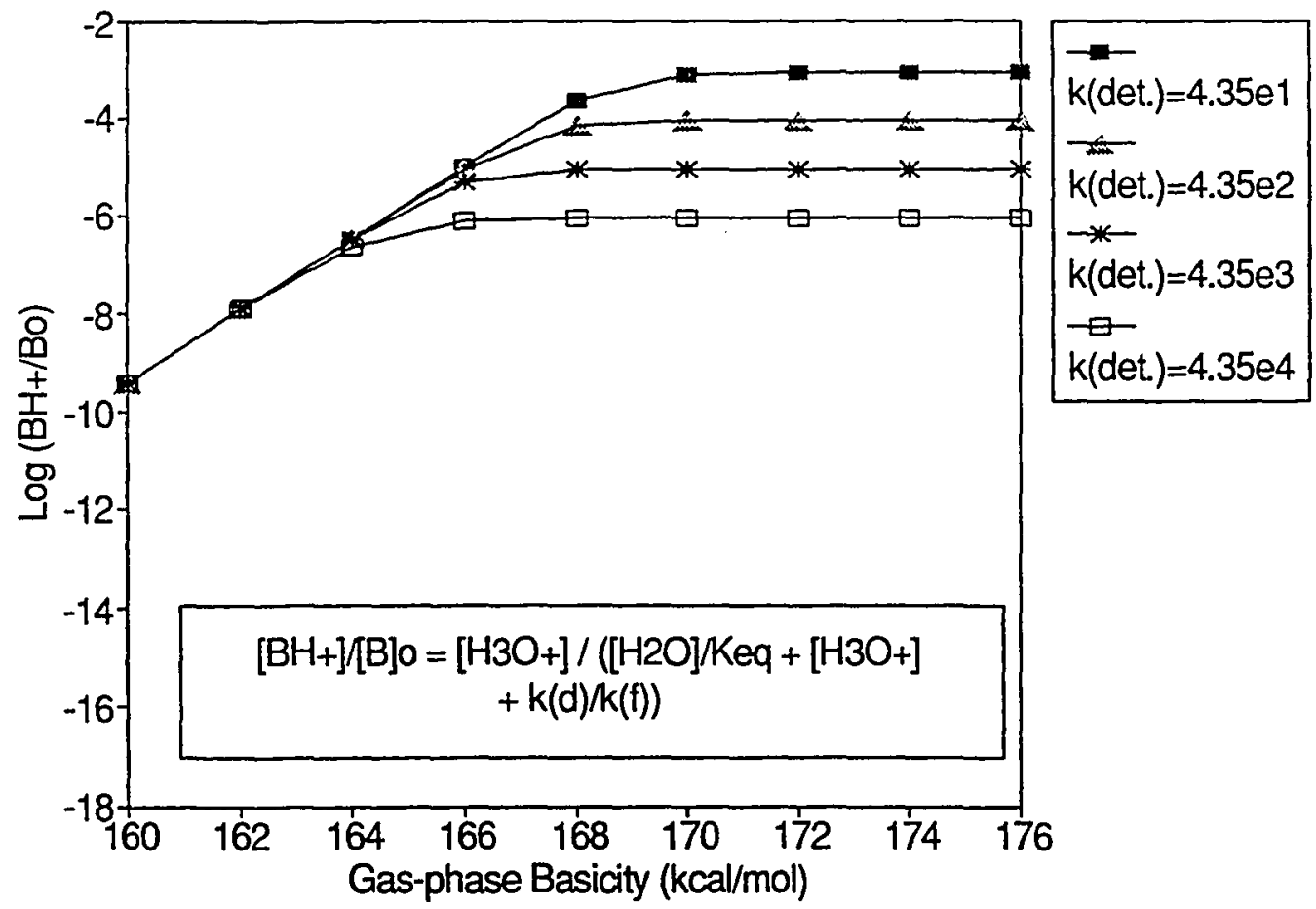

Figure 18. Analyte response in steady state model (R13) as a function of $\mathrm{GB}$ and $\mathrm{k}_{\mathrm{d}}$. Initial $\left[\mathrm{H}_{3} \mathrm{O}^{+}\right]_{0}=1.25 \mathrm{e} 07,\left[\mathrm{H}_{2} \mathrm{O}\right]=1.67 \mathrm{e} 17$ in units of molecules $\mathrm{cm}^{-3}$, and $\mathrm{k}_{\mathrm{f}}=3.0 \mathrm{e}-9 \mathrm{~cm}^{3} \mathrm{sec}$ molecules ${ }^{-1}$.

Analyte response increases with a decrease in the detection rate only for the high GB compounds. For lower GB's the ratio of $\left[\mathrm{H}_{2} \mathrm{O}\right] / \mathrm{K}_{\mathrm{eq}}$ continues to predominate. At high GB the ration of $k_{d} / k_{f}$ becomes the controlling factor for analyte response. As $k_{d}$ approaches zero quantitative detection of the analyte becomes possible, assuming adequate reagent ions, $\log ($ response $)=0$.

Steady State: Forward Rates. Figure 19 displays a family of curves where at each $\mathrm{GB}$ the value of $\mathrm{K}_{\mathrm{eq}}$ remains the same, based on the GB from $\mathrm{E} 9$, but the forward protonation rate was changed. As in previous cases, at small GBs the ratio of $\left[\mathrm{H}_{2} \mathrm{O}\right] / \mathrm{K}_{\text {eq }}$ continues to determine analyte response. At high GBs larger 
forward rate can decrease the contribution in the denominator from the ratio of $\mathrm{k}_{\mathrm{d}} / \mathrm{k}_{\mathrm{f}}$ allowing analyte response to increase.

\section{Kinetic Modeling-Rate Constants}

A still more complete approach to evaluating API response is to use chemical kinetics to model the reaction sequences. This approach does not assume any type of equilibrium, but must reproduce the results and conclusions of the previous methods if the mechanisms are integrated to equilibrium. Computer modeling was conducted with a variety of distinct chemical systems, each designed to examine a particular experimental process or aspect of API analysis. Knowledge of the rates of reaction for all the species is necessary to affect the modeling, yet experimental measurements of such rates are available for only a few species. Before discussing the models themselves we will direct our attention to the origins of the rate constants we will use.

Hydration. The first family of reactions that are of interest are the hydration reactions of water with hydronium ions. Kebarle et al. (Good, Durden, and Kebarle, 1970a; Good, Durden, and Kebarle, 1970b) have reported the rates of hydration for hydronium ions through the formation and dissociation of $\mathrm{H}_{3} \mathrm{O}^{+} \cdot\left(\mathrm{H}_{2} \mathrm{O}\right)_{\mathrm{n}}$ up to $\mathrm{n}=4$. Integrating these reactions alone gives the families of hydrated hydroniums (masses $19,37,55,73, \ldots$ which dominate the background of spectra in Chapters 2 and 3). The most abundant hydrate species in the family is determined by the total water vapor available. Figure 20 represents the integration of the hydration reactions which are presented in Table XI. Equilibrium is reached very quickly, within $0.1 \mu \mathrm{sec}$, and the dominant hydrate 


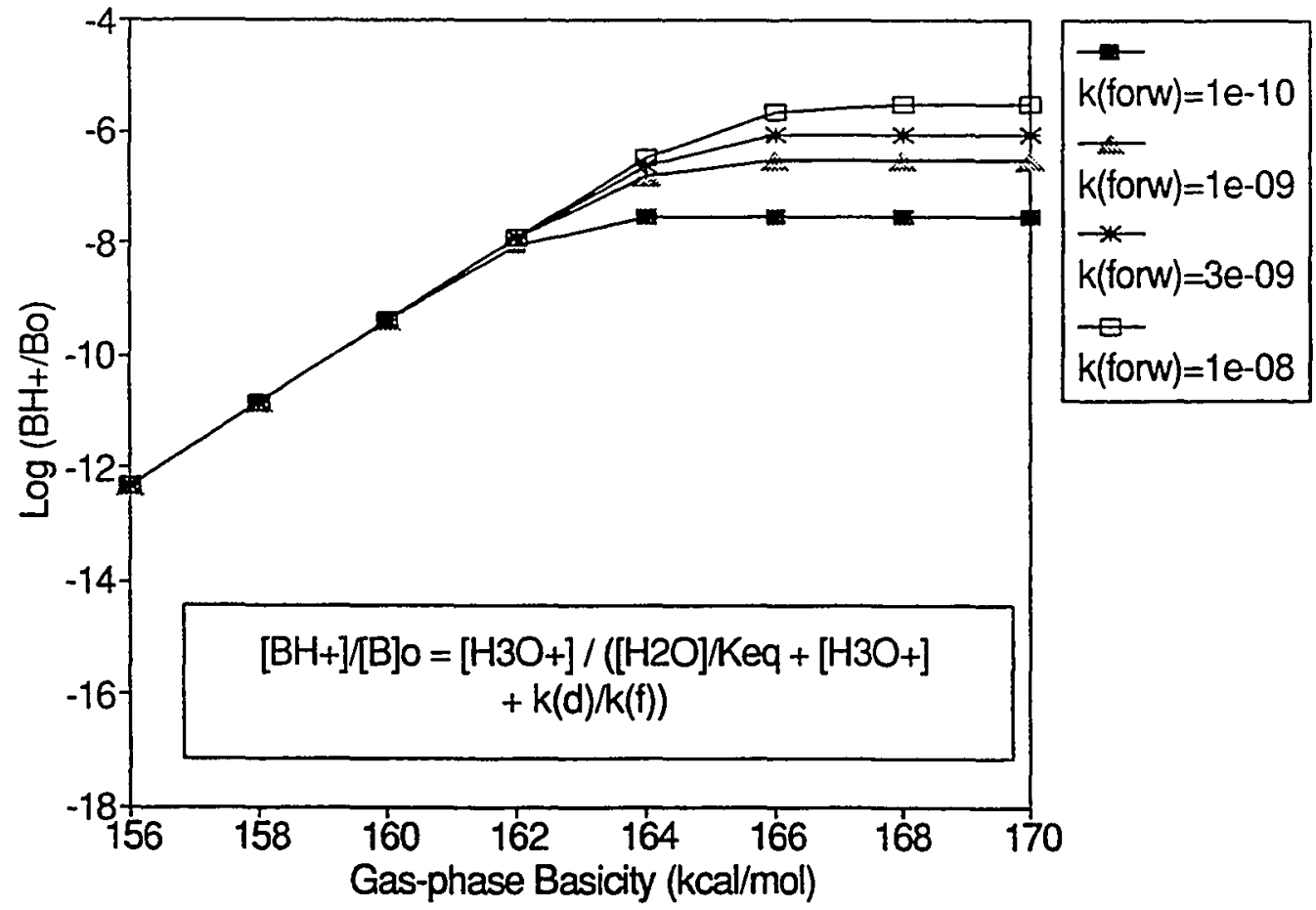

Figure 19. Analyte response in steady state model (R13) as a function of $\mathrm{GB}$ and $\mathrm{k}_{\mathrm{r}}$. Initial $\left[\mathrm{H}_{3} \mathrm{O}^{+}\right]_{0}=1.25 \mathrm{e} 07,\left[\mathrm{H}_{2} \mathrm{O}\right]=1.67 \mathrm{e} 17 \mathrm{in}$ units of molecules $\mathrm{cm}^{-3}$, and $\mathrm{k}_{\mathrm{d}}=4.35 \mathrm{e} 4 \mathrm{sec}^{-1}$.

occurs for $\mathrm{n}=3$ with a water concentration of $1.6 \times 10^{15}$ molecules $\mathrm{cm}^{-3}$. Although this water concentration is quite low, it is the water vapor concentration in the CID region at a pressure of about 1/760 atm which controls the cluster formation. Thus $1 \%$ water vapor concentration in the API source $\left(2.5 \mathrm{e} 17\right.$ molecules $\left.\mathrm{cm}^{-3}\right)$ would be reduced to about $2.5 \mathrm{e} 14$ in the CID region, and would be expected to result in peaks in the hydronium clusters of $n=3$ to $n=4$. Conversely, the protonation equilibrium $\mathrm{R} 9$ is unaffected by the expansion to lower pressure in the CID region, since this equilibrium is second order in both directions.

The hydration of protonated analytes is another reaction series of interest. The free energies of hydration for a variety of compounds having GBs ranging from 


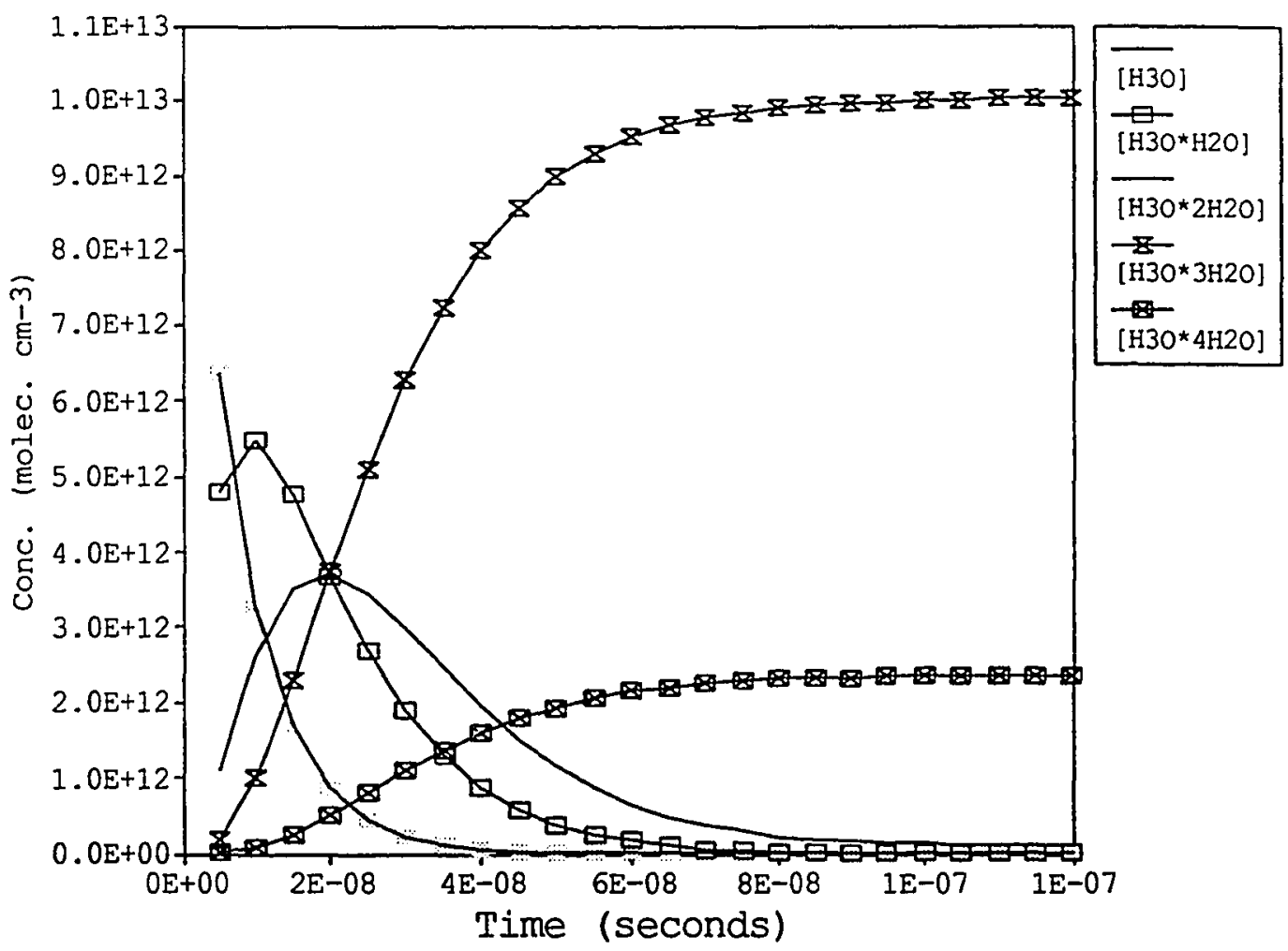

Figure 20. Kinetic modeling of hydration reactions for water with hydronium ions. Reaction rates based on experimental values of Good, Durden, and Kebarle (1970a), mechanism is given in Table XI.

that of water $(\mathrm{GB}=159 \mathrm{kcal} / \mathrm{mol})$ to that of pyridine $(\mathrm{GB}=213 \mathrm{kcal} / \mathrm{mol})$ have been measured (Nicol, Sunner, and Kebarle, 1988; Hiraoka, Takimoto, and Morise, 1986; Keesee and Castleman, 1986). In order to evaluate the equilibrium constant and derive deprotonation rates for an analyte as a function of its GB, it would be useful if there was a general relationship between the free energy for hydration and GB. Figure 21 was developed using the GBs (Lias, Liebman, and Levin, 1984) of the compounds for which hydration free energies have been measured. Figure 21 gives a new perspective on the relationship between analyte GB and the negative of the free energy of hydration for R2 where $\mathrm{n}$ is the number of hydrating water 
TABLE XI

MECHANISM FOR KINETIC MODELING OF HYDRONIUM HYDRATION

\begin{tabular}{|c|c|c|c|c|c|c|}
\hline \multirow{5}{*}{$\begin{array}{l}\mathrm{H} 3 \mathrm{O} \\
\mathrm{H} 3 \mathrm{O} 1 \\
\mathrm{H} 3 \mathrm{O} 1 \\
\mathrm{H} 3 \mathrm{O} 2 \\
\mathrm{H} 3 \mathrm{O} 2\end{array}$} & $\mathrm{H} 2 \mathrm{O}$ & M & $=\mathrm{H} 3 \mathrm{O} 1$ & M & & $3.4 \mathrm{E}-27$ \\
\hline & & & $=\mathrm{H} 3 \mathrm{O}$ & \multicolumn{2}{|c|}{$\mathrm{H} 2 \mathrm{O}$} & $7 \mathrm{E}-26$ \\
\hline & $\mathrm{H} 2 \mathrm{O}$ & M & $=\mathrm{H} 3 \mathrm{O} 2$ & M & & $2.3 \mathrm{E}-27$ \\
\hline & M & & $=\mathrm{H} 301$ & $\mathrm{H} 2 \mathrm{O}$ & $\mathrm{N}$ & $7 \mathrm{E}-18$ \\
\hline & $\mathrm{H} 2 \mathrm{O}$ & M & $=\mathrm{H} 3 \mathrm{O} 3$ & M & & $2.4 \mathrm{E}-27$ \\
\hline $\mathrm{H}$ & M & & $=\mathrm{H} 3 \mathrm{O} 2$ & $\mathrm{H} 2 \mathrm{O}$ & & $4 \mathrm{E}-14$ \\
\hline & $\mathrm{H} 2 \mathrm{O}$ & M & $=\mathrm{H} 3 \mathrm{O} 4$ & M & & $9 \mathrm{E}-28$ \\
\hline $\mathrm{H}^{3}$ & & & $=\mathrm{H} 3 \mathrm{O} 3$ & $\mathrm{H} 2 \mathrm{O}$ & 1 & $6 \mathrm{E}-12$ \\
\hline
\end{tabular}

\$INITIAL CONDITIONS

$\begin{array}{lll}\mathrm{M} & \mathrm{H} 3 \mathrm{O} & \mathrm{H} 2 \mathrm{O} \\ 2.450 \mathrm{E}+19 & 1.250 \mathrm{E}+13 & 1.612 \mathrm{E}+15\end{array}$

Notes: Reaction rates from Bohme, Mackay, and Tanner (1979). Rate constants have units of $\mathrm{cm}^{3}$ molecules ${ }^{-1}$ or $\mathrm{cm}^{6} \sec ^{2}$ molecules ${ }^{-1}$ as appropriate.

molecules. Each of the curves in Figure 21 represent a second order regression analysis for each value of $\mathrm{n}$. This allows the more generalized expression

$$
\mathrm{BH}^{+} \cdot\left(\mathrm{H}_{2} \mathrm{O}\right)_{\mathrm{n}-1}+\mathrm{H}_{2} \mathrm{O}=\mathrm{BH}^{+} \cdot\left(\mathrm{H}_{2} \mathrm{O}\right)_{\mathrm{n}}
$$

of the free energies as a function of GB. The use of the free energy to evaluate the equilibrium constant is described in a later section. As an aside, MOPAC was used to calculate the heat of reaction for the hydration of several compounds $(n=1)$ and found to track the free energies closely. The values derived for $\Delta \mathrm{H}_{\mathrm{rxn}}$ (MOPAC) are the solid squares above the experimental $n=1$ line. Table XII presents the heats of formation and hydration heat of reaction for compounds with a range of GBs, plotted in Figure 21 as filled squares. The small offset is a result of not accounting for the $T \Delta S$ term which relates the enthalpies calculated to the free energies which were plotted. Table XIII lists the regression analysis results from 


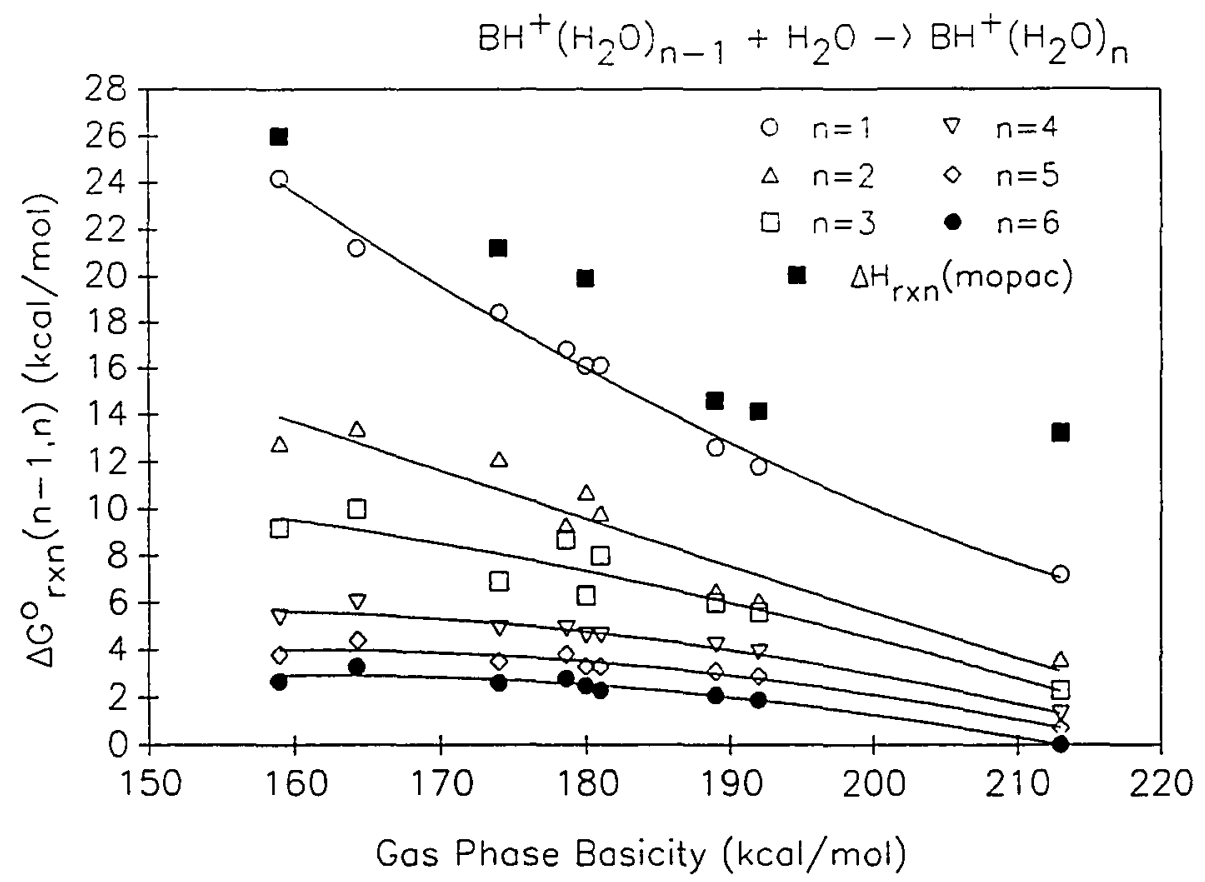

Figure 21. Free energy for the hydration reactions of protonated analytes as a function of GB. Experimental $\Delta G$ values from Nicol, Sunner, and Kebarle 1988; Hiraoka, Takimoto, and Morise, 1986; Keesee and Castleman, 1986. Enthalpies of the hydration reaction for $n=1$ calculated from MOPAC. Analysis of the curves is given in Table XIII

Figure 21 which are used to evaluate the equilibrium constant and thus the reverse rate as a function of GB.

Forward Protonation Rates. The forward rate constants for proton transfer from the hydronium, and from the first four hydrated hydronium clusters, have been experimentally determined for a variety compounds by Bohme, Mackay, and Tanner (1979). These rates were found to agree closely with rates predicted with average dipole orientation theory ( $\mathrm{Su}$ and Bowers, 1979; $\mathrm{Su}$ and $\mathrm{Su}, 1978$; Bass et al, 1975). These reactions are of the form shown in R17 where $n$ is the number of 
TABLE XII
SEMIEMPIRICAL CALCULATIONS OF HEATS OF REACTION FOR HYDRATION, $\mathrm{BH}^{+}+\mathrm{H}_{2} \mathrm{O}<-->\mathrm{BH}^{+} \bullet \mathrm{H}_{2} \mathrm{O}$

\begin{tabular}{lcccc} 
Compound & $\Delta \mathrm{H}_{\mathrm{f}}\left(\mathrm{BH}^{+}\right)$ & $\Delta \mathrm{H}_{\mathrm{f}}\left(\mathrm{BH}^{+} \bullet \mathrm{H}_{2} \mathrm{O}\right)$ & $\Delta \mathrm{H}_{\mathrm{rxn}}$ & $\mathrm{GB}(\mathrm{B})$ \\
\hline water & 143.8 & 58.6 & -26.0 & 159 \\
methanol & 138.3 & 57.9 & -21.2 & 174 \\
ethanol & 125.9 & 46.8 & -19.9 & 180 \\
acetone & 125.8 & 52.0 & -14.6 & 189 \\
diethyl ether & 114.2 & 40.87 & -14.1 & 192 \\
pyridine & 202.1 & 140.5 & -2.4 & 213 \\
\hline
\end{tabular}

Notes: All values are in units of $\mathrm{kcal} / \mathrm{mol} . \Delta \mathrm{H}_{\mathrm{f}}\left(\mathrm{H}_{2} \mathrm{O}\right)=-59.2$ $\mathrm{kcal} / \mathrm{mol}$. Gas phase basicities from Lias, Liebman, and Levin, 1984.

hydrating waters. Reactions which transfer some other fraction of the hydrating water molecules to the analyte B are also possible but were not experimentally

$$
\mathrm{B}+\mathrm{H}_{3} \mathrm{O}^{+} \cdot\left(\mathrm{H}_{2} \mathrm{O}\right)_{\mathrm{n}}=\mathrm{BH}^{+} \cdot \mathrm{H}_{2} \mathrm{O}_{\mathrm{n}}+\mathrm{H}_{2} \mathrm{O}
$$

distinguishable (Bohme, Mackay, and Tanner, 1979). Quantitatively, proton transfer rates are close to the collision rate right down to near zero exothermicity $\left(\Delta \mathrm{G}_{\text {proton transfer }} \leq 0\right)$ and do not seem to be functions of GB, as illustrated in Figure 22. All the forward proton transfer rates fall within the range of 1.5 to $3 \times 10^{-9} \mathrm{~cm}^{3}$ molecules ${ }^{-1} \sec ^{-1}$, with protonation faster for the smaller hydrates. Unless otherwise noted, the forward rates for protonation from hydrated hydroniums where $\mathrm{n}=0-3$ will be modeled at $3.0,2.5,2.0$ and $1.5 \times 10^{9}$ molecules $^{-1} \mathrm{~cm}^{3} \mathrm{sec}^{-1}$ respectively.

Reverse Protonation Rates. Reverse rate constants for protonation are not generally available experimentally but can be derived from the equilibrium constants and the forward rates. Consider the protonation of analyte molecules 
Table XIII

REGRESSION ANALYSIS OF FREE ENERGIES OF HYDRATION AS A
FUNCTION OF ANALYTE GB FOR BH $\mathrm{BH}^{+} \cdot \mathrm{H}_{2} \mathrm{O}_{\mathrm{n}-1}+\mathrm{H}_{2} \mathrm{O} \rightarrow \mathrm{BH}^{+} \bullet \mathrm{H}_{2} \mathrm{O}_{\mathrm{n}}$

\begin{tabular}{lllll}
$\mathrm{n}-1, \mathrm{n}$ & $\mathrm{a} 0$ & $\mathrm{a} 1$ & $\mathrm{a} 2$ & \multicolumn{1}{c}{$\mathrm{r}$} \\
\hline 0,1 & $1.57 \mathrm{E} 2$ & -1.21 & $2.4 \mathrm{E}-3$ & .998 \\
1,2 & $3.88 \mathrm{E} 1$ & $-1.31 \mathrm{E}-1$ & $-1.71 \mathrm{E}-4$ & .948 \\
2,3 & $3.58 \mathrm{E} 1$ & $1.86 \mathrm{E}-1$ & $-8.29 \mathrm{E}-4$ & .958 \\
3,4 & $-2.77 \mathrm{E}-1$ & 0.4175 & $-1.32 \mathrm{E}-3$ & .998 \\
4,5 & $-2.91 \mathrm{E} 1$ & 0.401 & $-1.23 \mathrm{E}-3$ & .994 \\
5,6 & $-2.91 \mathrm{E} 1$ & 0.386 & $-1.17 \mathrm{E}-3$ & .998 \\
\hline
\end{tabular}

Notes: $\Delta \mathrm{G}$ of reaction for the hydration of $\mathrm{BH}^{+}$ based on Figure 21. $\Delta \mathrm{G}(n-1, n)=a 0+a 1^{*} \mathrm{~GB}(B)+$ $\mathrm{a} 2 * \mathrm{~GB}(\mathrm{~B})^{2}$. GBs in $\mathrm{kcal} / \mathrm{mol}$.

from singly hydrated hydronium ions $\left(\mathrm{H}_{3} \mathrm{O}^{+} \bullet \mathrm{H}_{2} \mathrm{O}\right)$. The free energy for the reaction can be described in terms of: the gas-phase basicities of the analyte and water; the free energies of hydration for water, available from experiments; and the free energy of hydration of the analyte, available from the regression analysis in Table XIII using the analyte GB.

$$
\begin{gathered}
\mathrm{B}+\mathrm{H}_{3} \mathrm{O}^{+} \bullet \mathrm{H}_{2} \mathrm{O}<->\mathrm{BH}^{+} \bullet \mathrm{H}_{2} \mathrm{O}+\mathrm{H}_{2} \mathrm{O} \\
\Delta \mathrm{G}(\mathrm{R} 17)=\Delta \mathrm{G}\left(\mathrm{B}+\mathrm{H}^{+} \rightarrow \mathrm{BH}^{+}\right)-\Delta \mathrm{G}\left(\mathrm{H}_{2} \mathrm{O}+\mathrm{H}^{+} \rightarrow \mathrm{H}_{3} \mathrm{O}^{+}\right)-\Delta \mathrm{G}\left(\mathrm{H}_{3} \mathrm{O}^{+}+\right. \\
\left.\mathrm{H}_{2} \mathrm{O} \rightarrow \mathrm{H}_{3} \mathrm{O}^{+} \bullet \mathrm{H}_{2} \mathrm{O}\right)+\Delta \mathrm{G}\left(\mathrm{BH}^{+}+\mathrm{H}_{2} \mathrm{O} \rightarrow \mathrm{BH}^{+} \cdot \mathrm{H}_{2} \mathrm{O}\right) \\
\mathrm{K}_{\mathrm{eq}}(\mathrm{R} 17)=\exp (-\Delta \mathrm{G}(\mathrm{R} 17) / \mathrm{RT})=\exp \left[1 / \mathrm{RT}\left(-\mathrm{GB}(\mathrm{B})+\mathrm{GB}\left(\mathrm{H}_{2} \mathrm{O}\right)-\Delta \mathrm{G}\left(\mathrm{H}_{3} \mathrm{O}^{+}\right.\right.\right. \\
\left.+\mathrm{H}_{2} \mathrm{O} \rightarrow \mathrm{H}_{3} \mathrm{O}^{+} \bullet \mathrm{H}_{2} \mathrm{O}\right)+\Delta \mathrm{G}\left(\mathrm{BH}^{+}+\mathrm{H}_{2} \mathrm{O} \rightarrow \mathrm{BH}^{+} \bullet \mathrm{H}_{2} \mathrm{O}\right)
\end{gathered}
$$

Kinetic Modeling-Batch Mode

The simplest system to model and to understand considers the API source as a well mixed cell where reactants and products flow in and out at fixed rates. While this is not a strictly true representation of the API source it is sufficiently 


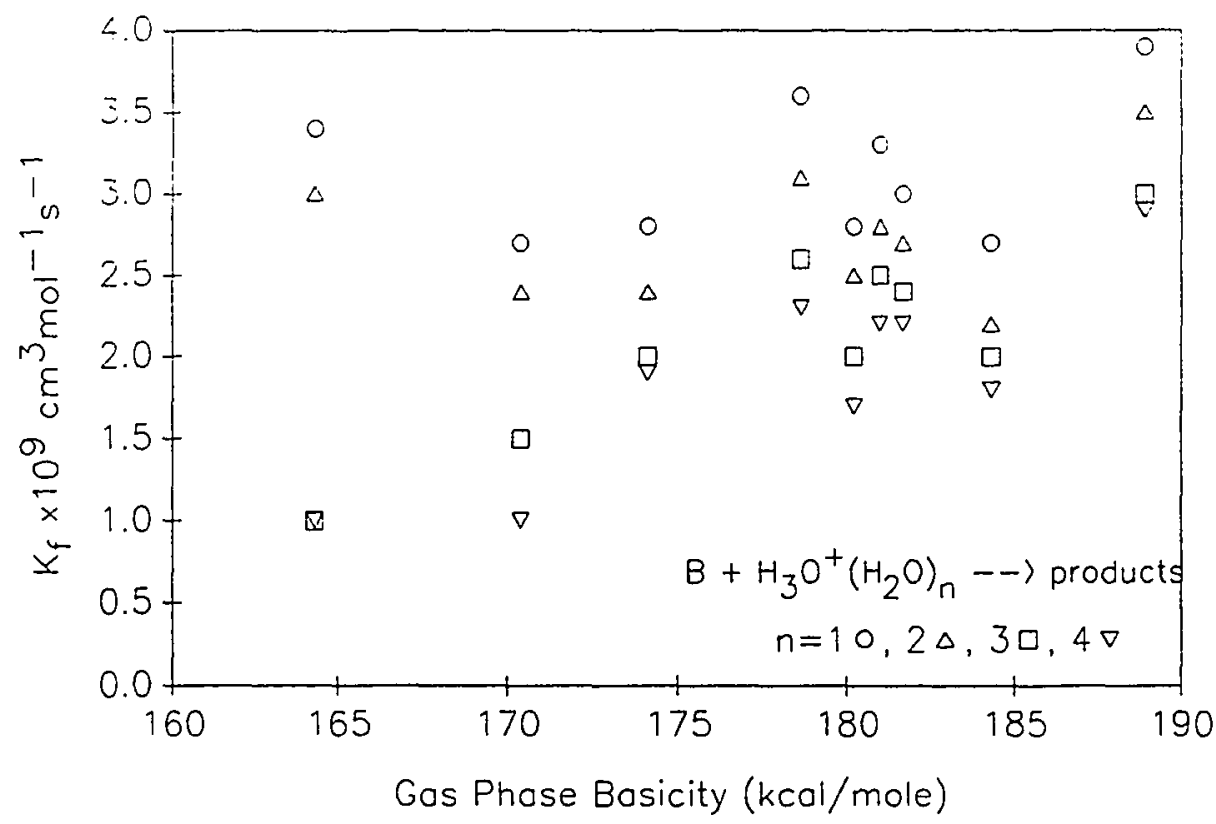

Figure 22. Forward rate constants for protonation as a function of analyte GB. Experimental data from Bohme, Mackay, and Tanner (1979).

close to provide valuable insights into API processes. Reagents flow into such a cell from sources whose concentrations remain fixed. The zero-order rates for these processes are based on the cell volume, the flow rate of the sample gas stream, and the concentration in this gas stream. Reversible proton transfer reactions occur in the cell. The rates for reversible proton transfer are obtained for an analyte of $\mathrm{GB}=180 \mathrm{kcal} / \mathrm{mol}$ using the analysis described above. All species leave the cell in first-order processes determined by their instantaneous concentrations in the cell, the flow rate, and the volume, forming lost species in the mechanism (ie. lh2o). In addition, charged species are removed in the detection steps; the loss rate to detection is based on the $3 \mathrm{kV}$ potential and $4.6 \mathrm{~mm}$ needle to orifice gap. 
Figure 23 plots the results of two separate integrations of the mechanism in Table XIV. The figure shows the concentrations present in the API source; the amount which reaches the detector of the mass spectrometer is simply $k_{d}$ times the API ion concentration. For these integrations the initial conditions were $\left[\mathrm{H}_{3} \mathrm{O}^{+}\right]=2.45 \times 10^{11},[\mathrm{~B}]=2.45 \times 10^{9},\left[\mathrm{H}_{2} \mathrm{O}\right]=1 \times 10^{16}$ molecules $\mathrm{cm}^{-3}$, and $\mathrm{k}_{\mathrm{f}}=3.0 \mathrm{e}-9 \mathrm{~cm}^{3}$ molecules $^{-1}$. The time scale of the x-axis represents the length of time required for the system to reach the steady-state conditions discussed in the previous section. The first integration, filled symbols, is based upon a detection rate of $4.35 \times 10^{4}$ $\mathrm{sec}^{-1}$, representative of our API source. The steady state concentration of reagent hydroniums, filled squares, is small relative to the analyte concentration, filled triangles. The rapid detection step has removed the hydroniums before proton transfer reactions can occur; quantitative protonation cannot occur under conditions where the analyte is in excess over the reagent in the API source.

The second integration in Figure 23 is based upon a detections rate of zero, representing the limit of improved analyte response possible. In this second integration the hydronium ions are in large excess over both the analyte and the protonated analyte. This case illustrates quantitative protonation of the analyte. The conditions under which analyte response can be improved are discussed in the summary, Chapter VII.

It is possible to have linear API response for analyte without having quantitative protonation. To illustrate this with the batch-mode model the mechanism in Table XIV was integrated at a range of initial analyte concentrations, keeping all other conditions the same as above for each integration. Analyte response is linear in the early portion of the plot when the hydronium ion 
TABLE XIV

BATCH MODE MODEL OF API RESPONSE

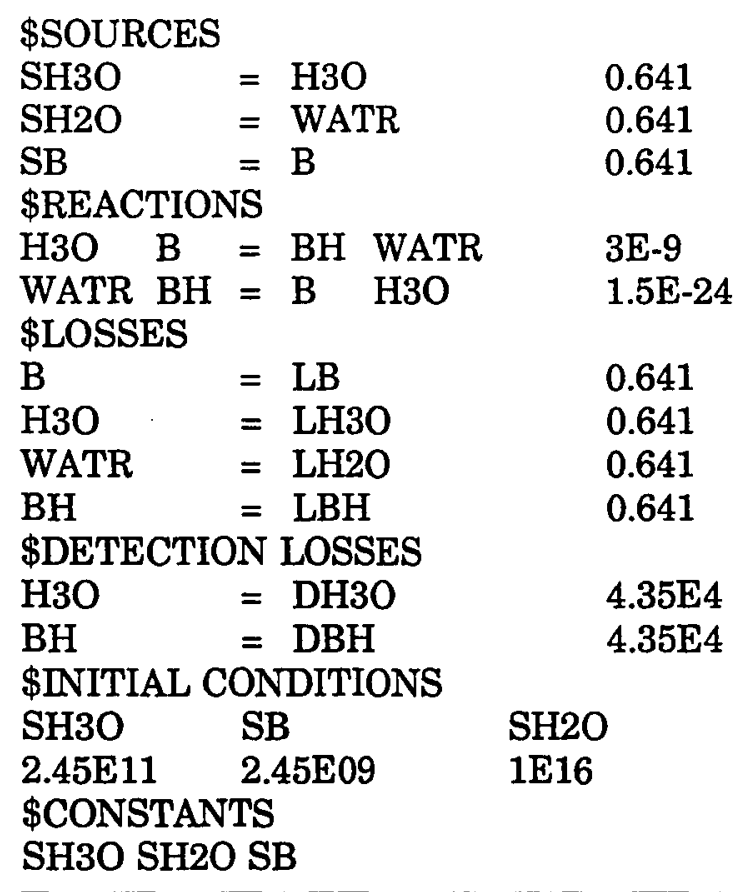

Notes: Source and loss rates for linear flow (0.641) are based on API source volume and inlet flow rate of $20 \mathrm{~cm}^{3} \mathrm{~min}^{-1}$. Forward protonation rate assumed, $\mathrm{k}_{\mathrm{b}}$ derived based on $\mathrm{GB}(\mathrm{b})=180 \mathrm{kcal} / \mathrm{mol}$.

concentration is in excess over the protonated analyte. Once the concentration of the protonated analyte in the source reaches that of the hydroniums the equilibrium becomes less favorable and the response decreases. The range of linear response can be estimated from this approach. The lower limit is based upon the sensitivity of the mass spectrometer and the background signal at the $\mathrm{m} / \mathrm{z}$ where the analyte is detected, the upper limit based on Figure 24 is near $100 \mathrm{ppb}$. This general appearance, slope and upper detection limit agree well with those found experimentally (Sunner, Nicol, and Kebarle, 1988; Grange, 1988). A 


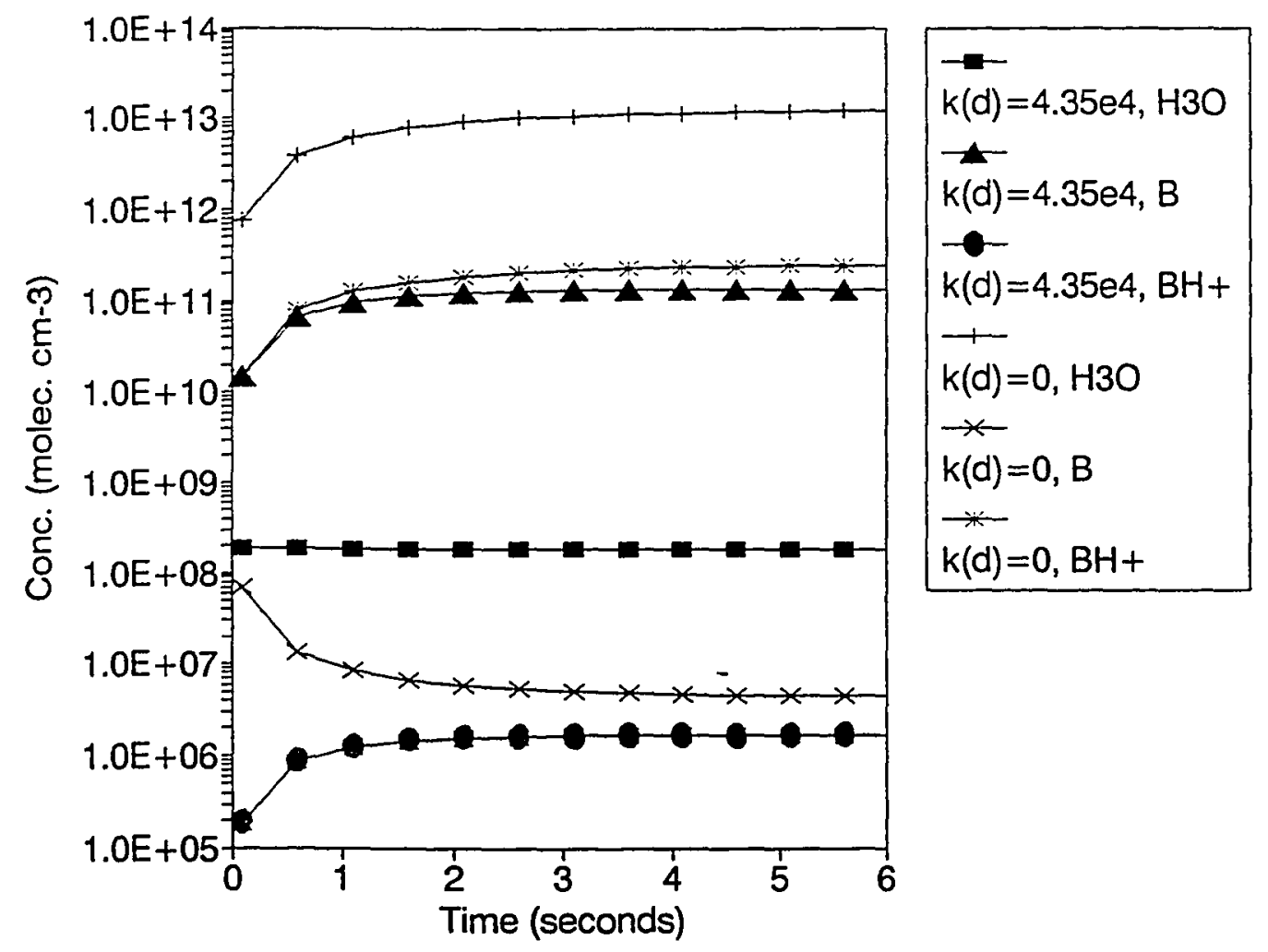

Figure 23. Batch-mode modeling of API source reactions at two detection rates. Reaction mechanism is given in Table XIV. Filled symbols are based on a detection rate of $4.35 e 4$, other points for $k_{d}=0$. Initial $\left[\mathrm{H}_{3} \mathrm{O}^{+}\right]_{0}=2.45 \mathrm{e} 11,\left[\mathrm{H}_{2} \mathrm{O}\right]=1 \mathrm{e} 16[\mathrm{~B}]_{0}=2.45 \mathrm{e}$.

response curve based on the TAGA system is shown in Figure 25 the triangles represent the pyridine response curve, the circles the results for acetone (Sunner, Nicol, and Kebarle 1988).

API analysis is generally carried out with complex mixtures where the analyte may be present with other compounds of interest and/or in a matrix of compounds whose identities and concentrations are not of concern. These other components may compete for the available charge carriers in the API source, affecting analyte response and linearity. To the mechanism of Table XIV a second compound was added whose equivalent $\mathrm{GB}=177 \mathrm{kcal} / \mathrm{mole}$. This second analyte, 


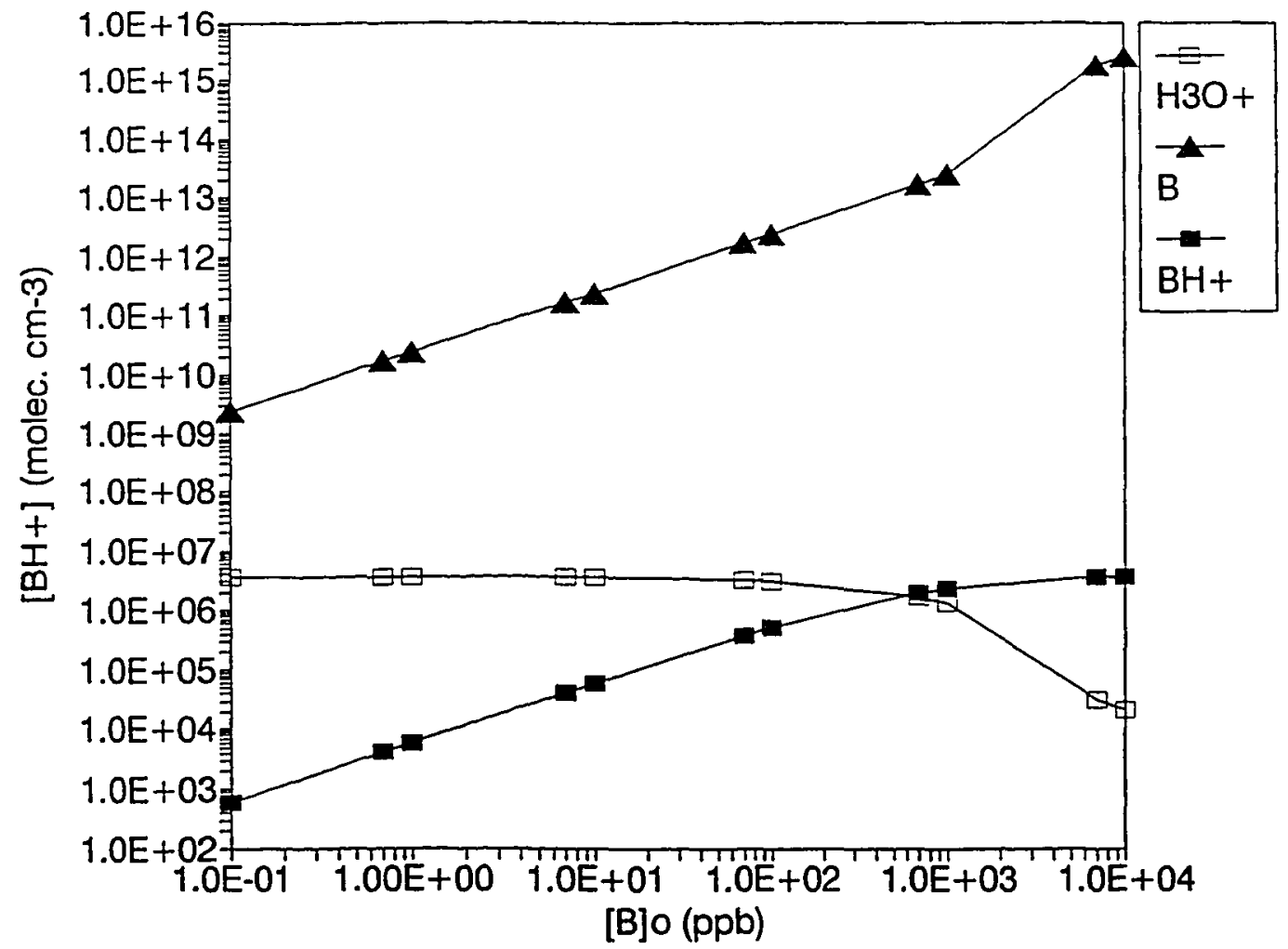

Figure 24. Batch-mode modeling of analyte response as a function of initial analyte concentration. Initial $\left[\mathrm{H}_{3} \mathrm{O}^{+}\right]_{0}=2.45 \mathrm{e} 11,\left[\mathrm{H}_{2} \mathrm{O}\right]=1 \mathrm{e} 16$. Response levels off as reagent hydroniums are consumed.

identified as ' $\mathrm{C}$ ', was increased in initial concentration from 0.1 to $10,000 \mathrm{ppb}$ while the concentration of the other analyte, 'A' $(G B=180)$, was held constant at $0.1 \mathrm{ppb}$. The results of this integration are presented in Figure 26. The protonated concentrations in the API source are identified with filled symbols, hydronium ion is identified with an asterisk. API log response for analyte $\mathrm{C}$ is linear at concentrations up to about $100 \mathrm{ppb}$, similar with published experimental findings, and the response of analyte $A$ is unperturbed by the presence of $C$ until consumption of the reagent hydroniums begins. 


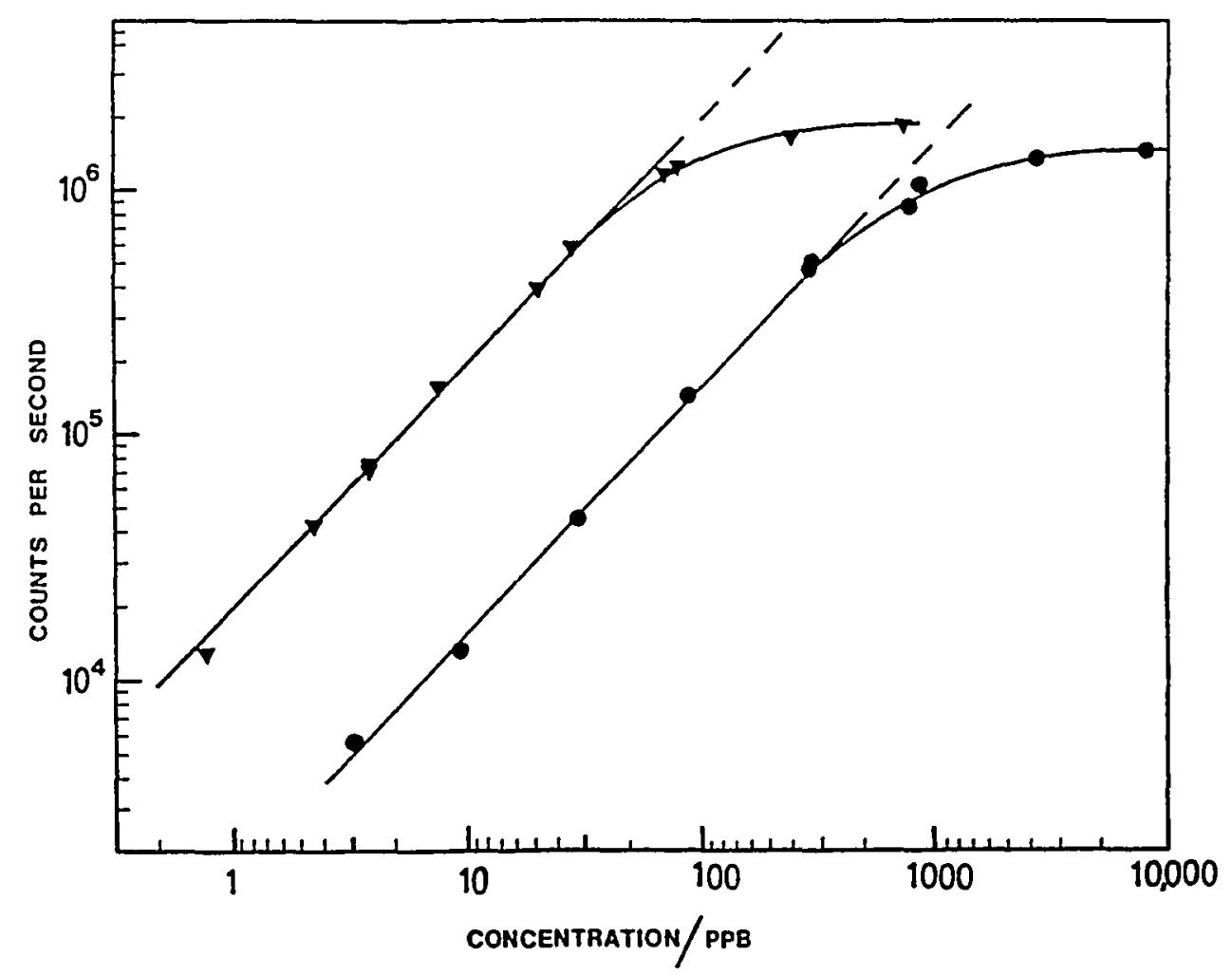

Figure 25. Experimental analyte response using TAGA APIMS as a function of analyte concentration. Filled triangles based on pyridine response, filled circles represent acetone response. Source: Sunner, Nicol, and Kebarle (1988).

The ion signal which will be seen at the detector is given by $k_{d}$ times the ion concentration in the source times the cell volume (V); for hydroniums this would be $\mathrm{k}_{\mathrm{d}}\left[\mathrm{H}_{3} \mathrm{O}^{+}\right] \mathrm{V}$. The presence of a large signal at the mass spectrometer of the mass spectrometer is significantly different than the concentration present in the API source, due to the extraction of ions by the electric field. In the case of Figure 26, for example, little of the initial analyte has been converted to protonated analyte and yet the concentration of hydroniums in the source is at least four orders of magnitude less than the initial concentration. The "missing" hydroniums were drawn out of the API source by the electric field and detected. This will result in a 


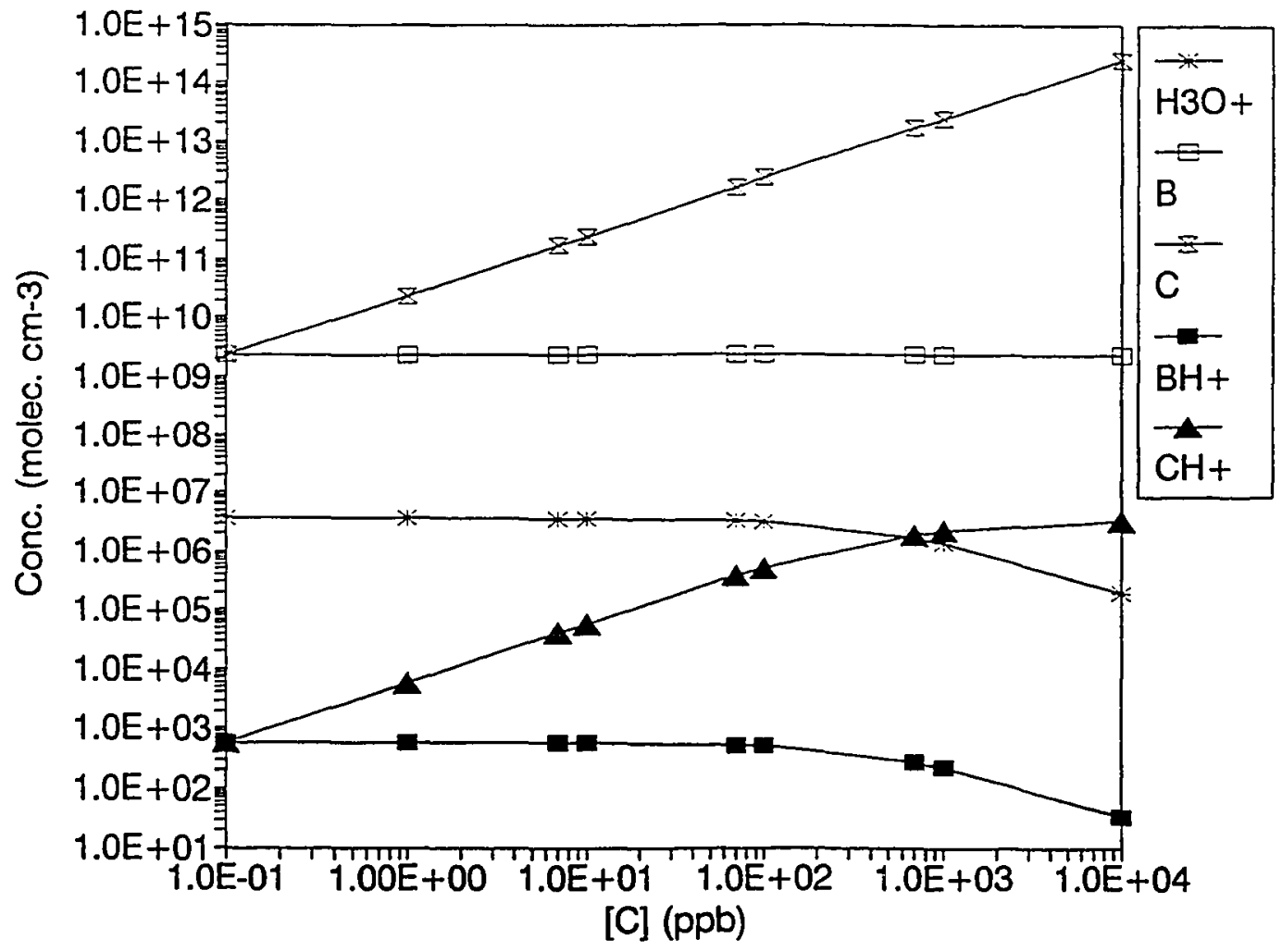

Figure 26. Batch-mode modeling of analyte response for mixtures. Analyte gas phase basicities: $\mathrm{GB}(\mathrm{B})=180, \mathrm{~GB}(\mathrm{C})=177$ each $\mathrm{kcal} / \mathrm{mol}$. Concentration of $B$ is held constant while $[C]$ is varied.

very large ion signal at the detector for reagent ions, while actually in the source their relative concentrations are much lower.

\section{CONCLUSIONS}

As mentioned earlier in the chapter, a prerequisite to quantitative analysis is that all analytes have equal responses, which are linear in analyte concentration. Another alternative is for analyte response to be calibrated, provided that response for one analyte is not perturbed by the presence of other analytes or the sample matrix. Quantitative protonation is the optimal situation 
and the most direct to evaluate, since all analytes will have a response which is proportional to their concentration. It is clear that this situation can be obtained using API only when the actual hydronium concentration is in large excess over the analytes' in the API source. This is illustrated in Figure 24 and is most nearly approached when using a slow detection step. It is necessary to specify "actual" concentration since the removal by the electric field depletes the concentration in the source while providing a large signal at the detector.

Linear response is possible in the API source even in if quantitation is not. This is illustrated in Figures 24 and 26 where the response for analytes, both singly and together, is linear up until the point of consumption of the reagents. The linear range based on this modeling is in agreement with the experimental results from Figure 25.

Conclusions relating the kinetic and thermodynamic control of proton transfer to API response may be questionable in that they relate high reagent signal in the spectra to high reagent concentrations in the source. The determinant factor in establishing the upper limits to response is apparently the rate of the detection step, and small differences in the forward rate constants for analytes determine how close to the upper limit the analyte response will be. Kinetic and equilibrium modeling presented here suggest that the API response, in the presence of sufficient reagents, should be uniformly high for all analytes. Our initial experiments under conditions where reagent ions are almost certainly consumed (Chapters III-IV) seem to bear this out, as do the API responses reported by others (Dumdei et al., 1988). Future experiments will stress minimizing the consumption of reagent ions to give direct quantitative assessment of yields. 


\section{CHAPTER VII}

\section{CONCLUSIONS AND APPLICATIONS}

\section{"Many things about chemistry that were once thought to be science fiction now actually are." (Davis, 1969)}

\section{PART I: HRKAPIMS}

In Chapters II-IV we described the development and applications of a new approach to the study of atmospheric oxidation processes based on the existing technique of atmospheric pressure ionization mass spectrometry. Fundamental to this new approach was the utilization of source-produced hydroxyl radicals, which can initiate the oxidation of compounds present in the source, to mimic atmospheric oxidation processes. When API is to be used to sample ambient air or closed reaction vessels, we have demonstrated how the use of carbon monoxide can eliminate interferences from HO chemistry. HRKAPIMS offers many advantages over other experimental techniques in its ability to evaluate both the stable oxidation products of a compound and the free radical intermediates, and to assign empirical formulas through the accurate mass assignments. The short residence time offers the opportunity to evaluate reaction kinetics and mechanisms by changing the concentrations of reagents. 


\section{Oxidation of Small Hydrocarbons}

The development of HRKAPIMS has been discussed in earlier chapters in the context of evaluating toluene oxidation mechanisms. Toluene oxidation is perhaps one of the most complicated mechanisms which might be undertaken for such a study. Future work might first focus on the products and free radical intermediates from simpler hydrocarbons to better understand the nature of the oxidation reactions and the API source reactions in general. Following such fundamental studies, the oxidation of such important NMHCs as isoprene and the larger terpene compounds could be undertaken. The following paragraphs outline and evaluate the oxidation mechanisms of several simple hydrocarbons and may serve to guide future work.

Tables XV-XVIII summarize the oxidation mechanisms for four simple hydrocarbons that would be likely candidates for a fundamental study using APIMS. These are partial mechanisms in that they do not follow the oxidation pathways all the way to the formation of carbon dioxide and water. The reactions in each of the four tables fall into two categories: atmospheric oxidation processes and protonation reactions. In the oxidation reactions the free radical intermediates are identified by a dot symbolizing the unpaired electron. Stable, closed-shell oxidation products are printed in italics. In the protonation reactions, the underlined atom was the lowest energy site for protonation. Heats of formation for the unprotonated and protonated species are listed in the first two columns. The enthalpies for these compounds are not available based on experimental measurements in Lias, Liebman, and Kebarle (1984), and are not corrected using the linear regression analysis given in an earlier chapter. The GBs are based upon 
the slope corrected values of the enthalpies and are themselves adjusted using the method described in this Chapter V. The final column provides the accurate mass for each protonated compound in Daltons.

Methane. Atmospheric oxidations are initiated by reactions with the hydroxyl radical (HO). In alkanes such as methane, $\mathrm{HO}$ abstracts a hydrogen from the compound. Methane oxidation, Table XV generates only two products with gas phase basicities greater than that of water. Any analyte with a GB less than water will have little desire to accept a proton from a hydronium ion.

TABLE XV

PARTIAL METHANE PHOTOOXIDATION MECHANISM

\begin{tabular}{|c|c|c|c|c|}
\hline & $\Delta H_{1}(B)$ & $\Delta \mathrm{H}_{\gamma}\left(\mathrm{BH}^{*}\right)$ & GB & Mass \\
\hline $\mathrm{CH}_{4}+\mathrm{H}^{+}>\underline{C H}_{3}^{+}$ & -8.8 & 226.3 & 114.7 & 17.039 \\
\hline \multicolumn{5}{|l|}{$\mathrm{CH}_{4}+\mathrm{HO} \cdot \rightarrow \mathrm{CH}_{3} \cdot$} \\
\hline $\mathrm{CH}_{3} \bullet+\mathrm{H}^{*} \rightarrow \underline{C H}_{4} \bullet+$ & 30.0 & 265.2 & 110.6 & 16.031 \\
\hline \multicolumn{5}{|l|}{$\mathrm{CH}_{3} \bullet+\mathrm{O}_{2} \rightarrow \mathrm{CH}_{3} \mathrm{O}_{2} \bullet$} \\
\hline $\mathrm{CH}_{3} \mathrm{O}_{2} \cdot+\mathrm{H}^{+} \rightarrow \mathrm{CH}_{3} \mathrm{OOH}{ }^{\bullet}$ & .9 .1 & 198.0 & 148.8 & 48.021 \\
\hline \multicolumn{5}{|l|}{$2 \mathrm{CH}_{3} \mathrm{O}_{2} \cdot \rightarrow 2 \mathrm{CH}_{3} \mathrm{O} \cdot+\mathrm{O}_{2}$} \\
\hline \multicolumn{5}{|l|}{$\mathrm{CH}_{3} \mathrm{O}_{2} \cdot+\mathrm{NO} \rightarrow \mathrm{CH}_{3} \mathrm{O} \bullet+\mathrm{NO}$} \\
\hline $\mathrm{CH}_{3} \mathrm{O} \bullet+\mathrm{H}^{\bullet} \rightarrow \mathrm{CH}_{3} \mathrm{OH} \bullet \bullet$ & .9 .2 & 185.9 & 162.9 & 32.026 \\
\hline \multicolumn{5}{|l|}{$\mathrm{CH}_{3} \mathrm{O} \cdot+\mathrm{O}_{2} \rightarrow \mathrm{CH}_{2} \mathrm{O}+\mathrm{HO}_{2} \cdot$} \\
\hline $\mathrm{CH}_{2} \mathrm{O}+\mathrm{H}^{+} \rightarrow \mathrm{CH}_{2} \mathrm{OH}^{+}$ & .31 .3 & 161.4 & 168.1 & 31.018 \\
\hline \multicolumn{5}{|l|}{$\mathrm{CH}_{2} \mathrm{O}+\mathrm{HO} \bullet \rightarrow \mathrm{CHO} \cdot+\mathrm{H}_{2} \mathrm{O}$} \\
\hline $\mathrm{CHO} \cdot+\mathrm{H}^{*} \rightarrow \mathrm{CHOH}^{*}$ & -2.0 & 206.9 & 145.9 & 30.011 \\
\hline \multicolumn{5}{|l|}{$\mathrm{CHO} \cdot+\mathrm{O}_{2} \rightarrow \mathrm{CO}+\mathrm{HO}_{2} \cdot$} \\
\hline $\mathrm{CO}+\mathrm{H}^{+} \rightarrow \mathrm{COH}^{+}$ & -5.7 & 229.5 & 115.3 & 29.003 \\
\hline
\end{tabular}

Notes: Heats of Formation for unprotonated $\Delta \mathrm{H}_{\mathrm{r}}(\mathrm{B})$ and protonated $\Delta \mathrm{H}_{\mathrm{r}}\left(\mathrm{BH}^{+}\right)$ are based on semi-empirical calculations using the program MOPAC. Gasphase Basicities (GB) are derived from corrected Heats of Formation using the methodology of Chapter V. Enthalpies and GB are in kcal/mol. Accurate masses for the protonated species are in Daltons. The underlined atoms represent the site of protonation. Italics denote stable products. 
Since the relative humidity is generally high in most ambient API analyses, we would not expect APIMS analysis to detect these compounds. Formaldehyde is the major oxidation product of methane oxidation, with a GB of only $168 \mathrm{kcal} / \mathrm{mol}$. As discussed in the previous chapter API response is determined by several factors acting singly and together. Increasing the hydronium ion concentration in the source will increase analyte response. This can be accomplished through the use of higher discharge currents and/or increased source residence time. Decreasing the water concentration increases response by shifting equilibrium toward the protonated form.

Protonation is also more favorable for reactions of the smaller hydrated hydroniums. The discussions in Chapter VI are focused on Reaction 9. Protonation from hydrated hydroniums takes the form of R18, which is written for the monohydrate species. The equilibrium constant is then a function of analyte and water GB as well as the free energies for hydration. Hydration free energies can be evaluated from Figure 21 in Chapter VI as a function of analyte GB. Protonation reactions and equilibrium constants for the other hydrated species is written similarly. The effect of the additional terms in E16 is to reduce the extent of proton transfer reaction for compounds with low GBs.

$$
\begin{gathered}
\mathrm{B}+\mathrm{H}_{3} \mathrm{O}^{+} \bullet \mathrm{H}_{2} \mathrm{O}<-->\mathrm{BH}^{+} \bullet \mathrm{H}_{2} \mathrm{O}+\mathrm{H}_{2} \mathrm{O} \\
\mathrm{K}_{\text {eq }}(\mathrm{R} 18)=\exp \left[\mathrm { RT } ^ { - 1 } \left(\mathrm{GB}(\mathrm{B})-\mathrm{GB}\left(\mathrm{H}_{2} \mathrm{O}\right)+\Delta \mathrm{G}\left(\mathrm{BH}^{+}+\mathrm{H}_{2} \mathrm{O} \rightarrow \mathrm{BH}^{+} \bullet \mathrm{H}_{2} \mathrm{O}\right)\right.\right. \\
\left.-\Delta \mathrm{G}\left(\mathrm{H}_{3} \mathrm{O}^{+}+\mathrm{H}_{2} \mathrm{O} \rightarrow \mathrm{H}_{3} \mathrm{O}^{+} \bullet \mathrm{H}_{2} \mathrm{O}\right)\right]
\end{gathered}
$$

Ethene. In the oxidation of alkenes, $\mathrm{HO}$ can either abstract a hydrogen or break the double bond in an addition reaction, with the latter pathway dominant for the smaller alkanes. The products of ethene oxidation, Table XVI, do not have 
TABLE XVI

PARTIAL ETHENE PHOTOOXIDATION MECHANISM

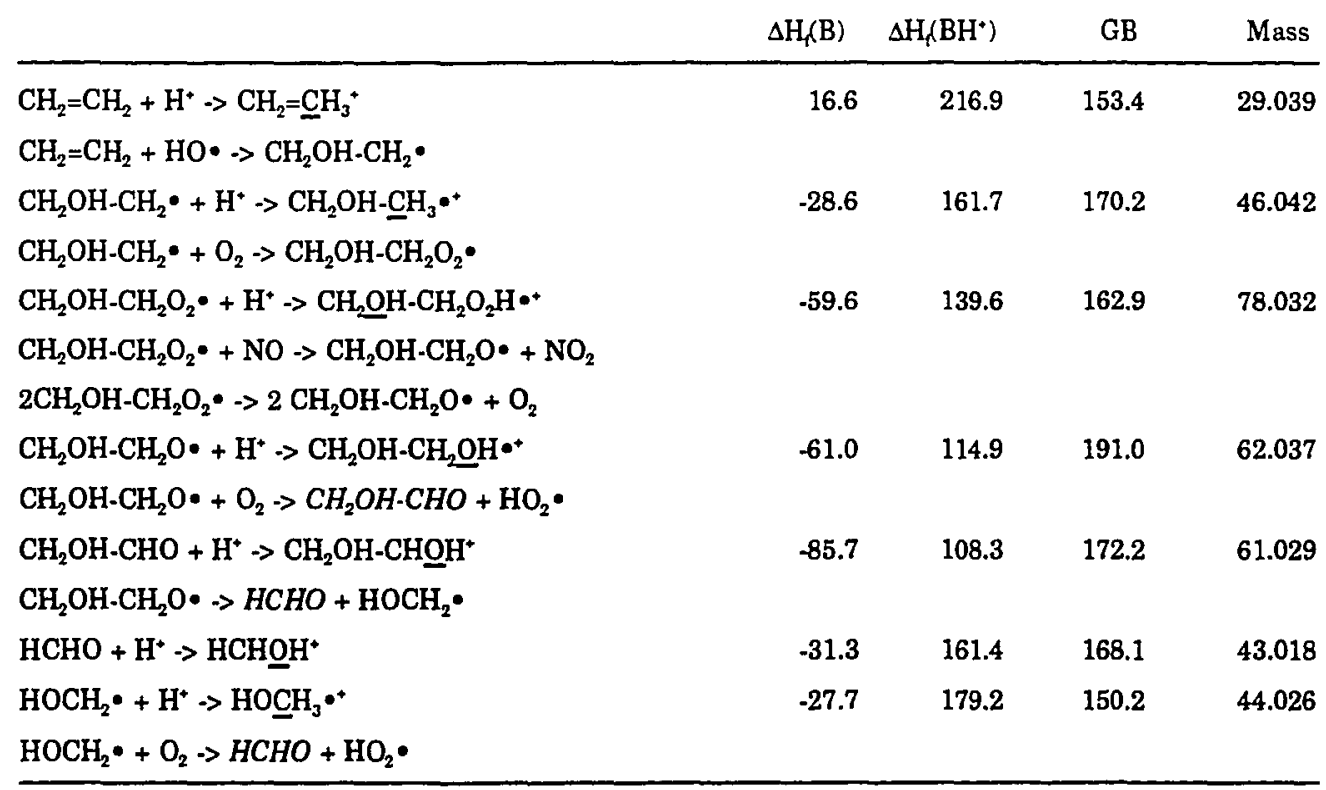

Note: Heats of Formation for unprotonated $\Delta \mathrm{H}_{\mathrm{r}}(\mathrm{B})$ and protonated $\Delta \mathrm{H}_{\mathrm{f}}\left(\mathrm{BH}^{+}\right)$ based on semi-empirical calculations using the program MOPAC. Gas-phase Basicities (GB) derived from corrected Heats of Formation using the methodology of Chapter V. Enthalpies and GB in $\mathrm{kcal} / \mathrm{mol}$, accurate masses for the protonated species in Daltons.

GBs much higher than those of methane's oxidation products. The major products formaldehyde and hydroxyethanal have GBs of 168 and $172 \mathrm{kcal} / \mathrm{mol}$ respectively. One of the free radical intermediates, $\mathrm{CH}_{2} \mathrm{OH}-\mathrm{CH}_{2} \mathrm{O} \cdot$, has a $\mathrm{GB}$ of 191 and might be detected using API.

Propene. With propene, HO addition can occur at the terminal or central carbon. These two oxidation pathways result in the same final products but the free radical intermediates will differ. Such information may provide insights into the lowest energy pathway to the formation of those products. While the isomeric structures and GBs of the intermediates may differ, their accurate masses are the 
TABLE XVII

PARTIAL PROPENE PHOTOOXIDATION MECHANISM

\begin{tabular}{|c|c|c|c|c|}
\hline & $\Delta H_{1}(\mathrm{~B})$ & $\Delta H_{f}\left(\mathrm{BH}^{+}\right)$ & GB & Mass \\
\hline $\mathrm{CH} 3 \mathrm{CH}=\mathrm{CH}_{2}+\mathrm{H}^{+} \rightarrow \mathrm{CH}_{3} \mathrm{CH}=\mathrm{CH}_{3}$ & 7.0 & 192 & 172.4 & 43.055 \\
\hline \multicolumn{5}{|l|}{$\mathrm{CH}_{3} \mathrm{CH}=\mathrm{CH}_{2}+\mathrm{HO} \bullet \rightarrow \mathrm{CH}_{3} \mathrm{CHOH}-\mathrm{CH}_{2} \bullet$} \\
\hline $\mathrm{CH}_{3} \mathrm{CHOH}-\mathrm{CH}_{2} \bullet+\mathrm{H}^{+} \rightarrow \mathrm{CH}_{3} \mathrm{CHOH}_{2}-\mathrm{CH}_{2} \bullet^{*}$ & -33.5 & 152.2 & 175.8 & 60.057 \\
\hline \multicolumn{5}{|l|}{$\mathrm{CH}_{3} \mathrm{CHOH}-\mathrm{CH}_{2} \bullet+\mathrm{O}_{2} \rightarrow \mathrm{CH}_{3} \mathrm{CHOH} \cdot \mathrm{CH}_{2} \mathrm{O}_{2} \bullet$} \\
\hline $\mathrm{CH}_{3} \mathrm{CHOH}-\mathrm{CH}_{2} \mathrm{O}_{2} \bullet+\mathrm{H}^{+} \rightarrow \mathrm{CH}_{3} \mathrm{CHOH}_{2}-\mathrm{CH}_{2} \mathrm{OO} \bullet+$ & -65.5 & 124.4 & 174.5 & 92.047 \\
\hline \multicolumn{5}{|l|}{$\mathrm{CH}_{3} \mathrm{CHOH}-\mathrm{CH}_{2} \mathrm{O}_{2} \bullet+\mathrm{NO} \rightarrow \mathrm{CH}_{3} \mathrm{CHOH}-\mathrm{CH}_{2} \mathrm{O} \bullet+\mathrm{NO}_{2}$} \\
\hline \multicolumn{5}{|l|}{$2 \mathrm{CH}_{3} \mathrm{CHOH}-\mathrm{CH}_{2} \mathrm{O}_{2} \bullet->2 \mathrm{CH}_{3} \mathrm{CHOH}-\mathrm{CH}_{2} \mathrm{O} \bullet+\mathrm{O}_{2}$} \\
\hline $\mathrm{CH}_{3} \mathrm{CHOH}-\mathrm{CH}_{2} \mathrm{O} \bullet+\mathrm{H}^{+} \rightarrow \mathrm{CH}_{3} \mathrm{CHOH}-\mathrm{CH}_{2} \mathrm{OH} \cdot+$ & -67.5 & 100.5 & 201.0 & 76.052 \\
\hline \multicolumn{5}{|l|}{$\mathrm{CH}_{3} \mathrm{CHOH}-\mathrm{CH}_{2} \mathrm{O} \cdot+\mathrm{NO}_{2} \rightarrow \mathrm{CH}_{3} \mathrm{CHOH}{ }_{2}-\mathrm{CH}_{2} \mathrm{ONO}_{2}$} \\
\hline $\mathrm{CH}_{3} \mathrm{CHOH}-\mathrm{CH}_{2} \mathrm{ONO}_{2}+\mathrm{H}^{+} \rightarrow \mathrm{CH}_{3} \mathrm{CHOH}_{2}-\mathrm{CH}_{2} \mathrm{ONO}_{2}$ & -86.6 & 103.6 & 176.3 & 122.049 \\
\hline \multicolumn{5}{|l|}{$\mathrm{CH}_{3} \mathrm{CHOH}-\mathrm{CH}_{2} \mathrm{O} \cdot+\mathrm{O}_{2} \rightarrow \mathrm{CH}_{3} \mathrm{CHOHCHOH}{ }^{+}$} \\
\hline $\mathrm{CH}_{3} \mathrm{CHOHCHO}+\mathrm{H}^{+} \rightarrow \mathrm{CH}_{3} \mathrm{CHOHCHOH}^{+}$ & -60.2 & 101.2 & 208.0 & 75.045 \\
\hline \multicolumn{5}{|l|}{$\mathrm{CH}_{3} \mathrm{CHOH}-\mathrm{CH}_{2} \mathrm{O} \bullet->\mathrm{HCHO}+\mathrm{CH}_{3} \mathrm{CHOH} \bullet$} \\
\hline $\mathrm{HCHO}+\mathrm{H}^{+} \rightarrow \mathrm{HCHOH}^{+}$ & -31.3 & 161.4 & 168.1 & 31.018 \\
\hline \multicolumn{5}{|l|}{$\mathrm{CH}_{3} \mathrm{CHOH} \bullet+\mathrm{O}_{2} \rightarrow \mathrm{CH}_{3} \mathrm{CHO}+\mathrm{HO}_{2} \bullet$} \\
\hline $\mathrm{CH}_{3} \mathrm{CHO}+\mathrm{H}^{*} \rightarrow \mathrm{CH}_{3} \mathrm{CHOH}^{+}$ & -41.3 & 141.8 & 180.4 & 45.034 \\
\hline \multicolumn{5}{|l|}{$\mathrm{CH}_{3} \mathrm{CH}=\mathrm{CH}_{2}+\mathrm{HO} \bullet \rightarrow \mathrm{CH}_{3} \mathrm{CH}(\bullet) \mathrm{CH}_{2} \mathrm{OH}$} \\
\hline $\mathrm{CH}_{3} \mathrm{CH}(\cdot) \mathrm{CH}_{2} \mathrm{OH}+\mathrm{H}^{+} \rightarrow \mathrm{CH}_{3} \mathrm{CH}(\cdot) \mathrm{CH}_{2} \mathrm{OH}_{2} \cdot$ & -40.7 & 145.5 & 176.3 & 60.057 \\
\hline \multicolumn{5}{|l|}{$\mathrm{CH}_{3} \mathrm{CH}(\bullet) \mathrm{CH}_{2} \mathrm{OH}+\mathrm{O}_{2} \rightarrow \mathrm{CH}_{3} \mathrm{CH}\left(\mathrm{O}_{2} \bullet\right) \mathrm{CH}_{2} \mathrm{OH}$} \\
\hline $\mathrm{CH}_{3} \mathrm{CH}\left(\mathrm{O}_{2} \bullet\right) \mathrm{CH}_{2} \mathrm{OH}+\mathrm{H}^{*} \rightarrow \mathrm{CH}_{3} \mathrm{CH}\left(\mathrm{O}_{2} \bullet\right) \mathrm{CH}_{2} \mathrm{OH}_{2}{ }^{+}$ & -67.9 & 123.9 & 172.5 & 92.047 \\
\hline \multicolumn{5}{|l|}{$\mathrm{CH}_{3} \mathrm{CH}\left(\mathrm{O}_{2} \bullet\right) \mathrm{CH}_{2} \mathrm{OH}+\mathrm{NO} \rightarrow \mathrm{CH}_{3} \mathrm{CH}(\mathrm{O} \bullet) \mathrm{CH}_{2} \mathrm{OH}+\mathrm{NO}_{2}$} \\
\hline \multicolumn{5}{|l|}{$2 \mathrm{CH}_{3} \mathrm{CH}\left(\mathrm{O}_{2} \bullet\right) \mathrm{CH}_{2} \mathrm{OH} \rightarrow 2 \mathrm{CH}_{3} \mathrm{CH}(\mathrm{O} \cdot) \mathrm{CH}_{2} \mathrm{OH}+\mathrm{O}_{2}$} \\
\hline $\mathrm{CH}_{3} \mathrm{CH}(\mathrm{O} \cdot) \mathrm{CH}_{2} \mathrm{OH}+\mathrm{H}^{+} \rightarrow \mathrm{CH}_{3} \mathrm{CH}(\underline{\mathrm{OH}} \cdot) \mathrm{CH}_{2} \mathrm{OH}^{+}$ & -67.1 & 100.0 & 202.0 & 76.052 \\
\hline \multicolumn{5}{|l|}{$\mathrm{CH}_{3} \mathrm{CH}\left(\mathrm{O} \bullet \mathrm{CH}_{2} \mathrm{OH}+\mathrm{NO}_{2} \rightarrow \mathrm{CH}_{3} \mathrm{CH}\left(\mathrm{ONO}_{2}\right) \mathrm{CH}_{2} \mathrm{OH}\right.$} \\
\hline $\mathrm{CH}_{3} \mathrm{CH}\left(\mathrm{ONO}_{2}\right) \mathrm{CH}_{2} \mathrm{OH}+\mathrm{H}^{*} \rightarrow \mathrm{CH}_{3} \mathrm{CH}\left(\mathrm{ONO}_{2}\right) \mathrm{CH}_{2} \mathrm{OH}_{2}$ & -86.5 & 102.4 & 177.9 & 122.049 \\
\hline \multicolumn{5}{|l|}{$\mathrm{CH}_{3} \mathrm{CH}(\mathrm{O} \cdot) \mathrm{CH}_{2} \mathrm{OH}+\mathrm{O}_{2} \rightarrow \mathrm{CH}_{3} \mathrm{C}(\mathrm{O}) \mathrm{CH}_{2} \mathrm{OH}$} \\
\hline $\mathrm{CH}_{3} \mathrm{C}(\mathrm{O}) \mathrm{CH}_{2} \mathrm{OH}+\mathrm{H}^{+} \rightarrow \mathrm{CH}_{3} \mathrm{C}(\underline{\mathrm{OH}}) \mathrm{CH}_{2} \mathrm{OH}$ & -93.5 & 85.1 & 191.2 & 75.045 \\
\hline \multicolumn{5}{|l|}{$\mathrm{CH}_{3} \mathrm{CH}(\mathrm{O} \cdot) \mathrm{CH}_{2} \mathrm{OH} \rightarrow \mathrm{CH}_{3} \mathrm{CHO}+\mathrm{CH}_{2} \mathrm{OH} \bullet$} \\
\hline $\mathrm{CH}_{2} \mathrm{OH} \bullet+\mathrm{O}_{2} \rightarrow \mathrm{HCHO}+\mathrm{HO}_{2} \bullet$ & & & & \\
\hline
\end{tabular}

Note: Heats of Formation for unprotonated $\left.\Delta \mathrm{H}_{\mathrm{f}} \mathrm{B}\right)$ and protonated $\Delta \mathrm{H}_{\mathrm{f}}\left(\mathrm{BH}^{+}\right)$based on semi-empirical calculations using the program MOPAC. Gas-phase Basicities (GB) derived from corrected Heats of Formation using the methodology of Chapter V. Enthalpies and GB in $\mathrm{kcal} / \mathrm{mol}$, accurate masses for the protonated species in Daltons. 
same and the isomers are indistinguishable using mass spectrometry. With propene's oxidation, Table XVI, both the number of products and the GB of the products increases dramatically over the first two examples. The GBs of the products and intermediates range from 168 to $208 \mathrm{kcal} / \mathrm{mol}$. Depending on analyte concentration and experimental conditions propene should be an excellent candidate for analysis using APIMS.

Butane. The oxidation of butane is more complex because of the multiple sites for hydroxyl radical attack. A complete discussion of the butane oxidation mechanism was undertaken by Baldwin et al. (1977). Hydroxyl abstraction of a hydrogen can occur at a terminal carbon where there are six equivalent hydrogens, or at an internal carbon where there are 4 equivalent sites. To simplify the interpretation of Table XVIII, the reactions have been categorized into reaction types. Within each type, i.e. ROO• representing the various peroxy radical species, the oxidation process is listed along with the protonation of the product or free radical intermediate. Alkanes have generally lower GBs than unsaturated or heteroatom containing compounds, and the GBs of butane oxidation products range from 144.6 to $194.5 \mathrm{kcal} / \mathrm{mol}$.

An early effort using API to identify the products of butane oxidation found many of these products. While the conditions were not suitable for quantitative assessment of the product yields, the presence of most of the products and many intermediates in the spectra is an important finding. Figure 27 shows two mass spectra from the oxidation of butane. Part (a) is the background scan with a relative humidity approximately $20 \%$ and the corona discharge operated at $2.0 \mu \mathrm{A}$. The peaks at $\mathrm{m} / \mathrm{z} 19,37,55,73,91, \ldots$ represent hydronium ion-water clusters. 
Part (b) is after the addition of butane vapor directly into API source. While there were background peaks due to hydroniums at $\mathrm{m} / \mathrm{z} 73$ and 91 , the relative sizes of these peaks has increased dramatically due to the formation of butane oxidation products. Methyl ethyl ketone is the major butane oxidation product with a large ion intensity in part (b). Other prominent species include acetaldehyde at $\mathbf{4 5}$ daltons and two of the ROOR species at 91 and 147 daltons. Asterisks in Table XVIII identify products or intermediates which were present in the analysis of butane oxidation in Figure 27. Butane chemistry is very interesting from a mechanistic standpoint and its reactions are well understood from studies using other methods (Baldwin et al., 1977). Butane should be a good candidate for further HRKAPIMS work, offering the potential to further verify the ability of the method to evaluate reaction kinetics and free radical intermediates of atmospheric oxidations.

\section{PART II: ANALYTE GB AND API RESPONSE}

\section{Gas-phase Basicities}

Gas-phase basicity is an important thermodynamic property which reflects a compounds potential response in API analysis, its willingness to participate in proton transfer and hydration reactions, and the equilibrium constant for these reactions. However, GBs are not available for many compounds of environmental significance. Of special interest to us are the atmospheric oxidation products for a wide range of organic compounds including nitrates, nitrites, nitro compounds, aldehydes, dialdehydes, ketones, di- and tri-ketones and a variety of multifunctional compounds. We have demonstrated the ability to evaluate a 
TABLE XVIII

PARTIAL BUTANE PHOTOOXIDATION MECHANISM

\begin{tabular}{|c|c|c|c|c|}
\hline & $\Delta H_{1}(B)$ & $\Delta \mathrm{H}_{(}\left(\mathrm{BH}^{*}\right)$ & GB & Mass \\
\hline \multicolumn{5}{|c|}{$\mathrm{RH}+\mathrm{HO} \bullet \rightarrow \mathrm{R} \bullet+\mathrm{H}_{2} \mathrm{O}$} \\
\hline \multicolumn{5}{|c|}{$\mathrm{CH}_{3} \mathrm{CH}_{2} \mathrm{CH}_{2} \mathrm{CH}_{3}+\mathrm{HO} \cdot \rightarrow \mathrm{CH}_{3} \mathrm{CH}_{2} \mathrm{CH}_{2} \mathrm{CH}_{2} \bullet+\mathrm{H}_{2} \mathrm{O}$} \\
\hline \multicolumn{5}{|l|}{$\mathrm{CH}_{3} \mathrm{CH}_{2} \mathrm{CH}_{2} \mathrm{CH}_{3}+\mathrm{HO} \bullet \rightarrow \mathrm{CH}_{3} \mathrm{CH}_{2} \mathrm{CH}(\bullet) \mathrm{CH}_{3}+\mathrm{H}_{2} \mathrm{O}$} \\
\hline $\mathrm{CH}_{3} \mathrm{CH}_{2} \mathrm{CH}_{2} \mathrm{CH}_{2} \bullet+\mathrm{H}^{+} \rightarrow \mathrm{CH}_{3} \mathrm{CH}_{2} \mathrm{CH}_{2} \mathrm{CH}_{3} \bullet+$ & 1.9 & 211 & 144.6 & *58.078 \\
\hline $\mathrm{CH}_{3} \mathrm{CH}_{2} \mathrm{CH}(\cdot) \mathrm{CH}_{3}+\mathrm{H}^{+} \rightarrow \mathrm{CH}_{3} \mathrm{CH}_{2} \mathrm{CH}(\mathrm{H} \cdot) \mathrm{CH}_{3}^{+}$ & -3.1 & 210.6 & 139.9 & 58.078 \\
\hline \multicolumn{5}{|c|}{$\mathrm{R} \cdot+\mathrm{O}_{2} \rightarrow \mathrm{ROO} \cdot$} \\
\hline \multicolumn{5}{|l|}{$\mathrm{CH}_{3} \mathrm{CH}_{2} \mathrm{CH}_{2} \mathrm{CH}_{2} \bullet+\mathrm{O}_{2} \rightarrow \mathrm{CH}_{3} \mathrm{CH}_{2} \mathrm{CH}_{2} \mathrm{CH}_{2} \mathrm{O}_{2} \bullet$} \\
\hline \multicolumn{5}{|l|}{$\mathrm{CH}_{3} \mathrm{CH}_{2} \mathrm{CH}(\bullet) \mathrm{CH}_{3}+\mathrm{O}_{2} \rightarrow \mathrm{CH}_{3} \mathrm{CH}_{2} \mathrm{CH}\left(\mathrm{OO} \bullet \cdot \mathrm{CH}_{3}\right.$} \\
\hline $\mathrm{CH}_{3} \mathrm{CH}_{2} \mathrm{CH}_{2} \mathrm{CH}_{2} \mathrm{O}_{2} \bullet+\mathrm{H}^{+} \rightarrow \mathrm{CH}_{3} \mathrm{CH}_{2} \mathrm{CH}_{2} \mathrm{CH}_{2} \mathrm{OOH} \bullet+$ & -29.0 & 166.9 & 164.1 & 90.068 \\
\hline $\mathrm{CH}_{3} \mathrm{CH}_{2} \mathrm{CH}(\mathrm{OO} \cdot) \mathrm{CH}_{3}+\mathrm{H}^{+} \rightarrow \mathrm{CH}_{3} \mathrm{CH}_{2} \mathrm{CH}(\mathrm{OOH} \cdot) \mathrm{CH}_{3} \cdot$ & -27.0 & 166.5 & 166.7 & 90.068 \\
\hline \multicolumn{5}{|c|}{$\mathrm{ROO} \bullet+\mathrm{NO}->\mathrm{RO} \bullet+\mathrm{NO}_{2}$} \\
\hline \multicolumn{5}{|c|}{$\mathrm{CH}_{3} \mathrm{CH}_{2} \mathrm{CH}_{2} \mathrm{CH}_{2} \mathrm{O}_{2} \bullet+\mathrm{NO} \rightarrow \mathrm{CH}_{3} \mathrm{CH}_{2} \mathrm{CH}_{2} \mathrm{CH}_{2} \mathrm{O} \bullet+\mathrm{NO}_{2}$} \\
\hline \multicolumn{5}{|l|}{$\mathrm{CH}_{3} \mathrm{CH}_{2} \mathrm{CH}(\mathrm{OO} \cdot) \mathrm{CH}_{3}+\mathrm{NO}->\mathrm{CH}_{3} \mathrm{CH}_{2} \mathrm{CH}(\mathrm{O} \cdot) \mathrm{CH}_{3}+\mathrm{NO}_{2}$} \\
\hline \multicolumn{5}{|c|}{$\mathrm{ROO} \bullet+\mathrm{R}^{\prime} \mathrm{OO} \cdot \rightarrow \mathrm{RO} \bullet+\mathrm{R}^{\prime} \mathrm{O} \cdot+\mathrm{O}_{2}$} \\
\hline \multicolumn{5}{|c|}{$2 \mathrm{CH}_{3} \mathrm{CH}_{2} \mathrm{CH}_{2} \mathrm{CH}_{2} \mathrm{O}_{2} \bullet \rightarrow 2 \mathrm{CH}_{3} \mathrm{CH}_{2} \mathrm{CH}_{2} \mathrm{CH}_{2} \mathrm{O} \bullet+\mathrm{O}_{2}$} \\
\hline \multicolumn{5}{|l|}{$2 \mathrm{CH}_{3} \mathrm{CH}_{2} \mathrm{CH}(\mathrm{OO} \bullet) \mathrm{CH}_{3} \rightarrow 2 \mathrm{CH}_{3} \mathrm{CH}_{2} \mathrm{CH}(\mathrm{O} \cdot) \mathrm{CH}_{3}+\mathrm{O}_{2}$} \\
\hline $\mathrm{CH}_{3} \mathrm{CH}_{2} \mathrm{CH}_{2} \mathrm{CH}_{2} \mathrm{O} \bullet+\mathrm{H}^{+} \rightarrow \mathrm{CH}_{3} \mathrm{CH}_{2} \mathrm{CH}_{2} \mathrm{CH}_{2} \mathrm{OH}^{\bullet+}$ & -29.3 & 155.8 & 176.8 & 74.073 \\
\hline $\mathrm{CH}_{3} \mathrm{CH}_{2} \mathrm{CH}(\mathrm{O} \bullet) \mathrm{CH}_{3}+\mathrm{H}^{+} \rightarrow \mathrm{CH}_{3} \mathrm{CH}_{2} \mathrm{CH}(\mathrm{OH}) \mathrm{CH}_{3} \bullet^{+}$ & -25.9 & 147.8 & 189.9 & *74.073 \\
\hline \multicolumn{5}{|c|}{$\mathrm{RO} \bullet+\mathrm{O}_{2} \rightarrow \mathrm{R}=\mathrm{O}+\mathrm{HO}_{2}$} \\
\hline \multicolumn{5}{|c|}{$\mathrm{CH}_{3} \mathrm{CH}_{2} \mathrm{CH}_{2} \mathrm{CH}_{2} \mathrm{O} \bullet+\mathrm{O}_{2} \rightarrow \mathrm{CH}_{3} \mathrm{CH}_{2} \mathrm{CH}_{2} \mathrm{CHO}+\mathrm{HO}_{2} \bullet$} \\
\hline \multicolumn{5}{|l|}{$\mathrm{CH}_{3} \mathrm{CH}_{2} \mathrm{CH}(\mathrm{O} \cdot) \mathrm{CH}_{3}+\mathrm{O}_{2} \rightarrow \mathrm{CH}_{3} \mathrm{CH}_{2} \mathrm{CH}(\mathrm{O}) \mathrm{CH}_{3}+\mathrm{HO}_{2} \bullet$} \\
\hline $\mathrm{CH}_{3} \mathrm{CH}_{2} \mathrm{CH}_{2} \mathrm{CHO}+\mathrm{H}^{+} \rightarrow \mathrm{CH}_{3} \mathrm{CH}_{2} \mathrm{CH}_{2} \mathrm{CHOH}^{+}$ & -54.5 & 126.4 & 184.4 & 73.065 \\
\hline $\mathrm{CH}_{3} \mathrm{CH}_{2} \mathrm{CH}(\mathrm{O}) \mathrm{CH}_{3}+\mathrm{H}^{+} \rightarrow \mathrm{CH}_{3} \mathrm{CH}_{2} \mathrm{CH}(\underline{\mathrm{OH}}) \mathrm{CH}_{3}^{+}$ & -53.6 & 118.3 & 194.9 & $* 73.065$ \\
\hline \multicolumn{5}{|l|}{$\mathrm{CH}_{3} \mathrm{CH}_{2} \mathrm{CH}(\mathrm{O} \bullet) \mathrm{CH}_{3} \rightarrow \mathrm{CH}_{3} \mathrm{CHO}+\mathrm{CH}_{3} \mathrm{CH}_{2} \bullet$} \\
\hline \multicolumn{5}{|l|}{$\mathrm{CH}_{3} \mathrm{CH}_{2} \cdot+\mathrm{O}_{2} \rightarrow \mathrm{CH}_{3} \mathrm{CH}_{2} \mathrm{OO}$} \\
\hline $\mathrm{CH}_{3} \mathrm{CH}_{2} \mathrm{OO} \bullet+\mathrm{H}^{+} \rightarrow \mathrm{CH}_{3} \mathrm{CH}_{2} \mathrm{OOH}_{2} \bullet \cdot$ & -16.1 & 181.9 & 160.1 & 62.037 \\
\hline \multicolumn{5}{|l|}{$\mathrm{CH}_{3} \mathrm{CH}_{2} \mathrm{OO} \cdot+\mathrm{NO} \rightarrow \mathrm{CH}_{3} \mathrm{CH}_{2} \mathrm{O} \cdot+\mathrm{NO}_{2}$} \\
\hline \multicolumn{5}{|l|}{$2 \mathrm{CH}_{3} \mathrm{CH}_{2} \mathrm{OO} \cdot \rightarrow 2 \mathrm{CH}_{3} \mathrm{CH}_{2} \mathrm{O} \cdot+\mathrm{O}_{2}$} \\
\hline $\mathrm{CH}_{3} \mathrm{CH}_{2} \mathrm{O} \bullet+\mathrm{H}^{+} \rightarrow \mathrm{CH}_{3} \mathrm{CH}_{2} \mathrm{OH} \cdot+$ & -15.9 & 173.4 & 170.5 & $* 46.042$ \\
\hline \multicolumn{5}{|l|}{$\mathrm{CH}_{3} \mathrm{CH}_{2} \mathrm{O} \bullet+\mathrm{O}_{2} \rightarrow \mathrm{CH}_{3} \mathrm{CHO}+\mathrm{HO}_{2} \bullet$} \\
\hline $\mathrm{CH}_{3} \mathrm{CHO}+\mathrm{H}^{+} \rightarrow \mathrm{CH}_{3} \mathrm{CHOH}^{+}$ & -41.3 & 141.8 & 180.4 & $* 45.034$ \\
\hline
\end{tabular}


TABLE XVIII

PARTIAL BUTANE PHOTOOXIDATION MECHANISM

(continued)

\begin{tabular}{|c|c|c|c|c|}
\hline & $\Delta \mathrm{H}_{\mathrm{f}}(\mathrm{B})$ & $\mathrm{H}\left(\mathrm{BH}^{+}\right)$ & GB & Mass \\
\hline \multicolumn{5}{|c|}{$\mathrm{ROO} \cdot+\mathrm{R}^{\prime} \mathrm{OO} \cdot-\mathrm{ROOR}^{\prime}+\mathrm{O}_{2}$} \\
\hline \multicolumn{5}{|c|}{$2 \mathrm{CH}_{3} \mathrm{CH}_{2} \mathrm{CH}_{2} \mathrm{CH}_{2} \mathrm{OO} \cdot \rightarrow \mathrm{CH}_{3} \mathrm{CH}_{2} \mathrm{CH}_{2} \mathrm{CH}_{2} \mathrm{OOCH}_{2} \mathrm{CH}_{2} \mathrm{CH}_{2} \mathrm{CH}_{3}+\mathrm{O}_{2}$} \\
\hline \multicolumn{5}{|c|}{$2 \mathrm{CH}_{3} \mathrm{CH}_{2} \mathrm{OO} \rightarrow \mathrm{CH}_{3} \mathrm{CH}_{2} \mathrm{OOCH}_{2} \mathrm{CH}_{3}+\mathrm{O}_{2}$} \\
\hline \multicolumn{5}{|c|}{$\mathrm{CH}_{3} \mathrm{CH}_{2} \mathrm{CH}_{2} \mathrm{CH}_{2} \mathrm{OO} \cdot+\mathrm{CH}_{3} \mathrm{CH}_{2} \mathrm{OO} \bullet \rightarrow \mathrm{CH}_{3} \mathrm{CH}_{2} \mathrm{CH}_{2} \mathrm{CH}_{2} \mathrm{OOCH}_{2} \mathrm{CH}_{3}$} \\
\hline \multicolumn{5}{|c|}{$\mathrm{CH}_{3} \mathrm{CH}_{2} \mathrm{CH}_{2} \mathrm{CH}_{2} \mathrm{OOCH}_{2} \mathrm{CH}_{2} \mathrm{CH}_{2} \mathrm{CH}_{3}+\mathrm{H}^{+}>\mathrm{CH}_{3} \mathrm{CH}_{2} \mathrm{CH}_{2} \mathrm{CH}_{2} \mathrm{OQ}(\mathrm{H}) \mathrm{CH}_{2} \mathrm{CH}_{2} \mathrm{CH}_{2} \mathrm{CH}_{3}^{+}$} \\
\hline & -65.5 & 124.1 & 173.3 & ${ }^{*} 147.139$ \\
\hline $\mathrm{CH}_{3} \mathrm{CH}_{2} \mathrm{OOCH}_{2} \mathrm{CH}_{3}+\mathrm{H}^{+} \rightarrow \mathrm{CH}_{3} \mathrm{CH}_{2} \mathrm{O} \underline{\mathrm{O}}(\mathrm{H}) \mathrm{CH}_{2} \mathrm{CH}_{3}^{+}$ & -38.4 & 152.3 & 171.2 & $* 91.076$ \\
\hline \multicolumn{5}{|c|}{$\mathrm{CH}_{3} \mathrm{CH}_{2} \mathrm{CH}_{2} \mathrm{CH}_{2} \mathrm{OOCH}_{2} \mathrm{CH}_{3}+\mathrm{H}^{+} \rightarrow \mathrm{CH}_{3} \mathrm{CH}_{2} \mathrm{CH}_{2} \mathrm{CH}_{2} \mathrm{O} \underline{\mathrm{O}}(\mathrm{H}) \mathrm{CH}_{2} \mathrm{CH}_{3}$} \\
\hline & -51.9 & 138.2 & 175.3 & 119.107 \\
\hline \multicolumn{5}{|c|}{$\mathrm{ROO} \bullet+\mathrm{HO}_{2} \bullet \rightarrow \mathrm{ROOH}+\mathrm{O}_{2}$} \\
\hline \multicolumn{5}{|c|}{$\mathrm{CH}_{3} \mathrm{CH}_{2} \mathrm{CH}_{2} \mathrm{CH}_{2} \mathrm{OO} \cdot+\mathrm{HO}_{2} \cdot \rightarrow \mathrm{CH}_{3} \mathrm{CH}_{2} \mathrm{CH}_{2} \mathrm{CH}_{2} \mathrm{OOH}+\mathrm{O}_{2}$} \\
\hline \multicolumn{5}{|l|}{$\mathrm{CH}_{3} \mathrm{CH}_{2} \mathrm{OO} \cdot+\mathrm{HO}_{2} \bullet \rightarrow \mathrm{CH}_{3} \mathrm{CH}_{2} \mathrm{OOH}+\mathrm{O}_{2}$} \\
\hline $\mathrm{CH}_{3} \mathrm{CH}_{2} \mathrm{CH}_{2} \mathrm{CH}_{2} \mathrm{OOH}+\mathrm{H}^{+} \rightarrow \mathrm{CH}_{3} \mathrm{CH}_{2} \mathrm{CH}_{2} \mathrm{CH}_{2} \mathrm{OOH}_{2}^{*}$ & -50.7 & 159.2 & 150.3 & 90.068 \\
\hline $\mathrm{CH}_{3} \mathrm{CH}_{2} \mathrm{OOH}+\mathrm{H}^{+} \rightarrow \mathrm{CH}_{3} \mathrm{CH}_{2} \mathrm{OHOH}^{*}$ & -37.1 & 160.8 & 154.9 & 62.037 \\
\hline
\end{tabular}

Note: Heats of Formation for unprotonated $\Delta \mathrm{H}_{\mathrm{r}}(\mathrm{B})$ and protonated $\Delta \mathrm{H}_{\mathrm{r}}\left(\mathrm{BH}^{+}\right)$based on semi-empirical calculations using the program MOPAC. Gas-phase Basicities (GB) derived from corrected Heats of Formation using the methodology of Chapter V. Enthalpies and GB in $\mathrm{kcal} / \mathrm{mol}$, accurate masses for the protonated species in Daltons. Asterisks denote compounds with strong signals in the mass spectrum, Figure 27

compounds' GB through the use of semi-empirical calculations, based on the heats of formation for the protonated and unprotonated forms. Clearly the next application of semiempirical calculations is to real environmental problems, in particular to evaluate the GB of many of toluene's actual oxidation products which we have analyzed using HRKAPIMS.

Table XIX lists the calculated GBs for 57 compounds based on semiempirical calculations of enthalpies of formation. None of these compounds 
TABLE XIX

\section{GAS-PHASE BASICITIES BASED ON SEMI-EMPIRICAL HEATS OF FORMATION}

\begin{tabular}{|c|c|c|}
\hline Compound & GB & $\begin{array}{l}\Delta \mathrm{H}_{\mathrm{f}} \Delta \mathrm{H}_{\mathrm{f}} \\
\text { (B) }\left(\mathrm{BH}^{+}\right) \text {Protonated Atom }\end{array}$ \\
\hline benzyl alcohol & 181.8 & $\begin{array}{l}-30.8149 .8 \text { ortho carbon } \\
152.2 \text { hydroxyl oxygen }\end{array}$ \\
\hline benzyl-NO2 & 176.0 & 17.3199 .4 terminal $\mathrm{O}$ in $\mathrm{NO} 2$ \\
\hline butenedial & 184.4 & $\begin{array}{l}-44.6135 .8 \text { carbonyl oxygen } \\
155.7 \text { carbonyl carbon; } H 2 \text { loss } \\
165.3 \text { carbon } 2\end{array}$ \\
\hline $\mathrm{CH} 3-\mathrm{ONO} 2$ & 159.9 & $\begin{array}{l}-31.0169 .0 \text { terminal } \mathrm{O} \text { in } \mathrm{NO} 2 \\
169.0 \text { nitrogen; } \mathrm{H} \text { shift to } \mathrm{O} \\
150.5 \text { inner } \mathrm{O} ; \mathrm{NO} 2 \text { loss }\end{array}$ \\
\hline CH3-OONO2 & 154.0 & $\begin{array}{l}-3.0199 .5 \text { terminal } \mathrm{O} \text { in NO2 } \\
203.6 \text { nitrogen; } \mathrm{H} \text { shift to O } \\
173.9 \text { outer O; NO2 loss } \\
216.3 \text { inner } \mathrm{O} \text {; NO2 loss }\end{array}$ \\
\hline $\mathrm{CH} 3-\mathrm{C}(\mathrm{O})-\mathrm{ONO} 2$ & 167.3 & $\begin{array}{l}-40.1154 .0 \text { carbonyl O } \\
161.6 \text { outer O in NO2 } \\
166.0 \text { nitrogen; H shift to O } \\
130.3 \text { outer O; NO2 loss } \\
148.4 \text { inner } \mathrm{O} ; \mathrm{HNO} 4 \text { loss }\end{array}$ \\
\hline dinitrotoluene o- p- & 171.5 & $\begin{array}{c}27.0212 .0 \text { ortho NO2 oxygen } \\
218.9 \text { para NO2 oxygen }\end{array}$ \\
\hline dioxohexenal & 207.4 & $\begin{array}{l}-77.5 \quad 86.3 \text { end carbonyl oxygen } \\
103.4 \text { center carbonyl oxygen } \\
98.1 \text { end carbonyl oxygen }\end{array}$ \\
\hline ethyl-ONO2 & 164.8 & $\begin{array}{l}-37.8158 .6 \text { terminal } O \\
158.6 \text { nitrogen; shifts to O } \\
142.6 \text { inner O; NO2 loss }\end{array}$ \\
\hline ethyl-OONO2 & 157.1 & $\begin{array}{l}-9.1191 .3 \text { terminal } \mathrm{O} \text { in NO2 } \\
195.2 \text { nitrogen; } \mathrm{H} \text { shift to O } \\
167.3 \text { inner O; NO2 loss }\end{array}$ \\
\hline ethyl-C(O)-NO2 & 171.3 & $\begin{array}{l}-46.3145 .0 \text { carbonyl oxygen } \\
154.5 \text { terminal O in NO2 } \\
158.7 \text { nitrogen; H shift to O } \\
123.9 \text { outer O; NO2 loss } \\
139.5 \text { inner O; HNO4 loss }\end{array}$ \\
\hline furfural & 194.6 & $\begin{array}{l}-24.5145 .1 \text { carbonyl oxygen } \\
162.4 \text { ring carbon } 1\end{array}$ \\
\hline glyoxyl & 165.7 & $\begin{array}{l}-58.2139 .3 \text { oxygen } \\
137.7 \text { carbon; dissociates }\end{array}$ \\
\hline
\end{tabular}


TABLE XIX

GAS-PHASE BASICITIES BASED ON SEMI-EMPIRICAL HEATS OF FORMATION

(continued)

$\Delta \mathrm{H}_{\mathrm{f}} \quad \Delta \mathrm{H}_{\mathrm{f}}$

Compound

$\mathrm{H}-\mathrm{C}(\mathrm{O})-\mathrm{OONO} 2$

hexadienal

hexadiendial

hydroxydioxohexenal

hydroxyhexadienal

hydroxyoxohexenal

indole

isobutanol

maleic acid

m-hydroxybenzaldehyde

methylglyoxyl

nitropentane

o-cresol

o-hydroxybenzaldehyde

o-hydroxy-m-cresol

o-nitrotoluene

o-nitrophenol

pentadienal

phenyl-CH2-ONO2

phenyl-CH2-OONO2

phenyl-C(O)-ONO2
GB (B) $\left(\mathrm{BH}^{+}\right)$Protonated Atom

$153.7-33.8 \quad 171.7$ terminal $\mathrm{O}$ in $\mathrm{NO} 2$ 168.8 carbonyl O; loss of NO2

$195.8 \quad-.5166 .0$ carbonyl oxygen

$197.7 \quad-32.8 \quad 135.3$ carbonyl oxygen 154.4 vinyl carbon

194.1-124.3 54.6 center carbonyl oxygen 55.0 end carbonyl oxygen 57.7 carbonyl $O$ by hydroxyl

$216.3 \quad-59.1 \quad 95.2$ carbonyl oxygen

205.9-104.6 62.5 terminal carbonyl oxygen

78.0 carbonyl oxygen

$213.7 \quad 60.3206 .2$ nitrogen

251.5 carbon 1

$180.8 \quad-74.0111 .3$ oxygen

206.2 -156.2 15.2 carbonyl oxygen

197.6 -51.6 117.9 carbonyl oxygen

$179.3-66.4119 .9$ carbonyl oxygen 1

119.9 carbon $1 ; \mathrm{H}$ shifts to $\mathrm{O}$

145.9 carbon 2 ; H2 loss

128.4 carbonyl oxygen 2

180.6 -37.1 145.9 oxygen

$225.7-29.1114 .1$ meta carbon

162.3 ortho carbon

163.0 hydroxy oxygen

$211.1-49.3108 .5$ carbonyl oxygen

$177.7 \quad-72.7115 .1$ hydroxy oxygen

176.419 .5201 .0 oxygen

222.3 nitrogen

$183.7-15.2163 .2$ oxygen

$197.3 \quad-.2165 .0$ carbonyl oxygen

$160.8 \quad-2.8 \quad 193.6$ nitrogen

178.3 center $\mathrm{O}$; loss of $\mathrm{HNO}$

156.826 .4223 .9 terminal O in NO2

200.6 outer 0 ; no2 loss

210.2 inner O; HNO4 loss

$201.8-29.4134 .5$ oxygen in NO2; NO loss

143.1 loss of HNO3 
TABLE XIX

\section{GAS-PHASE BASICITIES BASED ON SEMI-EMPIRICAL HEATS OF FORMATION \\ (continued)}

$\Delta \mathrm{H}_{\mathrm{f}} \quad \Delta \mathrm{H}_{\mathrm{f}}$

Compound

phenyl-C(O)-OONO2

phenyl-ONO

p-hydroxybenzaldehyde

p-nitrobenzaldehyde

propyl-ONO2

propyl-OONO2

pyruvic acid

tripropylamine

1-butyne

1-methylbutenedial

1-methylhexadienedial

2-HO-1-methylbutenedial

2-HO-1-Mehexadienedial

2-hydroxybutenedial
GB (B) $\left(\mathrm{BH}^{+}\right)$Protonated Atom

$175.5-4.4 \quad 179.6$ carbonyl oxygen 197.0 terminal $\mathrm{O}$ in NO2

196.9 nitrogen; $\mathrm{H}$ shift to $\mathrm{O}$

163.9 outer $\mathrm{O} ; \mathrm{NO} 2$ loss

175.2 inner $\mathrm{O}$; HNO4 loss

159.410 .9207 .6 terminal O in NO2

186.3 inner O; NO2 loss

$203.5 \quad-53.3111 .3$ carbonyl oxygen

$181.8 \quad .9179 .5$ oxygen on NO2 182.5 carbonyl oxygen

$\begin{array}{lll}156.8 & -44.7 & 159.1 \text { terminal O in NO2 }\end{array}$

$156.7-15.8185 .6$ terminal $\mathrm{O}$; in NO2

155.1 nitrogen; HNO2 loss

160.3 outer $\mathrm{O} ; \mathrm{NO} 2$ loss

197.5 inner O; NO2 loss

181.8-125.5 63.5 acid carbonyl oxygen

64.7 carbonyl oxygen

229.1 -34.0 107.2 nitrogen

172.422 .4206 .3 carbon 1

$195.5 \quad-53.7117 .7$ carbonyl oxygen 1

155.2 carbon $1 ; \mathrm{H}$ shifts to $\mathrm{C} 4$

155.2 carbon 2

156.3 carbon 3

126.1 carbonyl 4

$200.4-41.8124 .4$ carbonyl oxygen 2

129.3 carbonyl oxygen 6

$203.9-97.0 \quad 71.1$ carbonyl oxygen 4

80.5 carbonyl oxygen 1

$209.4 \quad-82.3 \quad 79.9$ carbonyl oxygen 6

88.8 carbonyl oxygen 1

$182.1 \quad-95.5 \quad 90.6$ carbon 4

95.3 carbonyl oxygen 1

128.3 carbon 2

102.8 carbon 4

92.4 carbonyl oxygen 4

120.1 hydroxyl oxygen 
TABLE XIX

\section{GAS-PHASE BASICITIES BASED ON SEMI-EMPIRICAL HEATS OF FORMATION \\ (continued)}

$$
\Delta \mathrm{H}_{\mathrm{f}} \quad \Delta \mathrm{H}_{\mathrm{f}}
$$

$\begin{array}{lll}\text { Compound } & \text { GB } & \text { (B) }\left(\mathrm{BH}^{+}\right) \text {Protonated Atom }\end{array}$

2-hydroxy 3-butyl-ONO2

2-hydroxy-3-oxo-butanal

2-hydroxypropanedial

2,6-dioxaheptane

3-HO-2-oxy-3,5-hexadiene

3-nitro-2-hydroxycresol

4-hydroxy-2-butenal

4-hydroxy-2,4-pentadienal

5-oxo-1,3-hexadiene
$176.1-89.7101 .0$ hydroxy oxygen

104.7 terminal -ONO2 oxygen

90.8 center oxygen; NO2 lost

189.5-120.4 62.0 carbonyl oxygen 3

69.3 carbonyl oxygen 1

153.9-113.5 98.1 hydroxy alcohol

92.1 carbonyl oxygen; splits

186.1-106.3 78.1 oxygen

201.8 -50.6 115.2 carbonyl oxygen

$194.1-22.3147 .9$ terminal O in NO2

$197.7-69.7101 .3$ carbonyl oxygen

134.9 carbon 3

$197.1-46.2123 .2$ carbonyl oxygen

$201.3-10.5152 .2$ carbonyl oxygen

Notes: Heats of formation for unprotonated $\left(\Delta \mathrm{H}_{\mathrm{f}}(\mathrm{B})\right)$ and protonated $\left(\Delta \mathrm{H}_{\mathrm{f}}\left(\mathrm{BH}^{+}\right)\right)$species are uncorrected values from MOPAC using keywords:

AM1 bonds precise and charge $=1$ as appropriate. Gas-phase basicities (GB) are based on the lowest energy protonation site and derived from the corrected heats of formation, adjusted using the linear regression analysis methodology of Chapter V. All values are in $\mathrm{kcal} / \mathrm{mol}$. Protonation sites are identified by the functionality of the protonated atom or the carbon number for alkyl chains.

were reported in Lias, Liebman, and Levin. (1984). The heats of formation in Table XIX are uncorrected values directly from MOPAC. In many cases there is more than one likely protonation site and little prior evidence for which site will have the lowest energy. The last column in Table XIX lists the protonated atom when more that one location was evaluated. The lowest energy site which did not lead to dissociation of the molecule was used to calculate the GB. This information 

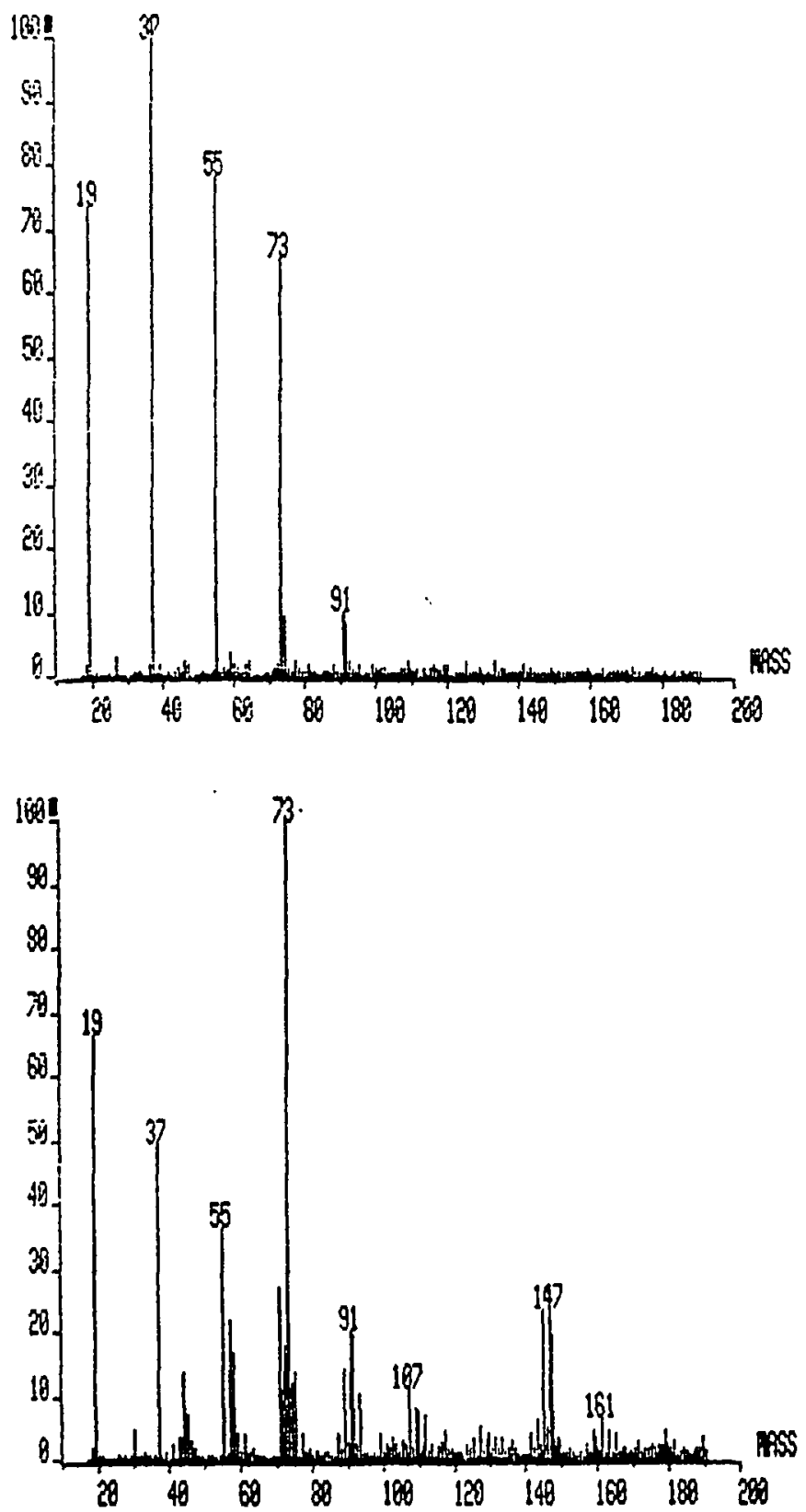

Figure 27. Low resolution mass spectra from APIMS analysis of butane. (a) Background spectrum, predominant peaks from hydrated hydroniums. (b) Spectrum after addition of butane. Oxidation products identified in Table XIX.

is valuable in assessing the potential API response for a compound (as described in Part I), for gaining insights into the stability of proposed oxidation products and 
evaluating the estimated product yields to be expected along alternate oxidation pathways.

The atmospheric oxidation mechanism of toluene is very complex, as has already been discussed. One portion of the toluene oxidation mechanism is illustrated in Figure 28. Hydroxyl radicals abstract a hydrogen from the methyl carbon, or add across an unsaturated bond in the aromatic ring. Figure 28 emphasizes the free radical intermediates, some of which were detected and identified in experiments described in Chapter IV. Using the method of Chapter V, gas phase basicities have been calculated for each of the species in Figure 28 and the results summarized in Table XX. The GBs of these products range from a low of 154 to a maximum of near $229 \mathrm{kcal} / \mathrm{mol}$. Very few compounds reported by Lias, Liebman, and Levin (1984) were free radical species, none were included in the analysis of Chapter $\mathrm{V}$, and none as were large and complex as these for toluene. While there may be some error in the GBs for the radical species estimated here, this type of analysis can give valuable insights into potential analyte response. This information is also vital in order to calibrate API spectra for use in quantitative analysis.

\section{Analyte Response in API}

The simplest approach to evaluating API response is the steady state model from the previous chapter. More sophisticated models can be developed to describe API response, yet the limiting equilibrium cases ultimately reduce to the simple steady state model of E13. 

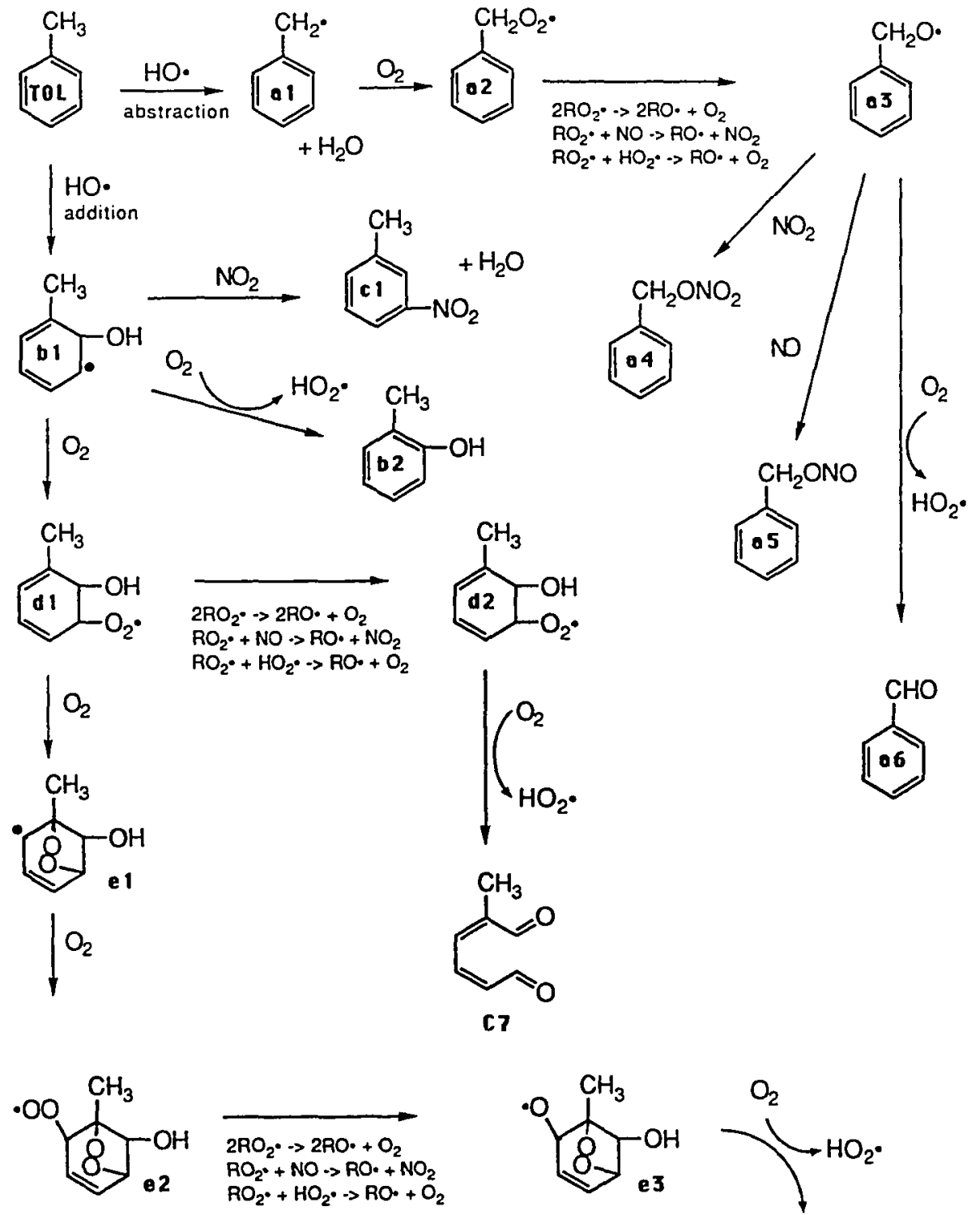

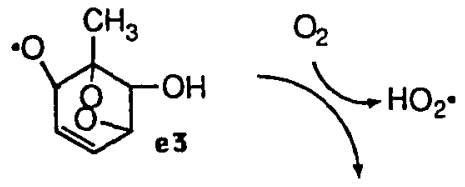<smiles>CC(=O)C=O</smiles>

Figure 28. Partial toluene photooxidation mechanism showing formation of major ring opened products and free radical intermediates. GBs of each species in Table XX. 
TABLE XX GAS PHASE BASICITY CALCULATIONS FOR TOLUENE
FREE RADICAL INTERMEDIATES AND PRODUCTS

\begin{tabular}{lrrr} 
Compound & $\Delta \mathrm{H}_{\mathrm{r}}(\mathrm{B})$ & $\Delta \mathrm{H}_{\mathrm{r}}\left(\mathrm{BH}^{+}\right)$ & $\mathrm{GB}(\mathrm{B})$ \\
\hline a1 & 38.9 & 216.2 & 178.2 \\
a2 & 13.4 & 199.8 & 176.3 \\
a3 & 17.6 & 173.9 & 206.0 \\
a4 & -3.1 & 188.6 & 166.3 \\
a5 & -8.3 & 176.7 & 174.8 \\
a6 & -8.3 & 161.6 & 192.6 \\
b1 & -18.4 & 148.7 & 196.5 \\
b2 & -28.6 & 163.6 & 167.9 \\
c1 & 18.2 & 194.6 & 182.2 \\
d1 & -25.4 & 144.5 & 194.4 \\
d2 & -28.2 & 115.4 & 225.7 \\
e1 & -20.1 & 183.5 & 153.6 \\
e2 & -8.6 & 165.2 & 153.6 \\
e3 & -9.9 & 118.1 & 242.2 \\
c7 & -41.8 & 124.4 & 200.4 \\
c5 & -53.7 & 117.7 & 195.5 \\
\hline
\end{tabular}

Notes: The structures for each product or intermediate are given the the mechanism of Figure 28. Heats of formation for the unprotonated and protonated forms are based on semiempirical calculations and are not corrected for systematic errors. Gas-phase basicities are calculated from the heats of formation using the method described in Chapter V. All values are in $\mathrm{kcal} / \mathrm{mol}$.

The key observation obtained in the modeling of the previous chapter is the effective depletion of the reagent hydronium ions in the API source due to the extraction by the electric field. Corona discharges are now the more common ion source for atmospheric pressure work due to their greater dynamic range of available currents. They also afford the opportunity to adjust analyte residence time through adjusting the needle alignment. There is a tradeoff, however, in terms of the "actual" hydronium concentration, since an increase in discharge 
current results from increasing the potential applied to the needle. This increased potential has the effect of increasing the ion velocity and decreasing the residence time for ions in the source. As an alternative to a corona discharge, radioactive $\mathrm{Ni}-63$ foil can provide the same ionization processes without the large potential gradient. While radioactive foil sources do not have as large an absolute ionization rate, it may be that the enhancement in analyte response resulting from a longer residence time when using $\mathrm{Ni}-63$ would offset the lower ionization currents.

\section{SUMMARY}

The previous chapters have described the development and application of a new approach to the study of atmospheric oxidation processes. The use of APIMS using ambient sampling techniques and in the analysis of "smog chamber" experiments can suffer from interferences due to hydroxyl radical reactions. Chapter II described one method to avoid the consumption of the sample due to $\mathrm{HO}$ reactions through the addition of about $1 \% \mathrm{CO}$ to the sample. A new alternative approach to studying atmospheric oxidation processes is described in Chapter III which uses the $\mathrm{HO}$ reactions themselves to simulate the oxidation reactions present in the atmosphere. The effectiveness of this in-situ approach is demonstrated in a study of toluene oxidation. Toluene is a common organic compound used as a solvent and a major component in fuels; its presence in polluted urban atmospheres is primarily a result anthropogenic activity. High resolution spectra of toluene oxidation provide accurate mass assignments allowing the identification of the oxidation products through their empirical formulas. Chapter IV described the valuable insights into reaction mechanisms and reaction 
kinetics that can be obtained from experiments which vary the experimental conditions. This approach, well matched to the short residence time of the API source, also provided insights into the free radical intermediates of toluene oxidation and their relative yields as experimental conditions were varied. This approach to the study of atmospheric oxidation processes using API source reactions, varied experimental conditions and accurate mass assignments we have termed High Resolution Kinetic Atmospheric Pressure Ionization Mass Spectrometry (HRKAPIMS).

Analyte response in HRKAPIMS is integrally linked to the gas-phase basicity of the analyte through the equilibrium constant for the proton transfer equilibrium. The gas-phase basicities of many compounds have been measured experimentally and are available in tabulated form. However many of the compounds are of interest to the environmental chemist have not yet been evaluated, particularly atmospheric oxidation products. Chapter V described the use of semiempirical calculations to estimate the GB of a large number of compounds, and to evaluate the error when these estimates are compared to experimental values. In the earlier portions of the present chapter these same semiempirical calculations were applied to compounds for which no experimental values are available, including toluene oxidation products, and the stable products and free radical intermediates for a variety of compounds. This information is useful in evaluating product yields and in guiding future experimental work. Finally, in Chapter VI the theoretical basis for API and HRKAPIMS sensitivity was addressed. Three different approaches were used to evaluate analyte response as a function of analyte GB: thermodynamic equilibrium; steady 
state equilibrium; and a integration of the reactions for a batch-mode reaction cell. Based on this study, insights into the experimental conditions necessary for linear response and for quantitative analysis were found which will form the basis for the future experiments.

HRKAPIMS is an important new technique for the analysis of atmospheric oxidation processes. It is hoped that through this study HRKAPIMS will find wide application in atmospheric chemistry, providing new insights and information into the important oxidation processes which dominate the lower atmosphere. 


\section{REFERENCES}

Arnts, R. and Meeks, S. Atmos. Environ. 1981, 15, 1643-1651.

Atkinson, R. Chem. Rev. 1986, 86, 69-201.

Atkinson, R. Atmos. Environ. 1990, 24A, 1-41.

Atkinson, R. "Kinetics and mechanisms of the gas-phase reactions of the hydroxyl radical with organic compounds. J. Phys Chem. Ref. Data (in press).

Atkinson, R.; Aschmann, S.M.; Arey, J.; Carter, W.P.L. Int. J. Chem. Kinet. 1989, $21,801-827$.

Atkinson, R.; Bull, D.C.; Shuff, P.J. Combust. Flame 1980, 39, 287.

Atkinson, R.; Carter, W.P.L.; Darnall, K.R.; Winer, A.M.; Pitts, J.N., Jr. Int. J. Chem. Kinet. 1980, 12, 779-836.

Atkinson, R.; Carter, W.P.L.; Winer, A.M. J. Phys. Chem. 1983, 87, 1605-1610.

Atkinson, R.; Darnall, K.R.; Lloyd, A.C.; Winer, A.M.; Pitts, J.N., Jr. In Advances in Photochemistry; Pitts, J.N., Jr.; Hammond, G.S.; Gollnick, K., Eds.; Grosjean, D., Assoc. Ed.; John Wiley \& Sons: New York, 1979; Vol. 11.

Atkinson, R. and Lloyd, A.C. J. Phys. Chem. Ref. Data 1984, 13, 315-444.

Bailey, W.F. and Monahan, A.S. J. Chem. Ed. 1978, 55, 489-493.

Baldwin, A.C.; Barker, J.R.; Golden, D.M.; Hendry, D.G. J. Phys. Chem 1977, 81, 2483-2492.

Bandow, H.; Washida, N.; Akimoto, H. Bull. Chem. Soc. Jpn. 1985, 58, 2531-2540.

Bass, L.; Su, T.; Chesnavich, W.J.; Bowers, M.T. Chem. Phys. Letters 1975, 34, 119 122.

Besemer, A.C. Atmos. Environ. 1982, 16, 1599-1602.

Bishop, D.M. and Laidler, K.J. J. Chem. Phys. 1965, 42, 1688. 
Black, F.M.; High L.E.; Lang, J.M. J. Air Pollut. Control Assoc. 1980, 30, 12161221.

Bohme, D.K.; Mackay, G.I.; Tanner, S.D. J. Am. Chem. Soc. 1979, 101, 3724-3730.

Carroll, D.I.; Dzidic, I.; Horning, E.C.; Stillwell, R.N. Appl. Spectrosc. Rev. 1981, 17, 337-406.

Carter, W.P.L. Atmos. Environ. 1990, 24A, 481-518.

Chameides, W.L.; Lindsay, R.W.; Richardson, J.; Kiang, C.S. Science 1988, 241, 1473.

Chase, M.W, Jr.; Curnutt, J.L.; Downey, J.R., Jr.; McDonald, R.A.; Syverud, A.N.; Valenzuela, E.A. J. Phys. Chem. Ref. Data 1982, 11, 695-940.

Cochran, J.W.H. High Res. Chrom. and Chrom. Comm. 1987, 10, 573-575.

Cooks, R.G. and Busch, K.L. Int. J. Mass Spectrom. Ion Phys. 1983, 53, 111.

Cox, R.D. and Earp, R.F. Anal. Chem. 1982, 54, 2265-2270.

Davis, C. Catholic School Journal 1969, December, 16-17.

Dewar, M.J.S.; Zoebisch, E.G.; Healy, E.F.; Stewart, J.J.P. J. Am. Chem. Soc. 1985, 107, 3902-3909.

Dumdei, B.E.; Kenny, D.V.; Shepson, P.B.; Kleindienst, T.E.; Nero, C.M.; Cupitt, L.T.; Claxton, L.D. Environ. Sci. Technol. 1988, 22, 1493-1498.

Dumdei, B.E. and O'Brien, R.J. Nature 1984, 311, 248-250.

Dzidic, I.; Carroll, D.I.; Stillwell, R.N.; Horning, E.C. Anal. Chem. 1976, 48, 17631768.

Eiceman, G.A.; Kremer, J.H.; Snyder, A.P.; Tofferi, J.K. Intern. J. Environ. Anal. Chem. 1988, 33, 161-183.

Facchetti, S. In Advances in Mass Spectrometry; Longevialle, P., Ed.; Heyden \& Son: London, 1989; Vol. 11B, pp 1542-1579.

Finlayson-Pitts, B.J.; Pitts, J.N., Jr. In Atmospheric Chemistry: Fundamentals and Experimental Techniques; John Wiley \& Sons: New York, 1986.

Fund, K. and Grosjean, D. Anal. Chem. 1981, 53, 168-171. 
Gery, M.W.; Fox, D.L.; Jeffries, H.E.; Stockburger, L.; Weathers, W.S. Int. J. Chem. Kinet. 1985, 17, 931-955.

Good, A.; Durden, D.A.; Kebarle, P. J. Chem. Phys. 1970a, 52, 212-221.

Good, A.; Durden, D.A.; Kebarle, P. J. Chem. Phys. 1970b, 52, 222-229.

Graedel, T.E. and Crutzen, P.J. Sci. Am. 1989, September, p 58-68.

Grange, A.H. Ph.D. Dissertation, Oregon Graduate Center, February 1988.

Grange, A.H.; O’Brien, R.J.; Barofsky, D.F. Rapid Comm. in Mass Spec. 1988a, 2, 163-166.

Grange, A.H.; O’Brien, R.J.; Barofsky, D.F. Rev. Sci. Instrum. 1988b, 59, 573-579.

Grange, A.H.; O’Brien, R.J.; Barofsky, D.F. Rev. Sci. Instrum. 1988c, 59, 656-658.

Grosjean, D. The Science of the Total Environment 1991 100, 367-414.

Halim, H.; Heinrich, N.; Koch, W.; Schmidt, J.; Frenking J. Comput. Chem. 1986, 7, 93-104.

Hiraoka, K.; Takimoto, H.; Morise, K. J. Am. Chem. Soc. 1986, 108, 5683-5689.

Horning, E.C.; Horning, M.G.; Carroll, D.I.; Dzidic, I; Stillwell, R.N. Anal. Chem. $1973,45,936-943$.

Houriet, R.; Schwarz, H.; Schleyer, P.v.R. Nouv. J. Chim. 1981, 5, 505.

Kambara, H. and Kanomata, I. Int. J. Mass Spectrom. Ion Phys. 1977, 25, 129-136.

Kass, S.R. J. Comput. Chem. 1990, 11, 94-104.

Keesee, R.G. and Castleman, A.W., Jr. J. Phys. Chem. Ref. Data 1986, 15, $1011-$ 1061.

Kenley, R.A.; Davenport, J.E.; Hendry, D.G. J. Phys. Chem. 1981, 85, 2740-2746.

Killus, J.; Witten, G. Environ. Sci. Technol. 1984, 18, 142-148.

Lacey, M.P. and Keough, T.; Rapid Comm. Mass Spec. 1989, 3, 46-50.

Lamb, B.; Westberg, H.H.; Allwire, G. J. Geophys. Res. 1985, 90, 2380-2390.

Leighton, P.A. In Photochemistry of Air Pollution; Academic Press: New York, 1961. 
Leone, J.A.; Flagan, R.C.; Grosjean, D.; Seinfeld, J.H. Int. J. Chem. Kinet. 1985, 17, 177-216.

Lias, S.G.; Liebman, J.F.; Levin, R.D. J. Phys. Chem. Ref. Data 1984, 13, 695-808.

Mahle, N.H.; Cooks, R.G.; Korzeniowski, R.W. Anal. Chem. 1983, 55, 2272-2275.

McDaniel, E.W. In Collision Phenomena in Ionized Gases; John Wiley: New York, 1964, Chapter 9.

Mitchum, R.K. and Korfmacher, W.A. Anal. Chem. 1983, 55, 1485-1499.

Moylan, C.R. and Brauman, J.I. Ann. Rev. Phys. Chem. 1983, 34, 187-215.

Nicol, G.; Sunner, J.; Kebarle, P. Int. J. Mass Spectrom. Ion Processes 1988, 84, 135-155.

Niki H. and Maker P.D. In Advances in Photochemistry; Volman, D.H.; Hammond, G.S.; Gollnick, K., Eds.; John Wiley \& Sons: New York, 1990, 69-137.

O’Brien, R.J.; Dumdei, B.E.; Hummel, S.V.; Yost, R.A. Anal. Chem. 1984, 56, 13291335.

O’Brien, R.J.; Green, P.J.; Doty, R.A.; Vanderzanden, J.W.; Easton, R.R.; Irwin, R.P. In Chemical and Biological Implications of Nitrogeneous Air Pollutants; Grosjean, D. Ed.; Ann Arbor Science: Ann Arbor, MI, 1979; pp 189-210.

O'Brien, R.J.; Green, P.J.; Nguyen, N.-L.; Doty, R.A.; Dumdei, B.E. Environ. Sci. Technol. 1983, 17, 183-186.

O'Brien, R.J. and Hightower, J.C. In The Alkylbenzenes; National Academy of Science: Washington, DC, 1981, Chapter I.

Perry, R.A.; Atkinson, R.; Pitts, J.N., Jr. J. Phys. Chem. 1977, 81, 296-304.

Pierotti, D.; Wofsy, S.C.; Jacob, D.; Rasmussen, R.A. J. Geophys. Res. 1990, 95, 1871-1881.

Plum, C.N.; Sanhueza, E.; Atkinson, R.; Carter, W.P.L.; Pitts, J.N., Jr. Environ. Sci. And Technol. 1983, 17, 479-484.

Proctor, C.J. and Todd, F.J.J. Org. Mass Spectrom. 1983, 18, 509-516.

Rasmussen, R. J. Air Polut. Control Assoc. 1972, 22, 537-543.

Rasmussen, R.; Khalil, A. Geophys. Res. 1988, 93, 1417-1421. 
Rasmussen, R.; Went, F.W. Proc. Natl. Acad. Sci., 1965, 53, 215-220.

Reid, N.M.; Buckley, J.A.; French, J.B.; Poon, C.C. Adv. Mass Spectrom. 1979, 8B, 1843.

Reid, N.M.; French, J.B.; Buckley, J.A.; Lane, D.A.; Lovett, A.M.; Rosenblatt, G. Proceedings, 4th Joint Conference on Sensing Environmental Pollutants, ACS: Washington, D.C. 1978.

Roboz, J. In Introduction to Mass Spectrometry: Instrumentation and Techniques; Interscience: New York, 1968; Chapter 10.

Sakairi, M. and Kambara, H. Anal. Chem. 1988, 60, 774-780.

Seinfeld, J.H. In Atmospheric Chemistry and Physics of Air Pollution; Wiley Interscience Publication: John Wiley and Sons, New York, 1986.

Seinfeld, J.H. Science 1989, 243, 745-752.

Shah, J.J. and Singh, H.B. Environ. Sci. Technol. 1988, 22, 1381-1388.

Shepson, P.B.; Edney, E.O.; Corse, E.W. J. Phys. Chem. 1984, 88, 4122-4126.

Shepson, P.B.; Kleindienst, T.E.; Edney, E.O.; Namie, G.R.; Pitmann, J.H.; Cupitt, L.T.; Claxton, L.D. Environ. Sci. Technol. 1985, 19, 249-255.

Singh, H.B.; Salas, L.J. Atmos. Environ. 1983, 17, 1057-1983.

Singh, H.B.; Salas, L.J.; Cantrell, B.K.; Redmond, R.M. Atmos. Environ. 1985, 19, 1911-1919.

Sloane, T.M. Chem. Phys. Lett. 1978, 54, 269-272.

Stewart, J. J. Comput. Chem. 1989, 10, 221-264.

Su, T. and Bowers, M.T. In Gas Phase Ion Chemistry; Bowers, M.T., Ed.; Academic: New York, 1979, Chapter 3.

Su, T. and Su, E.C.F. J. Chem. Phys. 1978, 69, 2243-2250.

Sunner, J.; Gordon, N.; Kebarle, P. Anal. Chem. 1988, 60, 1300-1307

Sunner, J.; Ikonomou, M.G.; Kebarle, P. Anal. Chem. 1988a, 60, 1308-1313.

Sunner, J.; Ikonomou, M.G.; Kebarle, P. Int. J. Mass Spectrom. Ion Proc. 1988b, 82, 221-237. 
Sunner, J.; Kulatunga, R.; Kebarle, P. Anal. Chem. 1986, 58, 1312-1316.

Tingey, D.T.; Manning, M.; Grothause, C.C.; Burns, W.F. Physiol. Plant 1979, 47, 112-118.

Tuazon, E.C. and Atkinson, R. Int. J. Chem. Kinet. 1990, 22, 1221-1236.

Tuazon, E.C.; Atkinson, R.; Mac Leod, H.; Biermann, H.W.; Winer, A.M.; Carter, W.P.L.; Pitts, J.N., Jr. Environ. Sci. Technol. 1984, 18, 981-984.

Tuazon, E.C.; Mac Leod, H.; Atkinson, R.; Carter, W.P.L. Environ. Sci. Technol. 1986, 20, 383-387.

Tully, F.P.; Ravishankara, A.R.; Thompson, R.L.; Nicovich, J.M.; Shah, R.C.; Dreutter, N.M.; Wine, P.H. J. Phys. Chem. 1981, 85, $2262-2269$.

Vandiver, V.J. Ph.D. Dissertation, New Mexico State University, Las Cruces, NM, May 1987.

Vandiver, V.J.; Leasure, C.S.; Eiceman, G.A. Int. J. Mass Spectrom. Ion Proc. 1985, $66,223-238$.

Voets, R.; Francois, J.-P.; Martin, J.M.L.; Mullens, J.; Yperman, J.; Van Poucke, L.C. J. Comput. Chem. 1989, 10, 449-467.

Washburn, H.W.; Wiley, H.F.; Rock, S.M. Ind. Eng. Chem. Anal. Ed. 1943, 15, 541.

Washburn, H.W.; Wiley, H.F.; Rock, S.M. Ind. Eng. Chem. Anal. Ed. 1945, 17, 74.

Weinstock, B. Science 1969, 166, 224-225.

Went, F.W. Proc. Natl. Acad. Sci. USA 1960, 46, 212-221.

Zellner, R.; Fritz, B.; Preidel, M. Chem. Phys. Letters 1985, 121, 412-416.

Zimmerman, P.R. Rep. EPA 904/9-77-028, Environ. Prot. Agency, Research Triangle Park, N.C., 1979.

Zimmerman, P.R.; Chatfield, R.B.; Fishman, J.; Crutzen, P.J.; Hanst, P.L. Geophys. Res. Lettrs. 1978, 5, 679-682.

Zimmerman, P.R.; Greenberg, J.P.; Westberg, C.E. J. Geophys. Res. 1988, 93, 14071416. 